\title{
ESPECTROSCOPIA E DIFRAÇÃO DE RAIOS X APLICADAS AOESTUDO DE FERRO E AÇO NITRETADOS POR PLASMA
}

Eduardo José Miola
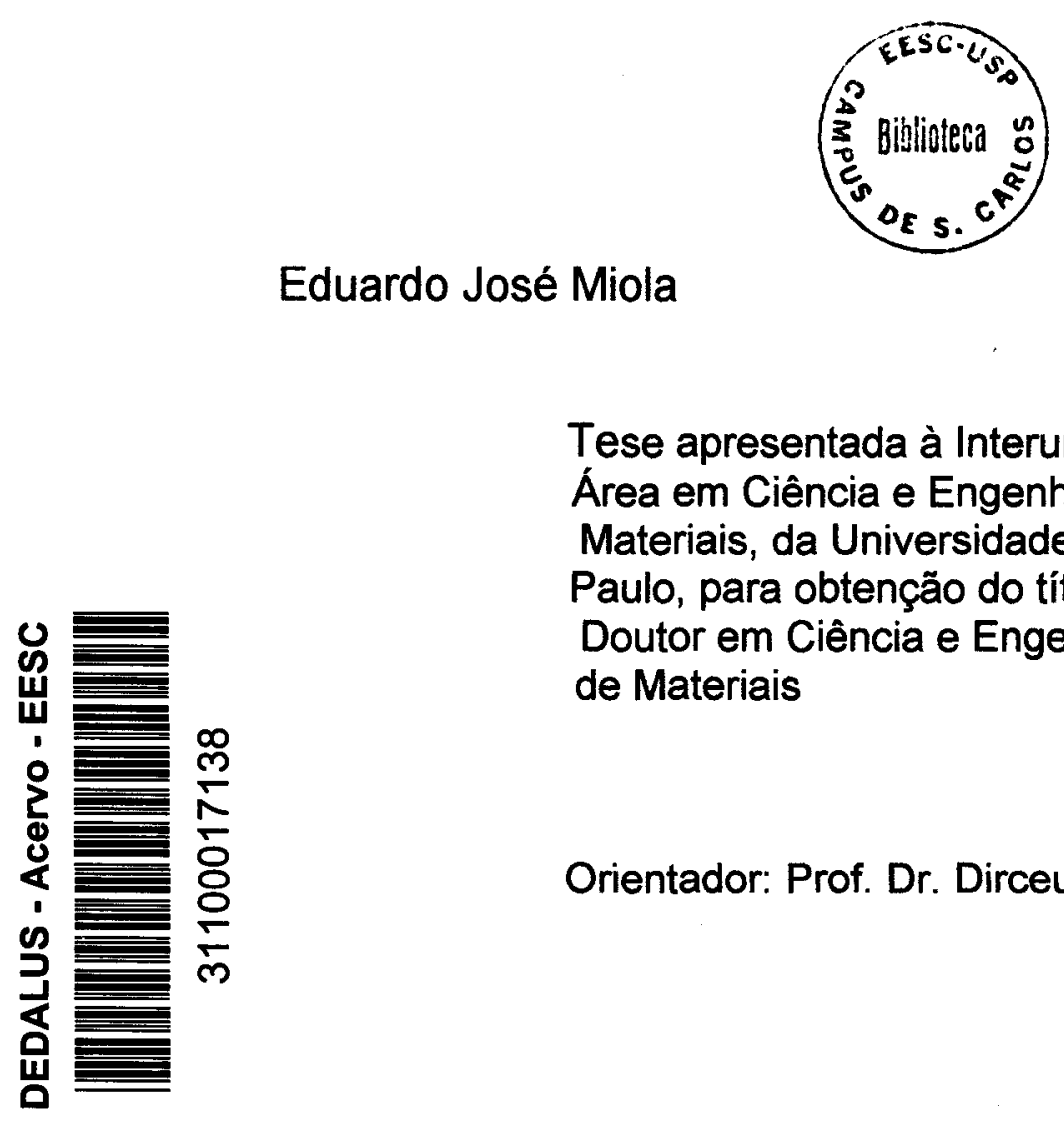

Tese apresentada à Interunidades, Área em Ciência e Engenharia de Materiais, da Universidade de São Paulo, para obtenção do título de Doutor em Ciência e Engenharia de Materiais

Orientador: Prof. Dr. Dirceu Spinelli

São Carlos

2000 
Clase. Tref-EEr
curt. $\frac{2666}{030101}$

Miola, Eduardo José

Espectroscopia Mössbauer e difração de

raios $X$ aplicadas ao estudo de ferro e aço nitretados por plasma/Eduardo José Miola.--São Carlos, 2000.

$159 \mathrm{p}$.

Tese (Doutorado)--Instituto de Física de São Carlos, Instituto Química de São Carlos e Escola de Engenharia de São Carlos, 2000.

Orientador: Prof. Dr. Dirceu Spinelli

1. Nitretação por Plasma. 2. Espectroscopia Mössbauer. I. Título. 
MEMBROS DA COMISSÃO JULGADORA DA TESE DE DOUTORADO DE EDUARDO JOSÉ MIOLA, APRESENTADA AO PROGRAMA DE PÓS-GRADUAÇÃO INTERUNIDADES, ÁREA EM CIÊNCIA $E$ ENGENHARIA DE MATERIAIS, DA UNIVERSIDADE DE SÃO PAULO, EM 25/08/2000.

\section{COMISSÃO JULGADORA:}
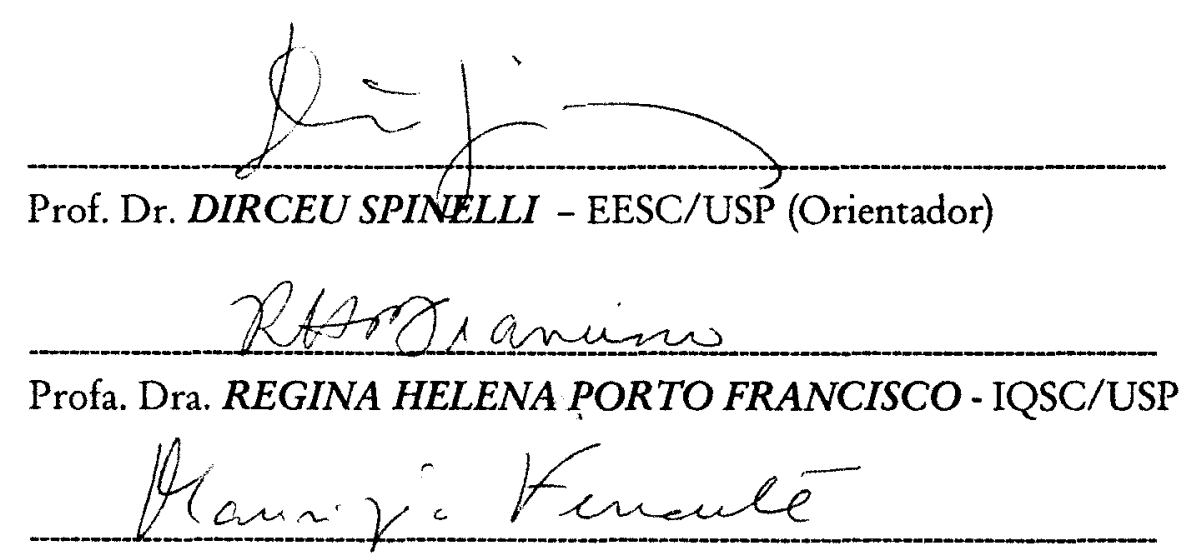

Prof. Dr. MAURIZIO FERRANTE - UFSCar

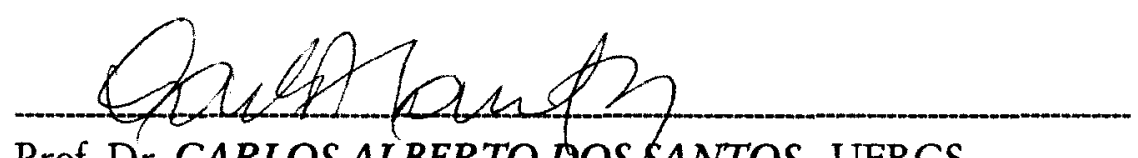

Prof. Dr. CARLOS ALBERTO DOS SANTOS - UFRGS

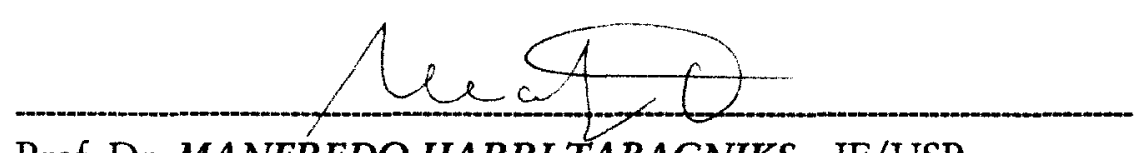

Prof. Dr. MANFREDO HARRI TABACNIKS - IF/USP 
A meus pais 


\section{AGRADECIMENTOS}

- Ao Professor Dirceu Spinelli, pela amizade e excelente orientação fornecida durante a elaboração deste trabalho.

- Aos Professores Sylvio Dionysio de Souza e Maristela O. M. Dionysio de Souza (DF-UFSCar), pela valiosa colaboração e ricas discussões nas interpretações do trabalho.

- Ao Professor Carlos Alberto dos Santos (IF-UFRGS), pelas discussões dos resultados de Mössbauer.

- Ao Professor Hercílio R. Rechenberg (IFUSP-USP), pela utilização do sistema de Mössbauer.

- Ao Professor Luiz Carlos Casteletti (EESC-USP), pela utilização do equipamento de nitretação por plasma.

- A Rosamel Melita Muñoz Riofano e Renato Cohen, pela amizade e colaboração neste trabalho.

- Ao Professor Clodomiro Alves Júnior, pelas sugestões no início do trabalho.

- A todos os funcionários, pós-graduandos e professores do Departamento de Engenharia de Materiais da EESC - USP, que direta ou indiretamente colaboraram para a realização deste trabalho.

- A CAPES, pela bolsa concedida. 


\section{PUBLICAÇÕES}

- Miola, E. J., Souza S. D., Olzon-Dionysio M. S., Spinelli D. Nascente A. P. P. \& Olivieri A. C., Surface Characterisation of Plasma-Nitrided Iron by X-Ray Photoelectron Spectroscopy, Applied Surface Science, v.144-145, 1999, p.272-277.

- Miola, E. J., Souza S. D., Olzon-Dionysio M. S., Spinelli D., \& Santos dos A. C., Nitriding of $\mathrm{H} 12$ tool steel by direct-current and pulsed plasmas, Surface and Coating Technology. v.116-119, 1999, p. 347-351.

- Miola, E. J., Souza S. D., Olzon-Dionysio M. S., Spinelli D., Soares M. R. F., Vasconcellos M. A. Z. \& Santos dos A. C., Near-Surface Composition and microhardness Profile of Plasma Nitrided H-12 Tool Steel, Materials Science and Engineering A - Structural Materials Properties Microstructure and Processing 256: v. 1-2, 1998, p.60-68.

- Miola, E. J., Souza S. D., Olzon-Dionysio M. S., Spinelli D., Carlos A. Olivieri, Hercílio R. Rechenberg \& Renato Cohen, Aplicaçőes da espectroscopia Mössbauer (CEMS) no Estudo de Aço carbono Nitretado , maio 1999, São Lourenço - MG, vol.1, pp.380.

- Miola, E. J., Souza S. D., Olzon-Dionysio M. S., Spinelli D., Paulo R. de SouzaNetto, Pedro A. P. Nascente \& Carlos A. Olivieri, Leonardo C. Gontijo, Rogério Machado, Aspectos Fisicos dos Residuos dos Desgastes do ferro Nitretado por Plasma, maio 1999, São Lourenço - MG, vol.1, pp.401.

- Miola, E. J., Souza S. D., Olzon-Dionysio M. S., Spinelli D., Paulo R. de SouzaNetto, Pedro A. P. Nascente \& Carlos A. Olivieri, Leonardo C. Gontijo, Rogério Machado, Homogeneidade da Nitretação por Plasma na Superficie dos Aços Baixo Carbono, maio 1999, São Lourenço - MG, vol.1, pp.399. 
- Miola, E. J., Souza S. D., Olzon-Dionysio M. S., Spinelli D., Pedro A. P. Nascente \& Carlos A. Olivieri, Caractenização de Ferro Nitretado por Plasma, pelas Técnicas CEMS e XRD , XXI Encontro Nacional de Física da Matéria Condensada, Junho 1998, Caxambu - MG, vol.1, pp.391.

- Miola, E. J., Souza S. D., Olzon-Dionysio M. S., Spinelli D.\& Rechenberg H. R., Estudo da Homogeneidade da Camada Superficial do Ferro Puro Nitretado por Plasma, pelas Técnicas CEMS e XRD , XXI Encontro Nacional de Fisica da Matéria Condensada, Junho 1998, Caxambu - MG, vol.1, pp.395.

- Miola, E. J., Souza S., D., Olzon-Dionysio M. S. \& Spinelli, D., Caracterizaçăo de camada Nitretadas do Ferro, utilizando Técnica de Desgaste e de Difratometria de Raio X., XX Encontro Nacional de Física da Matéria Condensada, Junho 1997, Caxambu - MG, vol.1, pp.374.

- Miola, E. J., Souza S. D., Olzon-Dionysio M. S. \& Spinelli, D., Nitretaçăo lónica no Aço Ferramenta H12: Método Dc Pulsado e năo Pulsado, XIX Encontro Nacional de Fisica da Matéria Condensada, Setembro 1996, Aguas de Lindoia - SP, vol.1, pp.638. 


\section{SUMÁRIO}

LISTA DE FIGURAS i

LISTA DE TABELAS V

LISTA DE ABREVIATURAS E SÍMBOLOS vii

RESUMO ix

ABSTRACT $\mathrm{x}$

1 INTRODUÇÃO 1

2 NITRETAÇÃO IÓNICA

2.1 INTRODUÇÃO

2.2 O PLASMA 6

2.2.1 Fundamentos da Descarga Elétrica 7

2.2.2 Descrição Geral da Descarga Luminescente 9

2.2.3 Aspectos Fundamentais da Química do Plasma 11

$\begin{array}{ll}2.2 .4 \text { Interaçōes do Plasma com a Superfície } & 14\end{array}$

2.3 DESCRIÇÃO DO EQUIPAMENTO E DO PROCESSO DE

$\begin{array}{ll}\text { NITRETAÇÃO POR PLASMA } & 18\end{array}$

2.3.1 Método de Aquecimento 23

$\begin{array}{ll}\text { 2.3.2 Vantagens da Nitretação lônica } & 25\end{array}$

2.4 MODELOS DA NITRETAÇÃO POR PLASMA 26

3 ESPECTROSCOPIA MÖSSBAUER 30

$\begin{array}{ll}3.1 \text { INTRODUÇÃO } & 30\end{array}$

3.2 ESPECTROSCOPIA MÖSSBAUER DE ELÉTRONS E DE RAIOS X DE CONVERSÃO

3.2.1 O Espectrômetro Mössbauer

3.2.2 A Fonte Mössbauer $\quad 40$

3.2.3 Detectores de Fluxo de Gás $\quad 41$

3.2.4 Calibração do Espectrômetro $\quad 42$

4 COMPOSIÇÃO E EVOLUÇÃO TÉRMICA DOS AÇOS NITRETADOS 47

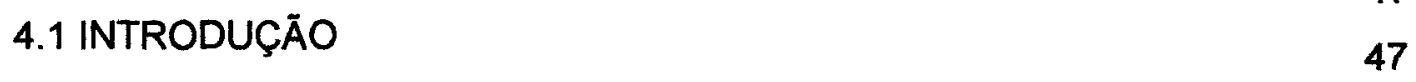

$\begin{array}{ll}4.2 & \text { SISTEMA Fe-C }\end{array}$ 


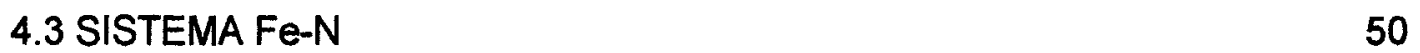

4.3.1 As Estruturas dos Nitretos de Ferro 53

4.4 CARBONITRETOS DE FERRO 63

5 MATERIAIS E MÉTODOS 65

5.1 INTRODUÇÃO 65

5.2 EQUIPAMENTO PARA NITRETAÇÃO IÓNICA 65

5.2.1 Operação do Equipamento 68

5.3 PREPARAÇÃO DAS AMOSTRAS DE FERRO 69

5.3.1 Caracterização Metalográfica $\quad 72$

$\begin{array}{ll}\text { 5.3.2 Difração de Raios X } & 73\end{array}$

5.3.3 Desgaste Mecânico $\quad 74$

$\begin{array}{ll}\text { 5.3.4 Ensaios de microdureza } & 76\end{array}$

5.3.5 Microscopia eletrônica de varredura (MEV) 78

$\begin{array}{ll}\text { 5.3.6 Espectroscopia Mössbauer } & 78\end{array}$

5.4 PREPARAÇÃO DAS AMOSTRAS DE AÇO AISI H12 80

5.4.1 Ensaios de Microdureza $\quad 81$

5.4.2 Difração de Raios X $\quad 81$

$\begin{array}{ll}\text { 5.4.3 Microanálise Eletrônica } & 81\end{array}$

5.4.4 Espectroscopia Mössbauer 82

6 RESULTADOS 83

6.1 - AMOSTRAS DE FERRO 83

6.1.1 Introduçăo 83

6.1.1.2 Nitretação em diferentes temperaturas $\quad 84$

6.1.1.3 Nitretaçăo durante tempos diferentes 95

6.1.1.4 Nitretação em diferentes freqüências 101

6.2 - AMOSTRAS DE AÇO AISI H12 110

6.2.1 Introdução 110

6.2.2 Estado cristalográico e químico da camada decompostos 111

6.2.3 Perfis do corte transversal das amostras $\quad 115$

7 DISCUSSÃO 118

7.1 ANÁLISES DOS RESULTADOS DAS AMOSTRAS DE FERRO 118

7.1.1 Fe nitretado em diferentes temperaturas 118

7.1.2 Fe nitretado em tempos diferentes $\quad 125$

7.1.3 Fe nitretado em diferentes freqüências 131

7.2 ANÁLISES DOS RESULTADOS DAS AMOSTRAS DO AÇO AISI H12 136

$\begin{array}{ll}7.3 \text { CORRELAÇÕES } & 147\end{array}$

8 SUGESTŐES PARA FUTUROS TRABALHOS 149

9 CONCLUSŐES 150

10 REFERÊNCIAS BIBLIOGRÁFICAS 153 


\section{LISTA DE FIGURAS}

Figura 1 - Curva característica da corrente versus voltagem 8

Figura 2 - Aspecto visual das regiões escuras e luminosas 10

Figura 3 - Interações que ocorrem na superfície do sólido 14

Figura 4 - Equipamento industrial automatizado para nitretação iônica ${ }^{[22,23]} \quad 18$

Figura 5 - Número de moléculas gasosas versus possibilidade de ionização ${ }^{[24]} 20$

Figura 6 - Voltagem e corrente em funçăo do tempo 22

Figura 7 - Densidade de corrente em função da voltagem 23

Figura 8 - Representação esquemática do modelo de Kölbel ${ }^{[9,32]} \quad 28$

Figura 9 - Esquema de níveis das transiçőes eletrônicas 30

Figura 10 - Distribuição de energia do processo ressonante 33

Figura 11 - Diagrama esquemático da desexcitação 36

Figura 12 - Geometria para o Efeito Mössbauer de retroespalhamento ${ }^{[42]} \quad 37$

Figura 13 - Efeito das Interações Hiperfinas nos niveis de energia do ${ }^{57} \mathrm{Fe} \quad 39$

Figura 14 - Diagrama de blocos para espectroscopia Mössbauer 40

Figura 15 - Esquema de decaimento do ${ }^{57} \mathrm{Co}^{[5,45]} 42$

Figura 16 - Corte transversal do detector proporcional de fluxo de gás $\quad 43$

Figura 17 - Espectros de energia (PHA). (a) espectro da fonte 45

Figura 18 - Espectro PHA de elétrons, com amostra (a), sem amostra (b) ${ }^{[45]} 46$

Figura 19 - Sítios intersticiais da ferrita. (a) Interstícios octaédricos 48

Figura 20 - Sítios intersticiais da austenita. (a) Interstícios octaédricos 49 
Figura 21 - Diagrama de fase do sistema Fe-N ${ }^{[50]} \quad 50$

Figura 22 - Sítios intersticiais da fase $\varepsilon$. (a) Interstícios octaédricos 51

Figura 23 - Espectro Mössbauer da austenita Fe-1,86\% $\mathrm{C}^{[53]} \quad 52$

Figura 24 - (a) Estrutura cristalina do nitreto $\alpha "-\mathrm{Fe}_{16} \mathrm{~N}_{2}$

Figura 25 - Espectro Mössbauer da martensita Fe-2,83\% N (em massa) 54

Figura 26 - Arranjo estrutural da fase $\gamma^{\prime}-\mathrm{Fe}_{4} \mathrm{~N}^{[57]} \quad 56$

Figura 27 - Espectro Mössbauer do nitreto $\gamma^{\prime}-\mathrm{Fe}_{4} \mathrm{~N}$

Figura 28 - Arranjo estrutural da fase $\varepsilon-\mathrm{Fe}_{3} \mathrm{~N}(\mathrm{a})$ e da fase $\varsigma(\mathrm{b})^{[49]}$

Figura 29 - Camada de planos de interstícios octraedrais para os nitretos $\quad 59$

Figura 30 - Variações das dimensões das fases $\varepsilon$ e $\xi$

Figura 31 - (a) Campos hiperfinos magnéticos do $\mathrm{Fe}_{\|} \quad 60$

Figura 32 - Espectro Mössbauer do nitreto $\varepsilon-\mathrm{Fe}_{3,2} \mathrm{~N}$ a 295K $\mathrm{K}^{[53]}$

Figura 33 - Espectro Mössbauer dos nitretos $\varepsilon$ e $\varsigma_{5}-\mathrm{Fe}_{2} \mathrm{~N}$

Figura 34 - Esquema do equipamento de nitretação por plasma 66

Figura 35 - Foto do equipamento de nitretação por plasma ${ }^{[69]} \quad 68$

Figura 36 - Dimensões da amostra em forma de pastiha 70

Figura 37 - Procedimento experimental para nitretação do Fe 71

Figura 38 - Esquema simplificado de uma máquina de ensaio 75

Figura 39 - (a) Disposição das mossas, para obtenção do perfil 77

Figura 40 - Esquema de blocos do espectrômetro Mössbauer 79

Figura 41 - Micrografia óptica do ferro (99,8\%). Ataque com Nital 2\% 84

Figura 42 - Perfil de microdureza ao longo da camada nitretada 85

Figura 43 - Micrografias das amostras de Fe nitretadas 86

Figura 44 - Micrografia típica da região da camada de difusão 87

Figura 45 - Difratogramas de GAXD da superfície das amostras de ferro 88

Figura 46 - Espectro de CEMS das amostras de aço H 12 nitretada 90

Figura 47 - Espectro Mössbauer para amostras nitretadas 91 
Figura 48 - Etapas do desgaste realizado nas amostras de Ferro nitretados

Figura 49 - Espectro de CEMS do ferro nitretado a $500^{\circ} \mathrm{C}$ durante $3 \mathrm{~h}$

Figura 50 - Perfil de microdureza ao longo da camada nitretada

Figura 51 - Micrografia ótica da evolução na espessura das camadas 96

Figura 52 - Difratogramas de GAXD das amostras de ferro

Figura 53 - Espectro Mössbauer para amostras nitretadas

Figura 54 - Espectro de CEMS do ferro nitretado a $500^{\circ} \mathrm{C}$ durante $6 \mathrm{~h}$ 100

Figura 55 - Perfil de microdureza ao longo da camada nitretada 102

Figura 56 - Micrografias (MEV) do Ferro nitretado por $3 \mathrm{~h}$ 103

Figura 57 - Difratogramas das amostras nitretadas durante $3 \mathrm{~h}$ 104

Figura 58 - Espectro de CEMS para amostras nitretadas 105

Figura 59 - Espectro de CEMS do ferro nitretado $2 \mathrm{kHz}$ 106

Figura 60 - Espectro de Mössbauer do ferro nitretado

Figura 61 - Difratogramas de raios $X \theta-2 \theta$ das amostras nitretadas

Figura 62 - Difratogramas de raios $\times \theta-2 \theta$ das amostras nitretadas

Figura 63 - Difratogramas de raios x com ângulo rasante

Figura 64 - Espectros de CEM das amostras nitretadas (AC)

Figura 65 - Espectro de CXMS da amostra nitretada em DC durante $1 \mathrm{~h}$

Figura 66 - Micrografia ótica do corte transversal das amostras nitretadas

Figura 67 - Perfis de microdureza Vickers

Figura 68 - Perfis do nitrogênio para amostras nitretadas em DC e AC

Figura 69 - Área espectral relativa de CEMS para as amostras nitretadas

Figura 70 - O "hard case" como função da raiz quadrada do tempo

Figura 71 - Área espectral relativa de CEMS para as amostras nitretadas 130

Figura 72 - Área espectral relativa de CEMS para as amostras nitretadas

Figura 73 - Áreas espectrais relativas para os espectros de CEMS 
Figura 75 - Espessura da camada de compostos e do "Hard case" 142

Figura 76 - "Hard case" como uma função da raiz quadrada do tempo 


\section{LISTA DE TABELAS}

Tabela I - Comparação entre a energia de recuo $\left(E_{R}\right)$

Tabela II - Resumo da maioria dos eventos durante o decaimento 37

Tabela III - Propriedades do nuclídeo Mössbauer ${ }^{57} \mathrm{Fe}^{[44]}$

Tabela IV - Nitretos formados no sistema Fe- $\mathrm{N}^{[49]}$

Tabela V - Parâmetros hiperfinos da austenita $(\gamma)$ e da martensita $\left(\alpha^{\prime}\right)$

Tabela VI - Parâmetros hiperfinos de alguns nitretos e carbonitretos 57

Tabela VII - Composição (\% em massa) dos elementos presentes no $\mathrm{Fe} \quad 69$

Tabela VIII - Condiçōes de tratamento da nitretação por plasma 71

Tabela IX - Condiçöes de tratamento da nitretaçăo por plasma 72

Tabela X - Composição (\% em massa) dos elementos presentes no aço $\quad 80$

Tabela XI - Condiçōes de tratamento da nitretaçăo do aço AISI H12 80

Tabela XII - Relação das amostras nitretadas e os parâmetros 92

Tabela XIII - Parâmetros Mössbauer de diferentes subespectros 94

Tabela XIV - Relação das amostras nitretadas com os parâmetros 99

Tabela XV - Parâmetros Mössbauer de diferentes subespectros 101

Tabela XVI - Relação das amostras nitretadas em diferentes freqüências $\quad 107$

Tabela XVII - Parâmetros Mössbauer de diferentes subespectros 108

Tabela XVIII - Parâmetros Mössbauer de diferentes subespectros 109

Tabela XIX - Valores típicos dos parâmetros obtidos no ajuste 114

Tabela XX - Concentração de nitrogênio em função da temperatura 121 
Tabela XXI - Concentração de nitrogênio em função da temperatura 128

Tabela XXII - Concentração de nitrogênio em função da freqüência 134

Tabela XXIII - Áreas espectrais relativas de CEMS e CXMS 137

Tabela XXIV - Áreas espectrais relativas de CEMS e CXMS 138 


\section{LISTA DE ABREVIATURAS E SÍMBOLOS}

\begin{tabular}{|c|c|}
\hline PHA & Analisador de Altura de Pulso \\
\hline $\mathrm{G}^{0}$ & Átomo do gás, no Estado fundamental \\
\hline $\mathrm{G}^{+}$ & Átomo do gás, no Estado lonizado \\
\hline$\gamma$ & Austenita \\
\hline$Q_{c}$ & Calor por Condução \\
\hline$Q_{c v}$ & Calor por convecção \\
\hline$Q_{r}$ & Calor por Radiação \\
\hline$Q_{t}$ & Calor Total Liberado \\
\hline$H$ & Campo Hiperfino Magnético \\
\hline$\varepsilon-\mathrm{Fe}_{2-3}(\mathrm{~N}, \mathrm{C})$ & Carbonitreto Épsilon \\
\hline$w$ & Ciclo de trabalho \\
\hline$\gamma_{i}$ & Coeficiente de emissão de elétrons secundários \\
\hline$\hbar$ & Constante de Planck \\
\hline$A C$ & Corrente Alternada \\
\hline DC & Corrente Direta \\
\hline $\operatorname{ccc}$ & Cúbica de Corpo Centrado \\
\hline cfc & Cúbica de Face Centrada \\
\hline$\delta$ & Desvio Isomérico \\
\hline DRX & Difração de Raios X \\
\hline GAXD & Difração de Raios X em Incidência Rasante \\
\hline HV & Dureza Vickers \\
\hline$E_{R}$ & Energia de Recuo \\
\hline$E_{0}$ & Energia de Transição \\
\hline hv & Energia do Fóton \\
\hline$E_{\gamma}$ & Energia do Fóton emitido \\
\hline$\varepsilon$ & Fase Épsilon \\
\hline$\xi$ & Fase Eta \\
\hline
\end{tabular}




\begin{tabular}{|c|c|}
\hline$\gamma$ & Fase Gama Linha \\
\hline f & Freqüência do Pulso \\
\hline$p(e)$ & Função Lorentziana \\
\hline$\Delta \mathrm{E}_{\mathrm{Q}}$ & Desdobramento Quadrupolar \\
\hline hcp & Hexagonal Compacta \\
\hline IPT & Instituto de Pesquisas e Tecnológicas \\
\hline $\mathrm{N}^{+}$ & ĺon Atômico de Nitrogênio \\
\hline $\mathrm{N}_{2}^{+}$ & Íon molecular do nitrogênio \\
\hline${ }^{57} \mathrm{Fe}$ & Isótopo do ferro \\
\hline keV & Kiloelétron-volt \\
\hline $\mathrm{kHz}$ & Kilohertz \\
\hline$\Gamma$ & Largura da linha a meia altura \\
\hline$\alpha^{\prime}$ & Martensita \\
\hline$\mu \mathrm{s}$ & Micro segundo \\
\hline$\mu \mathrm{m}$ & Micrometro \\
\hline MEV & Microscopia Eletrônica de Varredura \\
\hline мо & Microscopia Ótica \\
\hline $\mathrm{H}_{2}$ & Molécula de Hidrogênio \\
\hline $\mathrm{N}_{2}$ & Molécula de Nitrogênio \\
\hline$\alpha "-\mathrm{Fe}_{16} \mathrm{~N}_{2}$ & Nitreto de alfa duas linhas \\
\hline$\varepsilon-\mathrm{Fe}_{3} \mathrm{~N}$ & Nitreto Épsilon \\
\hline$\gamma^{\prime}-\mathrm{Fe}_{4} \mathrm{~N}$ & Nitreto Gama Linha \\
\hline a & Parâmetros de Rede \\
\hline W & Potência Fornecida pela Descarga \\
\hline Q & Quantidade de Calor Perdida para o Aquecimento do Catodo \\
\hline RF & Rádio Freqüência \\
\hline$T_{C}$ & Temperatura de Curie \\
\hline$t_{\text {off }}$ & Tempo de Plasma Desligado \\
\hline$t_{\text {on }}$ & Tempo de Plasma Ligado \\
\hline tcc & Tetragonal de Corpo Centrado \\
\hline mbar & Unidade de Pressão \\
\hline V & Volts \\
\hline
\end{tabular}




\section{RESUMO}

Este trabalho apresenta um estudo sobre a formação e evolução da camada de nitretos sobre substrato de ferro com pureza de $99,83 \%$ e do aço AISI $\mathrm{H} 12$, nitretados por plasma. As camadas foram obtidas com a variação sistemática das condições de nitretação, como temperatura, tempo e frequâencia do plasma. A atmosfera de trabalho empregada foi a de uma mistura gasosa de $20 \% \mathrm{~N}_{2}+80 \% \mathrm{H}_{2}$, mantida à pressão constante de 6 mbar, sob fluxo. Uma investigação detalhada da camada nitretada das amostras de ferro foi feita através de desgaste mecânico em passos sucessivos e após cada desgaste, as novas camadas foram analisadas por espectroscopia Mössbauer de elétrons de conversão (CEMS) auxiliadas por outras técnicas, como difração de raios X, microdureza e microscopia ótica e eletrônica. As análises superficiais demonstraram que a camada nitretada é formada por uma mistura de nitretos $\gamma^{\prime}-\mathrm{Fe}_{4} \mathrm{~N}, \varepsilon-\mathrm{Fe}_{3} \mathrm{~N}$ e $\varepsilon-\mathrm{Fe}_{3,2} \mathrm{~N}$, que variam suas proporçōes com as condiçōes de nitretação. Abaixo desta camada outros nitretos são formados como $\varepsilon-\mathrm{Fe}_{x} \mathrm{~N}(2 \leq \mathrm{x} \leq 3,2)$ e $\alpha "-\mathrm{Fe}_{16} \mathrm{~N}_{2}$. No aço $\mathrm{H} 12$, foi estudada a influência da nitretação por plasma em correntes contínua e pulsada. As amostras foram caracterizadas quanto ao perfil de microdureza, perfil de concentração de nitrogênio, difração de raios $X$ e espectroscopia Mössbauer de elétrons de conversão (CEMS) e de raios $X$ de conversão (CXMS). A camada composta próxima à superfície, como vista por CEMS, consiste de uma mistura de $\gamma^{\prime}-\mathrm{Fe}_{4} \mathrm{~N}$ e $\varepsilon-\mathrm{Fe}_{x}(\mathrm{~N}, \mathrm{C})$ enquanto a camada próxima à zona de difusão, investigada por CXMS, consiste de uma mistura de fases $\gamma^{\prime}-\mathrm{Fe}_{4} \mathrm{~N}, \varepsilon-\mathrm{Fe}_{\mathrm{x}}(\mathrm{N}, \mathrm{C}), \quad \alpha^{\prime \prime}-\mathrm{Fe}_{16} \mathrm{~N}_{2}$ e $\gamma$-austenita. $\mathrm{O}$ crescimento da camada nitretada quando difundida utilizando corrente contínua segue uma lei parabólica, $\mathrm{O}$ que não ocorre com o processo com corrente alternada. Este efeito deve ser devido à taxa de "sputerring" do catodo e da difusão auxiliada por radiação, que são mais acentuadas no caso de corrente alternada, para tempos de nitretação $t<2 \mathrm{~h}$. A situação é revertida para $\mathrm{t}>3 \mathrm{~h}$. 


\section{ABSTRACT}

This work investigates the formation and evolution of nitride layers on a $99.83 \%$ pure iron and a AISI $\mathrm{H}-12$ steel substrates by using plasma nitriding process. The layers were obtained by systematic variation of the nitriding conditions, such as temperature, time and plasma frequency. The employed atmosphere consisted of a gaseous mixture of $\mathrm{H}_{2}-20 \% \mathrm{~N}_{2}$, at a constant pressure of $6.0 \mathrm{mbar}$ in flux. A detailed investigation of the nitrided layer on iron samples was performed through surface mechanical wear in successive steps. After each step the layer was analysed by Conversion Electron Mössbauer spectroscopy (CEMS), as well as by other techniques, as X-ray diffraction, microhardness and optical and electronic metallography. The surface analysis of iron samples showed that the nitrided layers are formed by a mixture of $\gamma^{\prime}-\mathrm{Fe}_{4} \mathrm{~N}, \varepsilon-\mathrm{Fe}_{3} \mathrm{~N}$ and $\varepsilon-\mathrm{Fe}_{3,2} \mathrm{~N}$ nitrides, whose proportions have varied with the nitriding conditions. Below this layer, different nitrides are formed, $\varepsilon-\mathrm{Fe}_{x} \mathrm{~N}(2 \leq \mathrm{x} \leq 3.2)$ and $\alpha "-\mathrm{Fe}_{16} \mathrm{~N}_{2}$. For $\mathrm{H}-12$ steel substrates it was also studied the influence of direct and pulsed current on the layer. The samples were characterized related to the microhardness profile, nitrogen concentration profile, $X$ ray diffraction and Conversion Electron and X-ray Mössbauer spectroscopy (CEMS) and (CXMS). The near-surface compound layer, as probed by CEMS, consisted of a mixture of $\gamma^{\prime}-\mathrm{Fe}_{4} \mathrm{~N}$, and $\varepsilon-\mathrm{Fe}_{x}(\mathrm{~N}, \mathrm{C})$ phases. The near-diffusion zone compound layer, as probed by CXMS presented a mixture of $\gamma^{\prime}-\mathrm{Fe}_{4} \mathrm{~N}$, and $\varepsilon-\mathrm{Fe}_{\mathbf{x}}(\mathrm{N}, \mathrm{C}), \alpha^{\prime \prime}-$ $\mathrm{Fe}_{16} \mathrm{~N}_{2}$ and $\gamma$-austenite phases. For the plasma process, the growth of the nitrided layers in direct current follows the parabolic law, what does not occur when process with pulsed current is used. This effect is probably due to cathode rate sputtering and radiation-enhanced diffusion, the latter being more accentuated in the case of pulsed current, for nitriding times $t<2 h$. The situation is reversed for $t>3 h$. 


\section{1 - INTRODUÇĀO}

Nos últimos anos, o estudo das propriedades tribológicas das superficies dos materiais tornou-se fundamental em inúmeras aplicações industriais, quando estão presentes os fenômenos de desgaste e corrosão. Existem várias técnicas de tratamentos superficiais visando melhorar as propriedades superficiais dos materiais, incluindo processos mecânicos, térmicos, fisicos e químicos, sem que as propriedades de seu volume ${ }^{[1]}$ sejam alteradas. Nas últimas décadas, cada vez mais são utilizadas técnicas que fazem uso de feixe de íons ou feixes de elétrons, plasma, laser e deposição química e física de vapor, com tendência a abandonar as técnicas ditas convencionais, como: zincagem, galvanoplastia, nitretação gasosa, cementação e outras que também utilizam substâncias nocivas ao ambiente e de baixa eficácia. Existem dois métodos que utilizam partículas ionizadas para modificação da superfície ${ }^{[2,3]}$. Um deles é a implantação iônica, a qual consiste de um pequeno fluxo iônico com uma alta energia média por íon. O outro método é o de deposição assistida por plasma, que consiste de um grande fluxo iônico com energia média por ion, suficiente para causar pulverização catódica e defeitos na rede cristalina do material, conhecida como implantação iônica por imersão em plasma $\left(\mathrm{Pl}^{3}\right)$. Estes processos oferecem a possibilidade de se modificar as propriedades superficiais de materiais metálicos através do controle dos parâmetros do plasma.

A nitretação por plasma é um dos processos que utiliza a deposição assistida por plasma, também conhecida como nitretação iônica ou nitretação por 
descarga luminescente. Este processo termoquímico melhora o desempenho catalítico, a resistência à corrosão e à oxidação e também à adesão e as propriedades mecânicas da superfície, como dureza, fadiga, fricção e resistência ao desgaste $e^{[1]}$.

Embora a primeira patente desta técnica tenha sido registrada na década de 30 por J. J. Egan nos EUA e por Berghaus na Suiça ${ }^{[4,5,6]}$, somente por volta da década de 60 passou efetivamente a ser empregada, apesar do seu alto custo econômico e das várias dificuldades encontradas durante o processo, como abertura de arcos elétricos e o superaquecimento de partes das peças durante o tratamento. Atualmente, estes problemas foram praticamente resolvidos com 0 avanço tecnológico na área da eletrônica, principalmente com o desenvolvimento de fontes de tensão pulsada, sendo possivel variar a temperatura do tratamento somente com a variação do intervalo entre os pulsos, mantendo os demais parâmetros constantes, opção esta que não ocorria para o plasma com fonte de corrente direta (DC).

Na nitretação iônica, o fenômeno da descarga luminescente se forma quando um potencial elétrico é aplicado entre o anodo (câmara) e o catodo (a peça de trabalho), permitindo que um fluxo de gás na câmara inicie um processo de ionização, formando o plasma. A nitretação iônica diferencia-se dos outros processos convencionais de nitretação (gasosa e em banho de sais), por permitir o controle dos seus parâmetros. Este controle de variáveis permite pesquisar a influência dos parâmetros da nitretação, tais como: tempo, temperatura, mistura do gás, pressão e freqüência do pulso. Assim, as características metalúrgicas da superfície tratada podem ser estudadas, permitindo variar o tipo dos nitretos formados nas camadas de compostos e de difusão, de maneira a melhorar as propriedades superficiais tipo dureza, resistência ao desgaste, fadiga e corrosão. 
Desta forma, o conhecimento dos mecanismos que atuam na formação de uma camada nitretada, através da variação dos diferentes parâmetros no processo faz-se necessário, para que se possa prever quais condições e quais mecanismos otimizam a formação desta camada, de acordo com as necessidades de aplicação.

Vários modelos foram propostos para tentar explicar a cinética do processo de nitretaçăo iônica. Em 1973 Hudis $^{[]}$observou que os íons de nitrogênio e o íons das moléculas de nitrogênio - hidrogênio são os ingredientes principais do plasma. Propôs que os íons nitrogênio - hidrogênio são responsáveis pela melhora das propriedades produzidas na nitretação, comparando com as propriedades produzidas pelo gás nitrogênio ou pela mistura dos gases nitrogênio e argônio. Por outro lado, Tibbetts ${ }^{[8]}$, em 1974, sugeriu que a amostras são nitretadas principalmente pelas espécies neutras, átomos ou moléculas excitadas de nitrogênio. Em 1982, Petitjean ${ }^{1}$ apud Figueiredo (1991), adicionou ao mecanismo proposto por Tibbetts a reação entre as espécies do tipo $\mathrm{NH}_{\mathbf{x}}$ e a superfície da amostra. Já para Edenhofer ${ }^{[9]}$, a formação das camadas nitretadas pelo processo de nitretação iônica deve-se aos átomos de $\mathrm{Fe}$ arrancados da superfície ("sputtering"), que se combinam quimicamente com as espécies do plasma, formando nitretos de ferro (FeN) instáveis. Estes nitretos depositam-se sobre a superficie da amostra evoluindo termicamente para outras fases conhecidas mais estáveis, $\xi-\mathrm{Fe}_{2} \mathrm{~N}, \varepsilon-\mathrm{Fe}_{3} \mathrm{~N}$ e $\gamma^{\prime}-\mathrm{Fe}_{4} \mathrm{~N}$. Assim, pode-se avaliar que 0 entendimento completo do processo de nitretação por plasma ainda hoje não está claro.

\footnotetext{
'Petitjean, L. (1982). Etude d'une decharge eletrique dans un melange azote-hidrogene pour la nitruration de surfaces metallique. Paris, 1982. Tese (Doutorado) - ORSAY. apud Figueiredo, R. S. Análise de superfície em aços nitretados por espectroscopia Mössbauer. Florianópolis, 1991. 1p. Dissertação (Mestrado) - Universidade Federal de Santa Catarina.
} 
Desta forma, o objetivo deste trabalho é o de investigar a relação entre a formação das camadas de nitretos de ferro com os parâmetros de nitretação por plasma, bem como contribuir para o entendimento do mecanismo da nitretação iônica. Para um entendimento do mecanismo de formação e características microestruturais da camada de nitretos em diferentes temperaturas, freqüências de plasma e tempos de nitretação, utilizou-se o ferro com pureza de $99,87 \%$, por ser o principal constituinte da maioria dos materiais metálicos empregados industrialmente, e por se tratar de um sistema simples que não contém elementos de liga que possam influenciar nos resultados. A opção para realizar os estudos no ferro baseou-se também no fato de que a maior parte dos dados relatados na literatura são relativos aos aços ligados, cuja base é o ferro.

Já para o estudo da influência da nitretação por plasma tanto em corrente direta como pulsada, utilizou-se a aço AISI H12. Assim, neste trabalho foi investigada a formação de camadas de nitretos de ferro, usando como técnica principal a espectroscopia Mössbauer, em ambos os casos. 


\section{2 - NITRETAÇÃO IÔNICA}

\subsection{INTRODUÇÃO}

A nitretaçăo iônica é um processo termoquímico conhecido também como descarga luminosa ou nitretação por plasma. Esta técnica foi patenteada por J. J. Egan em 1931 nos E.U.A e por Bernhard Berghaus em 1932 na Suiça, mas somente por volta de 1960 , o processo passou a ser efetivamente usado industrialmente em peças automotivas, em equipamentos têxteis, etc ${ }^{[5,6]}$. Em 1973 já existiam 65 unidades empregando o processo, sendo sua maioria concentrada na Europa (Alemanha Ocidental, Alemanha Oriental, Suiça, Polônia, Espanha, Romênia e França $)^{[10]}$. Com o progresso em tecnologia de vácuo e no controle do processo, este número saltou para aproximadamente 1500 unidades em 1992, das quais somente 100 unidades estavam nos Estados Unidos da América ${ }^{[11]}$. A utilização deste processo por grandes companhias automotivas, como a Volkswagen, Peugeot, Citröen e Renault, através dos seus fornecedores de peças, indica que este poderá ser o principal processo de endurecimento superficial do futuro.

No Brasil, o processo não é muito utilizado no meio industrial, restringindo-se apenas às pesquisas desenvolvidas nas Universidades. As 3 principais Universidades pioneiras nesta área são UFRN, UFRGS e UFSC, que iniciaram suas pesquisas em $1985^{[3]}$. Em 1991 foi construído na Universidade Federal de São Carlos (UFSCar) um sistema de nitretação por plasma pulsado, 
com potência de $150 \mathrm{~kW}$, atualmente no Departamento de Materiais, Aeronáutica e Automobilística da Escola de Engenharia de São Carlos-USP. Com o objetivo de ampliar suas pesquisas, em 1996, o mesmo grupo construiu um equipamento de nitretação iônica com plasma contínuo e pulsado. $O$ interesse das empresas nacionais vem crescendo e rapidamente esta técnica irá substituir os antigos processos de nitretação gasosa e por banho de sais.

A seguir, será apresentada uma descrição genérica do plasma e da descarga elétrica utilizados no processo de nitretação.

\subsection{O PLASMA}

O plasma é considerado como o quarto estado da matéria e é definido como um gás constituído de espécies eletricamente carregadas e neutras como elétrons, íons, átomos e moléculas ${ }^{[9,12]}$. Na média, um plasma é eletricamente neutro, sendo que qualquer desequilíbrio de carga resultará em campos elétricos que tendem a mover as cargas de modo a restabelecer o equilíbrio. Como resultado disto, a densidade de elétrons mais a densidade de íons negativos deve ser igual à densidade de íons positivos ${ }^{[3]}$. Os plasmas diferem em muitos aspectos, de acordo com os quais são classificados e que incluem pressão, densidade de partículas carregadas e temperatura ${ }^{[13]}$. Para se produzir qualquer tipo de plasma é importante que exista uma descarga ou fluxo de corrente elétrica, através de um meio gasoso. A nitretação iônica utiliza o plasma no seu processo de tratamento superficial e também pode se chamada de nitretação por plasma, como é mais conhecida.

A seguir será apresentada uma descrição genérica dos fundamentos da descarga elétrica, utilizada nos processo de nitretação por plasma, bem como as reações que ocorrem no interior da descarga. 


\subsubsection{Fundamentos da Descarga Elétrica}

A descarga elétrica utilizada no tratamento de nitretação ocorre quando uma diferença de potencial elétrico é aplicada entre dois eletrodos, no interior de um sistema fechado e na presença de um gás a uma pressão parcial suficientemente baixa. No sistema utilizado, um dos eletrodos (o catodo) é a própria peça a ser tratada, enquanto que o outro é a própria parede do reator aterrada (o anodo). A descarga luminescente ocorre quando as moléculas deste gás, que deve possuir boa condutividade elétrica, são ionizadas pelas colisões com os elétrons viajando do cátodo (a peça a ser tratada) até o anodo (parede do reator). Os elétrons e os íons produzidos são acelerados pelo campo elétrico, colidindo com outras partículas e produzindo assim, mais íons e elétrons na seguinte combinação ${ }^{[3]}$ :

$$
e^{-}+G^{0} \rightarrow G^{+}+2 e^{-}
$$

onde $G^{0}$ é o átomo ou molécula do gás no estado fundamental e $G^{+}$é o íon deste gás.

Devido a esta ionização do gás, nesta pressão parcial, uma corrente elétrica é gerada e sustentada, dependendo da variação da diferença de potencial entre os eletrodos.

A Figura 1 mostra uma caracterização de corrente versus voltagem, de diferentes tipos de descarga. Na regiảo A-B (intervalo do tubo do contador Geiger), a corrente é extremamente baixa, porque poucas partículas são ionizadas e podem mover-se para os eletrodos. Nesta condição, o gás comporta-se como um mau condutor ôhmico. Com o aumento de voltagem, aumenta também a produção de ions e elétrons, que serão acelerados em direção aos eletrodos e neutralizados. Então a corrente começará a aumentar linearmente com a voltagem, até chegar a 
uma condição limite na qual todos os ions e elétrons alcançam os eletrodos, gerando uma corrente de saturação (região B-C). Com o aumento da voltagem, os elétrons adquirem energia para ionizar outros átomos, produzindo mais elétrons aumentando assim a corrente. Este aumento é exponencial e esta região B-C é chamada de descarga de Townsend. Nesta condição, os íons positivos, fótons e partículas neutras começam a bombardear o catodo, liberando elétrons secundários, produzindo desta maneira uma cascata de elétrons, responsável pela descarga auto-sustentada.

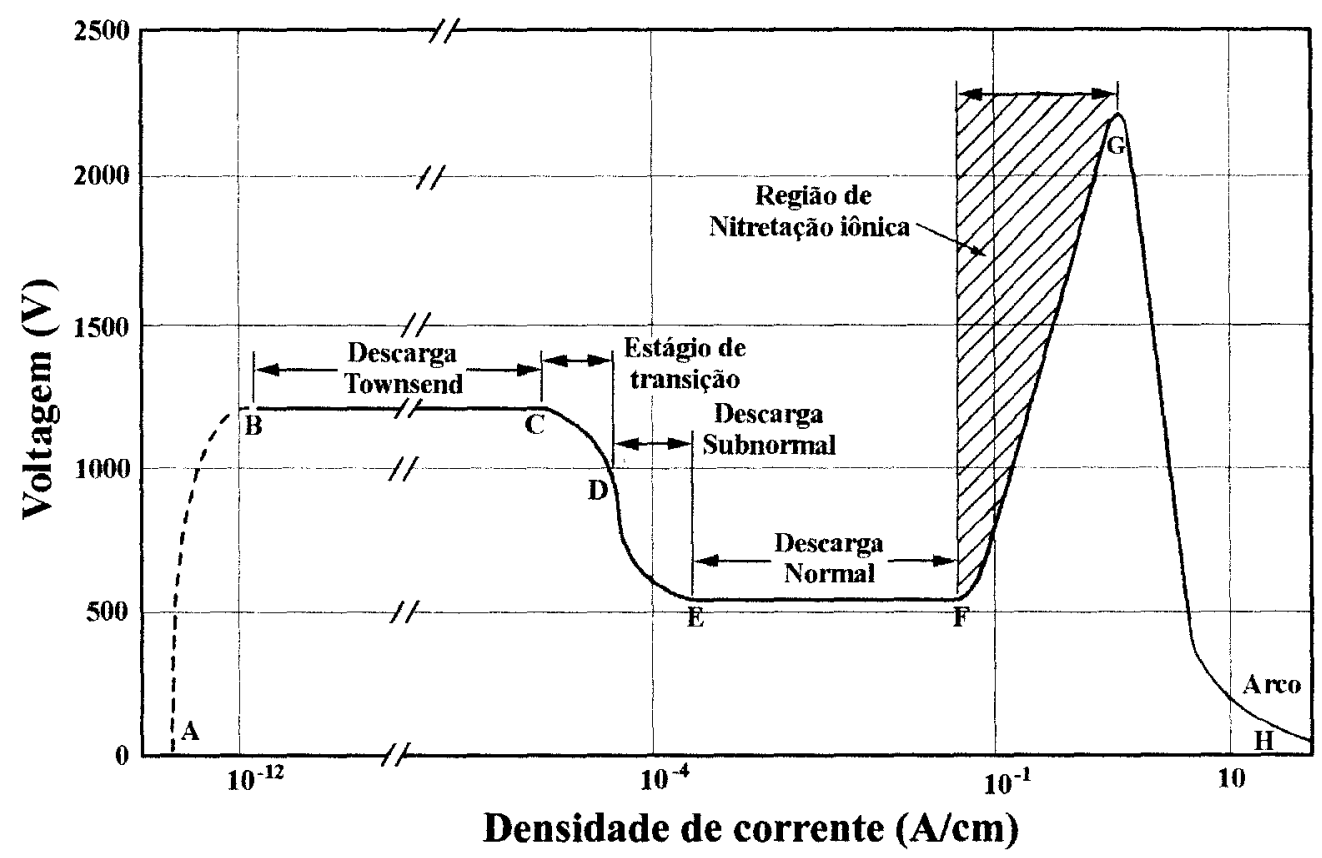

Figura 1 - Curva característica da corrente versus voltagem de diferentes tipos de descarga em gases, aplicada entre dois eletrodos ${ }^{[9]}$.

$\mathrm{Na}$ região a partir do ponto $\mathrm{C}$ há uma queda de voltagem, mesmo com o aumento da corrente, conhecida como luminescência subnormal. Então os elétrons secundários serão acelerados pelo forte potencial positivo do catodo, contra os átomos ou moléculas do gás, produzindo pares íons-elétrons através da colisão inelástica. Desta forma, os íons são acelerados para o catodo produzindo mais elétrons secundários, até a descarga se auto-sustentar. Enquanto este 
processo ocorre, o brilho na região do catodo se torna mais intenso. A região E-F é denominada de descarga normal, e é muito usada na industria de lâmpadas luminosas, tubos fluorescentes, etc. Depois de formada a luminescência, um acréscimo na voltagem é acompanhado de um aumento da corrente, para uma pressão constante. Esta região é chamada de luminescência anômala e é usada na maioria dos processos termoquímicos, como deposição de filmes finos, modificação superficial por oxidação, carbonetação, nitretação, etc., por apresentar uma alta densidade de corrente, e por promover o recobrimento completo e uniforme da superfície tratada. A densidade de corrente na região da descarga anômala é geralmente entre 0,1 e $5,0 \mathrm{~mA} / \mathrm{cm}^{2}$ para uma baixa voltagem entre 400 e $800 \mathrm{~V}^{[14]}$.

Se a voltagem é aumentada na região da descarga luminescente anômala, a densidade de corrente é aumentada. Este aumento em ambas as densidades, voltagem e corrente, produz um aquecimento local na superfície do catodo, cujo resultado é o aumento na emissão de elétrons, permitindo um aumento adicional na densidade de corrente. A descarga luminescente se concentrará nesta área superaquecida, provocando o arco elétrico. Uma descrição genérica de cada uma destas regiões é apresentada na seção abaixo.

\subsection{2 - Descrição Geral da Descarga Luminescente}

Na descarga luminescente anômala, no intervalo de interesse, existe um número de áreas luminosas e escuras, nas quais vários processos são dominantes. São três as áreas luminescentes e duas as escuras, entre o catodo (à esquerda) e o anodo (à direita), como ilustra a Figura 2. 


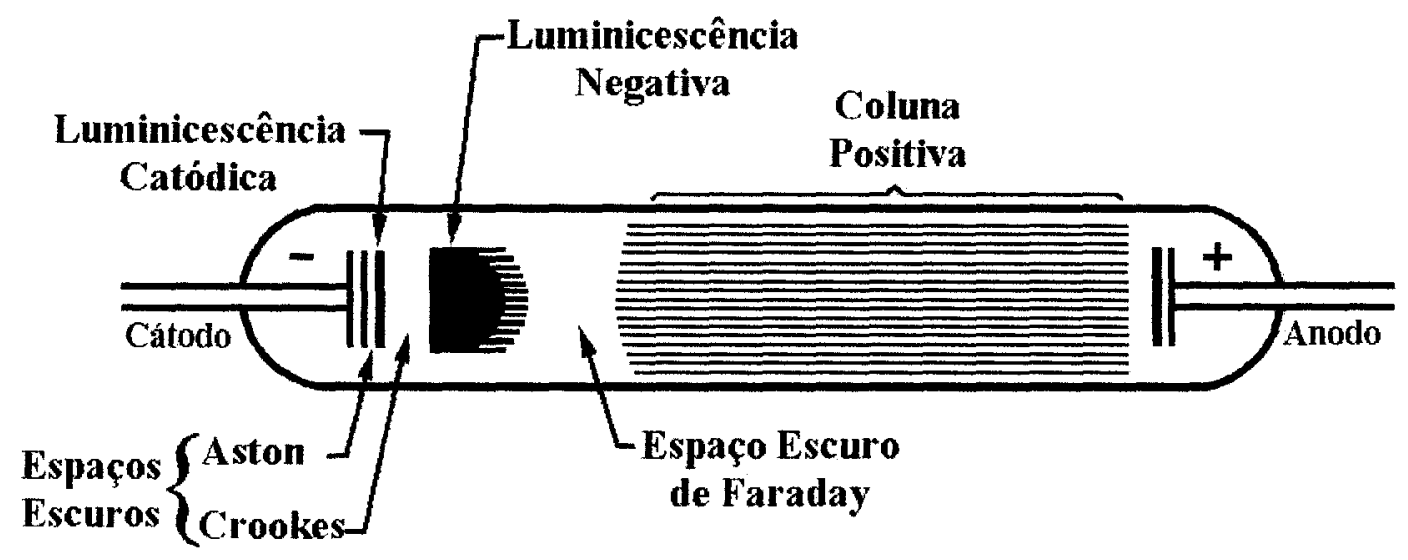

Figura 2 - Aspecto visual das regiões escuras e luminosas durante a descarga luminescente anômala ${ }^{[15]}$.

Devido às características distintas, estas áreas foram por muito tempo determinadas pelos seus nomes característicos. As áreas escuras são usualmente conhecidas pelos nomes de seus descobridores. $\mathrm{Na}$ frente do catodo existe uma área escura muito fina conhecida como espaço escuro de Aston, onde os elétrons com energia da ordem de $1 \mathrm{eV}$, não são capazes de excitar as moléculas do gás, que ocorre na faixa de energia de 5 a 10 eV. Próxima a esta área existe uma luminosidade chamada de luminescência catódica, que é caracteristica do material do catodo. Esta luminescência se forma devido à excitação dos átomos da superfície do catodo bombardeados pelas partículas do plasma. Adjacente a esta luminescência catódica existe um espaço escuro, conhecido como espaço escuro de Crookes, que é caracterizado por uma baixa concentração de elétrons devido ao grande campo elétrico. Devido à falta de carga, há pouca excitação das moléculas do gás, e por esta razão a região é aparentemente escura. Após esta área escura existe uma região muito luminosa e brilhante, chamada de região de luminescência negativa. É nesta região onde ocorrem a ionização e excitação do gás residual. $O$ íon positivo, depois de atravessar a interface entre a luminescência negativa e o espaço escuro de Crookes é acelerado em direção à superfície do catodo, pela diferença de potencial. $O$ bombardeamento dos íons não somente 
inicia a reação química para o processo de tratamento por plasma, mas também causa a produção de elétrons secundários, que são essenciais para a manutenção da descarga luminosa anômala.

As regiōes seguintes à luminescência negativa são o espaço escuro de Faraday e a coluna positiva. Como os elétrons perdem a maior parte de sua energia através das colisões ionizantes com outros elétrons na luminescência negativa, os elétrons ficam com pouca energia para excitar ou ionizar posteriormente o gás. Este é o início do espaço escuro de Faraday, aonde o campo elétrico vai aumentando gradualmente até um valor que caracteriza a coluna positiva.

\subsection{3 - Aspectos Fundamentais da Química do Plasma}

Como foi visto nas seçōes anteriores, o tratamento por plasma está associado a vários processos, onde íons e radicais ativos $\left(\mathrm{N}_{2}{ }^{+}, \mathrm{N}, \mathrm{NH}, \mathrm{CH}, \mathrm{C}\right)$ são produzidas na fase gasosa, através das colisões elétrons-moléculas, ou na superfície do catodo (peça de trabalho), através do bombardeamento dos íons, elétrons e fótons produzidos no plasma. Vários exemplos de processos elementares acontecem no plasma e na interface entre um plasma e a superficie do catodo e são descritas a seguir ${ }^{[16,17]}$.

lonização - Neste processo, os elétrons primários (mais energéticos), ao colidirem com as moléculas do gás, removem um elétron do átomo, produzindo um ín positivo e dois elétrons. Por exemplo, na nitretação, tem-se: 


$$
\begin{aligned}
& e^{-}+N_{2} \rightarrow 2 e^{-}+N_{2}^{+} \\
& e^{-}+H_{2} \rightarrow 2 e^{-}+H_{2}^{+} \\
& e^{-}+N_{x} H_{y} \rightarrow 2 e^{-}+N_{x} H_{y}^{+}
\end{aligned}
$$

Os dois elétrons produzidos pela colisão ionizante podem então ser acelerados pelo campo elétrico, adquirindo energia suficiente para provocar novas ionizações, e colaborando na manutenção da descarga luminescente. A energia mínima necessária para que ocorra o processo de ionização é igual à energia para remover um elétron fracamente ligado ao átomo e é conhecida como potencial de ionização. Para estas espécies, tem-se que o potencial de ionização é pouco superior a $10 \mathrm{eV}$.

Excitação - Quando a energia de colisão do elétron com o átomo ou molécula for menor do que aquela necessária para a ionização, um elétron do átomo é transferido para um nível de energia elevado, tornando-o excitado. Portanto se a energia de excitação for menor que o potencial de ionização, poderão ocorrer as seguintes reaçōes:

$$
\begin{aligned}
& e^{-}+N_{2} \rightarrow e^{-}+N_{2}^{*} \\
& e^{-}+H_{2} \rightarrow e^{-}+H_{2}^{*} \\
& e^{-}+N_{x} H_{y} \rightarrow e^{-}+N_{x} H_{y}^{*}
\end{aligned}
$$

Onde * representa os estados excitados.

Relaxação ou emissão - Como estes estados excitados destas espécies são instáveis, as moléculas tendem a retornar ao seu estado fundamental, através da transição dos elétrons para estados menos energéticos. Cada transição é 
acompanhada pela emissăo de fótons de energia específica, com a mesma diferença de energia entre os níveis, produzindo a luminescência característica. Através da análise espectroscópica desta luminescência é possivel identificar e determinar a concentração de várias espécies no plasma. Por exemplo:

$$
\begin{aligned}
& \mathrm{N}_{2}^{*} \rightarrow \mathrm{N}_{2}+\mathrm{hv} \\
& \mathrm{H}_{2}^{*} \rightarrow \mathrm{H}_{2}+\mathrm{hv} \\
& \mathrm{N}_{\mathrm{x}} \mathrm{H}_{\mathrm{y}}^{*} \rightarrow \mathrm{N}_{\mathrm{x}} \mathrm{H}_{\mathrm{y}}+\mathrm{hv}
\end{aligned}
$$

Recombinação - Da mesma maneira que a relaxação é o processo inverso da excitação, a recombinação é o processo inverso à ionização e ocorre quando as espécies ionizadas colidem com uma superfície, liberando elétrons e neutralizando as espécies de acordo com os seguintes processos de recombinação:

$$
\begin{aligned}
& \mathrm{N}_{2}^{+}+\mathrm{e}^{-} \rightarrow \mathrm{N}_{2} \\
& \mathrm{H}_{2}^{+}+\mathrm{e}^{-} \rightarrow \mathrm{H}_{2} \\
& \mathrm{~N}_{\mathrm{x}} \mathrm{H}_{\mathrm{y}}^{+}+\mathrm{e}^{-} \rightarrow \mathrm{N}_{\mathrm{x}} \mathrm{H}_{\mathrm{y}}
\end{aligned}
$$

Dissociaçăo - Neste processo, ocorre a ruptura de uma molécula, pela colisão com os elétrons no plasma. Dependendo da energia do elétron, poderá haver a formaçăo de espécies neutras, excitadas ou ionizadas. Para o caso particular do nitrogênio, tem-se:

$$
\begin{aligned}
& e^{-}+N_{2} \rightarrow e^{-}+N+N \\
& e^{-}+N_{2} \rightarrow e^{-}+N^{*}+N \\
& e^{-}+N_{2} \rightarrow 2 e^{-}+N^{+}+N^{*}
\end{aligned}
$$




\subsection{4 - Interações do Plasma com a Superfície}

A região catódica é onde se desenvolve a maioria dos fenômenos que ocorre na superfície de um sólido. Com a queda de potencial na região catódica os ions são acelerados na direção do catodo, adquirindo energia suficiente para causar a modificação na sua superfície. Ao colidirem com o catodo, vários fenômenos acontecem, como se pode ver na Figura 3. Dentre eles, destacam-se os seguintes $^{[18]}$ :

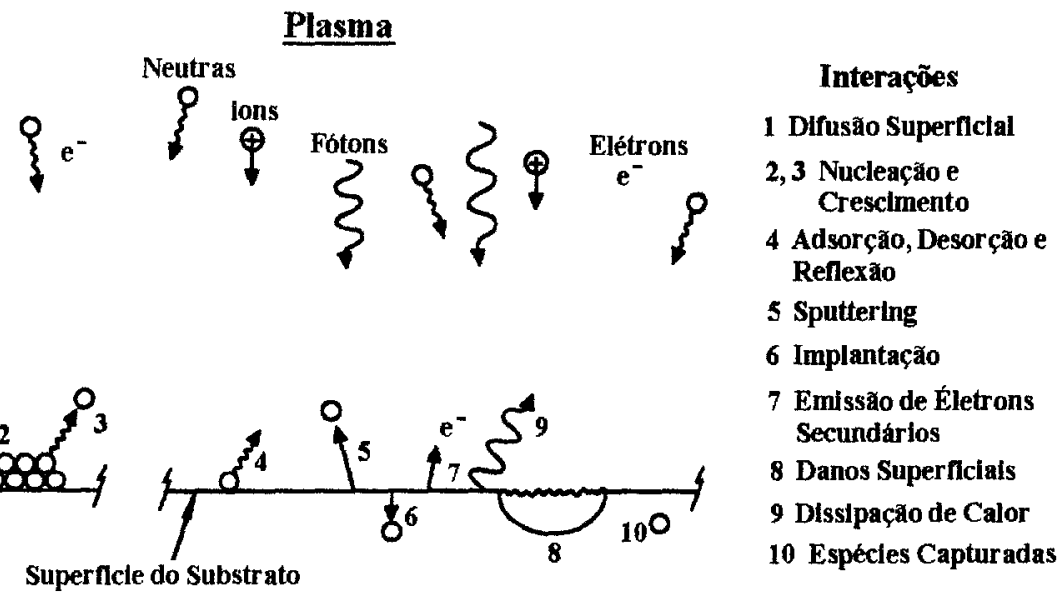

Figura 3 - Interações que ocorrem na superficie do sólido exposta a descarga luminosa. O lado direito da Figura indica os eventos gerais que acontecem, enquanto que $o$ lado esquerdo indica $o$ fenômeno encontrado na deposição ${ }^{[18]}$.

Difusão superficial - o momento transferido pelo bombardeamento de partículas na superfície do sólido pode resultar no aquecimento, na geração de defeitos e na interação de fônons na superfície e nas regiões próximas da superfície (poucas camadas acima do topo) de um sólido. Por estes modos de transferência de energia, a difusão superficial é melhorada, até mesmo a baixas energias de partícula $(<10 \mathrm{eV})$. Outros fatores ligados à difusão superficial são as mudanças morfológicas induzidas pelo bombardeamento de partículas. Estas 
alterações resultam na modificação na cristalinidade e na microestrutura e defeitos na estrutura dependendo da energia e da dose aplicada, afetando a cristalinidade da superficie. Para baixas energias $(\sim 10 \mathrm{eV})$, a incorporação e o aprisionamento predominam, enquanto que para altas energias $(\sim 100 \mathrm{eV})$, ocorre a aleatoriedade das orientações na superfície. Para energias próximas a $1 \mathrm{keV}$, os materiais podem ser amorfizados.

Implantação - as partículas energéticas podem penetrar na superfície onde permanecem implantadas. Este fenômeno está relacionando com a criação de locais de adsorsão e um aumento na probabilidade de incorporação é resultado da energia cinética associada com a reatividade química das espécies energéticas. Tal processo necessita de ions de média para baixa energia (50-500eV), e é utilizado extensivamente na dopagem de materiais na produção de circuitos integrados. Nos tratamentos termoquímicos, este processo é pouco usado devido à baixa energia dos íons.

Emissão de Elétrons secundários - a colisão de partículas energéticas sobre a superfície pode produzir a ejeção de elétrons, geralmente chamados de "secundários". Estes elétrons secundários são acelerados em direção ao plasma, devido ao campo na bainha catódica. A emissão de elétrons secundários é conseqüência do bombardeamento por elétrons, ions fótons e espécies neutras; cada um terá um coeficiente de elétron secundário diferente e uma dependência de energia diferente.

a) Bombardeamento por elétrons - os elétrons primários que atingem a superfície do sólido são muitas vezes elástica ou inelasticamente espalhados ${ }^{[15]}$. Alguns penetram no sólido liberando elétrons secundários, desde que a energia do elétron primário seja maior que a função trabalho do sólido. 
b) Bombardeamento por íons - para que haja emissão de elétrons secundários da superficie pelo bombardeamento iônico, a energia cinética deve ser duas vezes maior do que a função trabalho do metal. $O$ coeficiente de emissão de elétrons secundários para o bombardeamento iônico é dado pelo símbolo $\gamma_{i}$, é e muito dependente das condições da superfície do material (grau de contaminação) ${ }^{[15]}$.

c) Bombardeamento por espécies neutras - quando ions energéticos colidem com partículas neutras, elasticamente ou com troca de carga, há um aumento na energia destas partículas, suficiente para causar a emissão de elétrons secundários durante o bombardeamento da superficie.

d) Bombardeamento por fótons - a ejeção de elétrons devido ao bombardeamento por fótons é conhecida como fotoemissão. Para metais puros, a taxa de emissão depende da função trabalho do metal, isto é, da energia de ligação dos elétrons livres com o metal. As taxas fotoelétricas para muitos metais puros são da ordem de $10^{-4}$ a $10^{-3}$ elétrons por fóton próximos da freqüência do visível até o ultravioleta.

A somatória dos diferentes processos de bombardeamento descritos acima dá o coeficiente total de emissão de elétrons secundários.

Sputtering - é um processo de desarranjo e ejeção de átomos da superficie de um sólido (de mesmo ou de diferente material), devido à transferência de momento e das colisões em cascata associadas com o bombardeamento da superficie por partículas energéticas ${ }^{[7]}$. Para haver sputtering na superficie de um material, é necessário que a partícula incidente tenha a mesma ou maior energia do que a energia de ligação do átomo na superfície. 
De um modo geral, o "sputtering" da superficie de um sólido depende das massas relativas das partículas incidentes e as do alvo (catodo), da energia da partícula e do seu ângulo de incidência, da estrutura cristalográfica do material do alvo, da morfologia da superfície e da pressão do gás ${ }^{[3,15]}$.

Dissipação de Calor - durante o bombardeamento da superfície por íons ou por partículas neutras, uma grande porcentagem da energia dessas partículas é transferida para o catodo na forma de calor, não sendo necessário o aquecimento externo. Esta energia é usada em parte para aquecer e manter a temperatura de tratamento enquanto que a outra parte é dissipada por condução, convecção e principalmente por radiação para as paredes da câmara ${ }^{[19]}$. O calor total liberado, $Q_{t}$,é dado por ${ }^{[20]}$.

$$
Q_{t}=m c \frac{\Delta T}{\Delta t}+Q_{c}+Q_{c v}+Q_{r}
$$

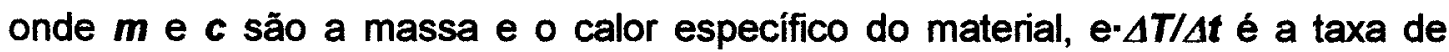
aumento de temperatura. Os demais parâmetros $Q_{c}, Q_{c v}$ e $Q_{r}$ são a quantidade de calor perdida para as paredes da câmara por condução, convecção e radiação, respectivamente. Quando a temperatura de tratamento é atingida, $\Delta T=0$, a energia térmica $\boldsymbol{Q}_{t}$ é dissipada para as paredes da câmara. A eficiência da energia de aquecimento pelo processo por plasma é dada por ${ }^{[21]}$ :

$$
\eta=\frac{Q}{W}
$$

onde $Q$ é a quantidade de calor perdida para o aquecimento do catodo e $\mathbf{W}$ é a potência fornecida pela descarga, dada pelo produto da voltagem entre os eletrodos e a corrente que passa entre eles. 
Estes tipos de interações do plasma com a superfície permitem a formação de uma camada superficial totalmente diferente do substrato, que no caso da nitretação e carbonitretação dos aços consiste de nitretos e carbonitretos, $\gamma^{\prime}$ $\mathrm{Fe}_{4} \mathrm{~N}, \varepsilon-\mathrm{Fe}_{3} \mathrm{~N}$ e $\varepsilon-\mathrm{Fe}_{2-3}(\mathrm{~N}, \mathrm{C})$, que são componentes decisivos na determinação das propriedades mecânicas e tribológicas. Portanto, torna-se conveniente uma revisão dos sistemas de equilibrio $\mathrm{Fe}-\mathrm{N}$, $\mathrm{Fe}-\mathrm{C}$ e Fe-N-C, o que será feito oportunamente.

\section{3 - DESCRIÇÃO DO EQUIPAMENTO E DO PROCESSO DE NITRETAÇÃO} POR PLASMA

As modernas unidades de nitretação iônica consistem de vários componentes, como mostra a Figura 4. O equipamento é normalmente constituído de um sistema de vácuo com bombeamento eficiente, uma unidade de distribuiçăo de gás, uma fonte de alimentaçăo (fonte de potência) e outros dispositivos de controle do processo.

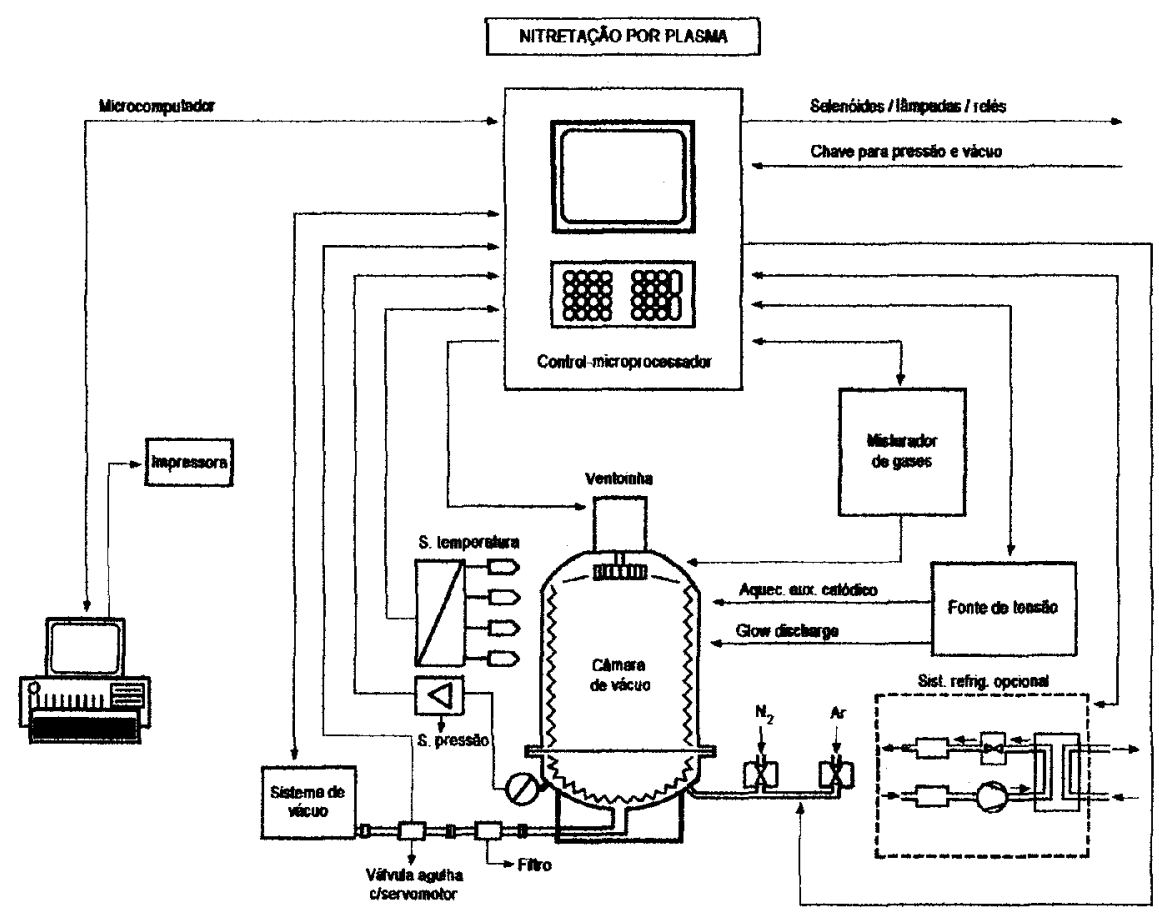

Figura 4 - Equipamento industrial automatizado para nitretaçāo iônica ${ }^{[22,23]}$. 
A cámara do forno usado neste processo, geralmente tem a forma cilíndrica, é construída em aço inoxidável, com saídas para medida da pressão, temperaturas e outros parâmetros de controle do processo. Devem existir também entradas para a mistura de gás nitretante. As paredes da câmara podem ser duplas, isoladas ou refrigeradas a água.

O sistema de vácuo deve ser capaz de atingir em torno de $10^{-2}$ mbar de pressão e possuir válvulas para controle da vazão e da mistura dos gases introduzidos no tratamento.

Para ocorrer à descarga luminosa, a pressăo parcial é um fator importante e afeta diretamente a probabilidade das moléculas da mistura de gás serem ionizadas. A distância que um elétron viaja depois de colidir com a molécula do gás é chamada de livre caminho médio. Este livre caminho médio é proporcional à temperatura e inversamente proporcional à pressão do gás. A Figura 5 mostra como a pressão influencia a probabilidade de ionização. Para uma pressão da ordem de $10^{-2}$ mbar o livre caminho médio será grande, com poucas moléculas no caminho do elétron entre os eletrodos. Portanto, a probabilidade de colisões entre os elétrons e as moléculas será pequena, para sustentar a corrente elétrica. Se a pressão parcial do gás é aumentada entre 0,01 e 10 mbar, o livre caminho médio decresce, e existirá um número suficiente de moléculas de gás para assegurar a ionização, e por conseqüência, sustentar a descarga luminosa. Se a pressão é aumentada ainda mais, haverá moléculas de gás mais que suficiente para assegurar colisões com elétrons. Embora os elétrons tenham um livre caminho médio menor entre as colisões, eles provavelmente não adquirem energia suficiente para causar ionização de qualquer molécula ${ }^{[23]}$. 


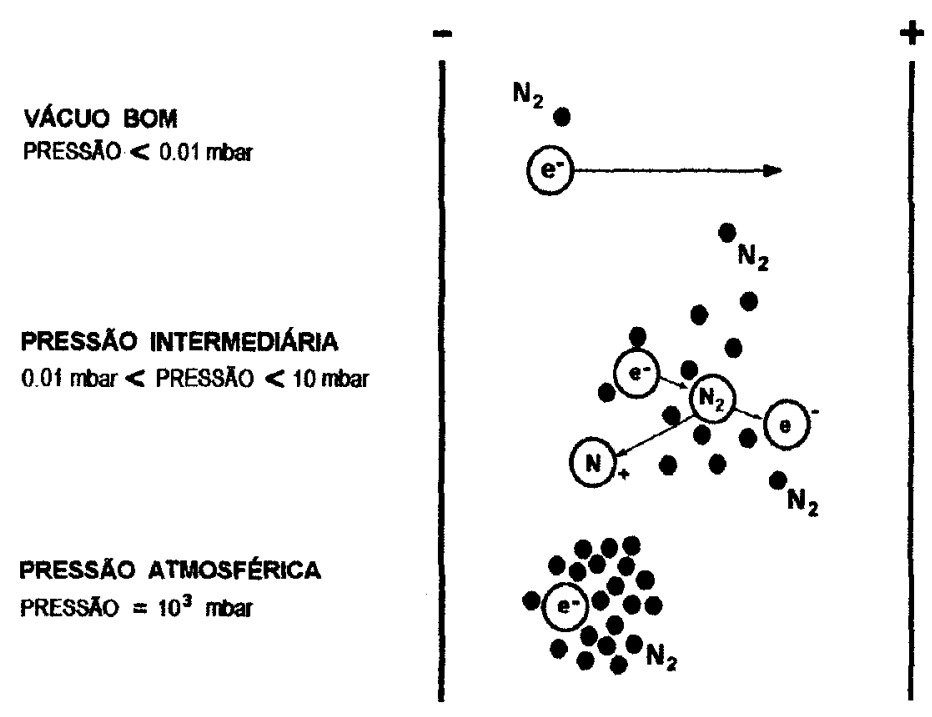

Figura 5 - Número de moléculas gasosas versus possibilidade de ionização ${ }^{[24]}$.

A fonte de potência possui um sistema de alimentação em corrente direta $(D C)$ e corrente alternada (AC), com uma voltagem máxima de $1000 \mathrm{~V}$ e uma corrente capaz de fornecer energia à câmara para aquecer a peça a uma temperatura entre 375 e $650^{\circ} \mathrm{C}^{[25]}$. Nos equipamentos de nitretação com fonte de potência DC uma voltagem contínua é aplicada ao sistema e, portanto, a densidade de corrente do plasma também é contínua ${ }^{[3]}$.

Este sistema de nitretação, com densidade de corrente do plasma continuo tem algumas desvantagens, devido aos problemas com abertura de arco, relacionadas com as impurezas retidas na superficie das peças e com sua geometria complexa das peças. Para resolver esse problema, várias soluçōes foram propostas e uma delas baseia-se na detecção e controle da variação da corrente com o tempo. Quando há variação da corrente com o tempo, isto significa a presença de arco e conseqüentemente interrupção de corrente, evitando a sua continuidade. Uma outra solução utilizada foi uma fonte de tensão retificada, com freqüência de $120 \mathrm{~Hz}$, que tinha como objetivo evitar o arco, ao em vez de desligá10 ${ }^{[3]}$. A solução final foi a utilização de um sistema de interrupção transistorizado com freqüência variando de 1 a $10 \mathrm{kHz}^{[26]}$. Os pulsos produzidos pela fonte de 
potência geram um alto nivel de energia do plasma, com alta voltagem e corrente baixa. Com estas características da fonte de potência, 0 arco praticamente não pode se formar, se o pulso apresentar certas características ${ }^{[27]}$, como:

- A forma do pulso deve ser quadrada, possibilitando um salto na voltagem de zero para o valor da descarga anômala.

- A largura do pulso deve ser menor que o tempo de desenvolvimento do

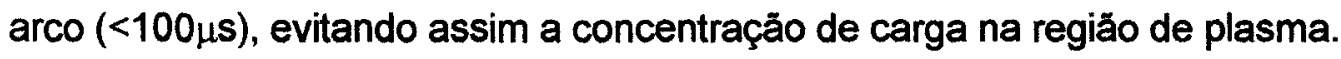

- O intervalo entre os pulsos deve ser pequeno o suficiente para permitir uma fácil ignição da descarga para o próximo pulso.

- A razão entre a largura e a interrupção do pulso deve ser variável, de forma a controlar a quantidade de energia consumida pelo plasma e assim controlar a temperatura da peça. Quanto maior o intervalo entre os pulsos, menor a energia do plasma e conseqüentemente menor a temperatura.

Os novos sistemas de nitretação já possuem fontes de tensão pulsada para geração de potência, diminuindo significativamente a presença de arco e o superaquecimento das peças. Segundo Dressler ${ }^{[2]]}$, o efeito de aquecimento do plasma pode ser controlado por um sistema que permite ajustar o tempo de plasma ligado e o tempo de plasma desligado, permitindo a escolha de outra variável, chamada de ciclo de trabalho, definida como:

$$
\text { POTÉNCIA - CICLO DE TRABALHO }=\frac{t_{\text {on }}}{t_{\text {on }}{ }^{t} t_{\text {off }}}
$$

onde $\boldsymbol{t}_{o n}$ é o tempo de plasma ligado, e $\boldsymbol{t}_{\text {oft }}$ é tempo de plasma desligado.

Com esta fonte de tensão pulsada, a voltagem do plasma pode ser aplicada continuamente para um ciclo de trabalho de $100 \%$ ou com tempos iguais de pulso ligado e desligado, para um ciclo de trabalho de $50 \%$. A Figura $6(a)$ mostra a 
relação de voltagem e corrente com o tempo, para uma freqüência de $10 \mathrm{kHz}$, produzindo uma potência de ciclo de trabalho de $50 \%$. Este ciclo de trabalho pode ser reduzido para $5 \%$ aumentando o intervalo de tempo desligado, sem efeitos indesejáveis na densidade dos ions $\mathrm{N}^{+}$na superfície da peça, Figura $6(\mathrm{~b})$. Portanto, a energia do plasma transferida para peça será pequena, não a aquecendo significativamente. Neste caso, aquecedores resistivos auxiliares são usados para produzir a temperatura necessária para o tratamento superficial. A densidade de corrente pode permanecer independente do ciclo de trabalho, contanto que a energia do plasma não aqueça o gás e que a peça permaneça completamente recoberta pela descarga luminosa ${ }^{[28]}$.

A Figura 7 apresenta uma pequena variação da voltagem e da densidade de corrente em relação à potência, para variações entre $5 \%$ e $50 \%$ do ciclo de trabalho, em uma descarga luminosa anormal.
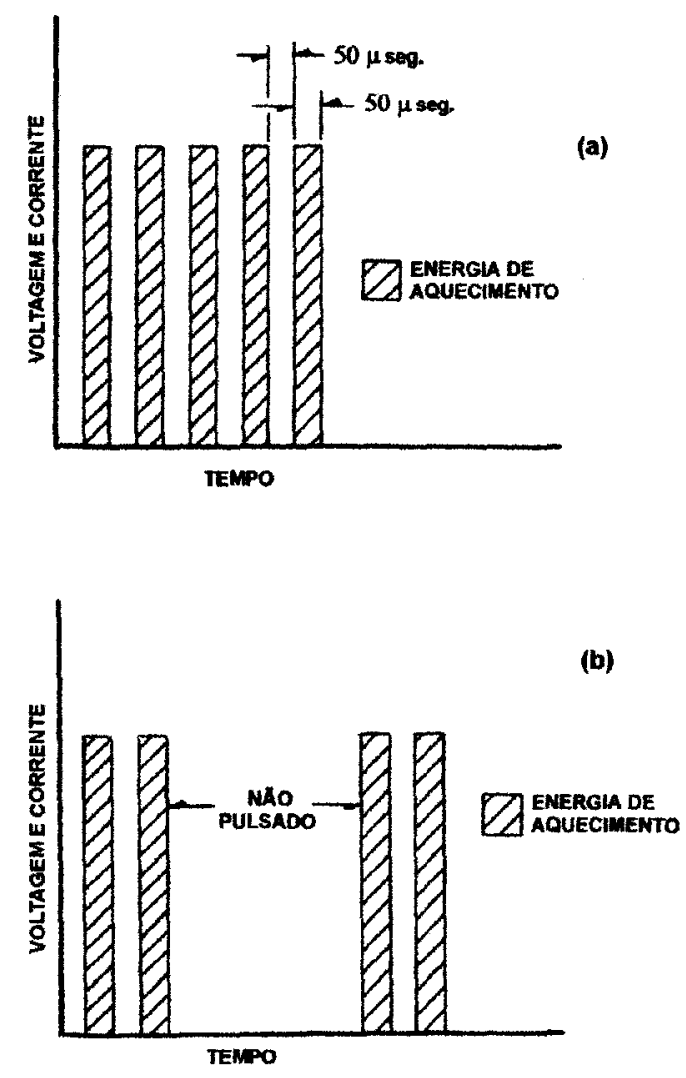

Figura 6 - Voltagem e corrente em função do tempo, com uma frequiência de pulso de $10 \mathrm{kHz}$ produzindo um: (a) ciclo de trabalho de $50 \%$; (b) um ciclo de trabalho de $5^{[28]}$. 


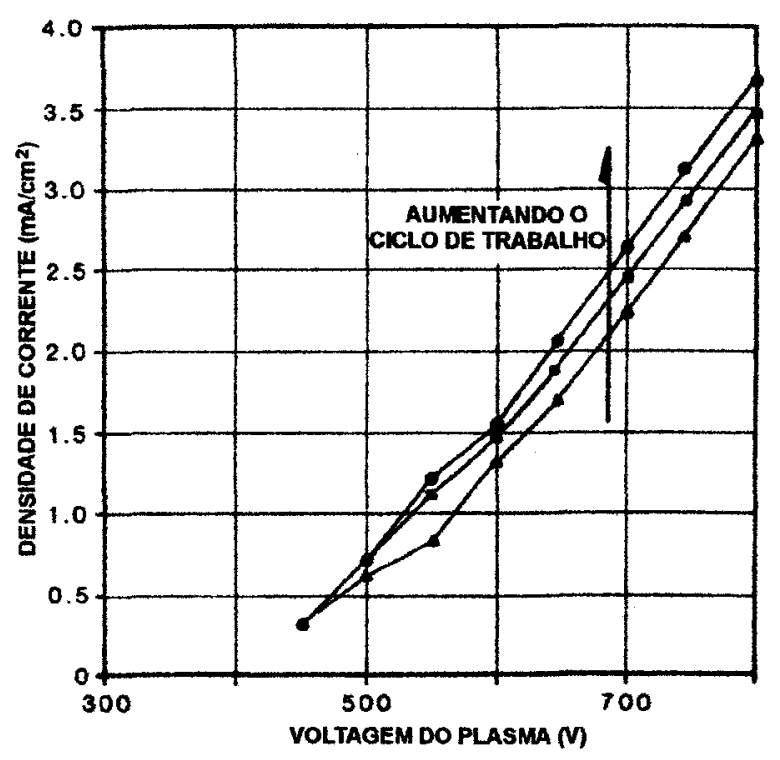

Figura 7 - Densidade de corrente em funçăo da voltagem do plasma e do ciclo de trabalho, para uma pressão de gás, temperatura da superficie e composição do gás fixa ${ }^{[28]}$.

\subsubsection{Método de Aquecimento}

A nitretação por plasma inicia-se quando a câmara está submetida a um vácuo de aproximadamente $4 \times 10^{-2} \mathrm{mbar}$, para então se introduzir o gás usado na nitretação (geralmente uma mistura de $\mathrm{N}_{2}+\mathrm{H}_{2}$ ), até que este gás alcance a pressão de 0,2 mbar. Em seguida, aplica-se uma diferença de potencial de aproximadamente $350 \mathrm{~V}$ entre os eletrodos, para iniciar um periodo de limpeza pelo bombardeamento iónico ${ }^{[29]}$. Nesta etapa surgem faíscas em alguns pontos da superfície contaminada do catodo, que săo limpas por "sputtering". Em seguida, introduz-se mais gás nitretante no interior da câmara até atingir a pressăo de trabalho, entre 1 a $10 \mathrm{mbar}$.

Para pressões abaixo desta faixa, a descarga luminescente possui uma cor rosada de pouca intensidade, característica do material do catodo e do gás. Quando se aumenta a pressão, esta luminescência fica mais intensa e localizada em torno do catodo. Nestas condições, o plasma reveste completamente 
o catodo e a peça a ser nitretada e os íons carregados positivamente e de alta energia cinética (resultados da colisão com as moléculas do gás) são acelerados para a superfície da peça ${ }^{[9]}$ e sua energia cinética é convertida em forma de calor, para o aquecimento da superfície da peça (catodo), até se atingir uma condição de descarga adequada à nitretação.

Segundo Wolfgang ${ }^{[23]}$, além deste tipo de aquecimento produzido pelo plasma, existem outros dois tipos de aquecimentos:

- Por convecção, onde o aquecimento é produzido em um forno a vácuo em pressão relativamente baixa, em uma atmosfera de nitrogênio. O gás é aquecido por elementos resistivos e circula por meio de um ventilador através do forno. O importante na transferência de calor dos elementos de aquecimento para a peça é o coeficiente de transferência de calor do gás, a capacidade calorífica do gás e a velocidade das moléculas ao longo do aquecedor e a superfície da peça. Para prevenir o aquecimento das paredes, a câmara é completamente isolada. Caso contrário, o gás transfere mais calor para as paredes da câmara, não aquecendo suficientemente a peça.

- Por radiação, em que o aquecimento também é produzido em um forno a vácuo com uma pressão menor que $133 \mathrm{mbar}$, onde o aquecimento por convecção não é significativo. A peça a ser aquecida é cercada pelos elementos resistivos. Estes elementos são aquecidos eletricamente ou podem possuir uma blindagem interna (aquecedor catódico), que é aquecido pela descarga luminosa do plasma. Existem três fatores importantes na transferência de calor dos elementos aquecedores para a peça. São eles: a diferença de temperatura entre a peça e os aquecedores, a razão entre área superficial da peça e do aquecedor e seus coeficientes de emissão. 


\subsubsection{Vantagens da Nitretação lónica}

A nitretaçăo iónica, quando comparada com os processos convencionais de nitretação (gás e banho de sal), oferece tanto um controle mais preciso do fornecimento de nitrogênio à superfície da peça, como a habilidade para selecionar uma camada monofásica $\varepsilon$ ou $\gamma^{\prime}$, que são escolhidas, dependendo da aplicação ou para prevenir a formação por completo da camada formada pela mistura de fases, denominada camada branca ${ }^{[30]}$.

Outras vantagens da nitretação iônica são:

- Tempo de tratamento menor quando comparado com os processos convencionais. Para uma nitretação gasosa de 40 a $60 \mathrm{~h}$, a nitretação iônica obtém a mesma espessura de camada num tempo aproximado de $20 \mathrm{~h}$, utilizando a mesma temperatura de tratamento.

- Reprodutibilidade segura do tratamento devido à flexibilidade no controle de seus parâmetros.

- Baixa temperatura de tratamento (menores que $375^{\circ} \mathrm{C}$ ), na qual é possivel se realizar a nitretação, evitando assim distorçōes nas dimensōes da peça, que ocorrem normalmente nos tratamentos de maior temperatura ${ }^{[23]}$.

- Uniformidade na espessura da camada nitretada, devido ao tratamento homogêneo em toda área superficial, até em pequenos furos e fendas evitando o superaquecimento.

- Economia de energia e do gás utilizado em relação aos outros processos convencionais. Na nitretação iônica trabalha-se com uma baixa pressão (1 a 10mbar) e um fluxo relativamente baixo, economizando o consumo de gás. Há redução do consumo de energia, devido ao aquecimento apenas da peça e não necessitando aquecer todo o forno, como ocorre nos fornos resistivos. 
- Facilidade na nitretação de partes da peça, utilizando uma proteção de cobre ou estanho sobre a região onde não se deseja realizar o tratamento.

- Facilidade de automação dos equipamentos de nitretação em assegurar um melhor controle dos parâmetros do processo, resultando numa maior confiabilidade e reprodutibilidade ${ }^{[26,31]}$.

A maioria das desvantagens que existe no processo já possui soluções. E algumas limitações passam a ser vantagens, sob alguns aspectos. Por exemplo, quando se nitreta peças com pequenos furos, existe um limite de diâmetro abaixo do qual o plasma não penetra. Este limite é de aproximadamente duas vezes o tamanho da bainha catódica ${ }^{[15]}$. Neste caso, a parte interna do furo não será nitretada. Portanto, esta limitação pode se transformar numa vantagem, caso, não se pretenda nitretar o furo ${ }^{[3]}$.

\subsection{MODELOS DE NITRETAÇÃO POR PLASMA}

Como foi mencionado anteriormente, somente na década de 60 a técnica de nitretação por plasma despertou o interesse, com novas pesquisas e com vistas à compreensão dos mecanismos da técnica. Antes de descrever os dados e estudos referentes à estrutura do Fe puro e propriedades dos sistemas Fe$\mathrm{N}$ e Fe-N-C, será feito um breve relato dos principais modelos no processo de interações plasma/superfície, transferência de massa e descargas elétricas, com o objetivo de fornecer uma melhor compreensão dos fenômenos envolvidos na formação da camada de compostos. Uns dos modelos mais aceitos pela maioria dos pesquisadores da área foi o proposto por Kölbel ${ }^{[9,}{ }^{32]}$, que é um mecanismo baseado no bombardeamento dos átomos de Fe do cátodo (peça) por íons de 
nitrogênio e partículas neutras altamente energéticas, possibilitando a ocorrência de importantes reaçőes, sem apontar o efeito dominante. A Figura 8 mostra os mecanismos de formação da camada pelo modelo de Kölbel para a nitretação por plasma. Os íons acelerados em direção a superfície da peça, além de aquecer a superfície, arrancam átomos de Fe ("sputtering"). Estes átomos arrancados reagem com as espécies reativas do plasma próximo à superfície da peça, formando compostos instáveis ( $\mathrm{FeN}$ ), que ao serem adsorvidos na superficie das peças decompõem-se em nitretos mais estáveis com teores mais baixos de nitrogênio ( $\xi$ $\mathrm{Fe}_{2} \mathrm{~N}, \varepsilon-\mathrm{Fe}_{2-3} \mathrm{~N}, \gamma^{\prime}-\mathrm{Fe}_{4} \mathrm{~N}$ ), liberando átomos de nitrogênio, que por sua vez, pelo processo de difusão a partir da superfície penetram no interior da peça.

No modelo descrito por Jones ${ }^{[33]} \circ$ mecanismo de nitretação predominante foi atribuído a transferência de massa dos íons $\mathrm{NH}^{+}$e $\mathrm{NH}_{2}{ }^{+}$. Neste experimento, ele demonstrou que a adsorção de moléculas de nitrogênio não é responsável pela nitretaçăo. Em outro experimento em atmosfera de $\mathrm{N}_{2}$ e $\mathrm{Ar}$, os ions de $\mathrm{N}^{+}, \mathrm{N}_{2}^{+}$e $\mathrm{Ar}^{+}$são espécies dominantes. $\mathrm{O}$ argônio tem uma taxa de "sputtering" maior do que a produzida pelo $\mathrm{H}_{2}$ e $\mathrm{N}_{2}$ juntos. Nestas condiçőes, 0 "sputtering" do ferro deve ser grande e os nitretos de ferro devem ser formados, 0 que não ocorre. Independente desta informação, estudos demonstraram que a mistura gasosa de $\mathrm{N}_{2}$ e $\mathrm{Ar}$ produzem camadas com menores durezas e profundidades. Quando o $\mathrm{H}_{2}$ é adicionado à mistura, a concentração dos íons de nitrogênio e argônio diminui consideravelmente, enquanto que as de $\mathrm{H}^{+}$e $\mathrm{NH}_{x}^{+}$ tornam-se predominantes. Nestas condições, a taxa de "sputtering" deve diminuir e a probabilidade de formação de nitretos deve ser menor devido à pequena concentração de nitrogênio. 


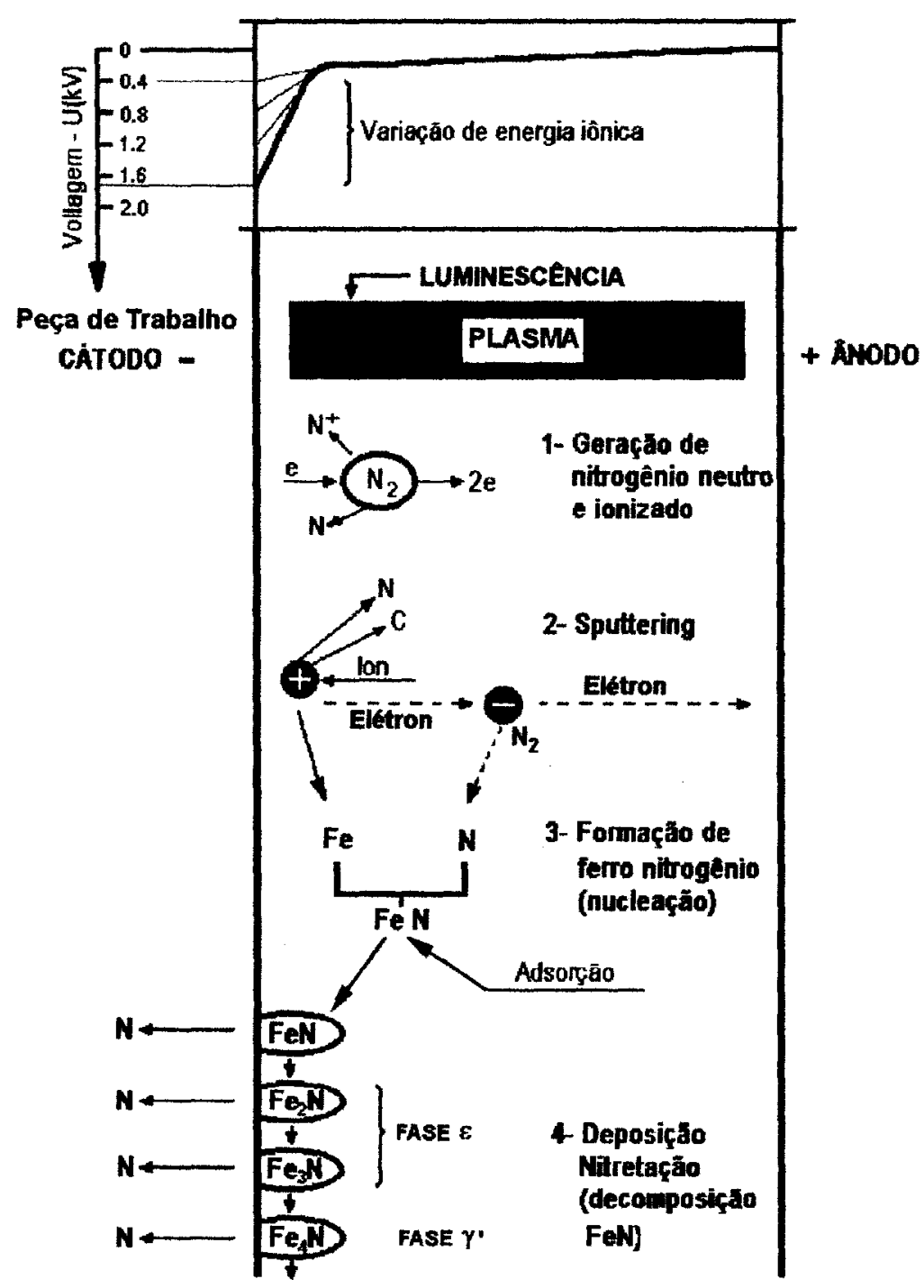

Figura 8 - Representação esquemática do modelo de Kölbel ${ }^{[9,32]}$.

Mas o que se observou foi um aumento na dureza da camada nitretada. Quando o Ar é completamente substituída pelo $\mathrm{H}_{2}$, a camada cresce mais ainda. Destas observaçōes, Jones concluiu que o processo deve ser controlado pelos radicais $\mathrm{NH}_{x}^{2}$.

Posteriormente, Tibbetts ${ }^{[8]}$ contrariou completamente 0 modelo acima, afirmando que os átomos neutros é que são responsáveis pela nitretação. Tibbetts nitretou amostras de aço e ferro envolvidas em uma grade de repulsão de íns positivos, presa no porta-amostra. Ele observou que a dissociação do 
nitrogênio na amostra foi a mesma com ou sem grade. Com estes resultados, concluiu que as espécies ionizadas na descarga luminescente não são importantes para a nitretação iônica. Outro arranjo experimental utilizando um tubo de aço colocado perpendicularmente próximo à uma grade catódica, proposto por Tibbetts para identificar quais as espécies responsáveis pela nitretação, demonstrou que as espécies ativas na nitretação são as espécies atômicas neutras. Portanto, a contribuição das espécies do tipo $\mathrm{NH}_{\mathrm{x}}$ para a nitretação proposto por Hudis é claramente de natureza secundária. A melhora na nitretação obtida por ele é devido ao efeito da redução dos óxidos da superfície pela mistura do $\mathrm{H}_{2}$.

Recentemente, Ricard ${ }^{[34,35]}$ e outros nitretaram amostras de aço em pós-descarga. Os resultados obtidos são comparáveis aos da descarga luminescente. Eles demonstraram que as espécies ativas com tempo de vida longo são as responsáveis pela nitretação na pós-descarga. A partir destes resultados, foi concluido que a pulverização não é o principal pré-requisito para a nitretação por plasma.

Como se pode observar, esta técnica de nitretaçăo trás muita controvérsia sobre os mecanismos de formação dos nitretos. Desta forma, não é possivel utilizar um único modelo para descrever os principais mecanismos de transferência de massa envolvidos na nitretação por plasma. É possível que todos os mecanismos estejam presentes no processo, mas, de acordo com diagnósticos de plasmas mais recentes, o mecanismo mais importante parece ser o da interação de átomos formados pelo plasma diretamente com a superfície da peça e sua subseqüente difusão dentro da mesma. 


\section{ESPECTROSCOPIA MÖSSBAUER}

\subsection{INTRODUÇÃO}

Um processo de absorção atômica é dito ressonante quando um fóton de energia $E=h v$, emitido por um átomo excitado é absorvido por um átomo idêntico, o qual se encontra no estado fundamental. Este fenômeno foi demonstrado por Wood ${ }^{[36]}$, utilizando um feixe de luz amarela proveniente de uma lâmpada de sódio, que ao passar por uma ampola de vapor do mesmo elemento, emitia luz amarela em todas as direções, em consequeência do decaimento dos átomos que haviam absorvido radiaçăo da fonte de luz.

Este processo, esquematizado na Figura 9, é chamado absorçăo ressonante de radiação eletromagnética.

ÁTOMO FONTE

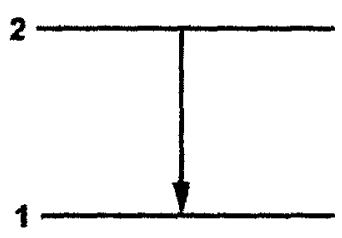

ÁTOMO ABSORVENTE

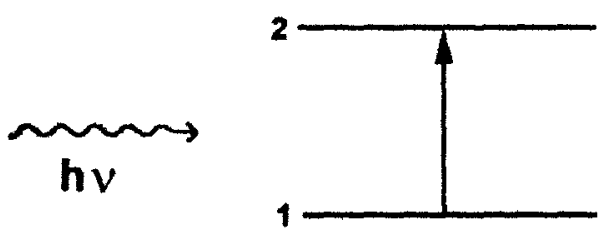

Figura 9 - Esquema de niveis das transiçóes eletrônicas no processo de absorção ressonante ${ }^{[3]}$.

A descriçăo completa do fenômeno envolve a conservação da energia, e a conservação de momento. De acordo com as leis de conservação, a 
emissão de um fóton por um átomo deverá recuar este átomo com um momento $p$, portanto com uma perda de energia de recuo:

$$
\begin{aligned}
& E_{R}=\frac{E_{\gamma}^{2}}{2 M c^{2}} \\
& E_{\gamma}=E_{0}-E_{R}
\end{aligned}
$$

onde $E \gamma$ é a energia do fóton emitido, $\boldsymbol{M}$ é a massa do átomo, $\boldsymbol{c}$ é velocidade da luz, e $E_{0}$ a energia de transição.

O átomo absorvedor, por outro lado, também recua ao adquirir a energia $E_{R}$ quando absorve o fóton. Portanto, o átomo absorvedor só será excitado, se o fóton tiver uma energia $E_{0}+E_{R}$. Teoricamente, o processo de absorção ressonante, que parecia trivial, tornou-se naturalmente impossível, a não ser que exista uma compensação da energia de recuo.

O que garante a existência da absorção ressonante é a incerteza na energia de transiçăo, dada pelo Princípio de Incerteza de Heisenberg. O Princípio de Incerteza estabelece que não é possivel conhecer, simultaneamente e com precisão absoluta, a energia e o tempo de vida de um estado excitado. A incerteza em energia, caracterizada pela largura de linha $\Gamma$, e a incerteza em tempo, caracterizada pela vida média $\tau$ do nivel, estão relacionadas, através do principio de incerteza, por:

$$
r=\hbar
$$

onde $\hbar$ é a constante de Planck dividida por $2 \pi$.

Ou seja, numa amostra macroscópica de átomos excitados a um mesmo nível, as energias desses átomos não são todas idênticas a $\boldsymbol{E}_{0}$, mas estão 
distribuidas em torno desse valor. Tem-se, na realidade, uma distribuição Lorentziana (Figura 10a) em torno de $\boldsymbol{E}_{0}$, descrita pela função:

$$
p(E)=\frac{2}{\Gamma \pi} \frac{1}{1+\left(\frac{E+E_{0}}{\Gamma / 2}\right)}
$$

onde $\Gamma$ é a largura de linha a meia altura.

Portanto, a absorção ressonante ocorrerá, desde que alguns fótons tenham energia suficiente para suprir a excitação e o recuo do absorvedor, isto é, desde que haja alguma superposição das distribuições de energia dos fótons emitidos (Figura 10b) e do estado excitado do absorvedor (Figura 10c), mostrada na Figura 10(d). A superposição das duas curvas ocorrerá, desde que seja satisfeita a condição:

$$
2 E_{R} \leq \Gamma
$$

onde $\Gamma$ é a largura natural do estado excitado.

O processo de absorção ressonante de fótons, em princípio, ocorre também com núcleos, pois as condições essenciais (existência de níveis de energia quantizados) são comuns aos dois sistemas. Apesar da semelhança existem alguns fatores que não influenciam muito no caso atômico, tais como a largura de linha a meia altura $\Gamma$ e a energia de recuo $E_{R}$ do átomo. 

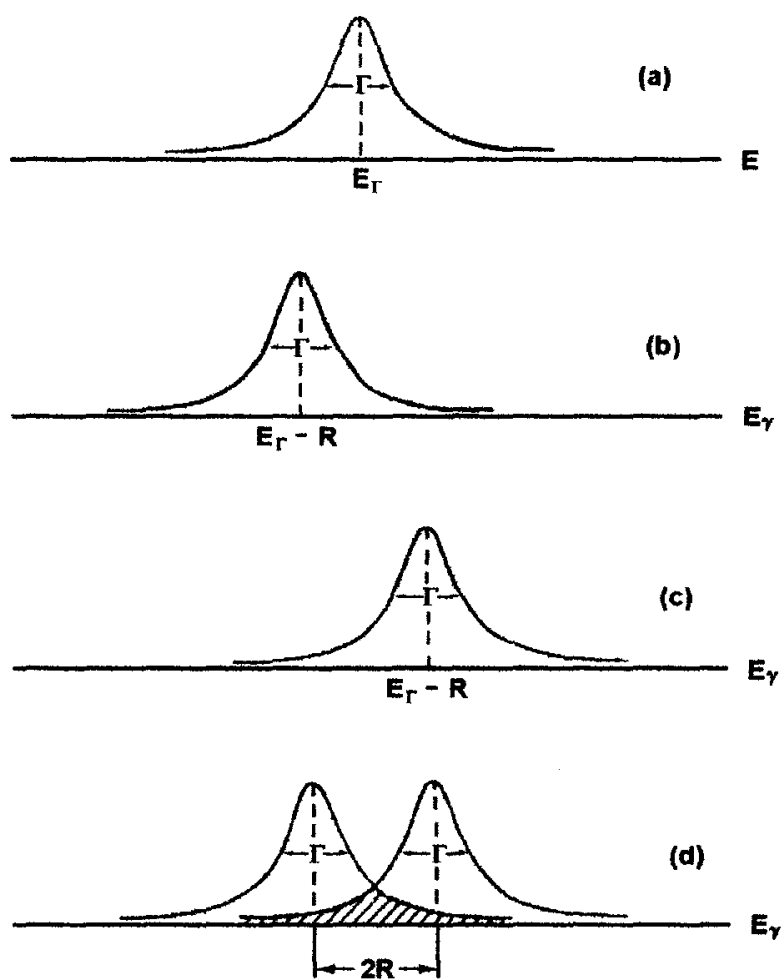

Figura 10 - Distribuição de energia do processo ressonante. (a) distribuiçăo de energia do estado excitado; (b) distribuição de energia dos fótons emitidos na transição para estado fundamental; (c) distribuição de energia necessária para excitar o absorvedor; (d) superposiçăo de (b) e (c) ${ }^{[b]}$.

As energias de recuo e larguras das linhas nos casos atômico e nuclear podem ser comparadas, analisando-se os dados da Tabela I para a transição da linha amarela do Sódio (caso atômico) e para a transição de $23,8 \mathrm{KeV}$ do Estanho 119 (caso nuclear) ${ }^{[37]}$.

Tabela I - Comparação entre a energia de recuo $\left(E_{R}\right)$ e a energia de transição $\left(E_{0}\right)^{[3]}$.

\begin{tabular}{|c|c|c|}
\hline Energia (eV) & Caso atómico (Na) & Caso nuclear ( $\left.{ }^{19} \mathrm{Sn}\right)$ \\
\hline$\Gamma$ & $4,4 \times 10^{-8}$ & $2,2 \times 10^{-8}$ \\
\hline$E_{0}$ & 2,1 & $2,38 \times 10^{4}$ \\
\hline$E_{R}$ & $10^{-10}$ & $2,5 \times 10^{-3}$ \\
\hline
\end{tabular}


No caso atômico, a largura de linha $\Gamma$ é da mesma ordem de grandeza do caso nuclear, enquanto a energia de recuo $E_{R}$ é muito menor. Por isto, a condição de ressonância atômica é facilmente satisfeita. Para o caso nuclear, a ressonância só poderá ocorrer se houver uma compensação da energia de recuo.

Entre os vários métodos utilizados para compensar a energia de recuo, dois são particularmente relacionados com o efeito Mössbauer. $O$ primeiro método consiste em movimentar o núcleo excitado (ou absorvedor) em direção ao absorvedor (ou núcleo excitado), compensando a energia de recuo via efeito Doppler, proposto por Moon ${ }^{[38]}$ em 1950. O segundo método, proposto em 1952 por Malmfors ${ }^{2}$ apud Santos (1984), era baseado no alargamento Doppler devido à agitação térmica dos núcleos excitados. Este alargamento aumenta a área de superposição das curvas de emissão e absorção, Figura 10.

Em 1957, o doutorando Rudolf L. Mössbauer, utilizando o método proposto por Malmfors ao medir a vida média do estado $5 / 2(129 \mathrm{keV})$ do ${ }^{191} \mathrm{Ir}$, tentou verificar o efeito da temperatura na absorção ressonante, submetendo a fonte e o absorvedor a baixas temperaturas ${ }^{[[]}$. Para esta transição à temperatura ambiente, $E_{R}=0,05 e V$, e o alargamento Doppler $E_{D}=0,1 e V$. Portanto, a absorção ressonante deveria ocorrer à temperatura ambiente e aumentar com o aumento da temperatura. Contrariando todas a expectativas, o que se observou foi que a baixas temperaturas a absorção cresceu significativamente. Este resultado inesperado foi corretamente interpretado por ele e ficou conhecido como "absorção ressonante nuclear sem recuo" ou "efeito Mössbauer", e valeu-lhe o prêmio Nobel de Física em 1961.

\footnotetext{
${ }^{2}$ MALMFORS, K. G. (1978). Apha, - Beta - and Gamma - ray spectroscopy. Amsterdam North-Holland, 1978. Tese. apud SANTOS, A. C. Composição superficial e propriedades mecânicas e tribológicas de aços carbono implantados com nitrogênio. Porto Alegre, 1984. 60p. Tese (Doutorado) - Universidade Federal do Rio Grande do Sul.
} 
Logo após sua descoberta, o efeito Mössbauer, transformou-se numa poderosíssima técnica de análise, com um grande campo de aplicação, possibilitando o estudo de interações hiperfinas em elementos tais como $\mathrm{Fe}, \mathrm{Sn}$, Ir entre outros. A espectroscopia Mössbauer pode também ser usada com sucesso para análise de superficies ${ }^{[38,39]}$.

Nas próximas secçōes serão discutidos os fundamentos das técnicas de espectroscopia Mössbauer de elétrons de conversão (CEMS), e da espectroscopia Mössbauer de raios $X$ de conversão, sem entrar em maiores detalhes sobre a física e a matemática envolvidas, pois este assunto é amplamente discutido em vários livros textos ${ }^{[36,37,40,43]}$.

\subsection{ESPECTROSCOPIA MÖSSBAUER DE ELÉTRONS E DE RAIOS X DE CONVERSÃO}

Os raios $\gamma$ são fótons provenientes de transições nucleares, assim como os raios $X$ são produzidos nas transições atômicas. Os fótons podem interagir com a matéria através de vários processos. São eles: espalhamento elástico, efeito fotoelétrico, efeito Compton e absorção ressonante. Do ponto de vista do efeito Mössbauer, o processo mais importante é o da absorção ressonante. Ao absorver um raio gama, o núcleo absorvente vai para um estado excitado. Sua subseqüente desexcitação para o estado fundamental pode ocorrer de duas maneiras competitivas: reemissão de um raio gama ou por um processo denominado conversão interna. No primeiro, o núcleo excitado emite um raio gama idêntico ao absorvido. No outro processo, devido à proximidade dos elétrons ou a penetração de alguns deles (elétrons s) no interior do núcleo, existe a probabilidade de que a energia de excitação do núcleo seja removida pela emissão desse elétron. Diz-se que o núcleo decai por conversão interna. 
O processo de conversão interna na camada K (emissão de elétron K) é acompanhado pela ocupação do buraco pelo elétron da camada $L$, havendo a emissão de raios $X$ característica da transição $L \rightarrow K$ ou, alternativamente a ejeção de elétrons pelo efeito Auger de elétrons da camada M, como mostra a Figura 11. Estes elétrons são denominados elétrons KLM. Portanto, como conseqüência da desexcitação de um núcleo, tem-se a emissão de raios gama, elétrons de conversão ( $K, L$ e M), raios $X$ e elétrons Auger. Na Tabela II são apresentados os eventos com maior probabilidade de ocorrência durante o decaimento do estado de spin $\mathrm{I}=3 / 2$ para o estado fundamental $(I=1 / 2)$ do ${ }^{57} \mathrm{Fe}$. Lembrar que a soma da proporçăo relativa dos elétrons das camadas $K, L$ e $M$, e dos raios gama deve ser 100. Portanto, a soma dos raios $X$ com os elétrons Auger deve ser igual à dos elétrons de conversão. Assim, de cada 100 núcleos excitados $(1=3 / 2)$, aproximadamente 9 decaem por reemissão de raios gama e 91 por conversão interna, dos quais $70 \%$ são seguidos por elétrons Auger, isto é, o preenchimento da camada $K$ resulta na emissão dos raios $X$ na proporção relativa de $27,3 \%(6,3 \mathrm{keV})$ e $63,7 \%$ para os elétrons Auger $(5,4 \mathrm{keV})$.

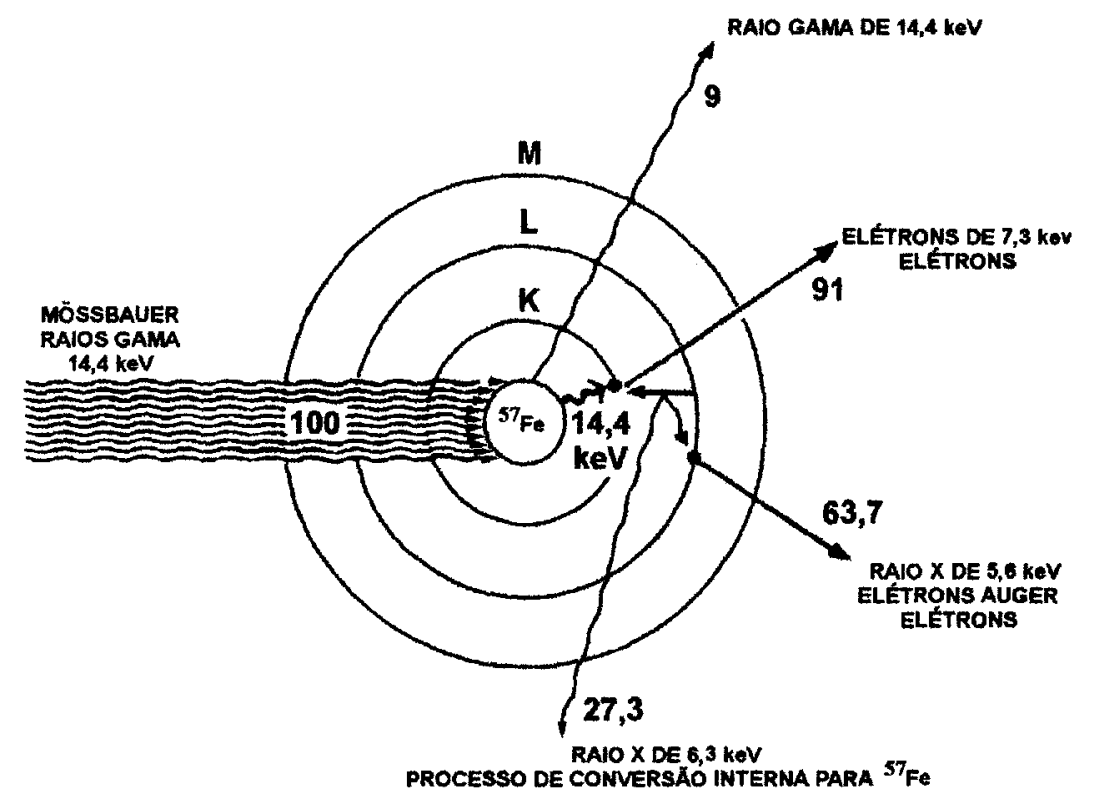

Figura 11- Diagrama esquemático da desexcitação do átomo de ${ }^{57} \mathrm{Fe}$ envolvido no Efeito Mössbauer, com a probabilidade de cada evento ${ }^{[41]}$. 
Em decorrência destes fenômenos, os espectros Mössbauer podem ser obtidos através da geometria de retroespalhamento, onde podemos detectar fótons ou elétrons retroespalhados, conforme mostra a Figura 12. Como os elétrons de conversão se atenuam rapidamente na matéria, somente aqueles elétrons produzidos nas regiōes próximas da superfície do sólido conseguem escapar. Portanto esta é uma excelente técnica a ser utilizada em amostras espessas, onde se deseja analisar uma camada fina da superficie.

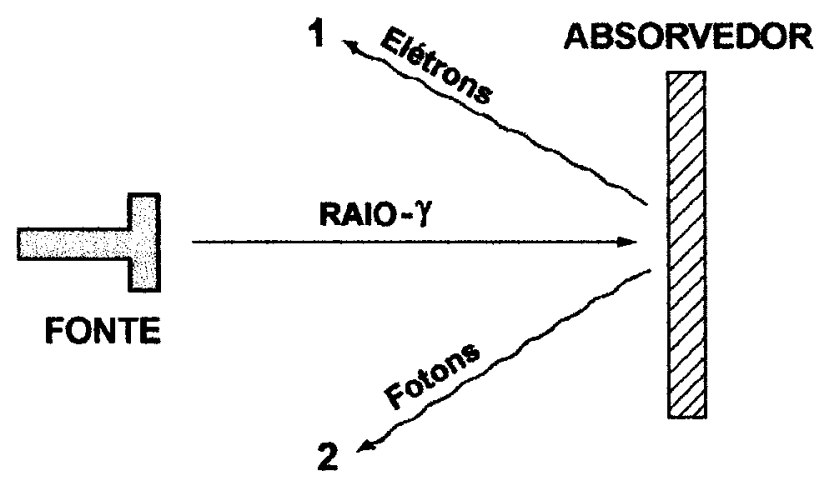

1 - El6trons Retroespalhados

2 - Fotons de Raio X e Raio $\gamma$ Retroespalhados

Figura 12 - Geometria para o Efeito Mössbauer de retroespalhamento ${ }^{[42]}$.

Tabela II - Resumo da maioria dos eventos durante o decaimento do estado excitado de spin $3 / 2$ do ${ }^{57} \mathrm{Fe}^{[5,43]}$.

\begin{tabular}{|c|c|c|c|}
\hline Radiação & $\begin{array}{c}\text { Energia } \\
(\mathrm{keV})\end{array}$ & $\begin{array}{c}\text { Proporçăo Relativa } \\
(\%)\end{array}$ & $\begin{array}{c}\text { Intervalo Máximo de } \\
\text { Profundidade em } \\
\text { Sólidos Típicos }\end{array}$ \\
\hline Raios $\gamma$ & 14,4 & 9 & $15 \times 10^{3} \mathrm{~nm}$ \\
\hline Raios X & 6,3 & 27,3 & $250 \mathrm{~nm}$ \\
\hline Elétrons de conversão K & 7,3 & 81 & $900 \mathrm{~nm}$ \\
\hline Elétrons de conversão L & 13,6 & 9 & - \\
\hline Elétrons de conversão M & 14,3 & 1 & - \\
\hline Elétrons Auger KLL & 5,4 & 63,7 & - \\
\hline Elétrons Auger KMM & 0,53 & - & \\
\hline
\end{tabular}




\section{Interaçães Hiperfina}

Chamam-se Interações Hiperfinas as interações entre o núcleo com os campos elétricos e magnéticos gerados pelas cargas ao seu redor, resultando no que se denomina interação hiperfina elétrica e magnética. Existem 2 tipos de interações hiperfinas elétricas (interações de monpolo e de quadrupolo elétrico) e um de interação hiperfina magnética (interação de dipolo magnético), cujas noções serão apresentada a seguir ${ }^{[5,37,41]}$.

\section{Deslocamento Isomérico ( $\delta$ )}

A interação de monopolo elétrico é a interação eletrostática entre a carga nuclear e a carga eletrônica presente no núcleo, que resulta no deslocamento dos niveis de energia do nuclear. Este deslocamento depende do estado de energia em que o núcleo se encontra e é causado, principalmente, pela interação eletrostática da carga nuclear com os elétrons s. A figura $13 \%(b)$ mostra a influência do da interação hiperfina referente ao deslocamento isomérico.

\section{Desdobramento Quadrupolar}

No deslocamento isomérico, assume-se a existência de esfericidade na distribuiçăo da carga nuclear. Entretanto, isto nem sempre ocorre. A distribuição de carga para núcleos em certos estados nucleares não é esférica. Este fato é caracterizado por uma quantidade $\mathrm{Q}$, denominada de momento de quadrupolo nuclear é uma medida do desvio da simetria esférica da massa nuclear. Quando um átomo no sólido se encontra cercado por vizinhos que observam uma simetria cúbica, a distribuição de carga eletrônica deste átomo é esférica e a interação do momento de quadrupolo nuclear com os elétrons que rodeiam o núcleo deste átomo será nula. Entretanto, se a simetria dos vizinhos difere da cúbica, existirá um gradiente de campo elétrico agindo no sítio atômico no qual o átomo em análise se encontra. Pela ação do gradiente de campo elétrico, a distribuição de carga 
eletrônica não será esférica. Esta distribuição não esférica de carga eletrônica interage com o momento de quadrupolo nuclear, dando origem ao desdobramento quadrupolar simbolizado, na espectroscopia Mössbauer, por $\Delta \mathrm{E}_{\mathrm{Q}}$. A figura $13(\mathrm{c})$ sintetiza o efeito do acoplamento quadrupolar nuclear.

\section{Interação Hiperfina Magnética}

A interação entre o momento de dipolo magnético nuclear e o campo magnético das cargas externas ao núcleo levanta completamente a degenerescência dos estados nucleares. Isto é, cada estado com Spin I será desdobrado em $21+1$ subniveis correspondentes às distintas orientaçőes do spin nuclear em relação ao campo magnético. Na figura $13(d)$ está esquematizado o efeito da interação hiperfina magnética.

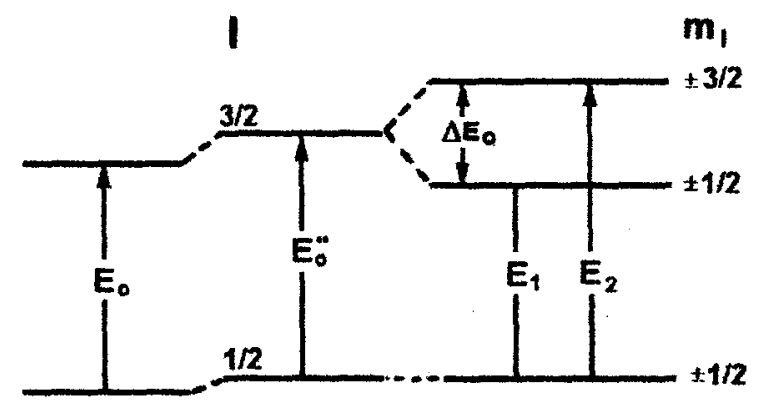

(a)

(b)

(c)

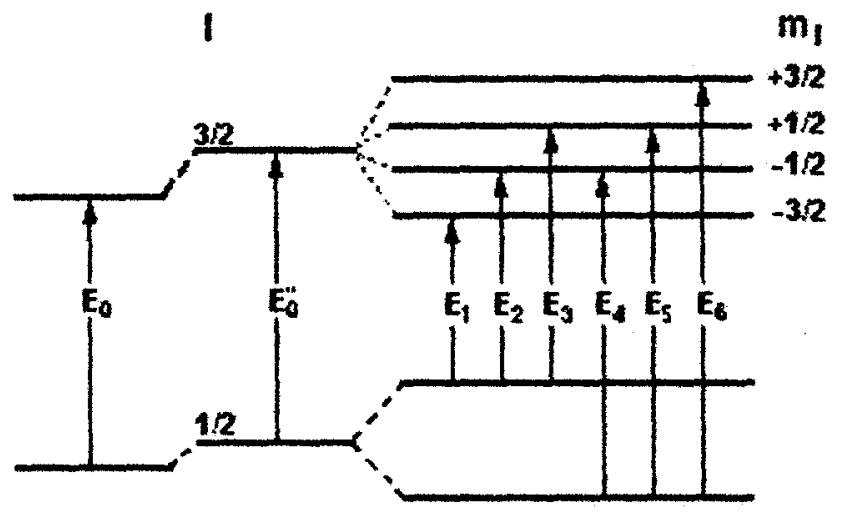

(d)

Figura 13 - Efeito das Interaçסes Hiperfinas nos niveis de energia do ${ }^{57} \mathrm{Fe}$. (a) sem interaçăo, (b) deslocamento isomérico, (c) desdobramento quadrupolar, (d) interaçåo hiperfina magnética ${ }^{[5,37,41]}$. 


\subsubsection{Espectrômetro Mössbauer}

A Figura 14 apresenta o diagrama de blocos de um espectrômetro Mössbauer.

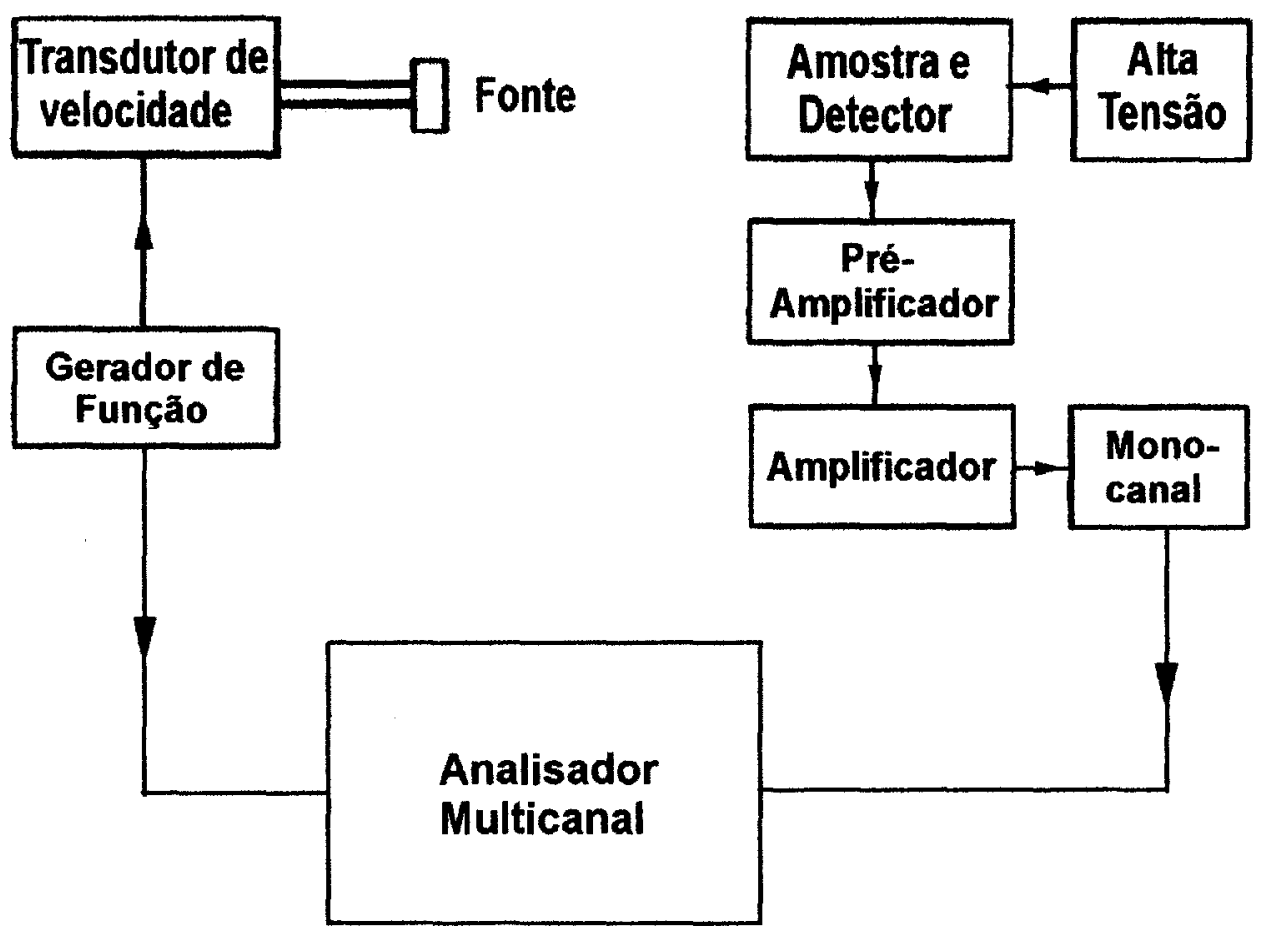

Figura 14 - Diagrama de blocos para espectroscopia Mössbauer de elétrons de conversão (CEMS) e de raios $X$ de conversão (CXMS) ${ }^{[5]}$.

Os detectores proporcionais, freqüentemente utilizados em espectroscopia Mössbauer, fornecem pulsos proporcionais à energia dissipada em seu interior. Para evitar radiações indesejáveis e o ruído de fundo, deve-se selecionar o pulso antes da aquisição do espectro. Essa discriminação dos pulsos pode ser realizada com auxilio de um analisador monocanal, descrito na seção 3.2.4.

Como foi dito anteriormente, a absorção ressonante é obtida quando a fonte ou a amostra encontram-se em movimento relativo. As diferenças de energia do núcleo fonte e da amostra, devido às interações hiperfinas, são compensadas pelo efeito Doppler. Para tanto, um gerador de funções alimenta o 
transdutor (onda triangular ou senoidal), ao mesmo instante em que sincroniza o movimento da fonte (ou da amostra) com a varredura do multicanal. Desta forma acumula-se o número de pulsos em função da velocidade da fonte.

\subsubsection{A fonte Mössbauer}

A fonte do experimento Mössbauer é usualmente um isótopo radioativo com meia vida longa. No caso do ${ }^{57} \mathrm{Fe}$, o isótopo radioativo é o ${ }^{57} \mathrm{Co}$, cujo esquema de decaimento é apresentado na figura 15 . O nuclídeo deve ser incorporado a uma matriz cúbica, não magnética, de modo que a inexistência de interações quadrupolares e magnéticas implica numa linha de emissão única. As matrizes mais usadas para $0^{57} \mathrm{Co}$ são: $\mathrm{Rh}, \mathrm{Pd}, \mathrm{Pt}, \mathrm{Cu}$ e aço inoxidável ${ }^{[[]}$.

Além destes aspectos, os núcleos ressonantes devem satisfazer alguns requisitos importantes, tais como[s]:

- A energia do raio $\gamma$ deve estar preferencialmente entre $10 \mathrm{e}$ $100 \mathrm{keV}$. Abaixo de $10 \mathrm{keV}$ eles são absorvidos pela matéria, e acima de $100 \mathrm{keV}$ a fração sem recuo, f, é muito pequena.

- O tempo de vida, $t_{1 / 2}$, do estado excitado deve estar entre 1 e 100ns. Se o tempo de vida $t_{1 / 2}$ for muito pequeno, a largura, $\Gamma$, será tão grande que poderá mascarar qualquer efeito da estrutura hiperfina. Para $t_{1 / 2}$ maiores, $\Gamma$, é tão estreita que qualquer ruído pode destruir as condiçōes de ressonância.

- A energia de recuo deve ser pequena $\left(\sim 10^{-2} \mathrm{eV}\right)$.

A seguir são apresentadas algumas propriedades do ${ }^{57} \mathrm{Fe}$ na Tabela III, que reúnem as condições mais favoráveis para a utilização da espectroscopia Mössbauer. 
Tabela III - Propriedades do nuclídeo Mössbauer de ${ }^{57} \mathrm{Fe}^{[44]}$.

\begin{tabular}{|c|}
\hline${ }^{5} \mathrm{Fe}$ \\
\hline$E \gamma=14,4 \mathrm{keV}$ \\
\hline$E_{R}=0,002 \mathrm{eV}\left(\Theta_{D}=400 \mathrm{~K} ; \mathrm{f}(0 \mathrm{~K})=0,92 ; \mathrm{f}(300 \mathrm{~K})=0,71\right)$ \\
\hline$\sigma_{0}=2,57 \times 10^{-18} \mathrm{~cm}^{2}$ \\
\hline $2 \Gamma=0,19 \mathrm{~mm} / \mathrm{s}$ \\
\hline Pai radioativo: ${ }^{57} \mathrm{Co}$ (captura eletrônica, $\mathrm{t}_{1 / 2}=270$ dias) \\
\hline
\end{tabular}

A Figura 15 mostra o esquema de decaimento do ${ }^{57} \mathrm{Co}$. Por captura de elétrons, obtém $-\mathrm{se} 0{ }^{57} \mathrm{Fe}$ no estado excitado com I $=5 / 2$, que decai para o estado $3 / 2$, ou diretamente para o estado fundamental I =1/2.

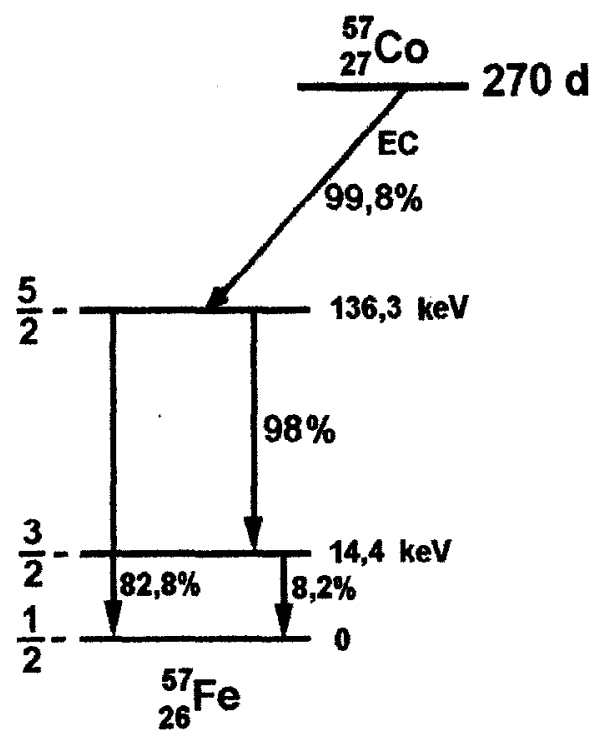

Figura 15 - Esquema de decaimento do ${ }^{57} \mathrm{Co}^{[5,45]}$

\subsubsection{Detectores de fluxo de gás}

O detector usado no espectrômetro CEMS é bastante simples. A Figura 16 mostra o esquema de uma câmara proporcional ${ }^{[5,38]}$, usada neste trabalho como detector. Este detector permite tanto a detecção (integral) de todos os elétrons de conversão interna e Auger, quanto os raios $\mathrm{X}$ gerados no processo de conversão interna, possibilitando a análise de camadas mais profundas ${ }^{[46]}$ (ver 
Tabela II). Tanto na detecção dos elétrons de conversão e Auger, quanto na dos raios $X$, pode-se usar 0 mesmo detector, bastando apenas escolher $\circ$ gás adequado, isto é, $\mathrm{He}-5 \% \mathrm{CH}_{4}$, para elétrons e $\mathrm{Ar}-5 \% \mathrm{CH}_{4}$ para raios $\mathrm{X}^{[5,38]}$.

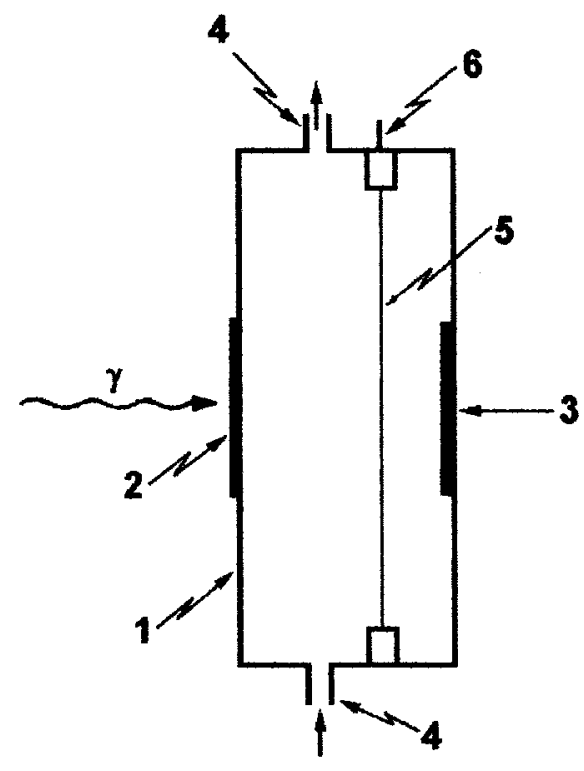

Figura 16 - Corte transversal do detector proporcional de fluxo de gás. (1) corpo de alumínio; (2) janela de mylar; (3) amostra; (4) entrada e saída de gás; (5) anodo de W com $50 \mu \mathrm{m}$ de diâmetro; (6) alta tensão de aproximadamente $1300 \mathrm{~V}$ para elétrons e $1800 \mathrm{~V}$ para os raios $\mathrm{X}^{[5,38]}$.

Os elétrons liberados na superfície da amostra săo acelerados na direção do anodo de tungstênio. Quando atingem a região de alto campo, nas proximidades do fio (aproximadamente 4 vezes o diâmetro do fio), ganham energia suficiente para ionizar os átomos de He por colisão, iniciando assim uma cascata de ionizaçōes ${ }^{[4]}$. Outro processo que ocorre é a excitação eletrônica dos átomos de He (para o primeiro estado excitado $20,6 \mathrm{eV}$ ), que decaem emitindo fótons. Os fótons emitidos produzirão outros elétrons, via efeito fotoelétrico, contribuindo para o ruído de fundo. Outro fenômeno que ocorre freqüentemente é o da emissão secundária. Um íon, ao ser neutralizado, pode permanecer num estado excitado até ceder sua energia de excitação para um elétron da parede do detector ou da própria amostra, elevando o ruído de fundo. Tanto o efeito fotoelétrico quanto a 
emissão de elétrons secundários, pode ser sensivelmente reduzidos pela ação de gases poliatômicos, como por exemplo, $\mathrm{CH}_{4}{ }^{[47,48]}$, que têm a função de absorver os fótons emitidos pelo He, evitando assim a liberação de elétrons da parede do detector.

\subsubsection{Calibração do Espectrômetro}

Antes de qualquer medida deve-se determinar 0 intervalo de velocidade a ser aplicado. Para isto utiliza-se uma amostra padrão com os parâmetros hiperfinos bem conhecidos. Geralmente utiliza-se o ferro com pureza de $99,99 \%$, dependendo do método a ser utilizado. Para CEMS ou CXMS, a calibração muda. No caso de CXMS, inicialmente deve-se selecionar o intervalo de energia de interesse através do analisador de altura de pulso (PHA), sem amostra, Figura $17(a)$. O que se vê são dois picos, um correspondendo aos raios $X(6,3 \mathrm{keV})$ e 0 outro aos raios $\gamma(14,4 \mathrm{keV})$. Adicionando-se um anteparo de mylar em frente ao detector, o pico dos raios $X$ desaparece, Figura $17(\mathrm{~b})$. Colocando-se a amostra, tem-se 0 aspecto típico apresentado pela Figura 17(c). Uma janela de energia feita pelo analisador monocanal limita o espectro à faixa de interesse, de acordo com a Figura 17(d), onde a região de interesse está indicada.

Feita a seleção de energia, segue-se à escolha da velocidade da fonte. Para espectros de materiais nitretados, com campos magnéticos da ordem de $400 \mathrm{kOe}$, a velocidade varia de $-7,5 \mathrm{a}+7,5 \mathrm{~mm} / \mathrm{s}$. Como os parâmetros hiperfinos do Fe metálico são bem conhecidos ( $H=330 \mathrm{kOe}, \Delta Q=0, \delta=0$, em relação ao $\mathrm{Rh}$ ), o modo que o ajuste de seu espectro permite determinar o fator de calibração. 


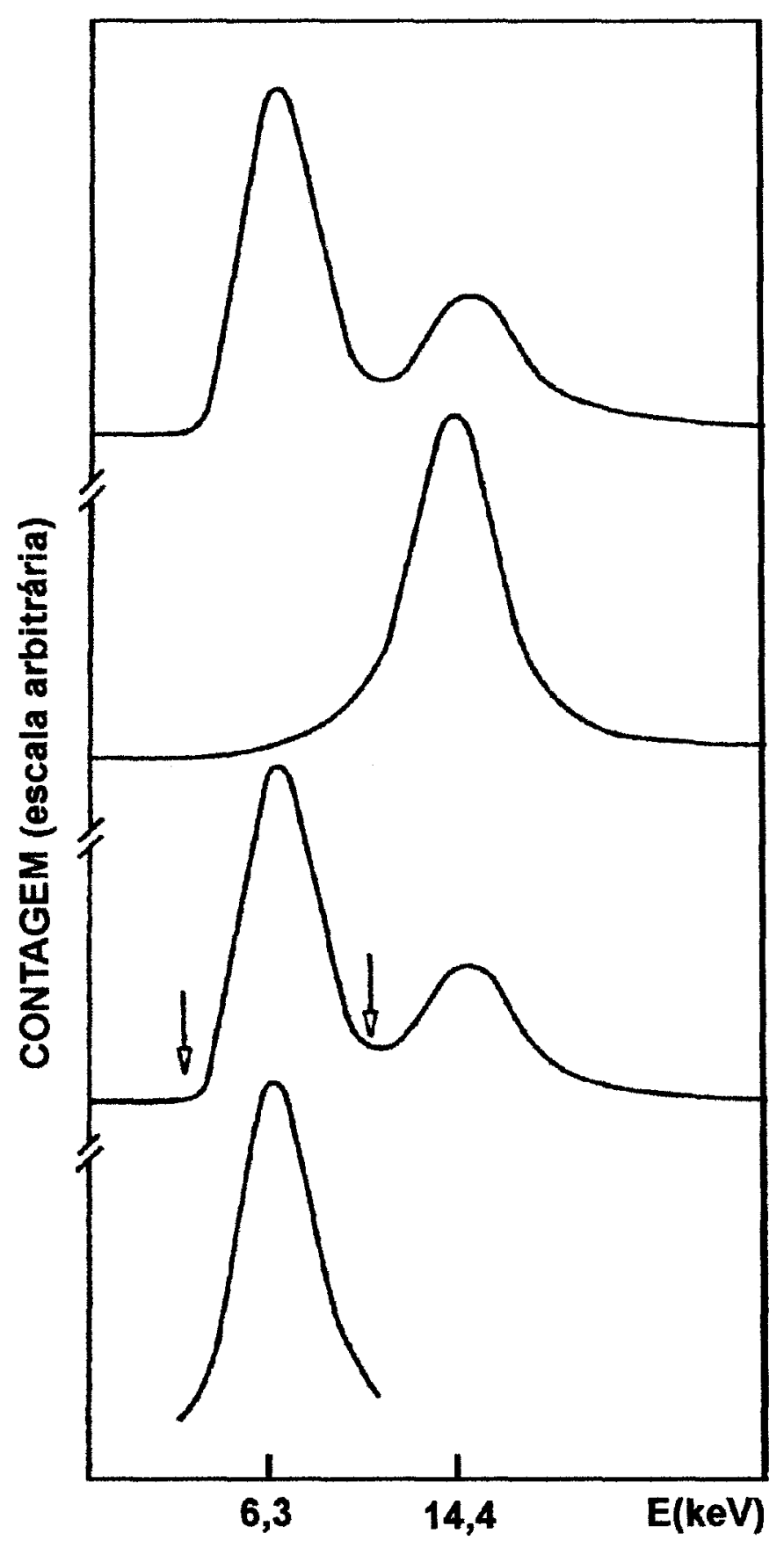

(a)

(b)

(c)

(d)

Figura 17 - Espectros de energia (PHA). (a) espectro da fonte; (b) eliminaçăo dos raios $X$ da fonte com anteparo de mylar; (c) PHA com amostra; (d) seleçăo da regiăo de interesse ${ }^{[5]}$.

No caso do CEMS, o procedimento é o mesmo usado nas medidas de CXMS. A Figura 18 apresenta espectros PHA com amostra "a" e sem amostra "b". A região de interesse está limitada pelas setas. A seleção é feita comparandase os dois espectros presentes na Figura 18(a) e 18(b). 


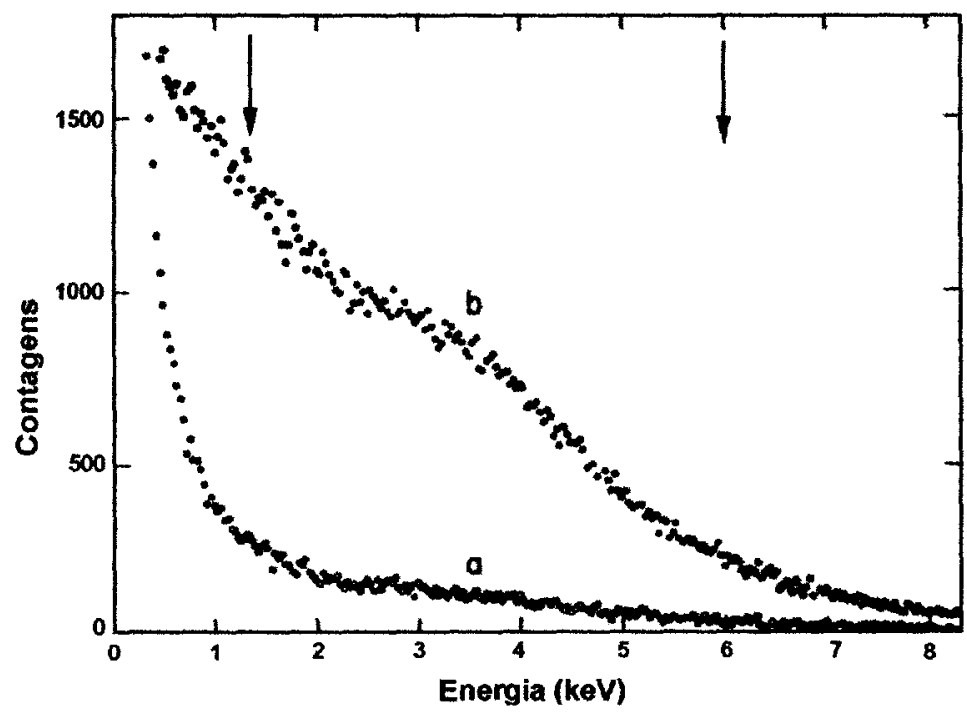

Figura 18 - Espectro PHA de elétrons, com amostra (a), sem amostra (b) ${ }^{[45]}$. 


\section{COMPOSIÇÃO E EVOLUÇÃO TÉRMICA DOS AÇOS NITRETADOS}

\section{1 - INTRODUÇÃO}

O conhecimento das composições superficiais dos aços nitretados é uma das primeiras etapas na direção do entendimento dos mecanismos responsáveis pela melhora das propriedades mecânicas e tribológicas.

Portanto, devido à importância destes compostos na superfície do material ferroso, torna-se necessário uma revisão dos sistemas de equilíbrio Fe-C, $\mathrm{Fe}-\mathrm{N}$ e Fe-N-C obtidos da literatura, para análise dos resultados experimentais. $\mathrm{O}$ que se segue abaixo é uma revisão destes sistemas, já extensivamente estudados.

\section{2 - SISTEMA Fe-C}

O ferro é um elemento alotrópico que, dependendo da temperatura, pode existir em mais de uma estrutura cristalográfica. Para temperaturas até $912^{\circ} \mathrm{C}$ o ferro possui estrutura cúbica de corpo centrado (ccc) denominada de fase $\alpha$ (ferrita), quando então se transforma numa estrutura cúbica de face centrada (cfc), denominada de fase $\gamma$ (austenita), permanecendo até a temperatura de $1394^{\circ} \mathrm{C}$ e a partir dai transforma-se novamente em uma estrutura cúbica de corpo centrado, denominada de fase $\delta$ (ferrita $\delta$ ). 
A diferença entre as estruturas da ferrita e da austenita no aço, com as fases correspondentes no ferro puro é capacidade de acomodação dos átomos de carbono. As Figuras 19 e 20 mostram dois tipos de sitios intersticiais, octaédricos e tetraédricos, que podem se tornar posições dos átomos de carbono nas estruturas ccc e cfc. É interessante lembrar que a estrutura cfc (austenita) possui sitios octaédrico maiores que os da estrutura ccc (ferrita).

$\mathrm{Na}$ austenita, assumindo os átomos de ferro como esferas em contato, um interstício octaédrico pode acomodar um átomo de raio da ordem de $0.52 \AA$, enquanto um interstício tetraédrico acomoda um átomo de raio da ordem de $0,28 \AA$. Portanto, os átomos de carbono, com raio atômico da ordem de $0,7 \AA$, são mais facilmente acomodados nos interstícios octaédricos.

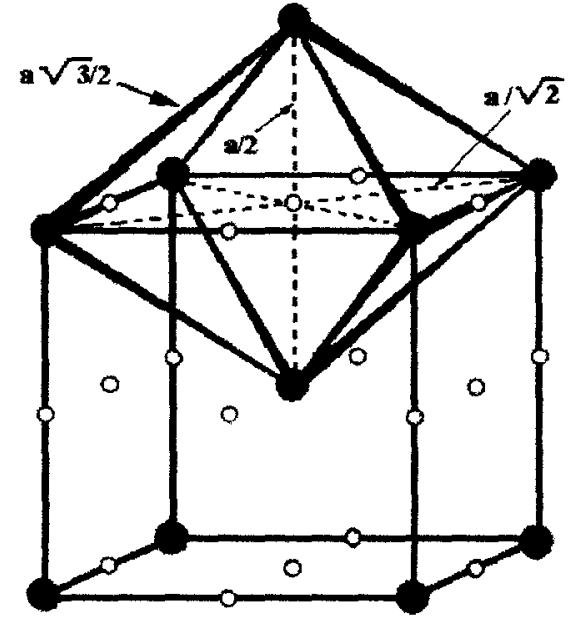

(a)
Atomos Metälicos

- Sítios Octraédricos

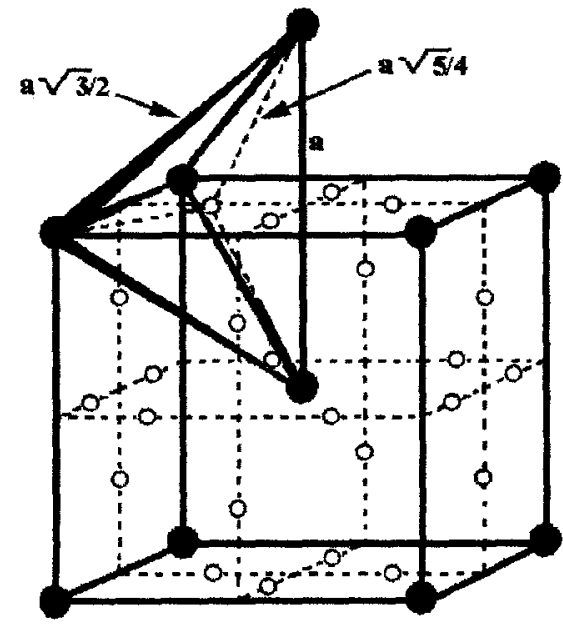

(b) Atomos Metálicos - Sítlos Tetraédricos

Figura 19 - Sítios intersticiais da ferrita. (a) Interstícios octaédricos e (b) Interstício tetraedricos ${ }^{[49]}$.

$\mathrm{Na}$ ferrita (ccc), um sítio tetragonal pode acomodar um átomo intersticial de raio $0,35 \AA$ e um sitio octraédrico, um átomo de raio $0,19 \AA$. Embora o interstício tetraédrico, na estrutura ccc da ferrita, permita a acomodação de átomos com raios maiores, os intersticios octaédricos são energeticamente mais favoráveis, 
devido ao deslocamento de apenas dois átomos vizinhos de ferro para a introdução de um átomo de carbono, enquanto nos interstícios tetraédricos é necessário deslocar quatro átomos de ferro.

A austenita (cfc), embora mais compacta que a estrutura da ferrita, possui intersticios octaédricos maiores. Estes interstícios estão no centro do cubo e no centro das arestas, para a estrutura cfc, enquanto para a estrutura ccc estão no centro das faces das arestas e no centro das arestas. A Figura 20 mostra os sítios octaédricos e tetraédricos para a estrutura cfc.

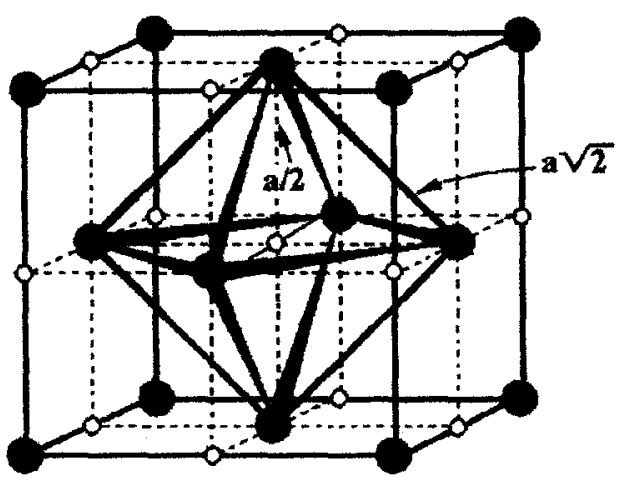

(a)

Atomos Metálicos - Sítios Octaédricos

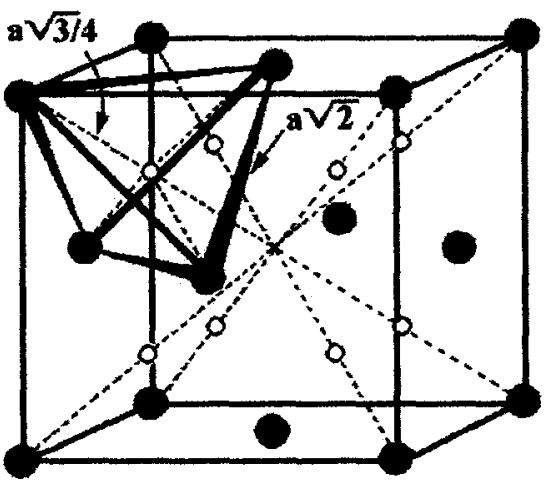

(b) Átomos Metálicos - Sítios Tetraédricos

Figura 20 - Sítios intersticiais da austenita. (a) Interstícios octaédricos e (b) Interstícios tetraédricos ${ }^{[49]}$.

A solubilidade máxima de $C$ na fase $\gamma$ é de $2 \%$ em peso. 0 resfriamento lento transforma a austenita em ferro $\alpha$ com precipitados de cementita $\left(\mathrm{Fe}_{3} \mathrm{C}\right)$. Esta decomposição será inibida se o resfriamento for suficientemente rápido. Neste caso, parte da austenita transforma-se em martensita, e parte é retida. A martensita, ou fase $\alpha^{\prime}$, é uma solução sólida de $C$ (ou N) em ferro $\alpha$ (ccc), que se transforma numa estrutura tetragonal de corpo centrado (tcc). 


\section{3 - SISTEMA Fe-N}

Este sistema Fe-N é muito semelhante ao do $\mathrm{Fe}-\mathrm{C}$, como mostra a Figura 21. Todas as fases existentes nos dois sistemas são isomorfas, com pequenas diferenças em suas propriedades.

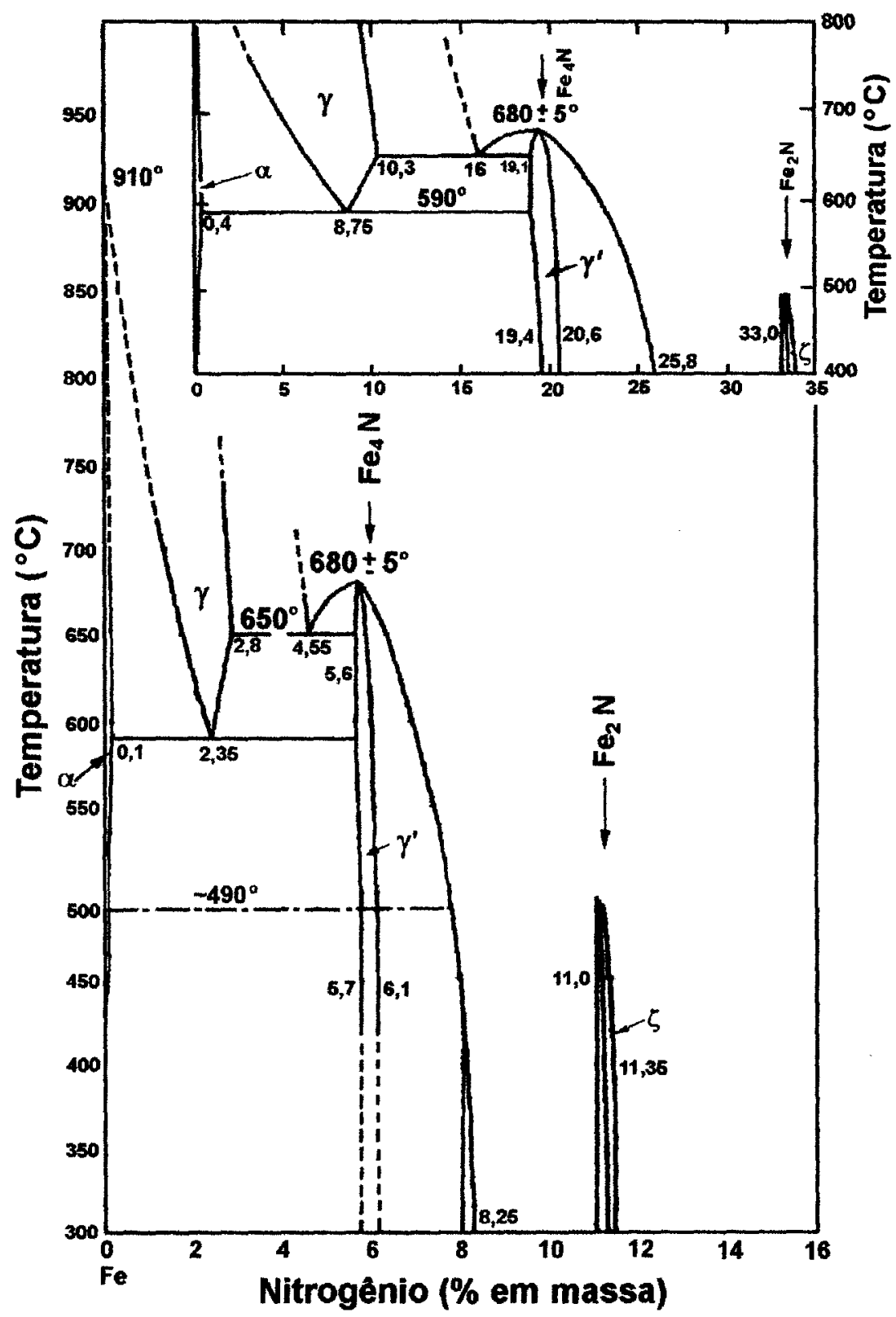

Figura 21 - Diagrama de fase do sistema Fe-N ${ }^{[50]}$.

Com relação à austenita e à martensita, a semelhança é ainda maior, sendo que a variação dos parâmetros de rede com concentração, tanto de $\mathrm{C}$ como de $\mathrm{N}$, é a mesma. Portanto, a solubilidade máxima do nitrogênio na austenita- $\gamma$ é de $2,8 \%$

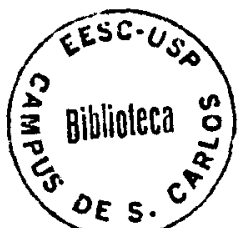


em massa, relativa à fase $\gamma^{\prime}$ a $T=650^{\circ} \mathrm{C}$ e como se pode ver na Figura 21 , é maior que a do carbono. Este resultado é devido à diferença do raio atômico do nitrogênio em relação ao carbono, $r_{N}=0,72 \AA$ e do $r_{C}=0,77 \AA$.

As soluções sólidas de $\mathrm{N}$, assim como as de $\mathrm{C}$, no ferro, são austenita- $\gamma$ (cfc), ferrita- $\alpha$ (ccc) e a fase $\varepsilon$. Nesta fase $\varepsilon$, os átomos de Fe formam uma estrutura hexagonal compacta (hcp), com os átomos de nitrogênio ocupando os sítios octaédricos ${ }^{[51]}$. Em todos o nitretos de ferro, os átomos de ferro rearranjamse de maneira a formar interstícios tetraédricos e octaédricos, com quatro ou seis átomos de $\mathrm{Fe}$ ao seu redor, respectivamente, como mostra a Figura 22, onde os átomos de nitrogênio sempre ocupam os interstícios octaédricos em todas as estruturas metálicas dos nitretos e nunca os interstícios tetraédricos. As estruturas cfc e hcp apresentam octaedros regulares, enquanto que na estrutura ccc os octaedros săo distorcidos ${ }^{[49]}$. A inserção de um átomo de nitrogênio intersticial recupera a regularidade do ambiente do átomo metálico, mas produz uma grande tensão anisotrópica nas vizinhanças da matriz. Conseqüentemente, a solubilidade dos átomos intersticiais no $\alpha-\mathrm{Fe}$ é muito pequena.

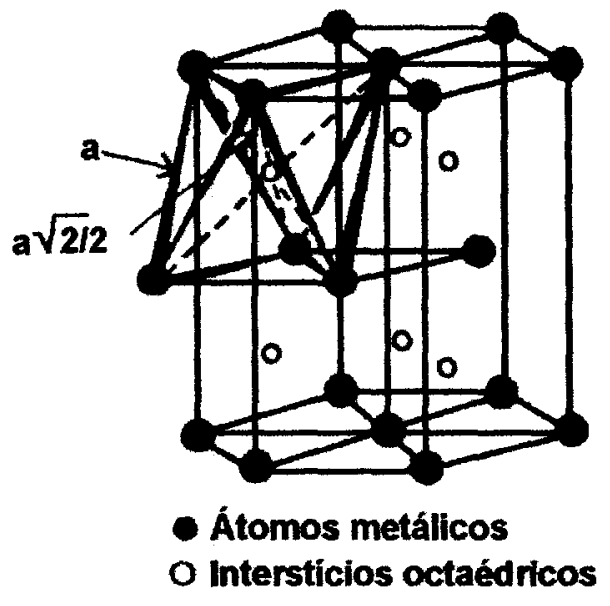

(a)

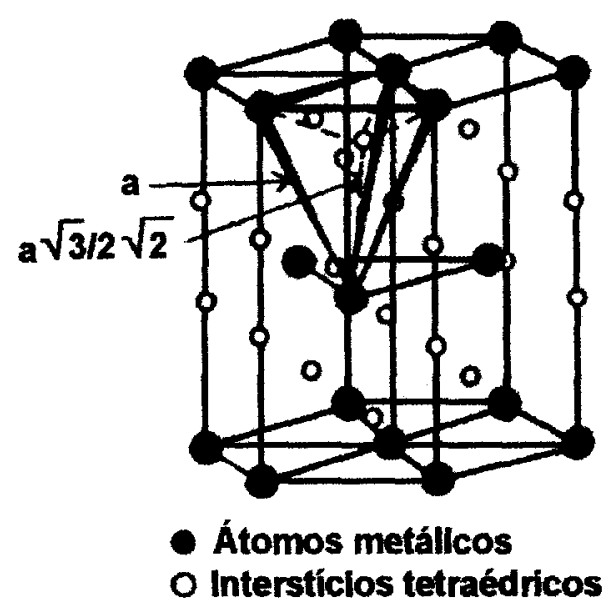

(b)

Figura 22 - Sítios intersticiais da fase $\varepsilon$. (a) Interstícios octaédricos e (b) Intersticios tetraédricos ${ }^{[52]}$. 
$\mathrm{O}$ espectro de Mössbauer da austenita contendo tanto $\mathrm{N}$ como $\mathrm{C}$ (Figura 23), segundo DeCristofaro ${ }^{[53]}$, apresenta algumas diferenças:

i) A perturbação da camada eletrônica de um átomo de $\mathrm{Fe}$, pela presença de um ocupante no interstício, é maior no caso do átomo de $\mathrm{C}$ do que no caso do $\mathrm{N}$.

ii) Átomos de ferro que são vizinhos dos átomos de nitrogênio têm um deslocamento isomérico $(\delta)$ maior na austenita do que átomos de ferro vizinhos ao de carbono. Isto provavelmente é devido às diferenças na interação de $\mathrm{Fe}-\mathrm{C}$ e $\mathrm{Fe}-\mathrm{N}$, pois enquanto os átomos de $\mathrm{C}$ contribuem com elétrons para a banda $4 \mathrm{~s}$ do $\mathrm{Fe}$, os de $\mathrm{N}$ contribuem para a banda $3 d$. 0 efeito do acréscimo na banda $4 s$ seria menor do que o efeito de blindagem da banda $3 d$.

A austenita contendo $\mathrm{N}$ transforma-se na martensita através do mesmo mecanismo descrito para o caso do $\mathrm{C}$, e a solubilidade máxima do $\mathrm{N}$ na martensita é $0,1 \%$ a $590^{\circ} \mathrm{C}$.

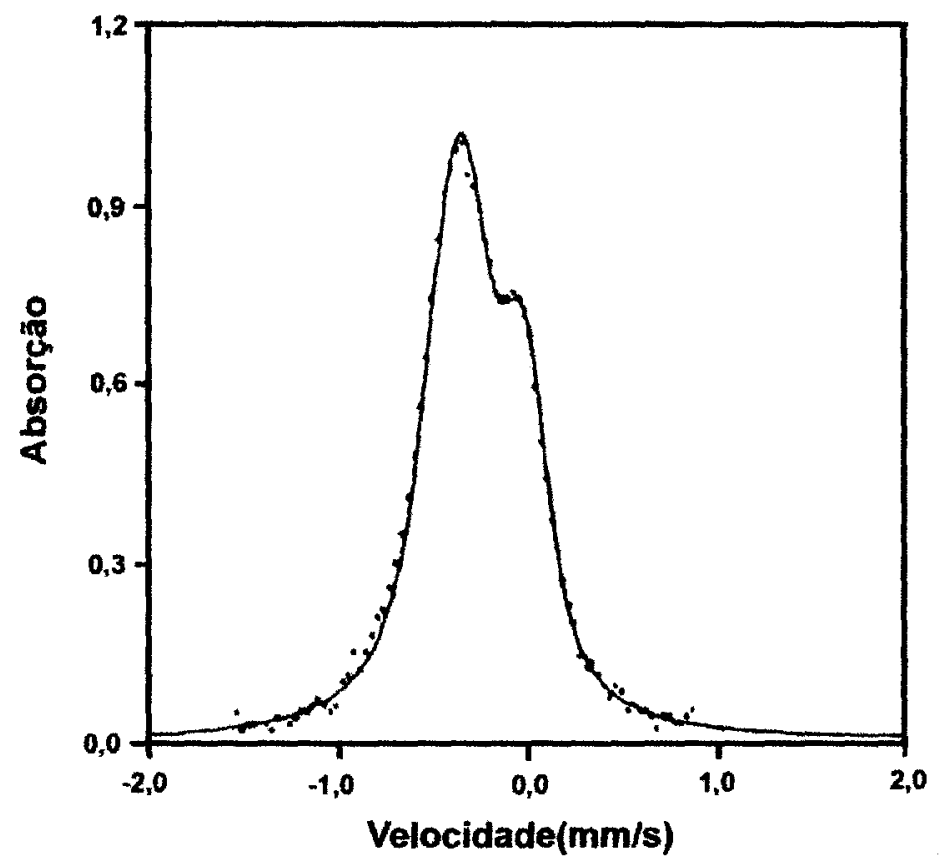

Figura 23 - Espectro Mössbauer da austenita $\mathrm{Fe}-1,86 \% \mathrm{C}^{[53]}$. 


\subsection{1 - As Estruturas dos Nitretos de Ferro}

O revenido da martensita $\mathrm{Fe}-\mathrm{N}$, a $120^{\circ} \mathrm{C}$ resulta na precipitação do nitreto $\alpha "-\mathrm{Fe}_{16} \mathrm{~N}_{2}$. A estrutura $\alpha$ " é essencialmente martensita contendo nitrogênio, na qual os átomos de nitrogênio são completamente ordenados. Análises de difração de raios $X$ feitos por Jack ${ }^{[54]}$, mostraram que sua célula unitária é constituída de oito células da fase tcc, Figura 24(a). Esta estrutura também apresenta uma estrutura cfc distorcida, conforme a Figura 24(b).

Como o arranjo dos átomos de $\mathrm{Fe}$ do nitreto $\gamma^{\prime}-\mathrm{Fe}_{4} \mathrm{~N}$ é cfc, com um átomo de nitrogênio no centro, Figura 26 a estrutura $\alpha$ " pode ser considerada como uma estrutura $\mathrm{Fe}_{4} \mathrm{~N}$, na qual a remoção alternada dos átomos de nitrogênio causa consideráveis distorçōes. Por esta razão, $\alpha "$ pode ser considerada como uma transição entre a estrutura martensítica $\left(\alpha^{\prime}\right)$ e $\gamma^{\prime}-\mathrm{Fe}_{4} \mathrm{~N}$.

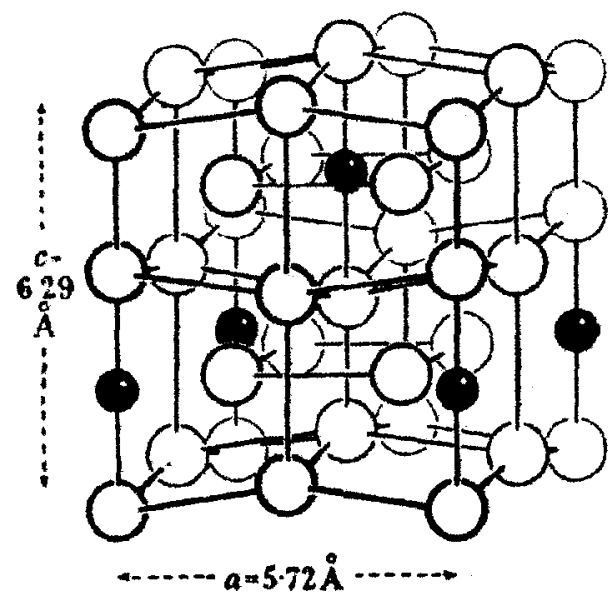

- Átomo de Nitrogênio $O$ Átomo de ferro

(a)

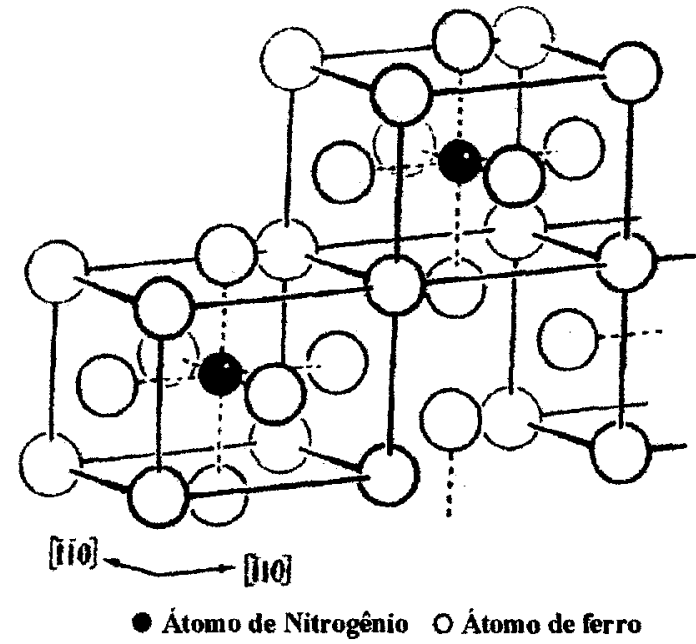

(b)

Figura 24 - (a) Estrutura cristalina do nitreto $\alpha "-\mathrm{Fe}_{18} \mathrm{~N}_{2}$; (b) estrutura do $\alpha "$ considerado como uma distorção na rede $\mathrm{cfc}^{[51,54]}$.

O primeiro estágio desta transição consiste no ordenamento dos átomos intersticiais, de forma que os átomos de ferro octraédricos sejam distribuídos regularmente ao longo da rede. Em seguida, por difusão, os átomos de $\mathrm{N}$ passam a ocupar os sitios vazios nas células cfc, formando o nitreto $\mathrm{Fe}_{4} \mathrm{~N}$. 
Portanto, a decomposição da martensita, tanto no caso $\mathrm{Fe}-\mathrm{N}$ como no $\mathrm{Fe}-\mathrm{C}$, são inteiramente análogas. Ambas contém fases de transição ( $\alpha$ " e $\varepsilon$, respectivamente), com estruturas intermediárias entre as fases iniciais $\left(\alpha^{\prime}\right)$ e finais $\left(\gamma^{\prime}\right.$ e $\theta$, respectivamente). Uma relação com a maioria dos nitretos do sistema $\mathrm{Fe}-\mathrm{N}$ é apresentada na Tabela IV.

Tabela IV - Nitretos formados no sistema Fe-N ${ }^{[49]}$.

\begin{tabular}{|c|c|c|c|c||}
\hline Fase & $\begin{array}{c}\text { Composiç } \\
\text { ão }\end{array}$ & $\%$ em massa de N & \% atômica de N & $\begin{array}{c}\text { Sistema } \\
\text { Cristalino }\end{array}$ \\
\hline Ferrita $(\alpha)$ & $\mathrm{Fe}$ & 0,1 & 0,4 & ccc \\
\hline Austenita $(\gamma)$ & $\mathrm{Fe}$ & 2,8 & 11 & cfc \\
\hline Martensita $\left(\alpha^{\prime}\right)$ & $\mathrm{Fe}$ & 2,6 & 10 & tcc \\
\hline$\alpha^{\prime \prime}$ & $\mathrm{Fe}_{16} \mathrm{~N}_{2}$ & 3,0 & 11,1 & tcc \\
\hline$\gamma^{\prime}$ & $\mathrm{Fe}_{4} \mathrm{~N}$ & 5,9 & 20 & cúbica \\
\hline$\varepsilon$ & $\mathrm{Fe}_{2+\times} \mathrm{N}_{1-x}$ & $4,5-11,0$ & $18-32$ & hexagonal \\
\hline$\zeta$ & $\mathrm{Fe}_{2} \mathrm{~N}$ & 11,14 & 33,3 & ortorrómbica \\
\hline
\end{tabular}

A Figura 25 mostra o espectro Mössbauer da martensita Fe-2,83\%N (\% em massa), recozida por $24 \mathrm{~h}$ a $100^{\circ} \mathrm{C}$, onde se destaca a componente do nitreto a". Os parâmetros Mössbauer obtido estão tabulados na Tabela V.

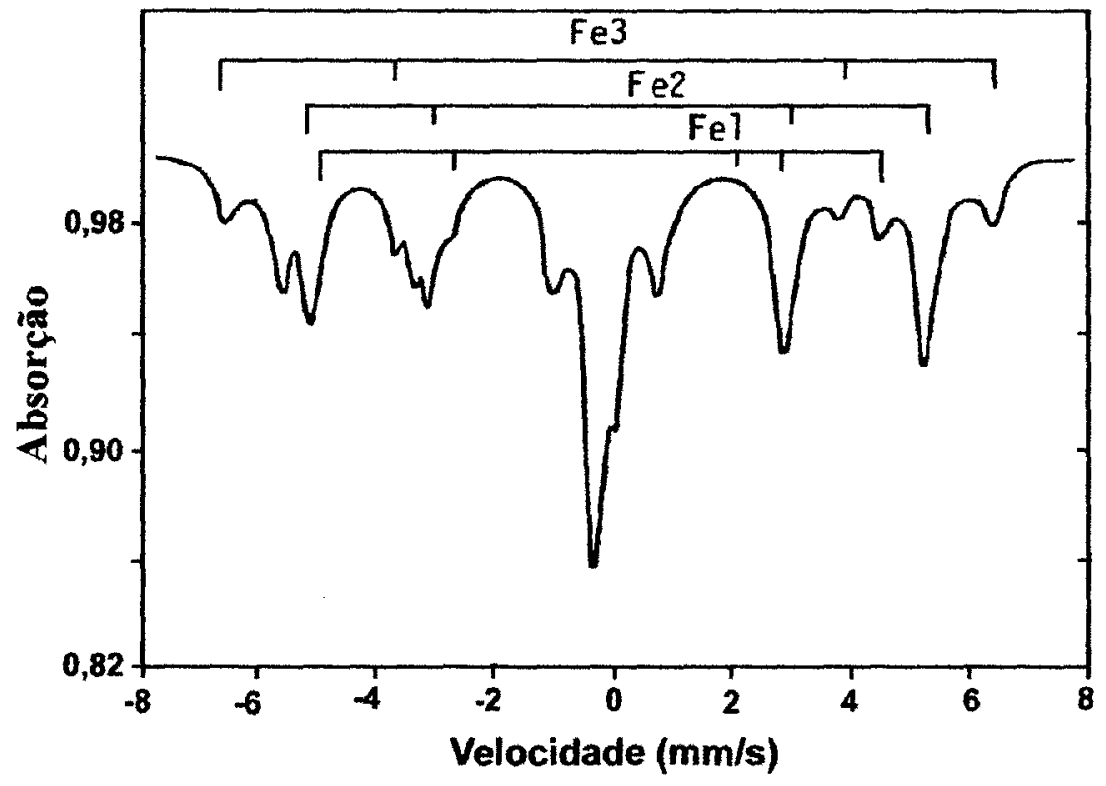

Figura 25 - Espectro Mössbauer da martensita Fe-2,83\%N (em massa) recozida por $24 \mathrm{~h}$ a $100^{\circ} \mathrm{C}$, com as componentes atribuídas ao nitreto $\alpha$ "$\mathrm{Fe}_{16} \mathbf{N}_{2}{ }^{[53]}$. 
Tabela V - Parâmetros hiperfinos da austenita $(\gamma)$ e da martensita ( $\left.\alpha^{\prime}\right)$; o campo hiperfino $\mathrm{H}(\mathrm{kOe})$, deslocamento isomérico, $\delta$, em relação ao $\mathrm{Fe}-\alpha$ e acoplamento quadrupolar $E_{Q}(\mathrm{~mm} / \mathrm{s})$. O $\mathrm{T}(\mathrm{K})$ é a temperatura da medida.

\begin{tabular}{|c|c|c|c|c|c|c|c|}
\hline Fase & Sítios & $\begin{array}{c}T \\
(K)\end{array}$ & $\begin{array}{c}\mathrm{H} \\
(\mathrm{KOe})\end{array}$ & $\begin{array}{c}\Delta \mathrm{E}_{\mathrm{Q}} \\
(\mathrm{mm} / \mathrm{s})\end{array}$ & $\begin{array}{c}\delta \\
(\mathrm{mm} / \mathrm{s})\end{array}$ & $\begin{array}{l}\% \text { dos } \\
\text { sítios }\end{array}$ & Referências \\
\hline$\gamma-\mathrm{Fe}_{2,34} \mathrm{~N}$ & $\begin{array}{l}\mathrm{Fe}_{0} \\
\mathrm{Fe}_{1}\end{array}$ & 300 & - & $\overline{-}, 29$ & $\begin{array}{c}-0,16 \\
0,05\end{array}$ & $\begin{array}{l}55 \\
45\end{array}$ & DeCristofaro $^{[53]}$ \\
\hline$\gamma-\mathrm{Fe}_{2,75} \mathrm{~N}$ & $\begin{array}{l}\mathrm{Fe}_{0} \\
\mathrm{Fe}_{1}\end{array}$ & 300 & - & $0, \overline{25}$ & $\begin{array}{c}-0,10 \\
0,15\end{array}$ & $\begin{array}{l}42 \\
58\end{array}$ & \multirow[b]{2}{*}{ Foct $t^{[55]}$} \\
\hline$\alpha^{\prime}-\mathrm{Fe}_{2,50} \mathrm{~N}$ & & 77 & $\begin{array}{l}343 \\
369 \\
335 \\
296\end{array}$ & $\begin{array}{l}0,02 \\
0,05 \\
0,09 \\
0,03\end{array}$ & $\begin{array}{l}0,04 \\
0,19 \\
0,39 \\
0,15\end{array}$ & $\begin{array}{l}35 \\
17 \\
29 \\
19\end{array}$ & \\
\hline$\alpha^{\prime}-\mathrm{Fe}_{2,83} \mathrm{~N}$ & $\begin{array}{l}F e_{1} \\
F e_{\| 1} \\
F e_{\| 1}\end{array}$ & 77 & $\begin{array}{l}316 \\
346 \\
370 \\
340\end{array}$ & $\begin{array}{c}-0,32 \\
0,12 \\
- \\
-\end{array}$ & $\begin{array}{c}0,12 \\
0,11 \\
0,17 \\
-\end{array}$ & $\begin{array}{l}22 \\
31 \\
30 \\
17\end{array}$ & DeCristofaro ${ }^{[53]}$ \\
\hline$\alpha^{\prime}-\mathrm{Fe}_{1,05} \mathrm{~N}$ & $\begin{array}{l}\mathrm{Fe}_{0} \\
\mathrm{Fe}_{1} \\
\mathrm{Fe}_{\|}\end{array}$ & 78 & $\begin{array}{l}314 \\
356 \\
348\end{array}$ & $\begin{array}{c}-0,12 \\
0,01 \\
0,02\end{array}$ & $\begin{array}{r}-0,01 \\
0,01 \\
0,08\end{array}$ & - & Moriya $^{[56]}$ \\
\hline
\end{tabular}

- Fase $\gamma^{\prime}-\mathrm{Fe}_{4} \mathrm{~N}$

O nitreto $y^{\prime}-\mathrm{Fe}_{4} \mathrm{~N}$ possui uma faixa estequiométrica entre 5,7 e $6,1 \%$ em peso de $\mathrm{N}(19,52$ a 20,63 em \% atômica de $N)$, sendo a fase mais estável do digrama $\mathrm{Fe}-\mathrm{N}$, com boa estabilidade abaixo de $680^{\circ} \mathrm{C}$, Figura 20 , com $\mathrm{T}_{\mathrm{C}}=495 \pm 5^{\circ} \mathrm{C}$. Como já mencionado, o arranjo estrutural do nitreto é cfc, semelhante à austenita com nitrogênio, com parâmetros de rede a variando entre 3,787 e $3,803 \AA$. Os átomos de nitrogênio ocupam um quarto do número de sítios octaédricos de uma maneira completamente ordenada, de modo a minimizar as tensões e a repulsão mútua entre os átomos de nitrogênio, como mostrado na Figura 26. Estudos por difraçâo de raios $X$, de nêutrons, elétrons, medidas magnéticas e espectroscopia Mössbauer, determinaram a existência de dois sítios para o Fe. Em um deles o $\mathrm{Fe}(\mathrm{I})$ situa-se nos cantos do cubo, enquanto no outro, o Fe(II) localiza-se nas faces 
do cubo. $A$ razão entre os sítios é $\mathrm{Fe}(\mathrm{I}): \mathrm{Fe}(\mathrm{II})=1: 3 . \mathrm{O}$ espectro Mössbauer desta fase $\gamma^{\prime}-\mathrm{Fe}_{4} \mathrm{~N}$ apresenta três subespectros ferromagnéticos correspondentes aos sítios do ferro, identificados como $\mathrm{Fe}(\mathrm{I}), \mathrm{Fe}(\mathrm{II})_{\mathrm{A}}$ e $\mathrm{Fe}(\mathrm{II})_{\mathrm{B}}$, como ilustra a Figura 27.0 que distingue os dois sítios $\mathrm{Fe}(\mathrm{II})$ são as interações quadrupolares diferentes ${ }^{[57]}$. Os parâmetros hiperfinos Mössbauer para a fase $\gamma^{\prime}$ são mostrados na Tabela VI.

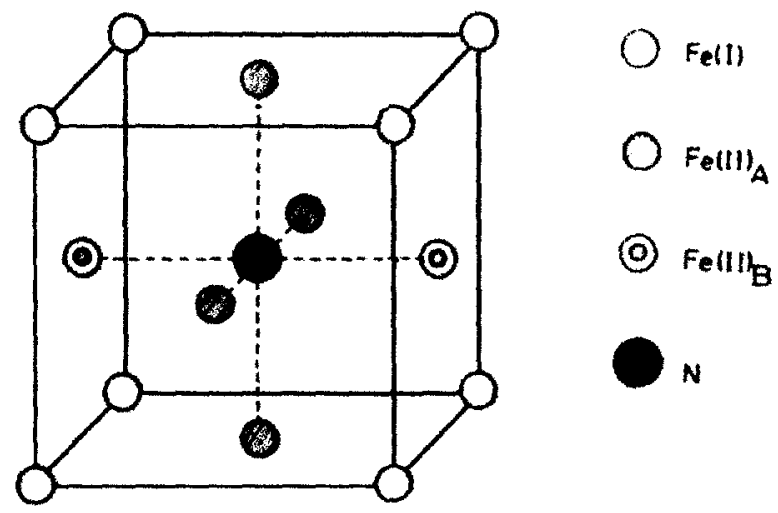

Figura 26 - Arranjo estrutural da fase $\gamma^{2}-\mathrm{Fe}_{4} \mathrm{~N}^{[57]}$.

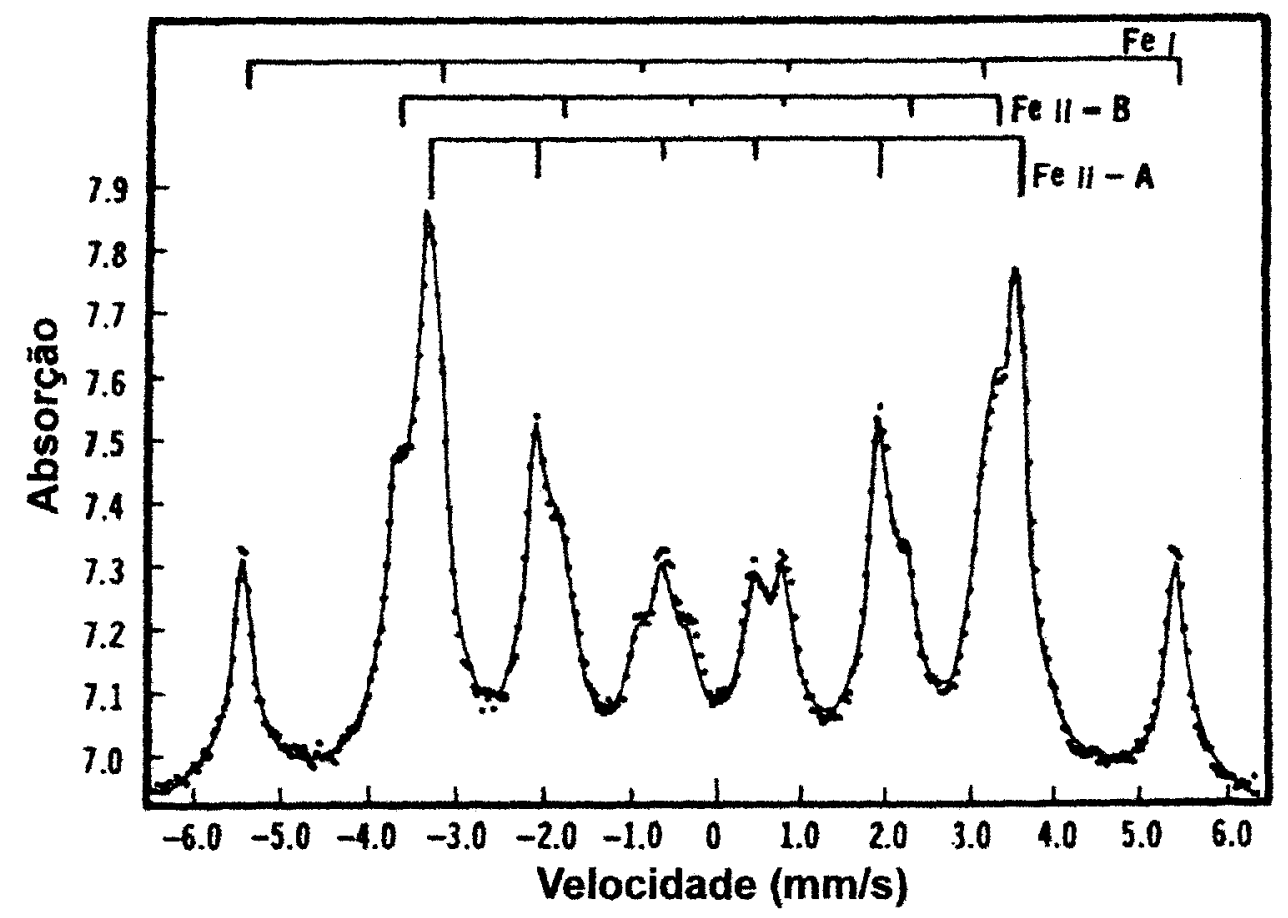

Figura 27 - Espectro Mössbauer do nitreto $\gamma^{\prime}-\mathrm{Fe}_{4} \mathrm{~N}$. As linhas sólidas representam o ajuste e as posiçőes das linhas dos três sítios do Fe são mostradas no topo da Figura ${ }^{[57]}$. 
Tabela VI - Parâmetros hiperfinos de alguns nitretos $\theta$ carbonitretos de ferro: o campo hiperfino $\mathrm{H}(\mathrm{kOe})$, deslocamento isomérico, $\delta$, em relação ao $\mathrm{Fe}-\alpha \mathrm{e}$ acoplamento quadrupolar $E_{Q}(\mathrm{~mm} / \mathrm{s})$. $O \mathrm{~T}(\mathrm{~K})$ é a temperatura da medida.

\begin{tabular}{|c|c|c|c|c|c|c|c|}
\hline Fase & Sítios & $\begin{array}{c}T \\
(K)\end{array}$ & $\begin{array}{c}\mathrm{H} \\
(\mathrm{KOe})\end{array}$ & $\begin{array}{c}\Delta \mathrm{E}_{\mathrm{Q}} \\
(\mathrm{mm} / \mathrm{s})\end{array}$ & $\begin{array}{c}\delta \\
(\mathrm{mm} / \mathrm{s})\end{array}$ & $\begin{array}{l}\% \text { dos } \\
\text { sitios }\end{array}$ & Referências \\
\hline$\alpha^{\prime \prime}-\mathrm{Fe}_{16} \mathrm{~N}$ & $\begin{array}{l}\mathrm{Fe}_{1} \\
\mathrm{Fe}_{\|} \\
\mathrm{Fe}_{\| 11}\end{array}$ & 300 & $\begin{array}{l}288 \\
314 \\
399\end{array}$ & $\begin{array}{r}-0,17 \\
0,09 \\
-0,09\end{array}$ & $\begin{array}{l}0,08 \\
0,17 \\
0,14\end{array}$ & $\begin{array}{l}25 \\
50 \\
25\end{array}$ & Moriya $a^{[56]}$ \\
\hline$\gamma^{\prime}-\mathrm{Fe}_{4} \mathrm{~N}$ & $\begin{array}{l}\mathrm{Fe}(\mathrm{I}) \\
\mathrm{Fe}(I I)_{\mathrm{A}} \\
\mathrm{Fe}(I I)_{\mathrm{B}}\end{array}$ & 300 & $\begin{array}{l}340 \\
215 \\
219 \\
\end{array}$ & $\begin{array}{c}- \\
0,22 \\
-0,43\end{array}$ & $\begin{array}{l}0,24 \\
0,30 \\
0,32\end{array}$ & $\begin{array}{l}25 \\
50 \\
25 \\
\end{array}$ & Nozik $^{[58]}$ \\
\hline$\varepsilon-\mathrm{Fe}_{3,2} \mathrm{~N}$ & $\begin{array}{l}\mathrm{Fe}_{\|} \\
\mathrm{Fe}_{\|}\end{array}$ & 295 & $\begin{array}{l}298 \\
238 \\
\end{array}$ & $\begin{array}{l}- \\
-\end{array}$ & $\begin{array}{l}0,24 \\
0,33 \\
\end{array}$ & $\begin{array}{l}12 \\
88 \\
\end{array}$ & Eickel $^{[59]}$ \\
\hline$\varepsilon-\mathrm{Fe}_{2} \mathrm{~N}$ & & 300 & - & 0,26 & 0,40 & - & Bainbridge $^{[60]}$ \\
\hline$\zeta-\mathrm{Fe}_{2} \mathrm{~N}$ & & 300 & - & 0,27 & 0,42 & - & \\
\hline$\alpha^{\prime}-(\mathrm{Fe}-\mathrm{N}-\mathrm{C})$ & & & - & $\begin{array}{c}0,32 \\
- \\
\end{array}$ & $\begin{array}{r}0,05 \\
-0,12 \\
\end{array}$ & - & \multirow{3}{*}{$\begin{array}{c}\text { Simon }^{[61]} \\
\text { DosSantos }^{[62]} \\
\text { DosSantos }^{[63]}\end{array}$} \\
\hline$\varepsilon-\mathrm{Fe}_{3,2}(\mathrm{C}, \mathrm{N})$ & & 300 & $\begin{array}{l}290 \\
243 \\
\end{array}$ & $\begin{array}{l}0,02 \\
0,29 \\
\end{array}$ & $\begin{array}{l}0,29 \\
0,21 \\
\end{array}$ & - & \\
\hline $\begin{array}{c}\varepsilon-\mathrm{Fe}_{2+x}(\mathrm{C}, \mathrm{N}) \\
x<1,2\end{array}$ & & 300 & $\begin{array}{c}285 \\
220 \\
90 \\
\end{array}$ & $\begin{array}{l}0,21 \\
0,21 \\
0,41\end{array}$ & $\begin{array}{l}0,02 \\
0,12 \\
0,11\end{array}$ & & \\
\hline
\end{tabular}

\section{- Fase $\varepsilon-\mathrm{Fe}_{\mathbf{x}} \mathbf{N}$}

O arranjo dos átomos metálicos na célula unitária do nitreto de ferro $\varepsilon$ é hexagonal, e os interstícios octaédricos desta estrutura são distribuídos em camadas perpendiculares ao eixo $c$, com espaçamento de $c / 2$, Figura 28 . Os intersticios de uma camada estão diretamente acima dos intersticios da camada de baixo, e juntos, eles podem ser imaginados como ocupando pontos de uma rede hexagonal simples de dimensões $a^{\prime}=a$ e $c^{\prime}=c$, onde a e c são os parâmetros da rede hexagonal compacta, formada pelos átomos de ferro. Para a composição $\mathrm{Fe}_{3} \mathrm{~N}, 1 / 3$ dos interstícios em cada camada săo ocupados, de maneira que cada átomo de nitrogênio é cercado por seis interstícios vizinhos, no mesmo plano e nos 
planos diretamente acima e abaixo ${ }^{[49]}$. Estes planos permanecem desocupados, dando uma seqüência $A B A B$ para os planos formados pelos átomos de nitrogênio, Figura 28(a).

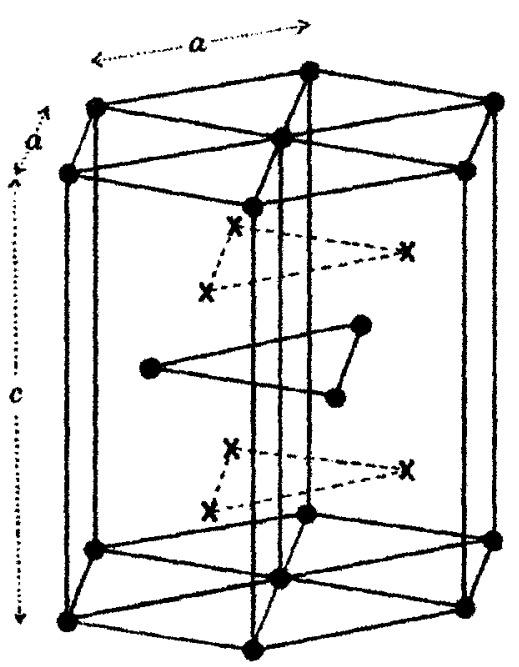

(a)

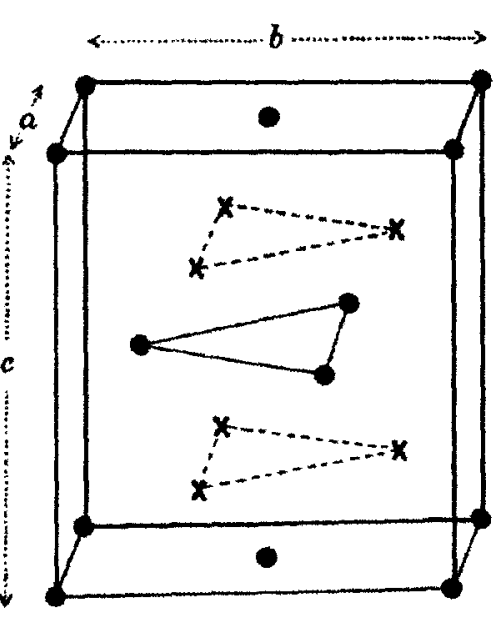

(b)

Figura 28 - Arranjo estrutural da fase $\varepsilon-\mathrm{Fe}_{3} \mathrm{~N}(\mathrm{a})$ e da fase $\varsigma(\mathrm{b})^{[49]}$.

Para concentrações maiores de nitrogênio, são formados outros arranjos ordenados, como a fase $\varepsilon-\mathrm{Fe}_{2} \mathrm{~N}$, formada pela adição de um átomo de nitrogênio na fase $\varepsilon-\mathrm{Fe}_{3} \mathrm{~N}$, ocupando somente os planos alternados, formando uma seqüência $A B^{\prime} A B^{\prime}$ para os planos intersticiais, conforme a Figura 29. Nesta seqüência de planos de átomos de nitrogênio, os planos $A$ são idênticos aos planos (A) da fase $\varepsilon-\mathrm{Fe}_{3} \mathrm{~N}$, e os planos ímpares B são $2 / 3$ preenchidos. Os interstícios que são preenchidos com átomos de nitrogênio nos planos ímpares são vazios nos planos pares e vice - versa, de modo que cada átomo de nitrogênio ainda possui um interstício desocupado nos planos adjacentes acima e abaixo dele. 


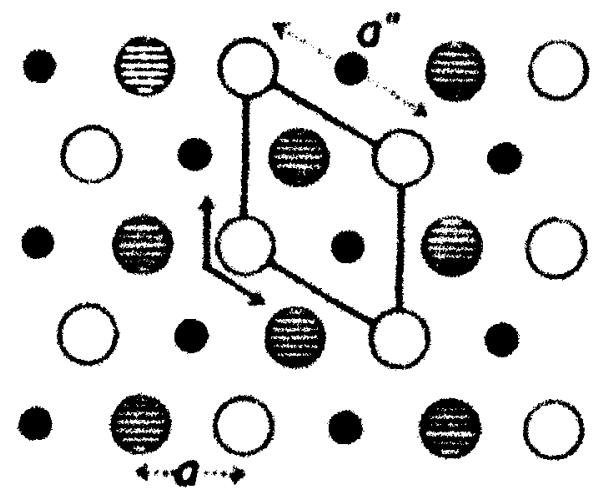

Ocupado nos planos pares $A$

Ocupado nos planos impares B

Desocupado para $\varepsilon-\mathrm{Fe}_{3} \mathrm{~N}$

Ocupado nos planos $B$ para $\varepsilon-\mathrm{Fe}_{2} \mathrm{~N}$

Figura 29 - Camada de planos de interstícios octraedrais para os nitretos $\varepsilon$ $\mathrm{Fe}_{3} \mathrm{~N}$ e $\varepsilon-\mathrm{Fe}_{2} \mathrm{~N}^{[49]}$.

Os parâmetros de rede a e c variam com a concentração de $\mathrm{N}$, de acordo com a curva dada pela Figura 30 .

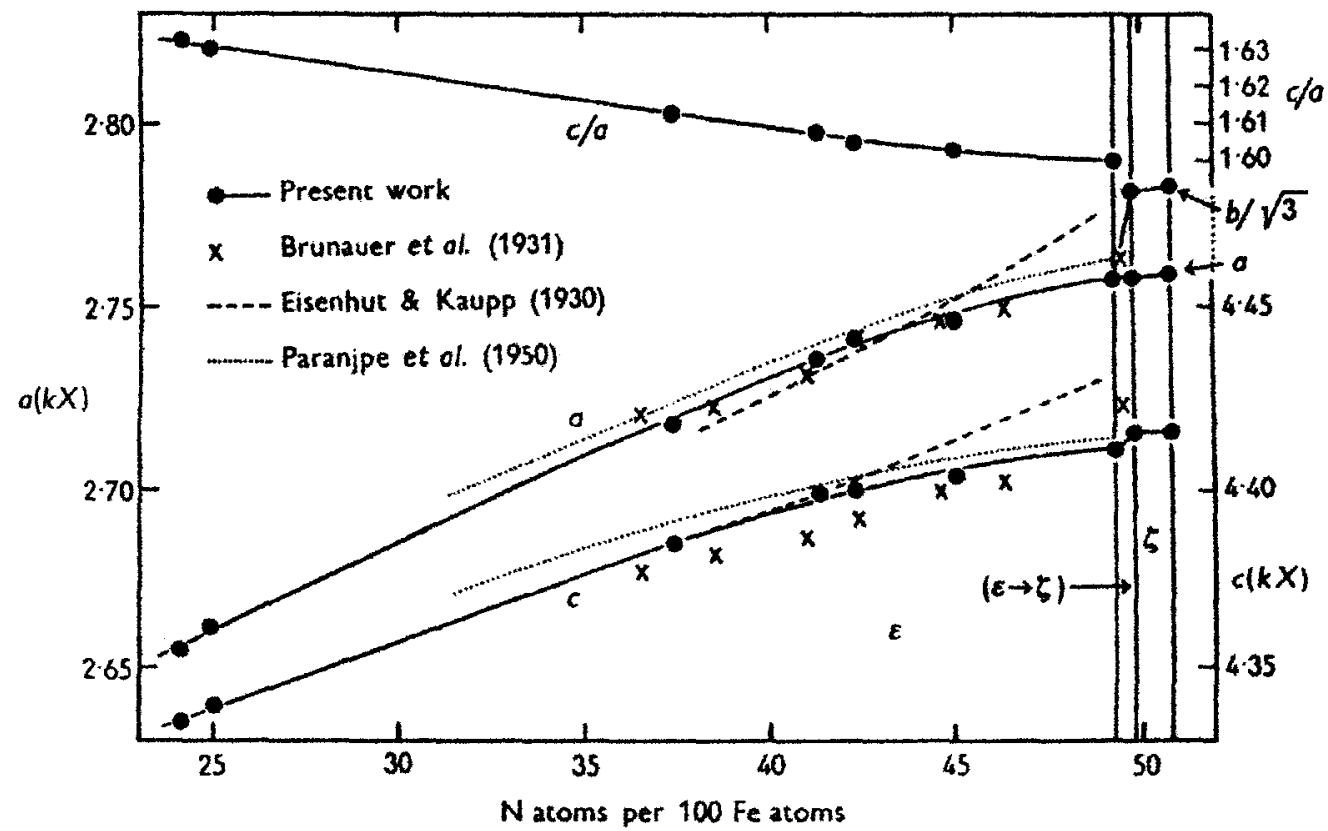

Figura 30 - Variaçōes das dimensóes das fases $\varepsilon$ e $\xi$ em funçăo da concentração de nitrogênio ${ }^{[49]}$. 
Trabalhos realizados com espectroscopia Mössbauer permitiram evidenciar os vários ambientes intersticiais dos átomos de ferro, especialmente na fase, $\varepsilon-F e_{x} N$. Nesta fase $\varepsilon-F e_{x} N(2 \leq x \leq 3.2)$, encontram-se sítios de ferro com 1, 2 ou 3 primeiros vizinhos de nitrogênio. $O$ campo hiperfino é inversamente proporcional ao número de primeiros vizinhos de nitrogênio e diretamente proporcional ao aumento do parâmetro de rede (a razâo c/a varia de 1,60 a 1,65) Ron $^{3}$ apud Figueiredo (1991). Por exemplo, ao adicionar uma pequena quantidade de nitrogênio a um sistema $\mathrm{Fe}-\mathrm{N}$, o parâmetro de rede aumenta, e conseqüentemente o campo hiperfino. Porém, para uma quantidade maior de nitrogênio, o sítio de ferro terá um número de primeiros vizinhos de nitrogênio aumentado, diminuindo o campo hiperfino ${ }^{[64]}$.

A Figura 31 (a) e (b) apresentam curvas da variação do campo hiperfino e da temperatura de Curie em função da concentração de nitrogênio ${ }^{[53]}$.

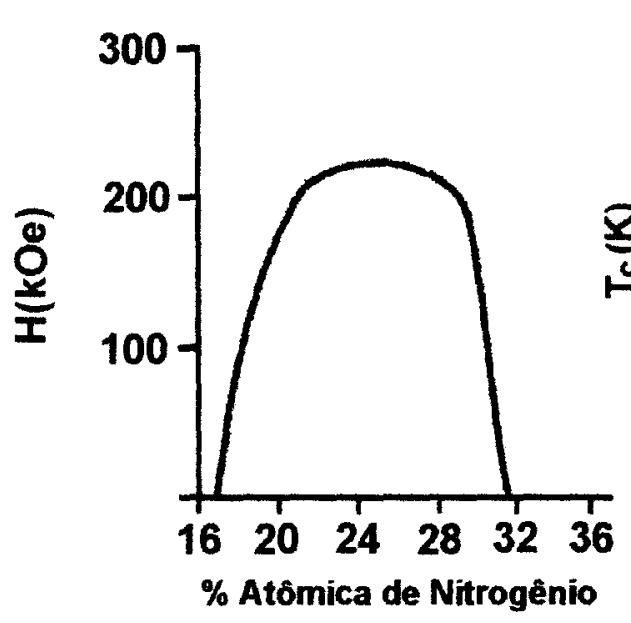

(a)

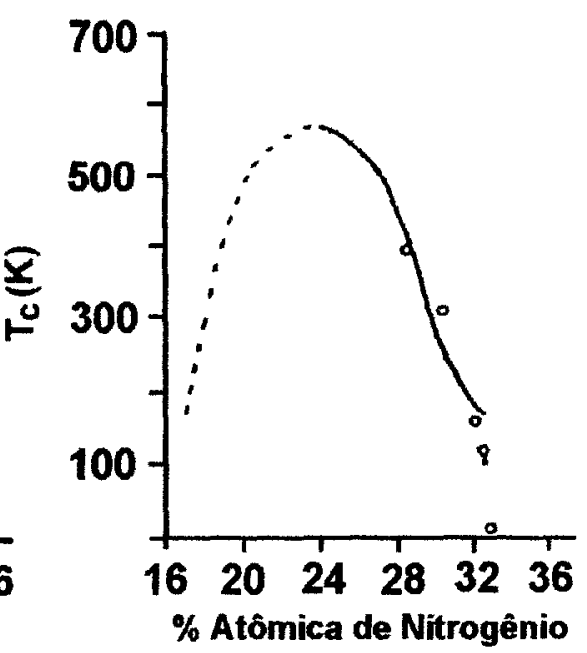

(b)

Figura 31 - (a) Campos hiperfinos magnéticos do $\mathrm{Fe}_{\|}$, como uma função da concentração de nitrogênio; (b) Temperatura de Curie do nitreto $\varepsilon$, como uma função da concentração de nitrogênio ${ }^{[53]}$.

\footnotetext{
${ }^{3}$ RON, M. (1976). Iron-carbon and iron-nitrogen sytems in applications of Mossbauer spectroscopy. New York, Academic Press, 1976. v.2, Cap.7. apud FIGUEIREDO, R. S. Análise de superfície em aços nitretados por espectroscopia Mössbauer. Florianópolis, 1991. 54p. Dissertação (Mestrado) - Universidade Federal de Santa Catarina.
} 
A Figura 32 apresenta um espectro Mössbauer do nitreto $\varepsilon-\mathrm{Fe}_{3,2} \mathrm{~N}$, que foi ajustado com duas componentes, atribuídas aos átomos $\mathrm{Fe}(\mathrm{I})$ e $\mathrm{Fe}(\mathrm{II})$, com 1 e 2 átomos de $\mathrm{N}$ como primeiros vizinhos (Tabela VI).

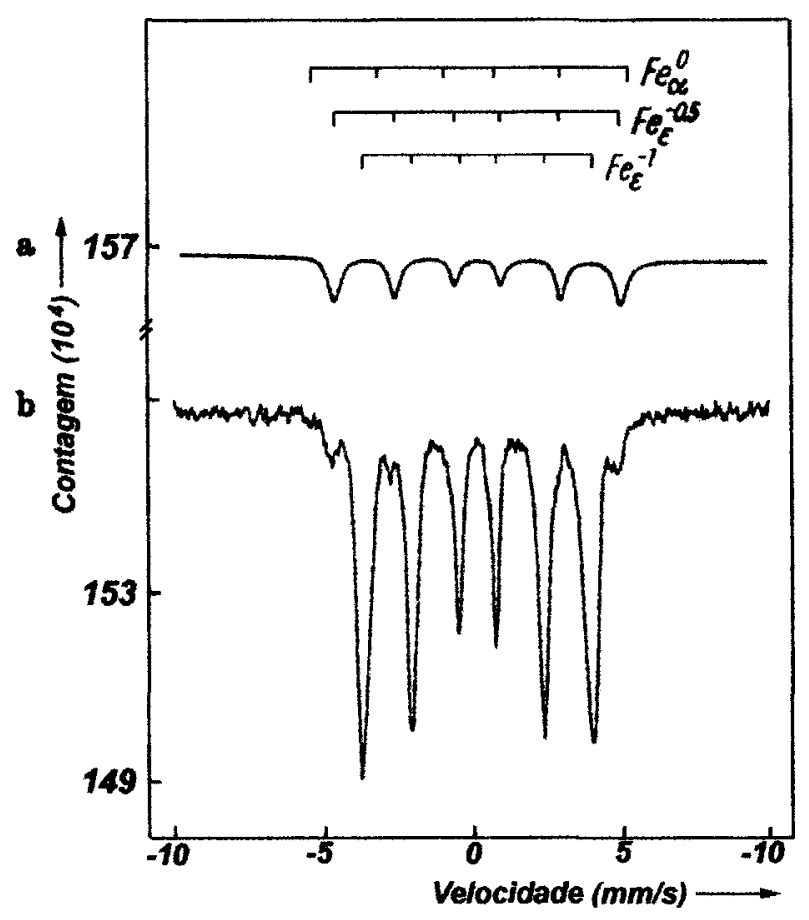

Figura 32 - Espectro Mössbauer do nitreto $\varepsilon-\mathrm{Fe}_{3,2} \mathbf{N}$ a $295 \mathrm{~K}^{[53]}$.

\section{- Fase $\zeta-\mathrm{Fe}_{2} \mathbf{N}$}

Para concentraçőes de nitrogênio entre 11,1 e 11,3\% em massa ocorre uma transição da fase de $\varepsilon$ para $\zeta$. Segundo Jack ${ }^{[56]}$ a fase $\varepsilon$ não contém 0 nitreto $\mathrm{Fe}_{2} \mathrm{~N}$, e a transição ocorre no momento em que a estequiometria vai ser atingida. Estruturalmente, esses nitretos são semelhantes, embora a fase $\varsigma$ seja ortorrômbica $(a=2,758 \AA, b=4,818 \AA$ e $c=4,416 \AA$ ), Figura $27(b)$. Na fase $\varepsilon$, os interstícios são ocupados em planos alternados, de tal maneira que os planos sucessivos $1 / 3$ e $2 / 3$ dos sítios estão ocupados, conforme Figura 28 . Na fase 5 , metade dos interstícios em cada um dos planos estão ocupados, de modo tal que os sítios acima e abaixo permaneçam vazios. A transição é do tipo ordem desordem, e ocorre pelo movimento dos átomos de $\mathrm{N}$ para os sítios vazios acima 
ou abaixo de sua localização. Através de estudos Mössbauer, Bainbridge ${ }^{[60]}$ demonstrou experimentalmente que a fase $\varsigma-\mathrm{Fe}_{2} \mathrm{~N}$ é paramagnética a $4,2 \mathrm{~K}$.

Nesta fase, todos os sítios de ferro têm como primeiros vizinhos três átomos de nitrogênio e portanto, o espectro Mössbauer apresenta um único dubleto que caracteriza a fase, semelhante à fase $\varepsilon$, conforme as Figuras $33(a)$ e (b). 0 espectro Mössbauer de $\varsigma$ apresenta o maior deslocamento Isomérico $(\delta)$ de todas as fases de nitretos de ferro, $0,445 \mathrm{~mm} / \mathrm{s}$ (com referência ao $\alpha$-Fe). Isto indica uma maior troca de carga entre o ferro e o nitrogênio. Ela também apresenta o maior desdobramento quadrupolar $\left(\Delta Q_{E}\right)$ dos nitretos do diagrama de fase da Figura 27, $(0,29 \mathrm{~mm} / \mathrm{s})$, o que reflete a menor simetria do átomo de ferro nesta fase. A fase $\varsigma$ é indesejável em aplicações mecânicas, devido à sua alta fragilidade e baixa aderência ao substrato ${ }^{[32,}{ }^{65]}$. Como esta fase $\zeta$ não é muito estável, em temperaturas da ordem de $447^{\circ} \mathrm{C}$, à pressão de 1 atm, já se decompõe, liberando nitrogênio e evoluindo para $\varepsilon-\mathrm{Fe}_{2+\mathrm{x}} \mathrm{N}^{[65]}$.

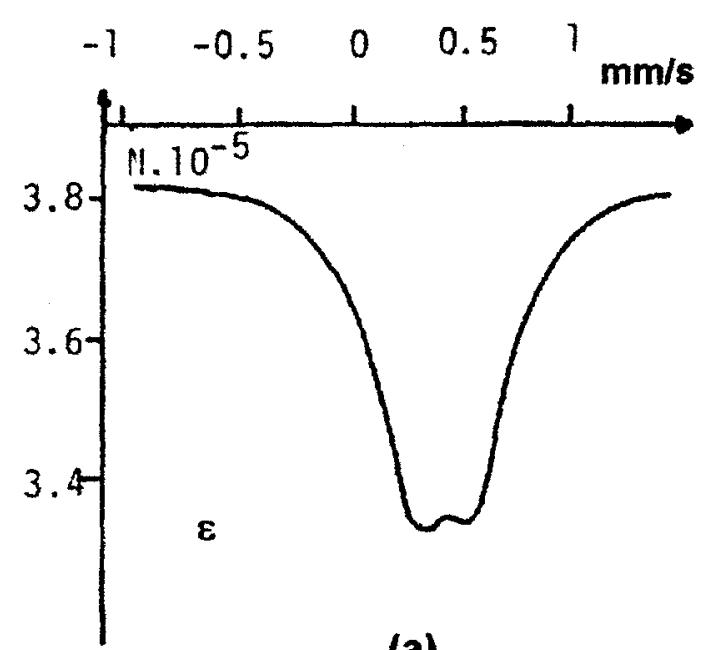

(a)

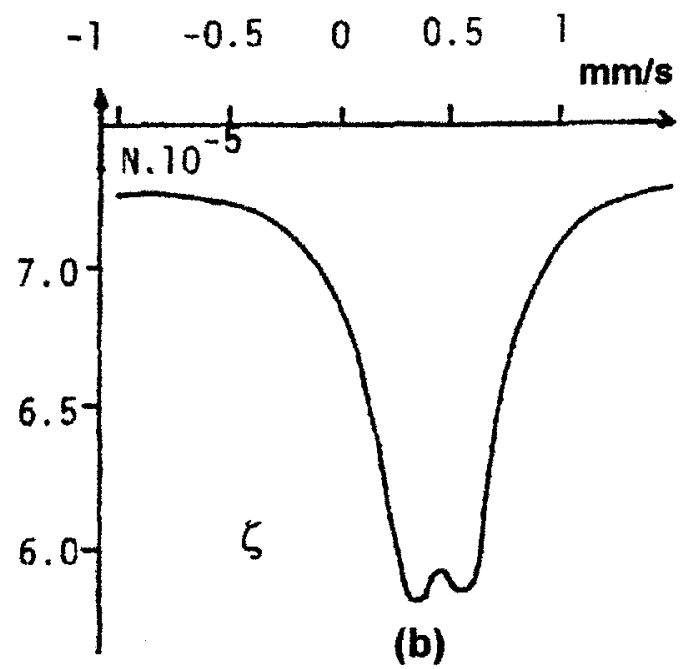

(b)

Figura 33- Espectro Mössbauer dos nitretos $\varepsilon$ e $\varsigma_{-}-\mathrm{Fe}_{2} \mathbf{N}$ (a $e$ b, respectivamente) ${ }^{[5,53,60]}$. 


\section{- Outras Fases}

O sistema $\mathrm{Fe}-\mathrm{N}$ apresenta outras fases metaestáveis citadas na literatura, que possuem caracteristicas importantes do ponto de vista cientifico e tecnológico ${ }^{[6]}$. Uma fase muito estudada é a $\alpha^{\prime \prime}-\mathrm{Fe}_{16} \mathrm{~N}_{2}$, devido às suas interessantes propriedades magnéticas com grande valor de campo hiperfino $\approx$ 400KOe. Como mencionado, este nitreto precipita na matriz ferrítica na forma de pequenas plaquetas ${ }^{[35,66]}$ durante 0 resfriamento lento (com temperatura de formação situada abaixo de $250^{\circ} \mathrm{C}$ ). Contudo, esta fase é metaestável e precipita em $\gamma^{\prime}-\mathrm{Fe}_{4} \mathrm{~N}$, motivo pelo qual o interesse por ela tenha diminuido.

Nitretos de ferro ricos em nitrogênio $\left(\mathrm{Fe}_{x} \mathrm{~N}\right.$ onde $\left.\mathrm{x}<2\right)$ ocorrem em diversos processos de nitretação, mas geralmente como precursores da formação superficial de camadas nitretadas. Fases como $\mathrm{FeN} \mathrm{e} \mathrm{Fe}_{3} \mathrm{~N}_{2}$ são pouco estudadas e normalmente obtidas através de reações no estado sólido.

\section{4 - CARBONITRETOS DE FERRO}

O sistema Fe-C-N é de grande interesse no entendimento e controle dos processos de cementação e carbonitretação. Carbonitretação é o nome mais comum para vários métodos comerciais de tratamentos térmicos. Todos estes processos produzem camadas compostas na superfície de um aço e abaixo dela, uma camada de difusão. Nos últimos anos, inúmeros trabalhos têm sido publicados na caracterização de aços submetidos a vários processos de carbonitretação. Apesar disto, ainda não se dispõe de um conhecimento aprofundado da termodinâmica e da cinética de formaçăo das várias fases formadas na camada de compostos e na de difusão ${ }^{[3,5,67]}$. A maior parte das análises relacionadas ao 
desenvolvimento microestrutural no processo de carbonitretação são baseados no diagrama de fases $\mathrm{Fe}-\mathrm{N}-\mathrm{C}^{[68]}$.

A seguir será apresentado um resumo das propriedades do sistema Fe-C-N baseado no trabalho de Jack $^{[68]}$, que explorou dois métodos de obt0enção de carbonitretos: cementação de nitretos e nitretação de carbetos. No primeiro método, foi observada a reação do CO com nitretos $\varepsilon$, contendo 31 a $33 \%$ atômica de Nitrogênio, a $450^{\circ} \mathrm{C}$, variando o tempo de 35 minutos à 47 horas.

Aumentando a concentração de carbono e diminuindo a concentração de nitrogênio, na mesma taxa, durante um tempo de aproximadamente $9 \mathrm{~h}$, o produto da reação é o carbonitreto $\zeta$ com aproximadamente $35 \%$ em átomos $(\mathrm{C}+\mathrm{N})$, com os mesmos parâmetros de rede do nitreto $\zeta$. Entre 25 e 40h de cementação, as fases formadas são o carbonitreto $\zeta$ e o carbeto $\chi(30,4$ $32,3 \%$ atômica de C), com quantias decrescentes da fase $\zeta$ e quantias crescentes da segunda fase $\chi$, com a concentração de nitrogênio próxima a zero. A partir deste momento, o carbonitreto desaparece. Para temperaturas acima de $450^{\circ} \mathrm{C}$, não são observados carbonitretos no produto final.

No segundo método, estudou-se a nitretação de uma mistura de carbeto $\chi$ e cementita, pela ação da $\mathrm{NH}_{3}$ durante $10 \mathrm{~h}$, a $450^{\circ} \mathrm{C}$, provocando a substituição do $C$ pelo $N$. Os produtos são carbonitretos $\varepsilon$ com uma concentração de aproximadamente $33 \%$ atômica de $\mathrm{C}$ e N, com os mesmos parâmetros de rede dos nitretos $\varepsilon$.

O recozimento em temperaturas da ordem de $350^{\circ} \mathrm{C}$ elimina o nitrogênio, transformando o carbonitreto $\zeta$ em $\varepsilon$. Estes carbonitretos são instáveis a $450^{\circ} \mathrm{C}$, transformando-se em nitretos $\gamma^{\prime}, \varepsilon$ e carbonetos $\theta$ e $\chi$, dependendo das concentrações de $\mathrm{C}$ e $\mathrm{N}$. 


\section{MATERIAIS E MÉTODOS}

\subsection{INTRODUÇÃO}

Esta seção está dividida em duas partes. A primeira descreve o equipamento de nitretação iônica e o procedimento experimental, relacionados com as amostras de ferro e aço AISI H12. A segunda é uma breve exposição sobre as técnicas de análises utilizadas, como: espectroscopia Mössbauer, difratometria de raios $X$ (DRX e GAXD), microscopia eletrônica de varredura (MEV) e microanálise eletrônica, além das técnicas tradicionais de caracterização metalográfica, de microdureza e desgaste. As amostras de ferro foram estudadas de forma sistemática, pelo desgaste sucessivo da camada nitretada, seguida de medidas de Espectroscopia Mössbauer. Já as amostras do aço ferramenta AISI H12 além de serem estudas por espectroscopia Mössbauer, foram também caracterizadas por microanálises por sonda de elétrons.

\subsection{EQUIPAMENTO PARA NITRETAÇÃO IÓNICA}

O equipamento utilizado neste estudo foi construído no Departamento de Engenharia de Materiais, da Escola de Engenharia de São Carlos. Em linhas gerais, consiste basicamente de uma câmara, uma fonte elétrica 
de alimentação, um sistema de vácuo e um sistema de aquisição de dados. A Figura 34 mostra o esquema do equipamento de nitretação por plasma.
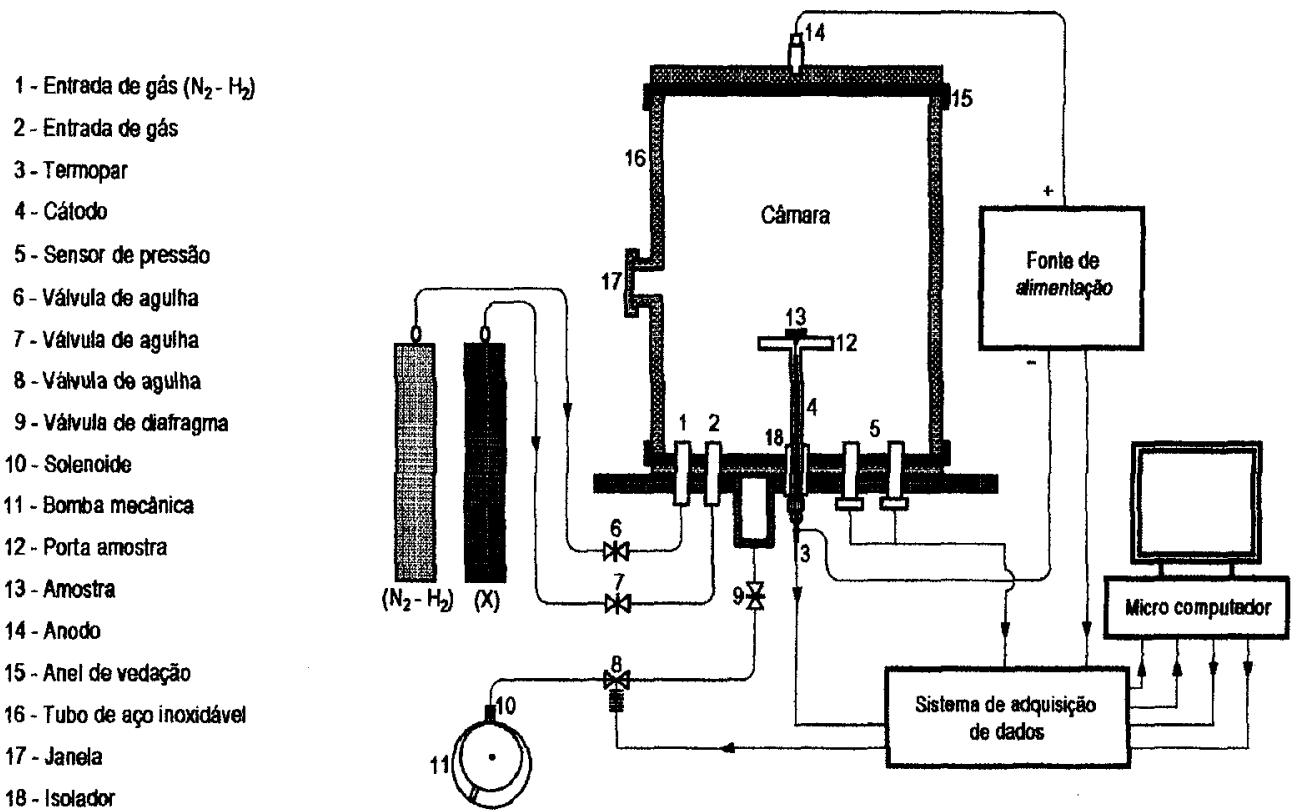

Figura 34- Esquema do equipamento de nitretação por plasma utilizado nos experimentos ${ }^{[69]}$.

A câmara é constituída de um tubo de aço inoxidável, com altura de $30 \mathrm{~cm}$ e diâmetro de $30 \mathrm{~cm}$, resultando num volume de $0.021 \mathrm{~m}^{3}$, com duas flanges em aço inoxidável, utilizadas para fechar a câmara. A flange superior, que é móvel, está ligada a um terminal positivo da fonte de potência, juntamente com a parede da câmara, constituindo o anodo. A flange inferior possui 7 orificios, sendo que no centro passa o termopar de cromel-alumel, eletricamente isolado. Os orifícios restantes são ocupados por conexões da instrumentação de leitura e de controle, como: sensores de pressão, válvulas de vácuo da câmara, entrada de gases, etc. 0 porta - amostra (catodo) consta de um disco de $9,0 \mathrm{~cm}$ de diâmetro e $0,4 \mathrm{~cm}$ de espessura, apoiado sobre blindagem elétrica permitindo uma maior eficiência no tratamento de nitretação. Os íons positivos do plasma são direcionados para a 
superfície da amostra, em contato elétrico com o anodo. A vedação das partes superior e inferior é feita com perfil " $L$ " de viton. Através de uma janela posicionada na parte dianteira da parede da câmara pode ser visualizada a nitretação.

A fonte de potência consiste de um sistema de retificação que recebe tensão da rede $(220 \mathrm{~V} / 60 \mathrm{~Hz})$. Possui uma tensão máxima de saída de $800 \mathrm{~V}$, em corrente direta (DC), ajustável continuamente, com uma potência máxima de 2KVA. Além da tensão contínua, uma tensão pulsada quadrada, também pode ser obtida, com freqüência (f) variável de 1 a $10 \mathrm{kHz}$, e ciclo de trabalho (W) de 30 a $90 \%$, como descrito na seção 2.3 .

A câmara é evacuada por um sistema de vácuo constituído por uma bomba mecânica rotativa, modelo E2M8 da Edwards, seguida por uma válvula de isolamento tipo solenóide (PV25EK-Edwards), montada na linha de entrada. A válvula de isolamento é eletricamente ligada em paralelo com o motor. Uma válvula diafragma está situada na entrada da câmara. Em todas as interligações bomba/câmara e válvulas foram usadas mangueiras de borracha adequadas para sistemas de vácuo.

O sistema de aquisição de dados deste conjunto é composto de uma placa conversora com 8 canais $A / D$ e 2 canais $D / A$, com interface com um microcomputador. O software utilizado na aquisição de dados foi desenvolvido pela Indústria de Aparelhos Médicos - Científicos Fac. Ltda., utilizando a linguagem LabView e uma placa A/D da National Instruments. Este programa faz a leitura da tensão da fonte, tensão entre os eletrodos, corrente, pressão e temperatura. Nesse programa, é possível efetuar a leitura dos dados em intervalos de tempo préestabelecidos.

No painel do equipamento de nitretação por plasma situam-se os mostradores de pressão (2), temperatura (1), freqüência (1), ciclo de trabalho (1), tensão (1) e corrente (1), juntamente com potenciômetro de ajustes grosso e fino de 
corrente e tensão, ajuste de freqüência e ciclo de trabalho, o que permite o monitoramento de todas as variáveis necessárias para o processo de nitretação. $\mathrm{A}$ Figura 35 apresenta a foto do equipamento de nitretação usado.

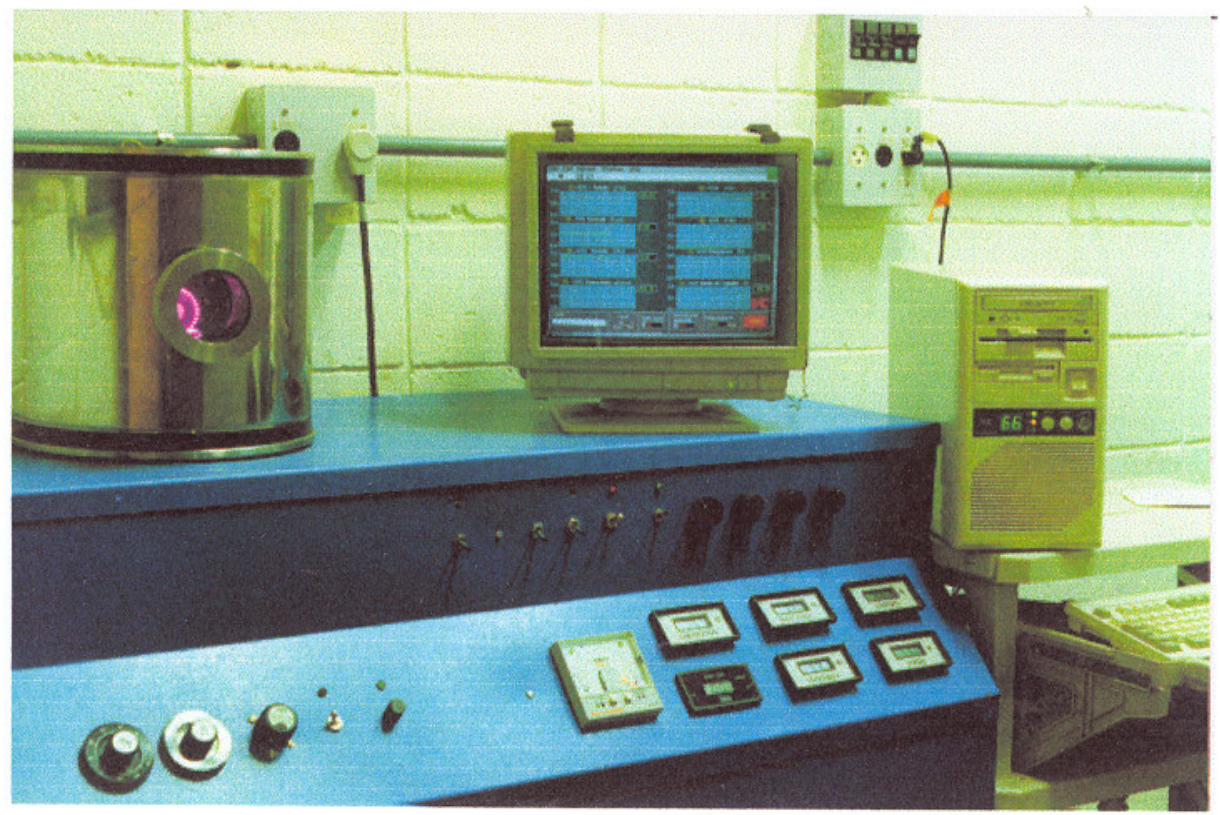

Figura 35 - Foto do equipamento de nitretação por plasma ${ }^{[69]}$.

\subsection{1 - Operação do equipamento}

O tratamento de nitretação por plasma inicia-se com a produção de vácuo na câmara, com a amostra previamente limpa, até à pressão de aproximadamente $4 \times 10^{-2} \mathrm{mbar}^{[69]}$. Este vácuo é quebrado com a introdução do gás de trabalho $\left(20 \% \mathrm{~N}_{2}-80 \% \mathrm{H}_{2}\right)$, para limpeza da câmara. Em seguida, produz-se novamente o vácuo. Esta operação é repetida duas a três vezes, dependendo do grau de contaminação na amostra. Quando a pressão na câmara atingir $0,1 \mathrm{mbar}$, a fonte de tensão é ligada. A voltagem é lentamente aumentada até o início da luminescência característica. Uma vez estabelecida a luminescência, libera-se lentamente a entrada de gás na câmara, aumentando-se gradativamente a corrente e voltagem. Inicia-se assim o bombardeamento iônico, provocando-se o 
aquecimento e a pulverização das impurezas aderidas parcialmente na superfície da amostra pelas reações quimicas do hidrogênio no plasma, que tem o poder de reduzir óxidos da superfície, aquecendo o conjunto amostra e catodo. Se durante o decorrer do aquecimento e da limpeza surgirem faíscas na superfície da peça, é um sinal de que ainda existem algumas impurezas na superficie e que estão sendo removidas. Depois de limpas, o aquecimento da amostra é retomado, até atingir o valor desejado. Nesta fase, a pressão e corrente são ajustadas para a condição de trabalho. Com as condições de tratamento estabelecidas, inicia-se a contagem do tempo de nitretação. Depois que o tratamento é completado, desliga-se o equipamento e a amostra é resfriada dentro da câmara. Quando a temperatura da amostra atingir um valor próximo ao da temperatura ambiente, a pressão da câmara é aumentada por admissão de ar. Em seguida, a câmara é aberta e a amostra é retirada.

\section{3 - PREPARAÇÃO DAS AMOSTRAS DE FERRO}

O material utilizado para o estudo dos nitretos de ferro formados durante a nitretação por plasma foi o ferro com uma pureza de $99,83 \%$, fornecido pelo IPT-SP (Instituto de Pesquisas Tecnológicas). A análise química do ferro é mostrada na Tabela VII.

Tabela VII - Composição (\% em massa) dos elementos presentes no Fe.

\begin{tabular}{|c|c|c|c|c|}
\hline $\mathbf{C}$ & $\mathbf{S i}$ & $\mathbf{M n}$ & $\mathbf{P}$ & $\mathbf{S}$ \\
\hline 0,02 & 0,03 & 0,01 & 0,1 & 0,013 \\
\hline
\end{tabular}


ferro não necessita de tratamento térmico prévio. As amostras foram usinadas no formato de pastilhas, cujas dimensões são mostradas na Figura 36.

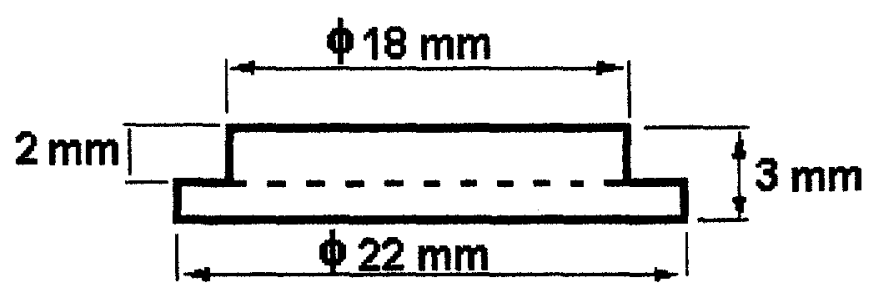

Figura 36 - Dimensões da amostra em forma de pastilha.

Após a usinagem, preparou-se a superfície a ser nitretada de todas as amostras. Inicialmente, cada amostra foi embutida em resina, tendo ao seu redor anéis de aço, para evitar o arredondamento da superfície durante o lixamento e o polimento. A resina endurece em aproximadamente 40 minutos, facilitando o manuseio e a sustentação das amostras na fase de lixamento. Nesta etapa, adotouse uma seqüência de lixas com granulações progressivas até o número 600 , conferindo-se microscopicamente para obtenção de um bom acabamento, para em seguida realizar o polimento em óxido de cromo de $10 \mu \mathrm{m}$ e posteriormente em alumina de 3,0 e $0,05 \mu \mathrm{m}$.

Com as amostras polidas, removeu-se o embutimento. Neste estágio, as amostras geralmente estão impregnadas com resíduos devido ao processo de embutimento, lixamento e polimento. Uma limpeza por ultra-som utilizando acetona foi feita com o objetivo de se manter as superfícies polidas adequadas para a nitretação por plasma.

Finalmente as amostras foram nitretadas seguindo três sistemáticas básicas para o estudo da modificação da camada nitretada, em relação aos seguintes parâmetros: tempo de tratamento, temperatura e freqüência do plasma (f). Para todos os experimentos usou-se uma mistura gasosa de $20 \% \mathrm{~N}_{2}-80 \% \mathrm{H}_{2}$. 
Na primeira sistemática, foram utilizados tempos de tratamento: 1,0h às $6 \mathrm{~h}$, com variação de $1 \mathrm{~h}$, na temperatura de $500^{\circ} \mathrm{C}$, em corrente direta (DC). $\mathrm{Na}$ segunda, foram utilizadas as temperaturas de $400,450,500$ e $550^{\circ} \mathrm{C}$, também em corrente direta, com tempo de tratamento de $3 \mathrm{~h}$. Na última sistemática, utilizou-se a freqüência de plasma de $2,4,6,8$ e $10 \mathrm{kHz}$ em temperatura de $500^{\circ} \mathrm{C}$ durante $3 \mathrm{~h}$. Para facilitar a compreensão do trabalho, a Figura 37 mostra um fluxograma do procedimento experimental.
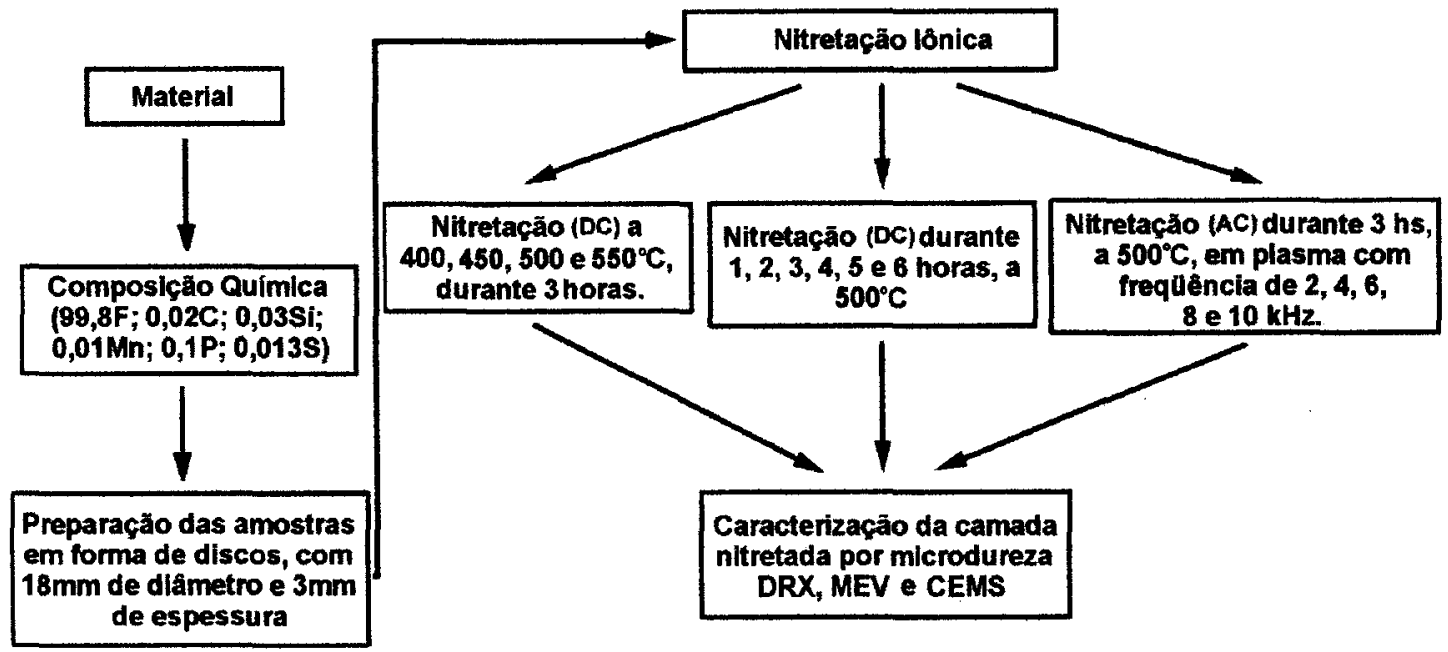

Figura 37 - Procedimento experimental para nitretaçăo do Fe.

As Tabelas VIII e IX apresentam as condiçōes de tratamento para corrente direta e corrente alternada respectivamente.

Tabela VIII - Condições de tratamento da nitretaçăo por plasma em corrente direta (DC).

\begin{tabular}{|c|c|c|c|c|}
\hline \multicolumn{5}{|c|}{ NITRETACÁO EM CORRENTE DIRETA (DC) } \\
\hline Temperatura $\left({ }^{\circ} \mathrm{C}\right)$ & $\begin{array}{c}\text { Pressão } \\
\text { (mbar) }\end{array}$ & $\begin{array}{c}\text { Tempo } \\
(\mathrm{h})\end{array}$ & $\begin{array}{c}\text { Tensão } \\
(\mathrm{V})\end{array}$ & Corrente (mA) \\
\hline $400( \pm 5)$ & 6 & 3 & 456 & $332( \pm 5)$ \\
\hline $450( \pm 5)$ & 6 & 3 & 468 & $358( \pm 5)$ \\
\hline $500( \pm 5)$ & 6 & 3 & 512 & $460( \pm 5)$ \\
\hline $550( \pm 5)$ & 6 & 3 & 528 & $563( \pm 5)$ \\
\hline $600( \pm 5)$ & 6 & 3 & 545 & $605( \pm 5)$ \\
\hline $500( \pm 5)$ & 6 & $\begin{array}{c}1,2,3, \\
4,5 \mathrm{e} 6\end{array}$ & 512 & $460( \pm 5)$ \\
\hline
\end{tabular}


Tabela IX - Condições de tratamento da nitretação por plasma em corrente alternada (AC).

\begin{tabular}{|c|c|c|c|c|c|c|}
\hline \multicolumn{7}{|c|}{ NITRETAC̆̊ EM CORRENTE ALTERNADA (AC) } \\
\hline $\begin{array}{c}\text { Temperat } \\
\text { ura }\left({ }^{\circ} \mathrm{C}\right)\end{array}$ & $\begin{array}{c}\text { Pressão } \\
(\mathrm{mbar})\end{array}$ & $\begin{array}{c}\text { Tempo } \\
(\mathrm{h})\end{array}$ & $\begin{array}{c}\text { Tensão } \\
(\mathrm{V})\end{array}$ & $\begin{array}{c}\text { Corrente } \\
(\mathrm{mA})\end{array}$ & $\begin{array}{c}\text { Ciclo de } \\
\text { trabalho } \\
(\%)\end{array}$ & $\begin{array}{c}\text { Freqüência } \\
(\mathrm{kHz})\end{array}$ \\
\hline $500( \pm 5)$ & 6 & 3 & 517 & $440( \pm 5)$ & 75 & 1,9 \\
\hline $500( \pm 5)$ & 6 & 3 & 512 & $443( \pm 5)$ & 75 & 4,1 \\
\hline $500( \pm 5)$ & 6 & 3 & 517 & $445( \pm 5)$ & 75 & 6,2 \\
\hline $500( \pm 5)$ & 6 & 3 & 523 & $439( \pm 5)$ & 75,1 & 8,1 \\
\hline $500( \pm 5)$ & 6 & 3 & 524 & $447( \pm 5)$ & 75 & 9,89 \\
\hline
\end{tabular}

Após a nitretação, as amostras foram analisadas por espectroscopia Mössbauer (CEMS) e difração de raios $X(G A X D)$ e depois, desgastadas e novamente medidas por CEMS, enquanto outro conjunto de amostras eram cortadas transversalmente para medidas de microdureza e análises metalográficas, utilizando-se as técnicas de microscopia ótica (MO) e microscopia eletrônica de varredura (MEV).

\subsection{1 - Caracterização Metalográfica}

A preparação metalográfica é uma técnica que varia dependendo da natureza do metal a ser analisado. No caso de amostras nitretadas, onde uma fina camada (filme) dura/(o) está presente sobre um substrato relativamente mole, o risco de desprendimento de partículas duras da camada nitretada e o arredondamento das bordas são grandes. Para se evitar estes efeitos indesejáveis, as amostras nitretadas, depois de cortadas transversalmente, foram embrulhadas em folhas de ligas de alumínio. Em seguida, as amostras foram embutidas em baquelite. No lixamento, utilizou-se o mesmo procedimento descrito na seção 5.3, seguido do polimento com pasta de diamante de 1 e $2,5 \mu \mathrm{m}$. 
Para a caracterizaçăo da microestrutura, foram realizados os seguintes ataques:

- Com Nital $2 \%$ ( $98 \mathrm{ml}$ de álcool etílico mais $2 \mathrm{ml}$ de ácido nítrico), que revela a camada de compostos e a zona de difusão ${ }^{[70]}$.

- Para distinguir as diferentes fases nas camadas nitretada, utilizou-se 0 reagente $\mathrm{Nital} 1 \%$ acrescido com de $0,1 \%$ de $\mathrm{HCl}$. Este reagente distingue as fases na camada de compostos, atacando fortemente a fase $\gamma^{\prime}$ e provocando uma diferença de altura entre as fases, tal que $\gamma^{\prime}$ aparece mais escura que a subcamada $\varepsilon^{[71]}$.

\subsection{2 - Difração de Raios $X$}

As estruturas cristalinas e os parâmetros de rede das superfícies nitretadas foram investigados pela técnica de difração de raios $X$ em incidência rasante (GAXD) utilizando-se um difratômetro D5000 da Siemens, equipado com um monocromador de grafite e um tubo de radiação $\operatorname{CuK}_{\alpha}(\lambda=1,54056 \AA)$. As medidas de difraçăo de raios $X$ foram feitas com passo de $0,05 \% / 2 \theta$, com $2 \theta$ variando de $30^{\circ}$ a $120^{\circ}$ e tempo de exposição de $2 \mathrm{~s}$. Já as medidas de baixo ângulo incidente foram obtidas com um ângulo de incidência fixo de $3^{\circ}$, com passo de $0,02^{\circ} / 2 \theta$ e tempo de exposição de $4 \mathrm{~s}$. Com este ângulo de incidência, a espessura da camada analisada pelos raios $\mathrm{X}$ é aproximadamente a mesma quando analisada pela técnica de espectroscopia Mössbauer de conversão de elétrons (CEMS), ou seja, de aproximadamente $0,2 \mu \mathrm{m}$, facilitando a comparação de resultados.

Para se traçar um perfil qualitativo das fases presentes em funçăo da profundidade da camada nitretada, as superficies das amostras foram submetidas a 
um desgaste progressivo. Após cada desgaste usou-se a técnica de GAXD nestas superfícies. Desta forma, foi possível comparar estes resultados com os de CEMS.

\subsection{3 - Desgaste Mecânico}

O desgaste pode ser definido como a remoção gradual de material de uma superfície, como resultado de uma ação mecânica. De acordo com este ponto de vista, distinguem-se dois tipos de desgaste: abrasivo e adesivo. Este último tipo de desgaste não será usado no presente trabalho. A técnica básica do desgaste abrasivo consiste no deslizamento de uma superfície sobre uma outra abrasiva, sob a ação de uma força normal a elas.

Os ensaios de desgaste abrasivo foram realizados em um equipamento do tipo pino-contra-disco modelo TE-79 de fabricação PLINT \& PARTNERS LTD, da Escola Politécnica - USP. O equipamento de ensaio pode ser divido em três partes principais: microcomputador com software para controle dos parâmetros de ensaio e aquisição de dados, a máquina pino-contra-disco propriamente dita e a interface que promove a comunicação entre as partes. A Figura 44 mostra os principais componentes deste sistema.

O equipamento utiliza um eixo acoplado a um disco. O pino a ser ensaiado é pressionado sobre o disco que está girando (com velocidade angular de 0 a $400 \mathrm{rpm})$, através de uma carga especifica $(0,1$ a $20 \mathrm{~N})$, normalmente por meio de um braço de alavanca com a carga aplicada na extremidade do braço (Figura 38). 


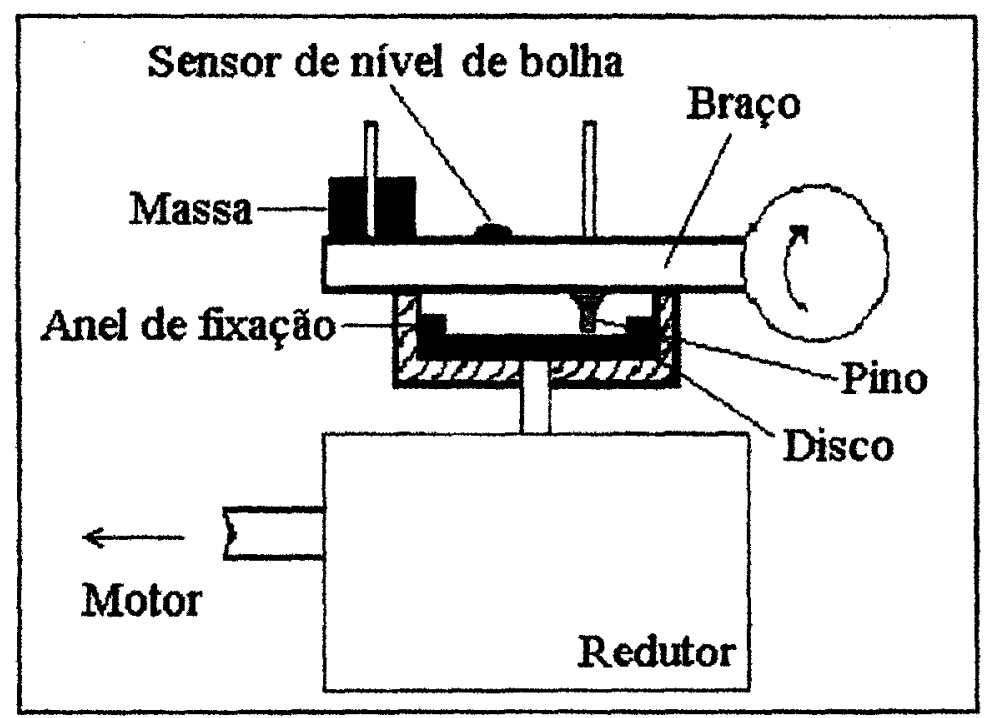

Figura 38 - Esquema simplificado de uma máquina de ensaio pino-contra$\operatorname{disco}^{[2]}$.

O equipamento faz a aquisição automática das medidas de força de atrito, número de rotações de disco, temperatura e umidade relativa do ambiente, além de calcular a velocidade tangencial e a distância percorrida durante o ensaio. Todos os ensaios foram realizados a seco e seguindo as recomendações da Norma ASTM G99-90 (1990), que são:

- Limpeza das amostras antes de cada ensaio;

- Perpendicularidade entre os eixos de centro do disco e do pino de $\pm 1^{\circ}$;

- Paralelismo entre a superfície de contato do pino com o plano do disco;

- Balanceamento da carga e carregamento;

- Início do ensaio com o pino em contato com o disco;

- Ensaios repetidos com amostras adicionais.

A lixa utilizada nos ensaios foi de $\mathrm{SiC}$ de $600 \mu \mathrm{m}$ (mesh), que foi fixada no disco giratório e uma carga constante de $2 \mathrm{~N}$ aplicada sobre a amostra. Assim a superfície plana da amostra era friccionada contra a superfície da lixa, com rotação de 50rpm. O desgaste foi investigado em condiçōes não lubrificadas e em temperatura ambiente e cada amostra ensaiada percorreu 150m, com intervalos a 
cada $10 \mathrm{~m}$ para troca de lixa e a pesagem da amostra. O desgaste das amostras foi quantificado pela perda de peso percentual com relação à massa inicial, isto é:

$$
\% \text { PERDA DE MASSA }=\frac{m_{i}-m_{n}}{m_{i}}
$$

Onde:

$\mathrm{m}_{\mathrm{i}}=$ massa inicial;

$m_{n}=$ massa da amostra para o número de giros específico.

Em cada pausa a amostra foi limpa e pesada numa balança com 0,0001g de precisão da marca Mettler e uma nova lixa foi utilizada a cada pausa.

\subsection{4 - Ensaios de microdureza}

A medida de microdureza Vickers é o mais sensível dos ensaios de dureza, além de ser mais versáteis, pois pode ser usado tanto para chapas finas, como para grandes volumes.

O ensaio de microdureza baseia-se na impressão produzida por um indentador Vickers padrão com ponta de diamante em forma de pirâmide de base quadrada, com ângulo de 136 graus entre as faces. Podem ser aplicadas cargas diversas, entre $1 \mathrm{gf}$ e 1000gf, com tempo de aplicação de 10 a 15 segundos, depois de atingido o valor total da carga. A dureza Vickers é obtida medido-se as diagonais produzidas pelo indentador, através da expressão:

$$
H V=\frac{2 F(\operatorname{sen} a / 2)}{d^{2}}=1,854 \frac{F}{d^{2}}
$$

onde $F$ = carga aplicada; $d$ é a média das diagonais da mossa; $\alpha$ ângulo entre as faces do penetrador $136^{\circ}$. 
Os ensaios de microdureza foram realizados sobre a superfície e ao longo do perfil da camada, utilizando-se um microdurômetro Micromet da série 2100, equipado com um indentador Vickers e cargas de 10 a 1000gf. A carga utilizada no ensaio de todas as amostras foi de $10 \mathrm{gf}$ na camada de compostos e 25gf na camada de difusão com tempo de aplicação da carga de 15s. 0 procedimento adotado para cada profundidade está de acordo com a norma JIS G0562 ${ }^{[73]}$, conforme mostra a Figura 39. Esta norma também foi utilizada como guia nas medidas das profundidades da camada de difusão e da camada de compostos.

Para se medir a indentação de microdureza e a espessura da camada usou-se um sistema de análise e processamento de imagem através do programa Qwin (Leica Q500mc).

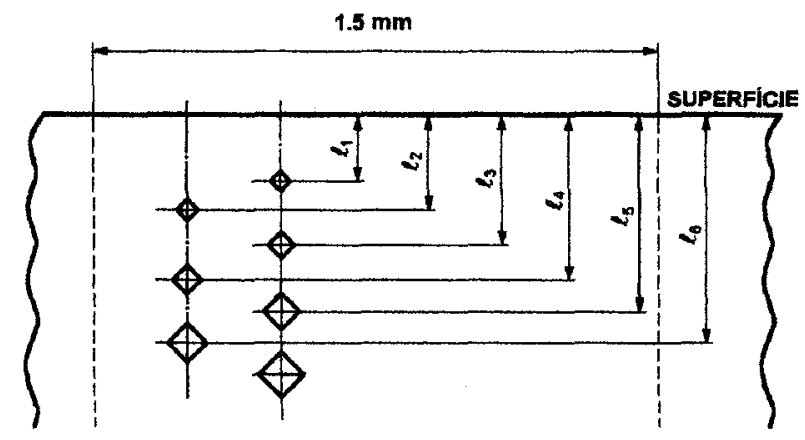

(a)

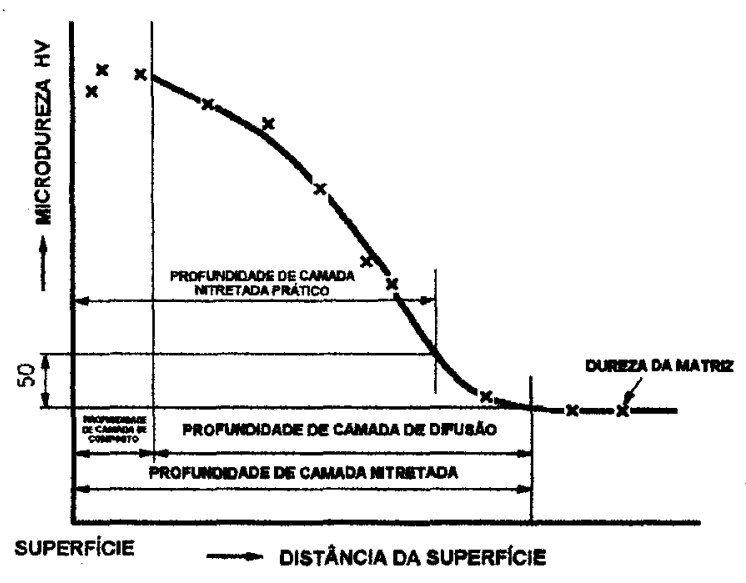

(b)

Figura 39 - (a) Disposiçăo das mossas, para obtençăo do perfil de microdureza, nas amostras nitretadas; (b) curva de microdureza (HV) om função da profundidade da camada ${ }^{[3]}$. 


\subsection{5 - Microscopia eletrónica de varredura (MEV)}

A morfologia da superficie nitretada, bem como a microestrutura do corte transversal das amostras foram examinadas utilizando-se um microscópio eletrônico de varredura modelo JSM-5800LV da JEOL. A camada nitretada quando atacada quimicamente com Nital $2 \%$ revelou camada de compostos e a camada de difusão, e quando atacadas com o Nital $1 \%+0,1 \% \mathrm{HCl}$ mostrou a diferença entre as fases $\gamma^{\prime}$ (escura) e $\varepsilon$ (clara) $^{[32]}$.

\subsection{6 - Espectroscopia Mössbauer}

Os dados de espectroscopia Mössbauer foram obtidos em uma geometria para retroespalhamento utilizando um contador proporcional com fluxo de uma mistura gasosa de $95 \% \mathrm{He}+5 \% \mathrm{CH}_{4}$ (para CEMS) e $95 \% \mathrm{Ar}+5 \% \mathrm{CH}_{4}$ (para CXMS), em um transdutor com aceleração constante. A fonte utilizada foi de ${ }^{57} \mathrm{Co}$ em uma matriz de $\mathrm{Rh}$, com uma atividade nominal de $50 \mathrm{mCi}$. Todas as medidas de CEMS e CXMS foram realizadas à temperatura ambiente. A calibração da velocidade foi realizada em uma chapa fina de $25 \mu \mathrm{m}$ de $\alpha-\mathrm{Fe}$, à temperatura ambiente. Os espectros foram armazenados em um analisador multicanal com 512 canais e ajustados de acordo com um programa de mínimos quadrados, pela sobreposição das linhas Lorentzianas.

O esquema do equipamento experimental utilizado neste trabalho pode ser visto na Figura 40. O sistema de Mössbauer é formado por um detector proporcional, construído durante realização deste trabalho, que fornece pulsos proporcionais a energia dissipada em seu interior. Um pré-amplificador (Ortec modelo 142PC) e amplificador de corrente (Canberra modelo 816 ) é utilizado para 
elevar o nivel do sinal captado. Uma vez amplificado, o sinal passa por um discriminador ou um analisador de altura de pulso (Hamner modelo NC-11), de acordo com a seção 3.2 e por um analisador multicanal (placa MCS EG\&G acoplada a um computador) onde é armazenado. Como dito anteriormente, a absorção ressonante é obtida quando a fonte e a amostra encontram-se em movimento relativo. As diferenças de energia do núcleo fonte e da amostra, devido as interação hiperfinas, são compensadas pelo efeito Doppler. Para isto, utilizou-se um gerador (função da Wissel modelo DFG-1200), que alimenta um transdutor eletromecânico (Wissel modelo MR-260A), com onda triangular, que sincroniza o movimento da fonte com a varredura do multicanal. Desta maneira, o número de pulsos é armazenado em função da velocidade da fonte.

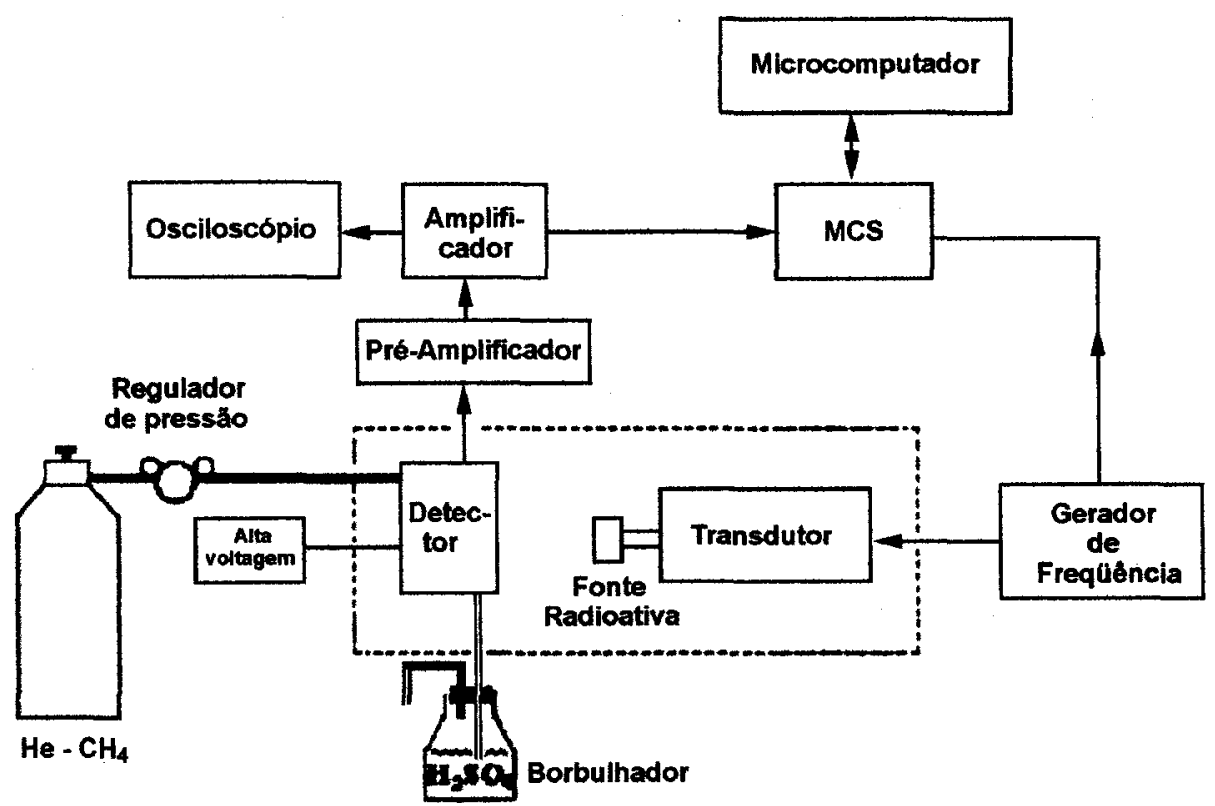

Figura 40 - Esquema de blocos do espectrómetro Mossbauer utilizado nas medidas experimentais. 


\section{4 - PREPARAÇÃO DAS AMOSTRAS DE AÇO AISI H12}

O material utilizado consistiu de uma barra de $100 \mathrm{~mm}$ de comprimento e $25 \mathrm{~mm}$ de diâmetro, que foi cortada em discos de $2,0 \mathrm{~mm}$ de espessura por $20 \mathrm{~mm}$ de diâmetro. As amostras foram temperadas a $950^{\circ} \mathrm{C}$ durante $1 \mathrm{~h}$, e resfriadas em óleo, e duplamente revenidas a $550^{\circ} \mathrm{C}$ durante 30 minutos. Em seguida foram lixadas e polidas, seguido o procedimento descrito na seção 5.3. A análise química nominal deste aço é dada na Tabela $X$.

Tabela X - Composiçăo (\% em massa) dos elementos presentes no aço AISI $\mathrm{H}^{12^{[4]}}$.

\begin{tabular}{|c|c|c|c|c|c|c|}
\hline $\mathbf{C}$ & $\mathbf{S i}$ & $\mathbf{M n}$ & $\mathbf{C r}$ & Mo & $\mathbf{V}$ & $\mathbf{W}$ \\
\hline 0,36 & 0,87 & 0,43 & 5,04 & 1,73 & 0,33 & 1,14 \\
\hline
\end{tabular}

As amostras preparadas metalograficamente foram nitretadas em dois diferentes modos: em corrente direta e alternada, com freqüência de $9,83 \mathrm{kHz}$. Fixou-se a temperatura em $500^{\circ} \mathrm{C}$, pressão em $6 \mathrm{mbar}$ e a mistura gasosa em $20 \% \mathrm{~N}_{2}-80 \% \mathrm{H}_{2}$, nos tempos de $1,2,3,4,5$ e $6 \mathrm{~h}$. A Tabela XI mostra as condições de voltagem e corrente para obtenção da temperatura de $500^{\circ} \mathrm{C}$.

Tabela XI - Condiçōes de tratamento da nitretação do aço AISI H12 em corrente alternada (AC) e direta (DC).

\begin{tabular}{|c|c|c|c|c|c|c|}
\hline \multicolumn{7}{|c|}{ NITRETAÇĀO EM CORRENTE DIRETA (DC) } \\
\hline $\begin{array}{c}\text { Temperatura } \\
\left({ }^{\circ} \mathrm{C}\right)\end{array}$ & $\begin{array}{c}\text { Pressão } \\
\text { (mbar) }\end{array}$ & $\begin{array}{c}\text { Tempo } \\
\text { (h) }\end{array}$ & $\begin{array}{c}\text { Tensão } \\
\text { (V) }\end{array}$ & $\begin{array}{c}\text { Corrente } \\
(\mathrm{mA})\end{array}$ & $\begin{array}{c}\text { Ciclo de } \\
\text { trabalho } \\
(\%)\end{array}$ & $\begin{array}{l}\text { Freqüência } \\
\qquad(\mathrm{kHz})\end{array}$ \\
\hline $500( \pm 5)$ & 6 & $\begin{array}{l}1,2,3 \\
4,5 \text { e } 6 \\
\end{array}$ & 481 & $449( \pm 5)$ & - & - \\
\hline \multicolumn{7}{|c|}{ NITRETAÇÃO EM CORRENTE ALTERNADA (AC) } \\
\hline $\begin{array}{c}\text { Temperatura } \\
\left({ }^{\circ} \mathrm{C}\right)\end{array}$ & $\begin{array}{l}\text { Pressão } \\
\text { (mbar) }\end{array}$ & $\begin{array}{l}\text { Tempo } \\
\text { (h) }\end{array}$ & $\begin{array}{l}\text { Tensão } \\
\text { (V) }\end{array}$ & $\begin{array}{l}\text { Corrente } \\
\text { (mA) }\end{array}$ & $\begin{array}{c}\text { Ciclo de } \\
\text { trabalho } \\
(\%)\end{array}$ & $\begin{array}{l}\text { Freqüência } \\
(\mathrm{kHz})\end{array}$ \\
\hline $500( \pm 5)$ & 6 & $\begin{array}{l}1,2,3 \\
4,5 \text { e } 6\end{array}$ & 698 & $480( \pm 5)$ & 75 & 9,83 \\
\hline
\end{tabular}




\subsection{1 - Ensaios de microdureza}

Todos os ensaios foram realizados sobre a superficie ao longo do perfil da camada. A Figura 39 ilustra o procedimento utilizado para as indentações, de acordo com a norma JIS $\mathrm{G}_{0562^{[73]}}$. As medidas foram realizadas em um microdurômetro Zeiss equipado com um indentador Vickers e com carga aplicada de $70 \mathrm{~g}$.

\subsection{2 - Difração de Raios X}

As análises de difração de raios $X$ foram realizadas com uma geometria $\theta-2 \theta(D R X)$ e geometria com incidência rasante (GAXD), por meio de um difratômetro D 500 , equipado com um monocromador de grafite e radiação de CuKa $(\lambda=1,5418 \AA)$. Para as medidas de DRX utilizou-se uma varredura com passo de $0,05^{\circ} / 2 \theta$ no intervalo $2 \theta$ de 10 a $80^{\circ}$, com um tempo fixo de exposição de 1s. Já as medidas de GAXD foram obtidas com ângulo de incidência de $3^{\circ}$, com uma varredura de passo $0,02^{\circ} / 2 \theta$ e tempo de exposição de $4 \mathrm{~s}$.

\subsection{3 - Microanálise Eletrônica}

A microanálise eletrônica foi utilizada para a determinação das concentrações dos elementos $\mathrm{C}$ e $\mathrm{N}$ na camada nitretada. Esta técnica consiste na incidência de um feixe de elétrons na superfície do material e da emissão de elétrons e raios $X$. Este último, utilizado na microanálise, uma vez que os fótons emitidos do volume do material são proporcionais ao número atômico dos 
elementos. As medidas de microanálises foram realizadas com um equipamento CAMECA SX50 usando uma voltagem de aceleração de $15 \mathrm{keV}$, uma corrente de $20 \mathrm{nA}$, com diâmetro de sonda de $1 \mu \mathrm{m}$ e um ângulo de partida de $40^{\circ}$. As intensidades das linhas $K \alpha$ para o nitrogênio e o carbono foram obtidas em passos de $1 \mu \mathrm{m}$ durante a varredura do feixe sobre a seção transversal da amostra. Estes elementos foram analisados com um cristal sintético de multicamada $(2 d=9,68 \mathrm{~nm})$. Cada perfil medido é uma média de cinco medidas, tomadas em pontos correspondentes ao longo de várias direções longitudinais.

\subsection{4 - Espectroscopia Mössbauer}

Os dados de espectroscopia Mössbauer foram obtidos em uma geometria de retroespalhamento (CEMS), como descrito na seção 5.3.6. A única diferença está na atividade nominal da fonte de ${ }^{57} \mathrm{Co}$ utilizada, que é de $25 \mathrm{mCi}$. 


\section{RESULTADOS}

Neste capítulo são apresentados os resultados experimentais obtidos por diversas técnicas em amostras de ferro $99,8 \%$ e do aço AISI H12 submetidas ao processo de nitretação por plasma, sob diferentes condições de tratamento. Para facilitar a exposição dos resultados, optou-se por dividir o presente capítulo em duas partes: na primeira serão apresentados os resultados das medidas no ferro nitretado, enquanto que na segunda serão apresentados os resultados das medidas no aço AISI H12.

\section{1 - AMOSTRAS DE FERRO}

\subsubsection{Introdução}

Com o objetivo de estudar o processo de nitretação por plasma variando os parâmetros de trabalho, o ferro foi nitretado em diferentes condições de temperatura, tempo e freqüência. A Figura 41 mostra a microestrutura típica de uma amostra de ferro, utilizado neste trabalho, que é composta por ferrita e poros, devido ao processo de fundição.

Primeiramente, a nitretaçăo foi realizada em DC, durante um tempo fixo de 3 h e a temperatura de nitretação variou de 400 a $550^{\circ} \mathrm{C}$. A seguir, as 
amostras foram nitretadas em $\mathrm{DC}$, à temperatura fixa de $550^{\circ} \mathrm{C}$, variando-se agora o tempo de nitretação de 1 a 6 horas. Por último foram nitretadas amostras variando-se a freqüência do plasma, fixando-se o tempo de nitretação em $3 \mathrm{~h}$ e a temperatura de $550^{\circ} \mathrm{C}$.

As amostras assim tratadas foram submetidas a análises pôr diversas técnicas como microdureza, difração de raios $\mathrm{x}$ e espectroscopia Mössbauer.

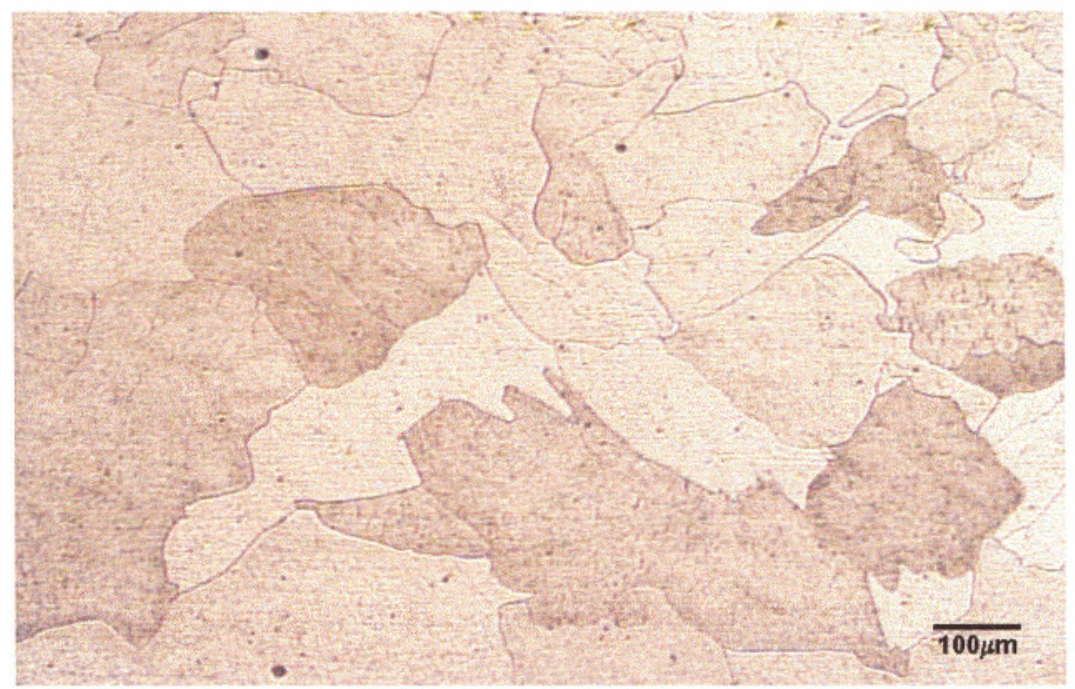

Figura 41 - Micrografia ótica do ferro (99,8\%). Ataque com Nital $2 \%$.

\subsubsection{Nitretação em diferentes temperaturas.}

a) Medidas de microdureza

O ferro foi nitretado em temperaturas de $400,450,500$ e $550^{\circ} \mathrm{C}$, durante $3 \mathrm{~h}$, sob a pressão de $6 \mathrm{mbar}$, em $\mathrm{DC}$ e as amostras foram depois caracterizadas quanto ao perfil de microdureza da camada nitretada. A Figura 42 ilustra estes resultados. 
A profundidade da camada nitretada com uma dureza característica, na literatura inglesa também chamada de "hard case" ${ }^{[75]}$, pode ser estimada pelo perfil de microdureza obtido, assumindo arbitrariamente $200 \mathrm{HV}$ como o mínimo de dureza da camada nitretada (a dureza do ferro, antes da nitretação, é de aproximadamente $100 \pm 10 \mathrm{HV}$ ). Como ilustrado na Figura 42, a espessura da camada com dureza a $200 \mathrm{HV}$, nas amostras nitretadas a 450,500 e $550^{\circ} \mathrm{C}$ é de aproximadamente 12, 20 e $42 \mu \mathrm{m}$, respectivamente.

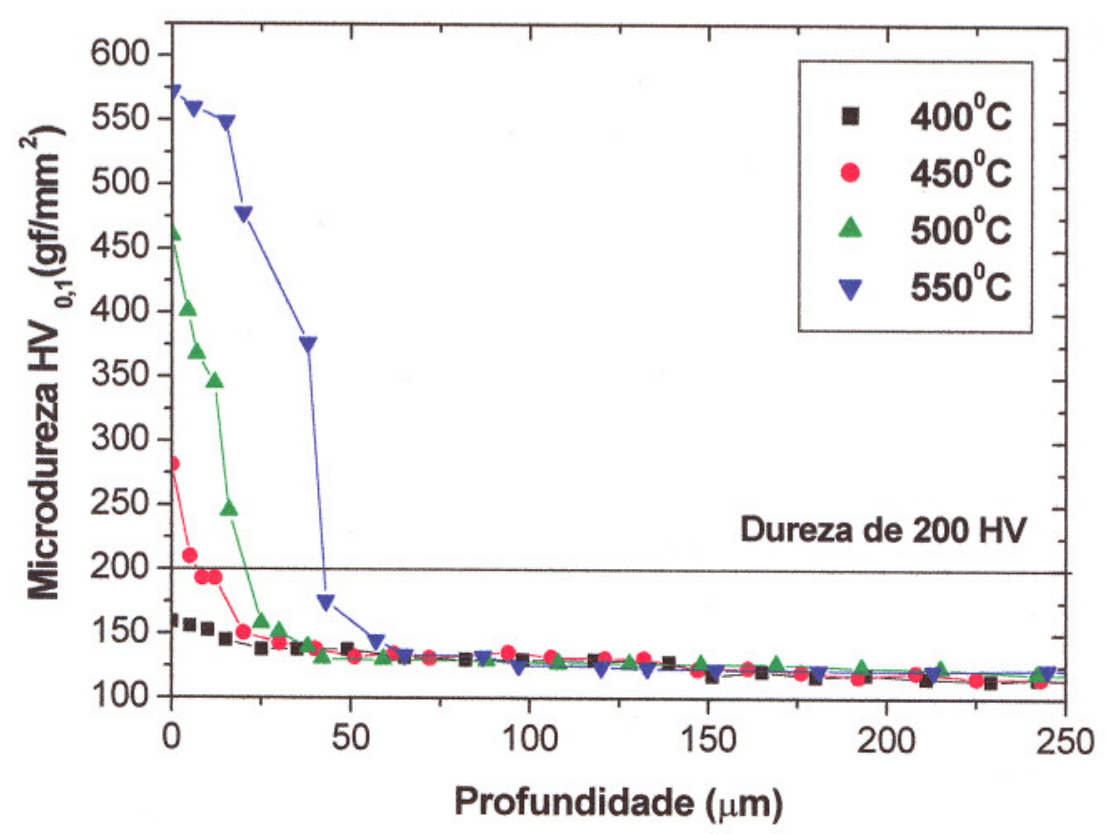

Figura 42 - Perfil de microdureza ao longo da camada nitretada, para tratamentos em DC nas temperaturas de $400,450,500$ e $550^{\circ} \mathrm{C}$, com tempo de nitretação de $3 \mathrm{~h}$.

b) Imagens obtidas por MEV

Através de medidas em imagens obtidas por MEV é possível também obter informações a respeito da espessura e da microestrutura das camadas 
superficiais nitretadas produzidas pelo processo de nitretação por plasma. A Figura 43 mostra micrografias dos cortes transversais nas amostras de ferro nitretado nas temperaturas entre 400 a $550^{\circ} \mathrm{C}$. Quando atacados com Nital $1 \%+0,1 \% \mathrm{HCl}$, o que se observa é a presença de regiões distintas na camada de compostos.

A Figura 43(a) exibe duas regiões distintas. A primeira próxima à superfície denominada de camada de compostos é formada por uma camada de espessura não homogênea. Com o aumento da temperatura de nitretação, a camada de compostos se torna contínua e homogênea, Figura 43(b), juntamente com uma camada de difusão.
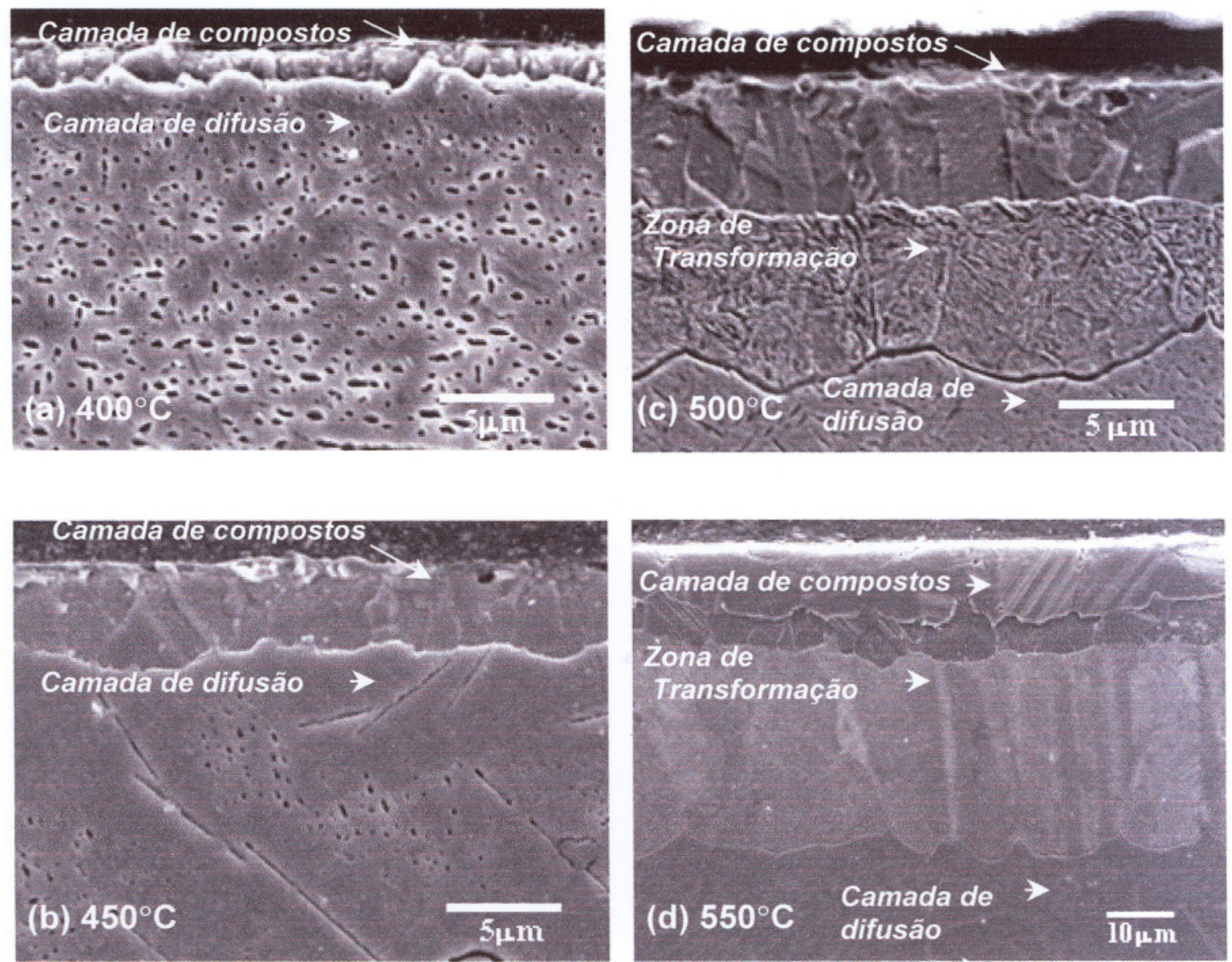

Figura 43 - Micrografias das amostras de Fe nitretadas em diferentes temperaturas (a) $400^{\circ} \mathrm{C}$, (b) $450^{\circ} \mathrm{C}$, (c) $500^{\circ} \mathrm{C}$ e (d) $550^{\circ} \mathrm{C}$. 
A morfologia da camada nitretada nas temperaturas de 500 e $550^{\circ} \mathrm{C}$ apresentam varias regiões distintas. Para amostra nitretada a $500^{\circ} \mathrm{C}$ observa-se à presença de 3 regiões. No caso da amostra nitretada a $550^{\circ} \mathrm{C}$ observa-se à presença de 4 regiões. A Figura 44 apresenta a morfologia da camada de difusão para as amostras nitretadas em temperaturas acima de $450^{\circ} \mathrm{C}$.

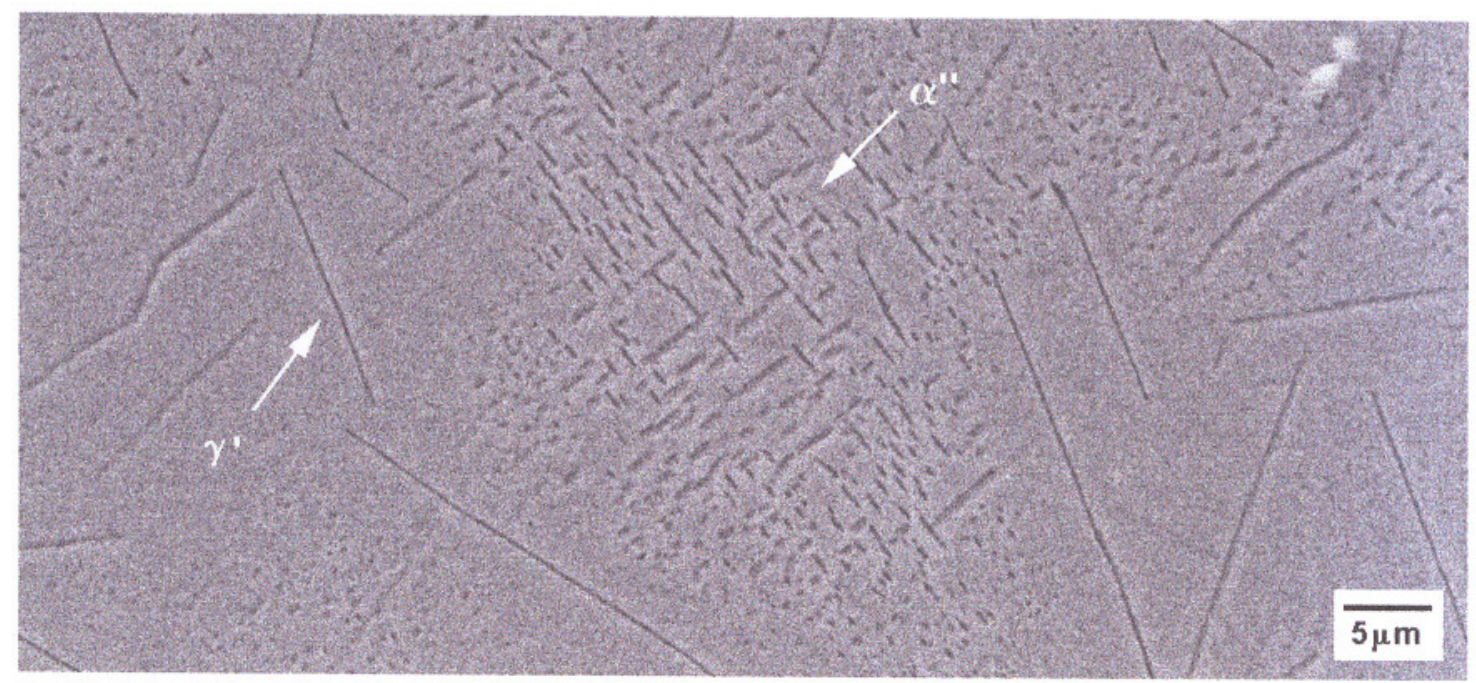

Figura 44 - Micrografia típica da região da camada de difusão da amostra nitretada (DC) na temperatura de $500^{\circ} \mathrm{C}$ durante $3 \mathrm{~h}$, mostrando os precipitados $\left(\gamma^{\prime}-\mathrm{Fe}_{4} \mathrm{~N}\right.$ e $\alpha$ "'-Fe $\left.{ }_{16} \mathrm{~N}_{2}\right)$.

c) Medidas por difração de raios $\mathrm{x}$

Os resultados da difração de raios $X(G A X D)$ na região mais superficial da camada nitretada revelaram a presença das fases $\varepsilon-\mathrm{Fe}_{3} \mathrm{~N}, \gamma^{\prime}-\mathrm{Fe}_{4} \mathrm{~N}$ e $\alpha-\mathrm{Fe}$, para as temperaturas de 400 e $450^{\circ} \mathrm{C}$, enquanto que para temperaturas de $\mathrm{T}=500$ e $550^{\circ} \mathrm{C}$, apenas as fases $\varepsilon$ e $\gamma^{\prime}$ foram observadas, como mostra a Figura 45. 


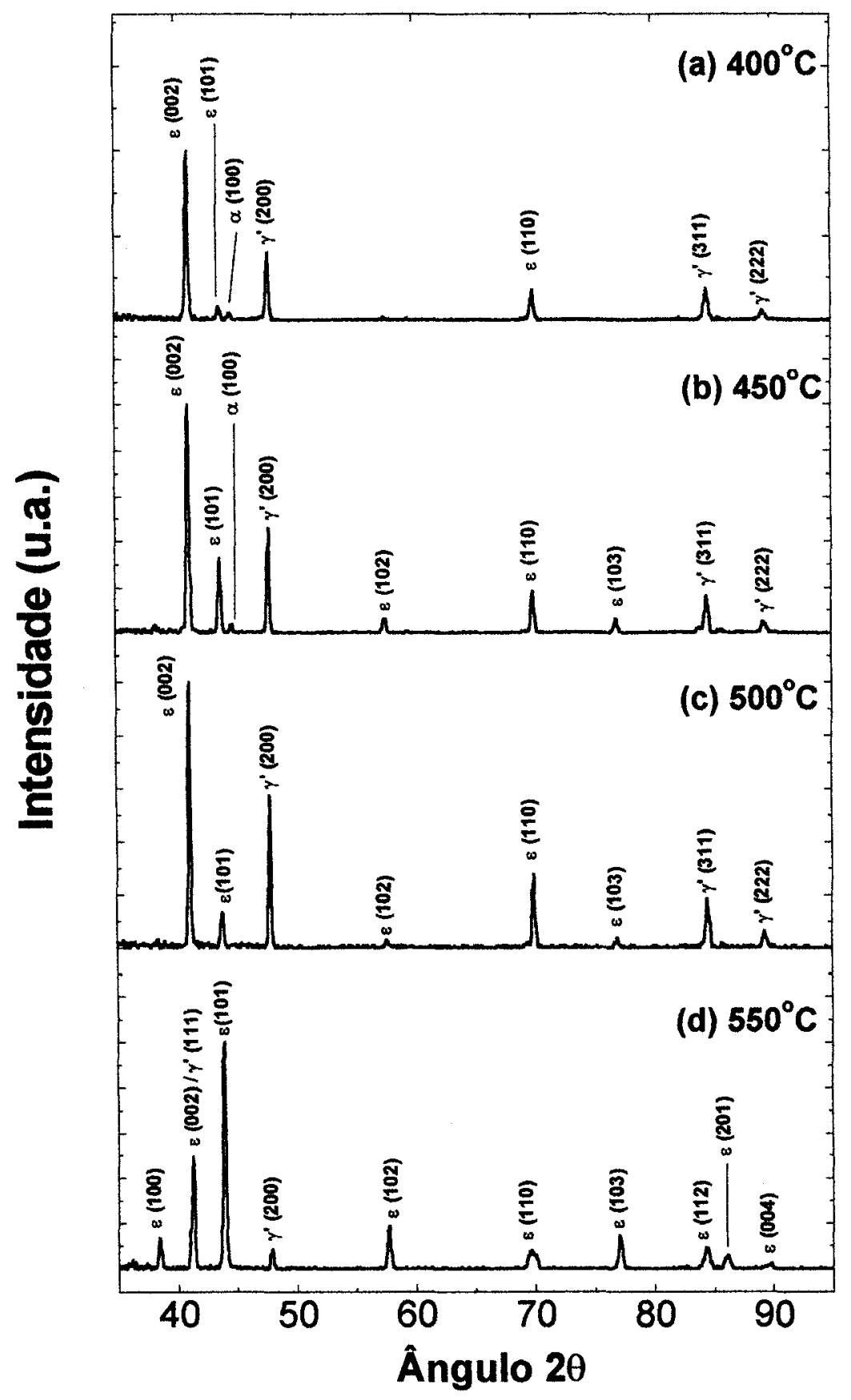

Figura 45 - Difratogramas de GAXD da superficie das amostras de ferro, nitretadas a temperaturas de: (a) $400^{\circ} \mathrm{C}$; (b) $450^{\circ} \mathrm{C}$; (c) $500^{\circ} \mathrm{C}$ e (d) $550^{\circ} \mathrm{C}$. 


\section{b) Análise das amostras nitretadas por CEMS}

Quanto à técnica de Mössbauer, os resultados são apresentados na forma de espectros CEMS, bem como de tabelas dos correspondentes parâmetros hiperfinos, obtidos a partir do ajuste dos dados experimentais. As figuras, assim como as tabelas, estão divididas de modo a mostrar a cinética de formação dos nitretos nas diferentes condiçōes de nitretação (temperatura, freqüência de plasma e tempo). As amostras foram identificadas por um código, por exemplo, E001.

O deslocamento isomérico $(\delta)$ relativo ao $\alpha-F e$ é dado em $\mathrm{mm} / \mathrm{s} ; \Delta E_{Q}$ significa o desdobramento quadrupolar medido em $\mathrm{mm} / \mathrm{s} ; H$ é o campo hiperfino e está dado em kOe e $\Gamma$ representa a largura do pico interno do espectro, cujo valor é dado em $\mathrm{mm} / \mathrm{s}$. Os ajustes Mössbauer foram feitos em um microcomputador, utilizando um programa especifico para ajustes deste tipo de espectro, através da soma de Lorentzianas. Este programa permite ajustes de no máximo dez sítios. Os valores a serem ajustados são selecionados, enquanto que as demais variáveis têm seus valores pré-fixados. A linha contínua em vermelho, nos espectros Mössbauer, representa a curva ajustada aos pontos experimentais. Um ajuste típico de um espectro é ilustrado na Figura 46 para uma amostra nitretada durante 1 h. Estes espectros foram ajustados com subespectros correspondendo a $30 \%$ de $\alpha^{\prime}, 30 \%$ de $\gamma^{\prime}, 33 \%$ de $\varepsilon_{3}$ e $7 \%$ de $\varepsilon_{x}$. O subespectro $\varepsilon_{3}$ representa o carbonitreto $\varepsilon-F e_{3,2}(C, N)$, enquanto que $\varepsilon_{x}$ corresponde a $\varepsilon-\mathrm{Fe}_{\mathrm{x}}(\mathrm{C}, \mathrm{N})$, com $2 \leq \mathrm{x} \leq 3,2$. 


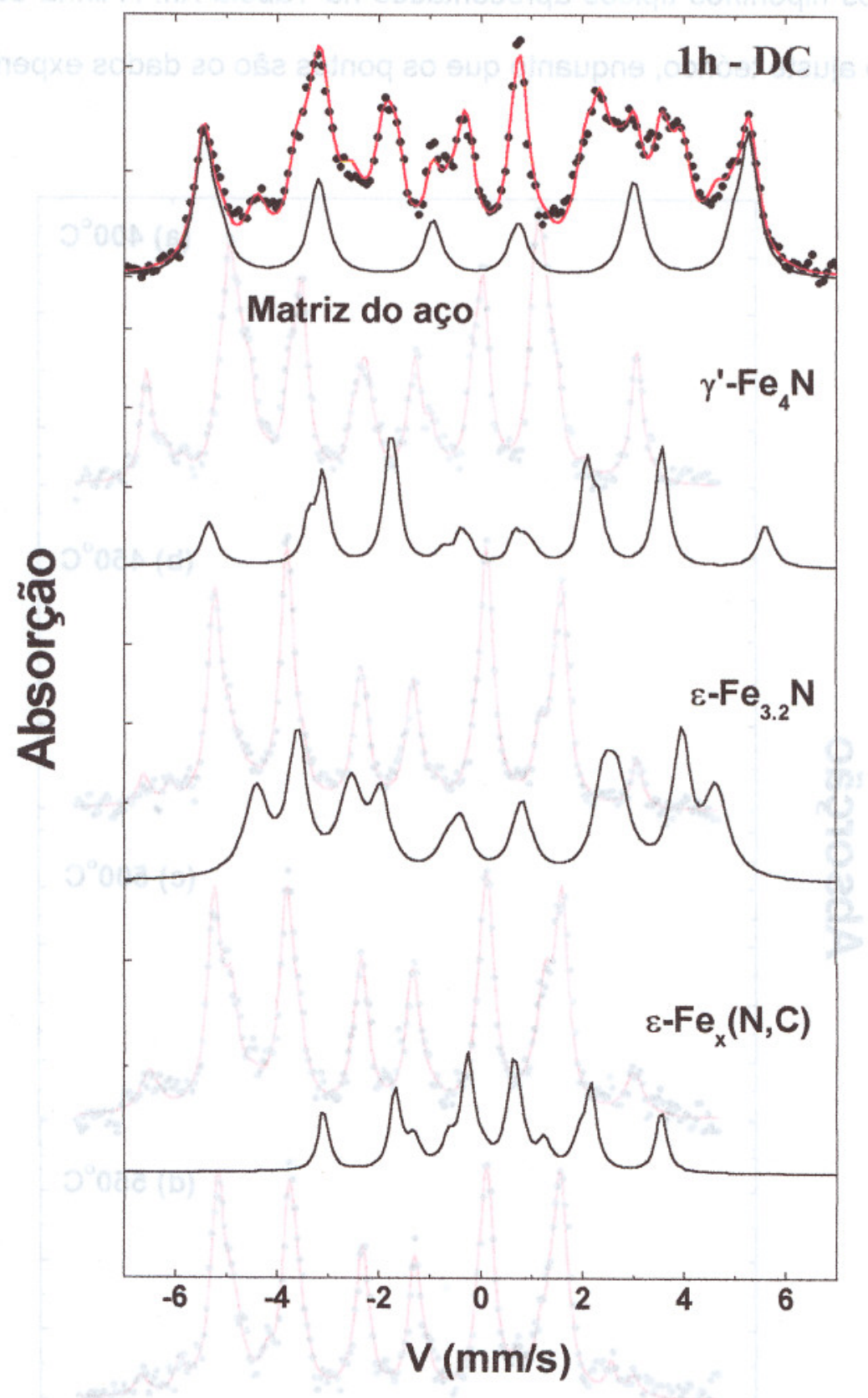

Figura 46 - Espectro de CEMS das amostras de aço H 12 nitretada em corrente direta durante $1 \mathrm{~h}$, juntamente com os subespectros usados no procedimento de ajuste ${ }^{[74]}$.

A Figura 47 apresenta a cinética de formação dos nitretos de ferro para as amostras nitretadas em temperaturas que variam de $400^{\circ} \mathrm{C}$ à $550^{\circ} \mathrm{C}$, para o tempo de tratamento de $3 \mathrm{~h}$, analisadas por CEMS. Estes espectros foram ajustados 
pela adição de subespectros correspondentes às fases $\alpha, \varepsilon, \gamma^{\prime}$ e a um dubleto, com os parâmetros hiperfinos típicos apresentados na Tabela XII. A linha contínua em vermelho é o ajuste teórico, enquanto que os pontos são os dados experimentais.

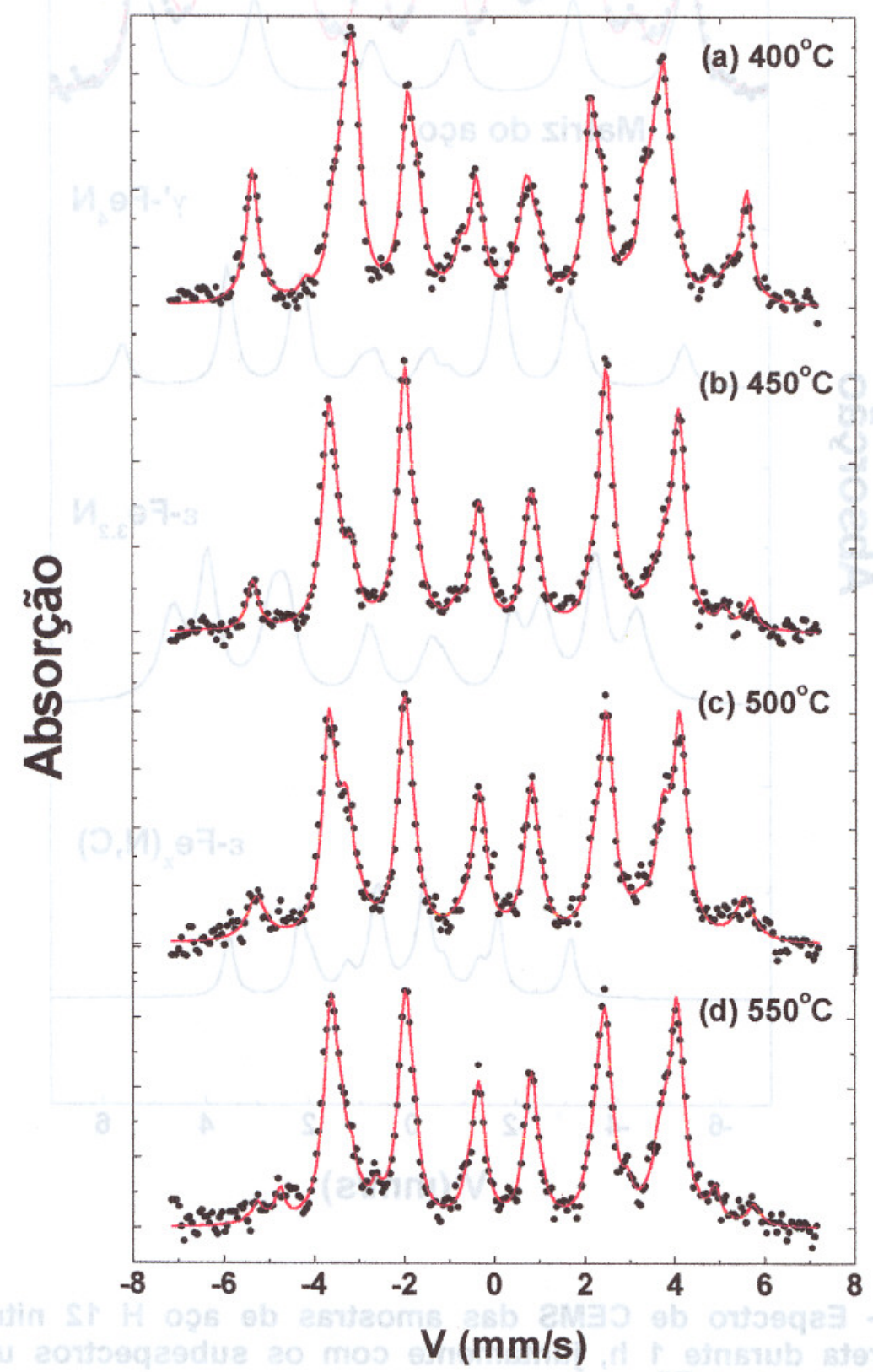

Figura 47 - Espectro Mössbauer para amostras nitretadas em diferentes temperaturas, durante $3 \mathrm{~h}$. (a) $\mathrm{E} 008,400^{\circ} \mathrm{C}$; (b) $\mathrm{E} 004,450^{\circ} \mathrm{C}$; (c) $\mathrm{E} 010,500^{\circ} \mathrm{C}$; (d) $E 005,550^{\circ} \mathrm{C}$. A linha contínua (em vermelho) é a curva ajustada aos pontos experimentais. 
Tabela XII - Relação das amostras nitretadas e os parâmetros obtidos no ajuste dos espectros Mössbauer.

\begin{tabular}{|c|c|c|c|c|c|c|}
\hline $\begin{array}{c}\text { Amostra } \\
\left({ }^{\circ} \mathrm{C}\right)\end{array}$ & Fase & $\begin{array}{c}\delta \\
(\mathrm{mm} / \mathrm{s})\end{array}$ & $\begin{array}{c}\Delta E_{Q} \\
(\mathrm{~mm} / \mathrm{s})\end{array}$ & $\Gamma(\mathrm{mm} / \mathrm{s}$ & $\begin{array}{c}\mathrm{H} \\
(\mathrm{kOe})\end{array}$ & $\begin{array}{c}\text { Área } \\
\text { Relativa (\%) }\end{array}$ \\
\hline \multirow{6}{*}{$\begin{array}{c}400 \\
(E 008)\end{array}$} & $\alpha-\mathrm{Fe}$ & 0 & 0 & 0,30 & 330 & 8 \\
\hline & Dubleto & 0,35 & 0,92 & 0,30 & 0 & 1,5 \\
\hline & $\gamma^{\prime}-\mathrm{Fe}_{4} \mathrm{~N}$ & $\begin{array}{l}0,24 \\
0,30\end{array}$ & $\begin{array}{c}0 \\
0,10\end{array}$ & $\begin{array}{l}0,27 \\
0,25\end{array}$ & $\begin{array}{l}340 \\
216 \\
\end{array}$ & $\begin{array}{l}17,5 \\
15,0 \\
\end{array}$ \\
\hline & $\varepsilon-\mathrm{Fe}_{3} \mathrm{~N}$ & 0,27 & 0 & 0,37 & 217 & 25,0 \\
\hline & $\varepsilon-\mathrm{Fe}_{2,67} \mathrm{~N}$ & 0,30 & 0 & 0,35 & 204 & 18,0 \\
\hline & $\varepsilon-\mathrm{Fe}_{3,2} \mathrm{~N}$ & 0,30 & 0 & 0,30 & 234 & 15,0 \\
\hline \multirow{5}{*}{$\begin{array}{c}450 \\
(E 004)\end{array}$} & $\alpha-\mathrm{Fe}$ & 0 & 0 & 0,26 & 330 & 1,5 \\
\hline & Dubleto & 0,35 & 1,08 & 0,36 & 0 & 5,0 \\
\hline & $\gamma^{\prime}-\mathrm{Fe}_{4} \mathrm{~N}$ & $\begin{array}{l}0,22 \\
0,34 \\
0,31 \\
\end{array}$ & $\begin{array}{c}0 \\
0,10 \\
-0,21 \\
\end{array}$ & $\begin{array}{l}0,70 \\
0,25 \\
0,41 \\
\end{array}$ & $\begin{array}{l}340 \\
216 \\
218 \\
\end{array}$ & $\begin{array}{c}14,0 \\
9,5 \\
8,0 \\
\end{array}$ \\
\hline & $\varepsilon-\mathrm{Fe}_{3} \mathrm{~N}$ & 0,28 & 0 & 0,35 & 217 & 10,0 \\
\hline & $\varepsilon-\mathrm{Fe}_{3,2} \mathrm{~N}$ & 0,32 & 0 & 0,36 & 236 & 52,0 \\
\hline \multirow{4}{*}{$\begin{array}{c}500 \\
(E 010)\end{array}$} & $\alpha-\mathrm{Fe}$ & 0 & 0 & 0,30 & 330 & 2,7 \\
\hline & Dubleto & 0,33 & 1,06 & 0,25 & 0 & 4,3 \\
\hline & $\gamma^{\prime}-\mathrm{Fe}_{4} \mathrm{~N}$ & $\begin{array}{l}0,20 \\
0,28 \\
0,27 \\
\end{array}$ & $\begin{array}{c}0 \\
0,10 \\
-0,20 \\
\end{array}$ & $\begin{array}{l}0,20 \\
0,27 \\
0,28 \\
\end{array}$ & $\begin{array}{l}340 \\
216 \\
217 \\
\end{array}$ & $\begin{array}{l}6,5 \\
9,5 \\
6,7 \\
\end{array}$ \\
\hline & $\varepsilon-\mathrm{Fe}_{3,2} \mathrm{~N}$ & 0,30 & 0 & 0,30 & 234 & 70,3 \\
\hline \multirow{5}{*}{$\begin{array}{c}550 \\
(E 005)\end{array}$} & $\alpha-\mathrm{Fe}$ & 0 & 0 & 0,27 & 330 & 3,0 \\
\hline & Dubleto & 0,34 & 1,06 & 0,25 & 0 & 4,5 \\
\hline & $\gamma^{\prime}-\mathrm{Fe}_{4} \mathrm{~N}$ & $\begin{array}{l}0,30 \\
0,31 \\
\end{array}$ & $\begin{array}{c}0 \\
0,10 \\
\end{array}$ & $\begin{array}{l}0,25 \\
0,25 \\
\end{array}$ & $\begin{array}{l}340 \\
216 \\
\end{array}$ & $\begin{array}{l}3,5 \\
9,0 \\
\end{array}$ \\
\hline & $\varepsilon-\mathrm{Fe}_{3} \mathrm{~N}$ & 0,26 & 0 & 0,30 & 219 & 13,0 \\
\hline & $\varepsilon-\mathrm{Fe}_{3,2} \mathrm{~N}$ & $\begin{array}{l}0,31 \\
0,20 \\
\end{array}$ & $\begin{array}{l}0 \\
0\end{array}$ & $\begin{array}{l}0,35 \\
0,25 \\
\end{array}$ & $\begin{array}{l}236 \\
297 \\
\end{array}$ & $\begin{array}{l}62,0 \\
5,0 \\
\end{array}$ \\
\hline
\end{tabular}

Para se obter informações importantes a respeito dos nitretos formados na camada de compostos e na camada de difusão, foram feitos sucessivos desgastes de 5, 10 e $50 \mu \mathrm{m}$ na camada nitretada de todas as amostras de ferro nitretadas, acompanhadas pelas medidas de espectroscopia Mössbauer (CEMS). A Figura 48 ilustra como foram realizados os desgastes.

A Figura 49 mostra os espectros Mössbauer que representam a constituição da camada de compostos e da camada de difusão da amostra nitretada à temperatura de $500^{\circ} \mathrm{C}$, por $3 \mathrm{~h}$, depois de vários desgastes. 
Camada

Nitretada

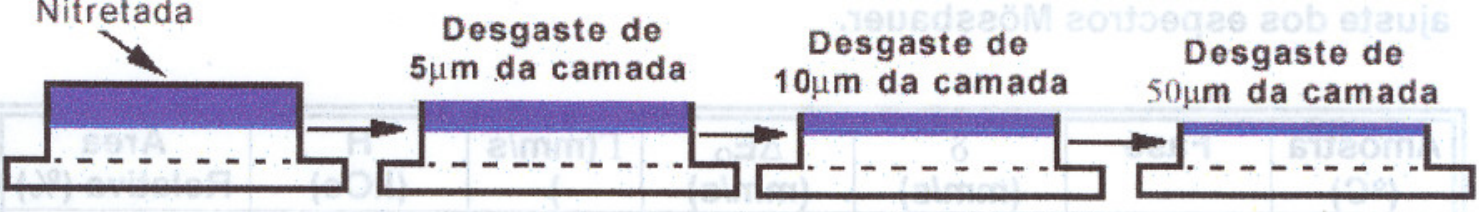

Figura 48 - Etapas do desgaste realizado nas amostras de Ferro nitretados.

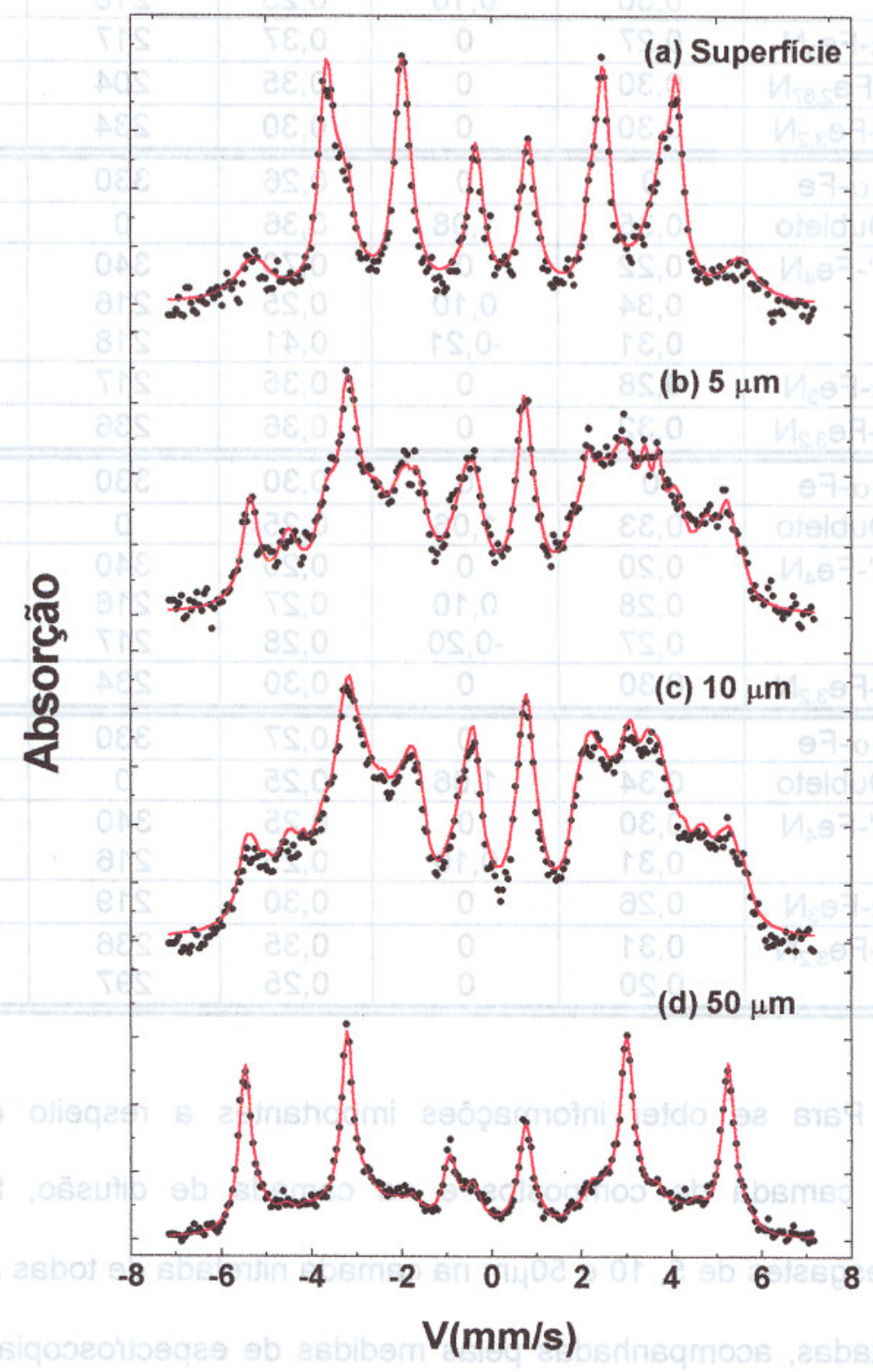

Figura 49 - Espectro de CEMS do ferro nitretado a $500^{\circ} \mathrm{C}$ durante $3 \mathrm{~h}$ : (a) espectro da superfície; (b), (c) e (d) são espectros depois do desgaste de 5, 10 e $50 \mu \mathrm{m}$ da camada nitretada, respectivamente. A linha contínua em vermelho é a curva ajustada aos pontos experimentais. 
Na Figura 49(a) e (b) estão os espectros de CEMS da camada de compostos da superfície e depois da remoção de aproximadamente $5 \mu \mathrm{m}$ desta camada, respectivamente. A Figura 49(c) mostra o espectro depois da remoção de $10 \mu \mathrm{m}$, referente à zona de transformação. Finalmente, é mostrado o espectro da interface desta camada com a de difusão, Figura 49(d). A Tabela XIII apresenta os parâmetros usados no ajuste dos espectros Mössbauer, para os vários desgastes.

Tabela XIII - Parâmetros Mössbauer de diferentes subespectros representados na Figura 49.

\begin{tabular}{|c|c|c|c|c|c|c|}
\hline $\begin{array}{c}\text { Profundidade } \\
(\mu \mathrm{m})\end{array}$ & Fase & $\begin{array}{c}\delta \\
(\mathrm{mm} / \mathrm{s})\end{array}$ & $\begin{array}{c}\Delta E_{Q} \\
(\mathrm{~mm} / \mathrm{s})\end{array}$ & $\begin{array}{c}\Gamma \\
(\mathrm{mm} / \mathrm{s})\end{array}$ & $\begin{array}{c}\mathrm{H} \\
\text { (kOe) }\end{array}$ & $\begin{array}{c}\text { Área } \\
\text { Relativa (\%) }\end{array}$ \\
\hline \multirow{5}{*}{$\begin{array}{l}\text { Superficie } \\
\text { (E010) }\end{array}$} & $\alpha-\mathrm{Fe}$ & 0 & 0 & 0,27 & 330 & 3,0 \\
\hline & Dubleto & 0,34 & 1,06 & 0,25 & 0 & 4,5 \\
\hline & $\gamma^{\prime}-\mathrm{Fe}_{4} \mathrm{~N}$ & $\begin{array}{l}0,30 \\
0,31\end{array}$ & $\begin{array}{c}0 \\
0,10\end{array}$ & $\begin{array}{l}0,25 \\
0,25\end{array}$ & $\begin{array}{l}340 \\
216\end{array}$ & $\begin{array}{l}3,5 \\
9,0\end{array}$ \\
\hline & $\varepsilon-\mathrm{Fe}_{3} \mathrm{~N}$ & 0,26 & 0 & 0,30 & 219 & 13,0 \\
\hline & $\varepsilon-\mathrm{Fe}_{3,2} \mathrm{~N}$ & $\begin{array}{l}0,31 \\
0,20\end{array}$ & $\begin{array}{l}0 \\
0\end{array}$ & $\begin{array}{l}0,35 \\
0,25\end{array}$ & $\begin{array}{l}236 \\
297\end{array}$ & $\begin{array}{c}62,0 \\
5,0\end{array}$ \\
\hline \multirow{7}{*}{$\begin{array}{c}5 \\
(E 019)\end{array}$} & $\alpha-\mathrm{Fe}$ & 0 & $-0,01$ & 0,45 & 329 & 10 \\
\hline & Dubleto & 0,34 & 1,2 & 0,34 & 0 & 2,5 \\
\hline & $\gamma^{\prime}-\mathrm{Fe}_{4} \mathrm{~N}$ & 0,24 & 0 & 0,25 & 340 & 2,0 \\
\hline & $\varepsilon-\mathrm{Fe}_{3} \mathrm{~N}$ & $\begin{array}{l}0,27 \\
0,23 \\
\end{array}$ & $\begin{array}{c}0,02 \\
0\end{array}$ & $\begin{array}{l}0,25 \\
0,50 \\
\end{array}$ & $\begin{array}{l}216 \\
288 \\
\end{array}$ & $\begin{array}{c}7,0 \\
17,5 \\
\end{array}$ \\
\hline & $\varepsilon-\mathrm{Fe}_{2,47} \mathrm{~N}$ & 0,25 & 0 & 0,60 & 185 & 21,0 \\
\hline & $\varepsilon-\mathrm{Fe}_{2,67} \mathrm{~N}$ & 0,30 & $-0,01$ & 0,28 & 203 & 9,0 \\
\hline & $\varepsilon-\mathrm{Fe}_{3,2} \mathrm{~N}$ & 0,31 & 0 & 0,60 & 239 & 26 \\
\hline \multirow{8}{*}{$\begin{array}{c}10 \\
(E 035)\end{array}$} & $\alpha-\mathrm{Fe}$ & 0 & 0 & 0,40 & 334 & 15 \\
\hline & Dubleto & 0,27 & 1,2 & 0,40 & 0 & 2,0 \\
\hline & $\gamma^{\prime}-\mathrm{Fe}_{4} \mathrm{~N}$ & 0,26 & 0 & 0,40 & 338 & 6,0 \\
\hline & $\varepsilon-\mathrm{Fe}_{3} \mathrm{~N}$ & $\begin{array}{l}0,27 \\
0,21 \\
\end{array}$ & $\begin{array}{l}0 \\
0\end{array}$ & $\begin{array}{l}0,42 \\
0,60\end{array}$ & $\begin{array}{l}219 \\
285\end{array}$ & $\begin{array}{l}12 \\
24 \\
\end{array}$ \\
\hline & $\varepsilon-\mathrm{Fe}_{2,47} \mathrm{~N}$ & 0,25 & 0 & 0,37 & 176 & 8,0 \\
\hline & $\varepsilon-\mathrm{Fe}_{2,67} \mathrm{~N}$ & 0,30 & 0 & 0,39 & 204 & 10 \\
\hline & $\varepsilon-\mathrm{Fe}_{3,2} \mathrm{~N}$ & 0,30 & 0 & 0,60 & 239 & 21 \\
\hline & $\alpha^{\prime \prime}-\mathrm{Fe}_{16} \mathrm{~N}_{2}$ & 0,15 & 0,05 & 0,32 & 313 & 2,0 \\
\hline \multirow{7}{*}{$\begin{array}{c}50 \\
(E 026)\end{array}$} & $\alpha-\mathrm{Fe}$ & 0 & 0 & 0,34 & 333 & 51 \\
\hline & Dubleto & 0,28 & 1,2 & 0,30 & 0 & 3,0 \\
\hline & $\gamma^{\prime}-\mathrm{Fe}_{4} \mathrm{~N}$ & 0,28 & 0 & 0,25 & 336 & 5,0 \\
\hline & $\varepsilon-\mathrm{Fe}_{3} \mathrm{~N}$ & $\begin{array}{l}0,32 \\
0,21\end{array}$ & $\begin{array}{l}0 \\
0\end{array}$ & $\begin{array}{l}0,30 \\
0,59\end{array}$ & $\begin{array}{l}215 \\
284\end{array}$ & $\begin{array}{l}5,0 \\
10 \\
\end{array}$ \\
\hline & $\varepsilon-\mathrm{Fe}_{2,47} \mathrm{~N}$ & 0,29 & 0 & 0,60 & 190 & 10 \\
\hline & $\varepsilon-\mathrm{Fe}_{3,2} \mathrm{~N}$ & 0,29 & 0 & 0,25 & 240 & 15 \\
\hline & $\alpha^{\prime \prime}-\mathrm{Fe}_{16} \mathrm{~N}_{2}$ & 0,14 & 0,06 & 0,25 & 311 & 1,0 \\
\hline
\end{tabular}




\subsubsection{Nitretação durante tempos diferentes}

a) Medidas de microdureza

Os perfis de microdureza para amostras tratadas a $500^{\circ} \mathrm{C}$ em diferentes tempos de nitretação $1,2,3,4,5$ e $6 \mathrm{~h}$, são mostrados na Figura 50 . A profundidade da camada nitretada com uma dureza característica pode ser estimada pelo perfil de microdureza obtido, assumindo arbitrariamente $200 \mathrm{HV}$ como - mínimo de dureza da camada nitretada. Como mostrado na Figura 50, a espessura da camada nitretada com dureza a $200 \mathrm{HV}$ é aproximadamente a mesma, $40 \mu \mathrm{m}$.

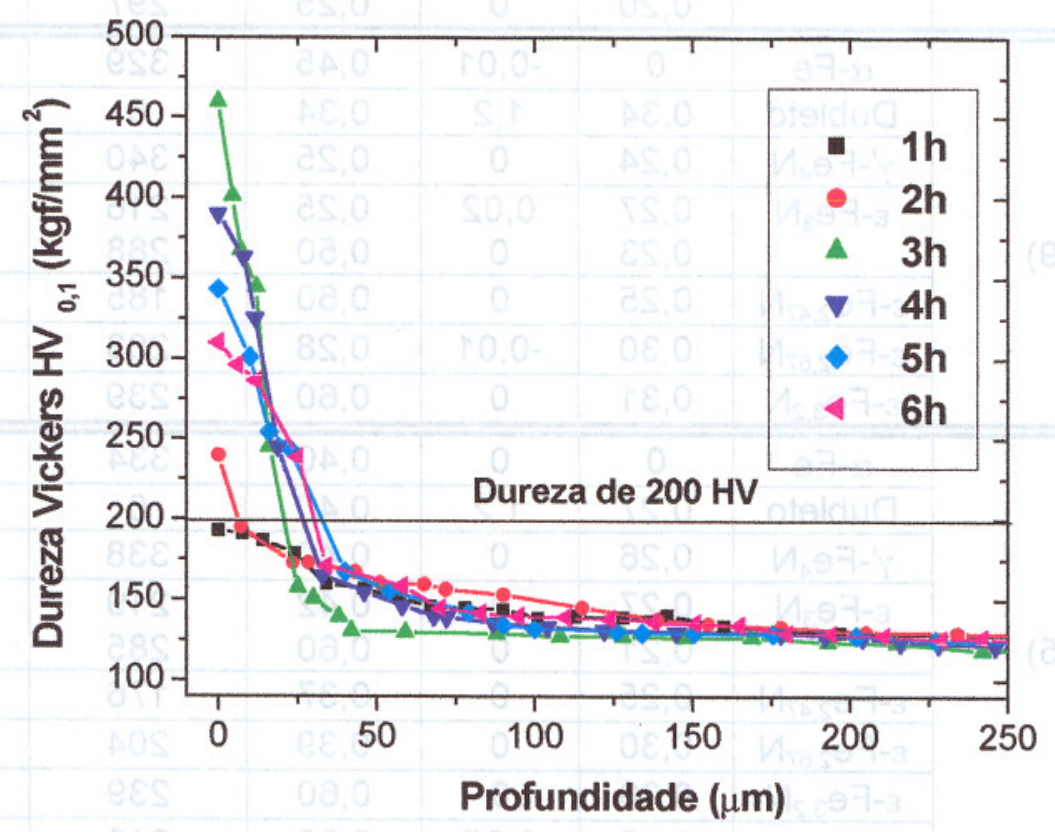

Figura 50 - Perfil de microdureza ao longo da camada nitretada, do ferro, para diferentes tempos de tratamentos $1,2,3,4,5$ e $6 \mathrm{~h}$. 
b) Imagem obtida por microscopia ótica

O aspecto microestrutural das camadas nitretadas, para os diferentes tempos de nitretação, não apresentaram nenhuma modificação apreciável. A Figura 51 mostra um exemplo da camada nitretada durante $3 \mathrm{~h}$ à temperatura de $500^{\circ} \mathrm{C}$.

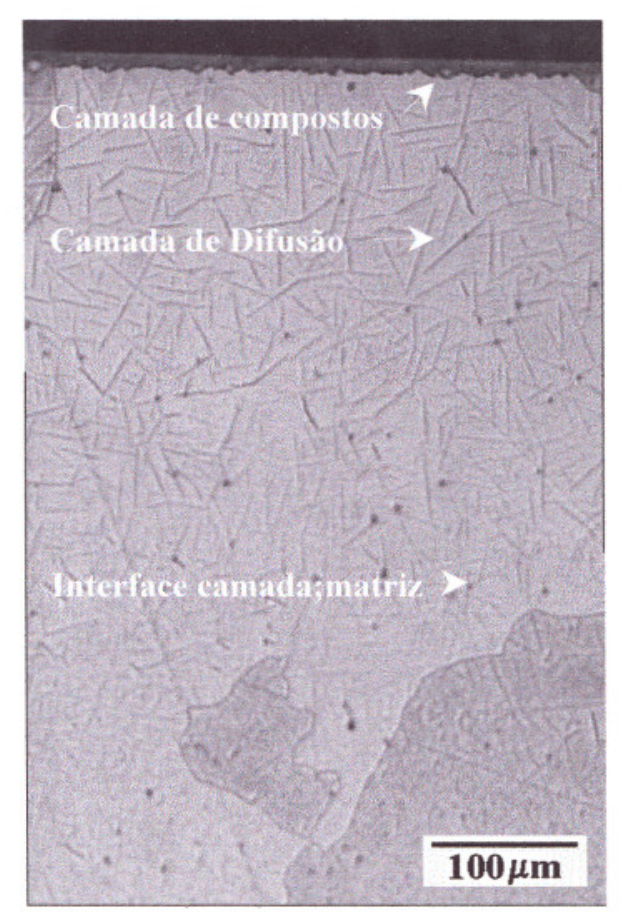

Figura 51 - Micrografia ótica da evolução na espessura das camadas de nitretos, correspondendo à nitretação da amostra de Fe durante $3 \mathbf{h}$.

\section{c) Medidas de por difração de raios $X$}

A difração de raios $X$ em incidência rasante nas amostras nitretadas a $500^{\circ} \mathrm{C}$ durante $1,2,3,4,5$ e $6 \mathrm{~h}$, são apresentados na Figura 52 , onde se pode observar a variação nas intensidades dos picos correspondentes aos nitretos, dando uma idéia aproximada de suas quantidades. 


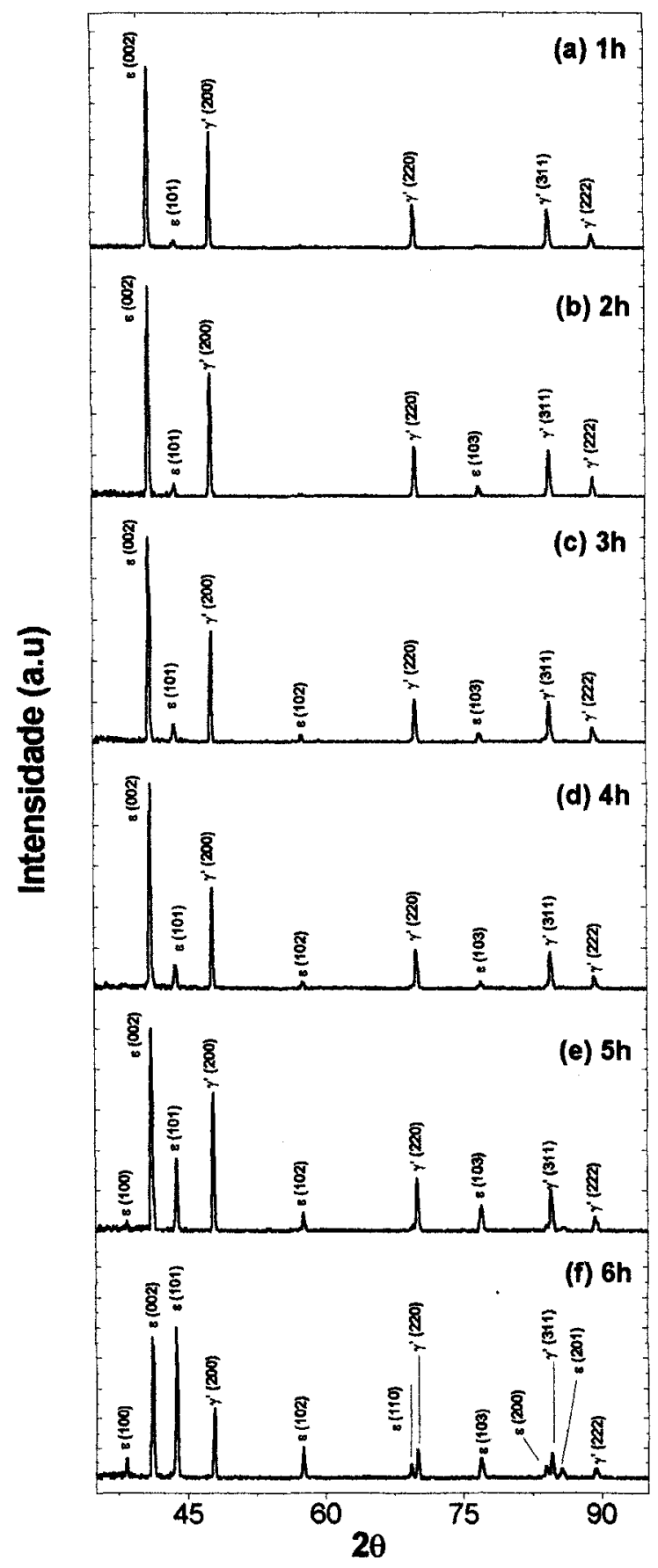

Figura 52 - Difratogramas de GAXD das amostras de ferro, nitretadas em diferentes tempos: (a) $1 \mathrm{~h}$; (b) $2 \mathrm{~h}$; (c) $3 \mathrm{~h}$; (d) $4 \mathrm{~h}$, (e) $5 \mathrm{~h}$ e (f) $6 \mathrm{~h}$.

d) Análise das amostras por CEMS

Um dos caminhos utilizados para observar a formação dos nitretos de ferro no plasma é através da variação do tempo de nitretação, fixando a 
temperatura em $500^{\circ} \mathrm{C}$. A Figura 53 mostra os espectros CEMS referentes à cinética de formação do nitreto de ferro para diferentes tempos de tratamento de 1 a 6 horas, com os parâmetros hiperfinos típicos apresentados na Tabela XIV.

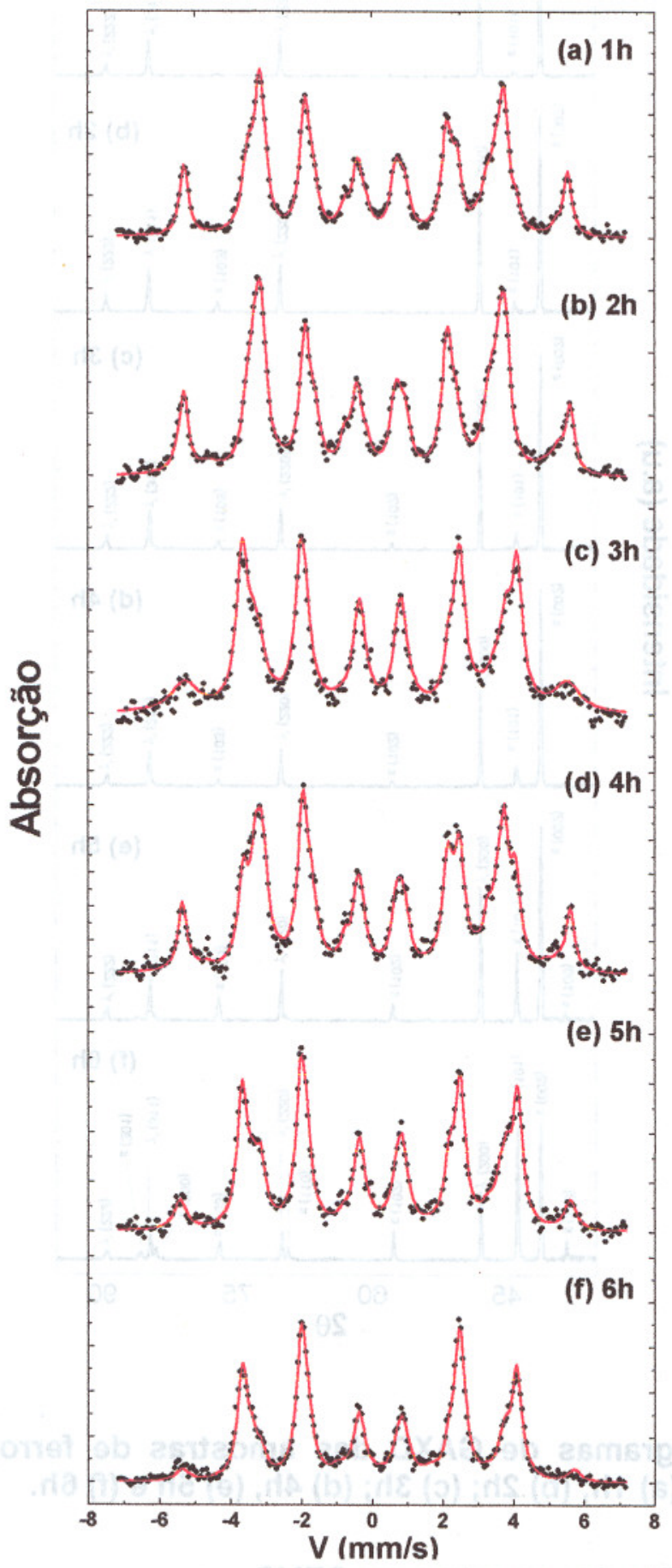

Figura 53 - Espectro Mössbauer para amostras nitretadas em diferentes tempos, à temperatura de $500^{\circ} \mathrm{C}$. (a) E001, 1h; (b) E013, 2h; (c) E010, 3h; (d) E016, 4h; (e) E015, 5h; (f) E006, 6h. A linha contínua (em vermelho) é a curva ajustada aos pontos experimentais. 
Tabela XIV - Relação das amostras nitretadas com os parâmetros obtidos no ajuste dos espectros Mössbauer.

\begin{tabular}{|c|c|c|c|c|c|c|}
\hline $\begin{array}{c}\text { Amostra } \\
(\mathrm{h})\end{array}$ & Fase & $\begin{array}{c}\delta \\
(\mathrm{mm} / \mathrm{s})\end{array}$ & $\begin{array}{c}\Delta E_{Q} \\
(\mathrm{~mm} / \mathrm{s})\end{array}$ & $\begin{array}{c}\Gamma \\
(\mathrm{mm} / \mathrm{s})\end{array}$ & $\begin{array}{c}\mathrm{H} \\
(\mathrm{kO \theta})\end{array}$ & $\begin{array}{c}\text { Área } \\
\text { Relativa }(\%)\end{array}$ \\
\hline \multirow{7}{*}{$\begin{array}{c}1 \\
(E 001)\end{array}$} & $\alpha-\mathrm{Fe}$ & 0 & 0,006 & 0,25 & 330 & 3 \\
\hline & Dubleto & 0,26 & 1,10 & 0,33 & 0 & 3,5 \\
\hline & & 0,22 & 0,012 & 0,30 & 336 & 18,5 \\
\hline & $\gamma^{\prime}-\mathrm{Fe}_{4} \mathrm{~N}$ & 0,30 & 0,10 & 0,33 & 214 & 44,5 \\
\hline & & 0,29 & $-0,20$ & 0,34 & 218 & 20,5 \\
\hline & $\varepsilon-\mathrm{Fe}_{3} \mathrm{~N}$ & 0,33 & $-0,002$ & 0,25 & 216 & 4,5 \\
\hline & $\varepsilon-\mathrm{Fe}_{3,2} \mathrm{~N}$ & 0,39 & 0,004 & 0,25 & 234 & 5,5 \\
\hline \multirow{7}{*}{$\begin{array}{c}2 \\
(E 013)\end{array}$} & $\alpha-\mathrm{Fe}$ & 0 & $-0,06$ & 0,43 & 331 & 6 \\
\hline & Dubleto & 0,33 & 1,14 & 0,25 & 0 & 2 \\
\hline & $\gamma^{\prime}-\mathrm{Fe}_{4} \mathrm{~N}$ & 0,23 & 0,02 & 0,28 & 338 & 13,0 \\
\hline & & 0,30 & 0,11 & 0,34 & 215 & 36,5 \\
\hline & & 0,27 & $-0,21$ & 0,36 & 215 & 21 \\
\hline & $\varepsilon-\mathrm{Fe}_{3} \mathrm{~N}$ & 0,27 & $-0,001$ & 0,26 & 215 & 16,5 \\
\hline & $\varepsilon-\mathrm{Fe}_{3,2} \mathrm{~N}$ & 0,27 & 0,02 & 0,69 & 295 & 5 \\
\hline \multirow{6}{*}{$\begin{array}{c}3 \\
(E 010)\end{array}$} & $\alpha-\mathrm{Fe}$ & 0 & 0 & 0,30 & 330 & 2,7 \\
\hline & Dubleto & 0,33 & 1,06 & 0,25 & 0 & 4,3 \\
\hline & $\gamma^{\prime}-\mathrm{Fe}_{4} \mathrm{~N}$ & 0,20 & 0 & 0,20 & 340 & 6,5 \\
\hline & & 0,28 & 0,10 & 0,27 & 216 & 9,5 \\
\hline & & 0,27 & $-0,20$ & 0,28 & 217 & 6,7 \\
\hline & $\varepsilon-\mathrm{Fe}_{3,2} \mathrm{~N}$ & 0,30 & 0 & 0,30 & 234 & 70,3 \\
\hline \multirow{5}{*}{$\begin{array}{c}4 \\
(E 016)\end{array}$} & $\alpha-\mathrm{Fe}$ & 0 & 0 & 0,68 & 330 & 6,0 \\
\hline & $\gamma^{\prime}-\mathrm{Fe}_{4} \mathrm{~N}$ & $\begin{array}{l}0,22 \\
0,27\end{array}$ & $\begin{array}{l}0,01 \\
011\end{array}$ & $\begin{array}{l}0,25 \\
025\end{array}$ & $\begin{array}{l}340 \\
214\end{array}$ & 12,0 \\
\hline & $\varepsilon-\mathrm{Fe}_{267} \mathrm{~N}$ & 0,32 & $\frac{0,11}{0,009}$ & $\frac{0,25}{0,40}$ & $\frac{274}{207}$ & $\frac{2,0}{27.0}$ \\
\hline & $\varepsilon-\mathrm{Fe}_{3} \mathrm{~N}$ & 0,27 & 0,05 & 0,29 & 219 & 18,0 \\
\hline & $\varepsilon-\mathrm{Fe}_{3,2} \mathrm{~N}$ & $\begin{array}{l}0,33 \\
0,24\end{array}$ & $\begin{array}{c}-0,02 \\
-0,007\end{array}$ & $\begin{array}{l}0,34 \\
0,25\end{array}$ & $\begin{array}{l}239 \\
298\end{array}$ & $\begin{array}{c}30,0 \\
5,0\end{array}$ \\
\hline \multirow{6}{*}{$\begin{array}{c}5 \\
\text { (E015) }\end{array}$} & $\alpha-\mathrm{Fe}$ & 0 & 0 & $\overline{0.27}$ & 330 & $\overline{3.0}$ \\
\hline & Dubleto & 0,33 & 1,02 & 0,25 & 5,7 & 5,0 \\
\hline & $\gamma^{\prime}-\mathrm{Fe}_{4} \mathrm{~N}$ & 0,21 & 0,008 & 0,41 & 342 & 12,0 \\
\hline & & 0,24 & 0,10 & 0,27 & 216 & 10,0 \\
\hline & $\varepsilon-\mathrm{Fe}_{3} \mathrm{~N}$ & 0,26 & 0,02 & 0,42 & 218 & 18,0 \\
\hline & $\varepsilon-\mathrm{Fe}_{3,2} \mathrm{~N}$ & 0,32 & $-0,009$ & 0,33 & 241 & 52,0 \\
\hline \multirow{5}{*}{$\begin{array}{c}6 \\
(E 006)\end{array}$} & Dubleto & 0,29 & 1,1 & 0,50 & 0 & 4,0 \\
\hline & $\gamma^{\prime}-\mathrm{Fe}_{4} \mathrm{~N}$ & 0,25 & 0,03 & 0,40 & $\begin{array}{l}342 \\
215\end{array}$ & 5,5 \\
\hline & & 0,31 & 0,10 & 0,25 & 215 & 6,5 \\
\hline & $\varepsilon-\mathrm{Fe}_{3} \mathrm{~N}$ & 0,30 & $-0,05$ & 0,30 & 219 & 15,0 \\
\hline & $\varepsilon-\mathrm{Fe}_{3,2} \mathrm{~N}$ & $\begin{array}{l}0,33 \\
0,20\end{array}$ & $\begin{array}{c}-0,01 \\
0\end{array}$ & $\begin{array}{l}0,35 \\
0,25\end{array}$ & $\begin{array}{l}240 \\
297\end{array}$ & $\begin{array}{c}64,0 \\
5,0\end{array}$ \\
\hline
\end{tabular}

Analogamente aos espectros Mössbauer dos desgastes do ferro nitretado em diferentes temperaturas, seção 6.1.1.2e, o desgaste das amostras 
nitretadas em diferentes tempos apresentaram as mesmas fases de nitretos formada. A Figura 54(a) - (c) mostra os espectros CEMS da superfície e depois da remoção de 5 e $10 \mu \mathrm{m}$, da amostra nitretada durante $6 \mathrm{~h}$ a $\mathrm{T}=500^{\circ} \mathrm{C}$, respectivamente. A Figura 54(d) representa o espectro depois da remoção de $50 \mu \mathrm{m}$ da camada de compostos, atingindo a camada de difusão. A Tabela XV apresenta os parâmetros usados no ajuste dos espectros Mössbauer dos vários desgastes.

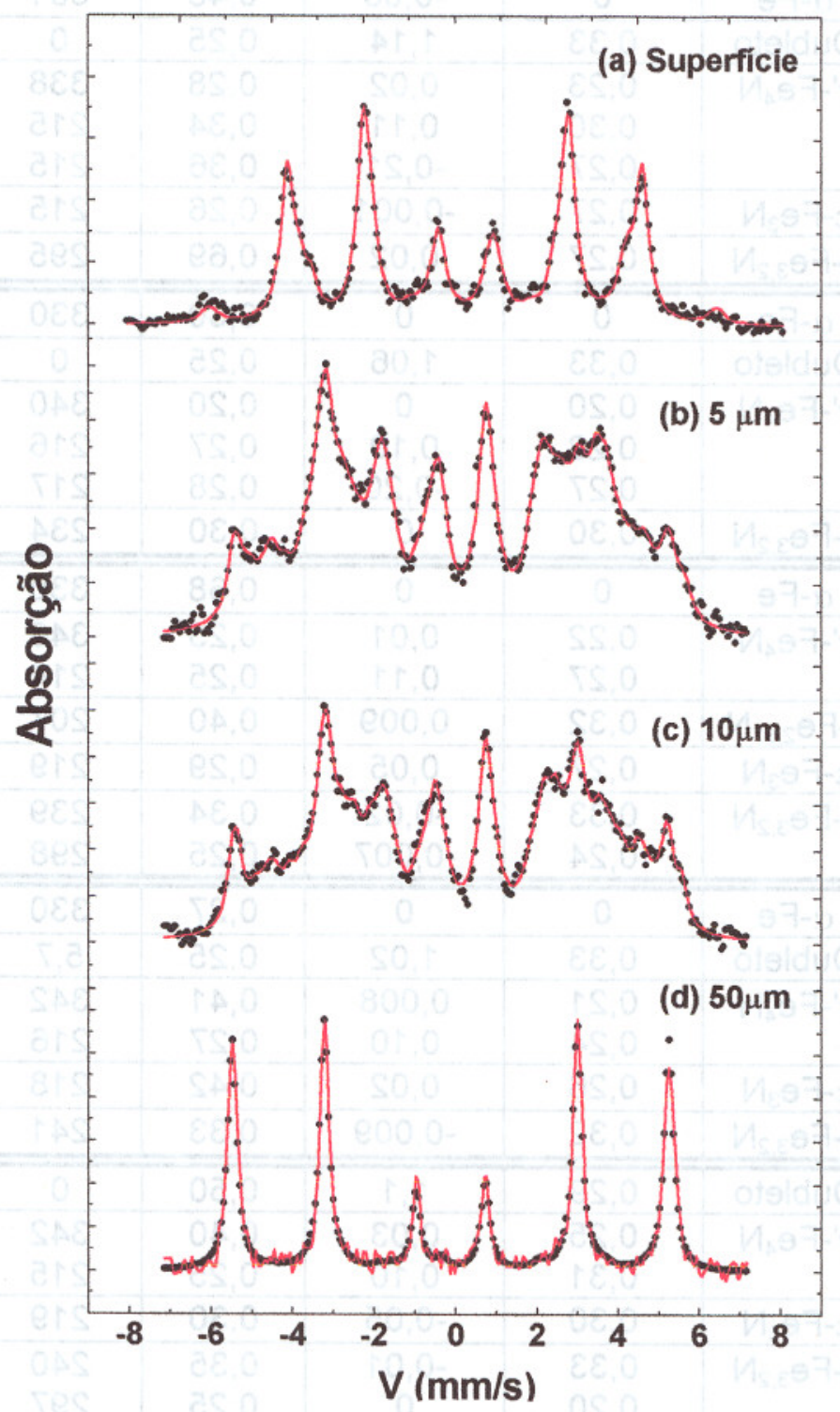

Figura 54 - Espectro de CEMS do ferro nitretado a $500^{\circ} \mathrm{C}$ durante $6 \mathrm{~h}$ : (a) espectro da superfície; (b), (c) e (d) são espectros depois do desgaste de 5, 10 e $50 \mu \mathrm{m}$ da camada nitretada, respectivamente. A linha contínua (em vermelho) é a curva ajustada aos pontos experimentais.

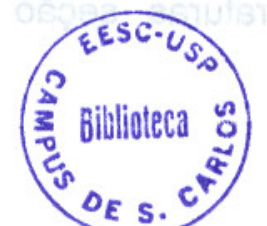


Tabela XV - Parâmetros Mössbauer de diferentes subespectros representados na Figura 54.

\begin{tabular}{|c|c|c|c|c|c|c|}
\hline $\begin{array}{c}\text { Profundidade } \\
(\mu \mathrm{m})\end{array}$ & Fase & $\begin{array}{c}\delta \\
(\mathrm{mm} / \mathrm{s})\end{array}$ & $\begin{array}{c}\Delta E_{Q} \\
(\mathrm{~mm} / \mathrm{s})\end{array}$ & $\begin{array}{c}\Gamma \\
(\mathrm{mm} / \mathrm{s})\end{array}$ & $\begin{array}{c}\mathrm{Hi} \\
(\mathrm{kOe})\end{array}$ & $\begin{array}{c}\text { Area } \\
\text { Relativa (\%) }\end{array}$ \\
\hline \multirow{4}{*}{$\begin{array}{l}\text { Superfície } \\
\text { (E006) }\end{array}$} & $\alpha-\mathrm{Fe}$ & 0,29 & 1,1 & 0,50 & 0 & 4,0 \\
\hline & Dubleto & $\begin{array}{l}0,25 \\
0,31 \\
\end{array}$ & $\begin{array}{l}0,03 \\
0,10 \\
\end{array}$ & $\begin{array}{l}0,40 \\
0,25\end{array}$ & $\begin{array}{l}342 \\
215 \\
\end{array}$ & $\begin{array}{l}5,5 \\
6,5 \\
\end{array}$ \\
\hline & $\gamma^{\prime}-\mathrm{Fe}_{4} \mathrm{~N}$ & 0,30 & $-0,05$ & 0,30 & 219 & 15,0 \\
\hline & $\varepsilon-F e_{3,2} \mathrm{~N}$ & $\begin{array}{l}0,33 \\
0,20\end{array}$ & $\begin{array}{c}-0,01 \\
0\end{array}$ & $\begin{array}{l}0,35 \\
0,25\end{array}$ & $\begin{array}{l}240 \\
297\end{array}$ & $\begin{array}{c}64,0 \\
5,0\end{array}$ \\
\hline \multirow{8}{*}{$\begin{array}{c}5 \\
(E 033)\end{array}$} & $\alpha-\mathrm{Fe}$ & 0 & 0 & 0,38 & 330 & 10 \\
\hline & Dubleto & 0,25 & 1,22 & 0,42 & 0 & 5,0 \\
\hline & $\gamma^{\prime}-\mathrm{Fe}_{4} \mathrm{~N}$ & 0,26 & 0 & 0,45 & 340 & 6,5 \\
\hline & $\varepsilon-\mathrm{Fe}_{3} \mathrm{~N}$ & $\begin{array}{l}0,29 \\
0,18\end{array}$ & $\begin{array}{l}0 \\
0\end{array}$ & $\begin{array}{l}0,41 \\
0,60\end{array}$ & $\begin{array}{l}219 \\
285\end{array}$ & $\begin{array}{l}13,5 \\
21,5\end{array}$ \\
\hline & $\varepsilon-\mathrm{Fe}_{2,47} \mathrm{~N}$ & 0,27 & 0 & 0,47 & 185 & 10,0 \\
\hline & $\varepsilon-\mathrm{Fe}_{2,67} \mathrm{~N}$ & 0,26 & 0 & 0,38 & 205 & 12,0 \\
\hline & $\varepsilon-\mathrm{Fe}_{3,2} \mathrm{~N}$ & 0,29 & 0 & 0,62 & 238 & 18,5 \\
\hline & $\alpha^{\prime \prime}-\mathrm{Fe}_{16} \mathrm{~N}_{2}$ & 0,16 & 0,05 & 0,41 & 315 & 3,0 \\
\hline \multirow{8}{*}{$\begin{array}{c}10 \\
\text { (E038) }\end{array}$} & $\alpha-\mathrm{Fe}$ & 0 & 0 & 0,35 & 330 & 20,0 \\
\hline & Dubleto & 0,23 & 1,21 & 0,35 & 0 & 5,0 \\
\hline & $y^{\prime}-\mathrm{Fe}_{4} \mathrm{~N}$ & 0,24 & 0 & 0,28 & 338 & 4,5 \\
\hline & $\varepsilon-\mathrm{Fe}_{3} \mathrm{~N}$ & $\begin{array}{l}0,30 \\
0,20\end{array}$ & $\begin{array}{l}0 \\
0\end{array}$ & $\begin{array}{l}0,62 \\
0,60\end{array}$ & $\begin{array}{l}219 \\
274 \\
\end{array}$ & $\begin{array}{l}22,0 \\
20,0\end{array}$ \\
\hline & $\varepsilon-\mathrm{Fe}_{2,47} \mathrm{~N}$ & 0,25 & 0 & 0,49 & 174 & 8,5 \\
\hline & $\varepsilon-\mathrm{Fe}_{2,67} \mathrm{~N}$ & 0,27 & 0 & 0,45 & 208 & 15,0 \\
\hline & $\varepsilon-\mathrm{Fe}_{3,2} \mathrm{~N}$ & 0,28 & 0 & 0,38 & 242 & 6,5 \\
\hline & $\alpha^{\prime \prime}-\mathrm{Fe}_{16} \mathrm{~N}_{2}$ & 0,18 & 0,04 & 0,55 & 312 & 6,0 \\
\hline $\begin{array}{c}50 \\
(E 025) \\
\end{array}$ & $\alpha-F e$ & 0 & 0 & 0,27 & 332 & 100 \\
\hline
\end{tabular}

\subsubsection{Nitretação em diferentes freqüências.}

a) Medidas de microdureza

No que se refere ao perfil de microdureza, como mostrado na Figura 55 para as cinco condições de tratamento, nota-se uma tendência de diminuição de dureza para valores maiores da freqüência. 
A profundidade da camada nitretada com uma dureza característica pode ser estimada pelo perfil de microdureza obtido, assumindo arbitrariamente $200 \mathrm{HV}$ como o mínimo de dureza da camada nitretada. Como ilustrado na Figura 55 , a espessura da camada com dureza a $200 \mathrm{HV}$, nas amostras nitretadas a freqüência de 4,6 e $8 \mathrm{kHz}$ é de aproximadamente $5 \mu \mathrm{m}$, enquanto que para 2 e $10 \mathrm{kHz}$ a espessura é de 22 e $10 \mu \mathrm{m}$, respectivamente.

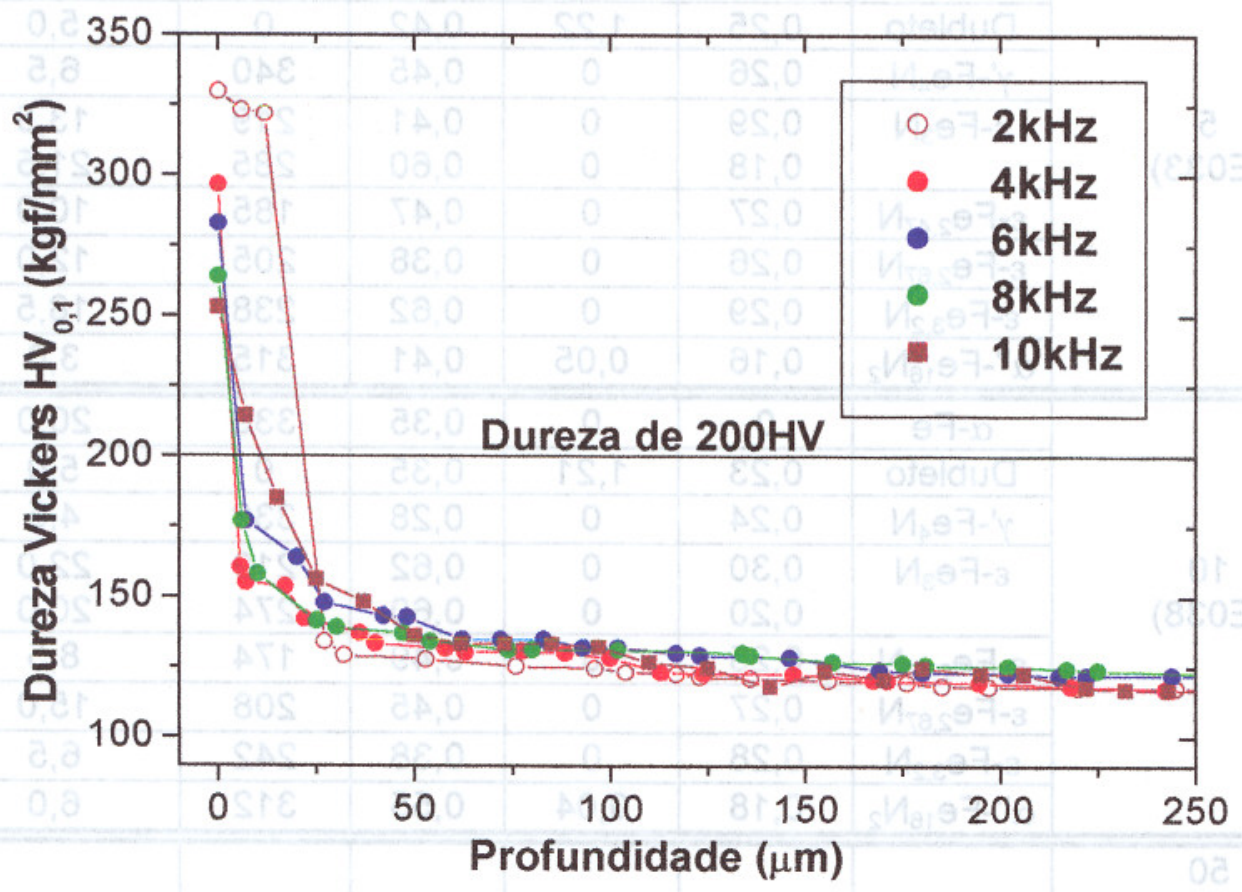

Figura 55 - Perfil de microdureza ao longo da camada nitretada, para diferentes freqüências de plasmas, durante $3 \mathrm{~h}$ a temperatura de $500^{\circ} \mathrm{C}$.

b) Imagens obtidas por MEV

A Figura 56 mostra as micrografias referentes à nitretação, realizadas no ferro, com freqüência de plasma de 2, 4, 6, 8 e $10 \mathrm{kHz}$. 

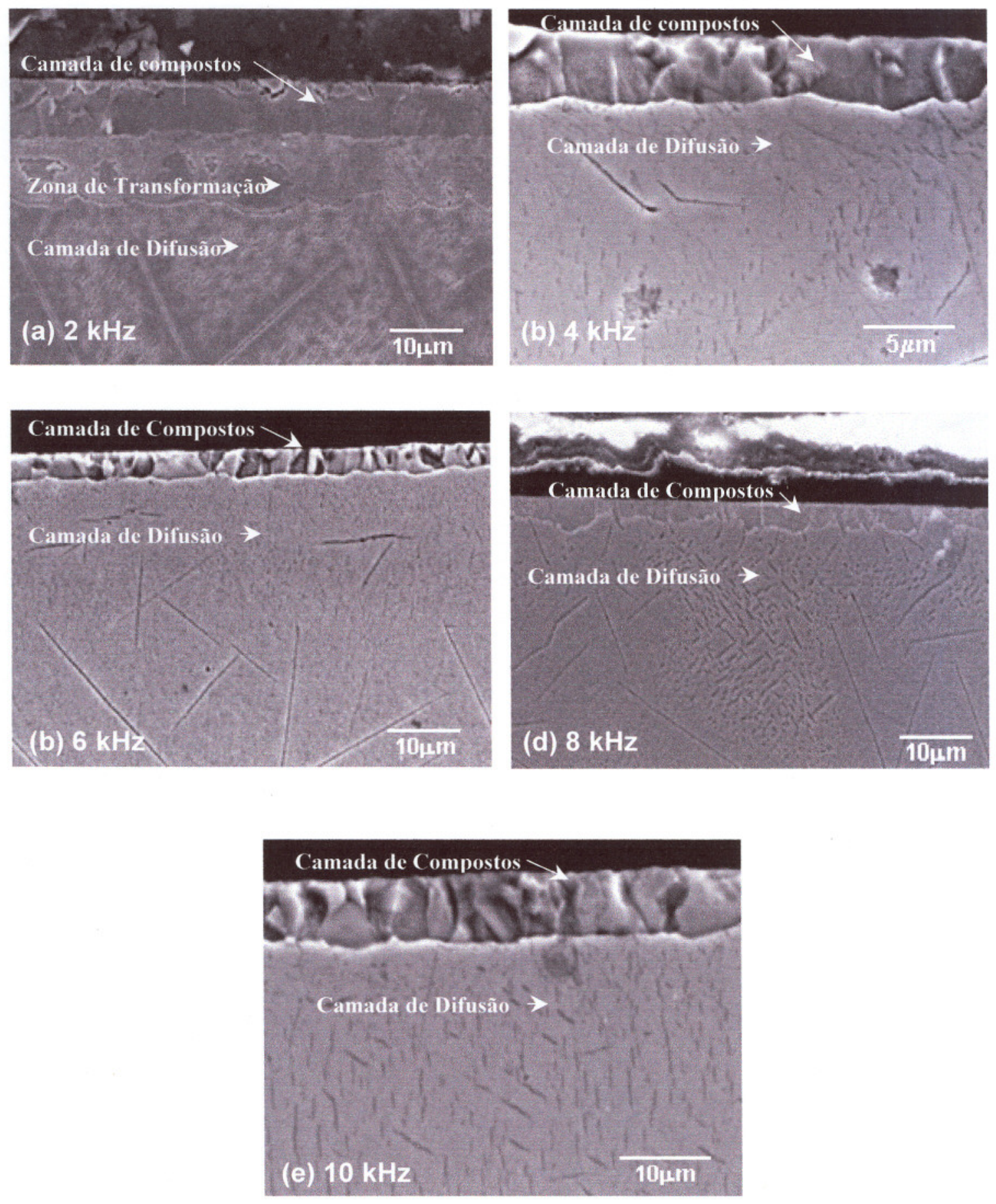

Figura 56 - Micrografias (MEV) do Ferro nitretado por $3 \mathrm{~h}$, à temperatura de $500^{\circ} \mathrm{C}$ nas diferentes freqüências: (a) $2 \mathrm{kHz}$, (b) $4 \mathrm{kHz}$, (c) $6 \mathrm{kHz}$, (d) $8 \mathrm{kHzC}$ e (e) $10 \mathrm{kHz}$. 
c) Medidas por difração de raios $X$

As superfícies nitretadas foram analisadas por difração de raios $X$ com incidência rasante. A Figura 57 mostra os difratogramas referentes às diferentes condições de freqüência.

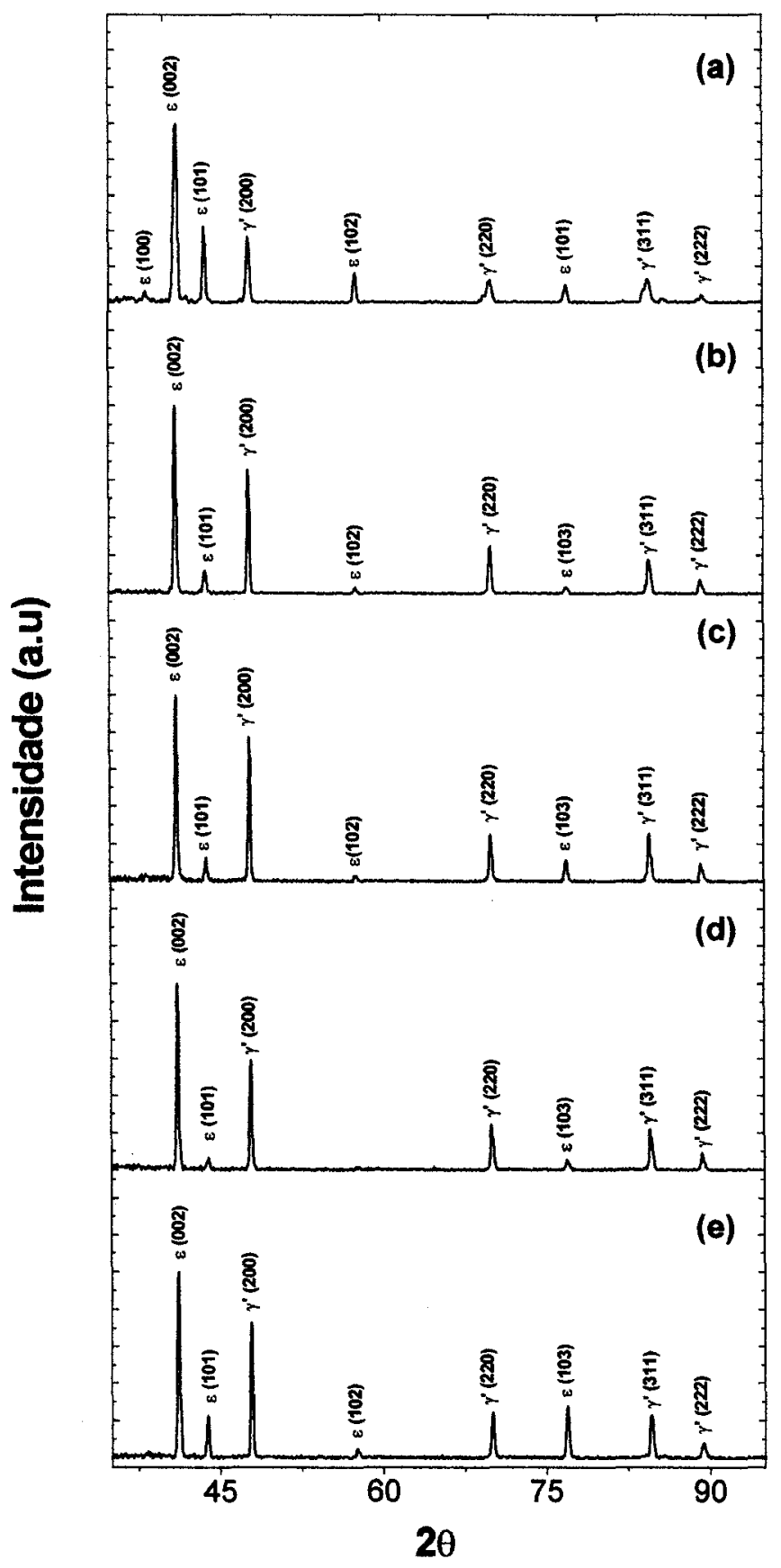

Figura 57 - Difratogramas das amostras nitretadas durante $3 \mathrm{~h}$ à temperatura de $500^{\circ} \mathrm{C}$ em diferentes freqüências: (a) $2 \mathrm{kHz}$; (b) $4 \mathrm{kHz}$; (c) $6 \mathrm{kHz}$; (d) $8 \mathrm{kHz} \theta$ (e) $10 \mathrm{kHz}$. 
d) Análise das amostras por CEMS

A Figura 58 exibe espectros CEMS para amostras nitretadas em corrente alternada com freqüências de 2, 4, 6, 8 e 10kHz, cujos difratogramas são mostrados na Figura 56. Nos espectros Mössbauer ajustados a contribuição do subespectro pertencente à fase $\alpha-\mathrm{Fe}$ é pequena e apenas as amostras nitretadas com freqüências de 4 e $10 \mathrm{kHz}$ apresentaram algum traço da fase $\alpha$ (ver Tabela $\mathrm{XVI})$.

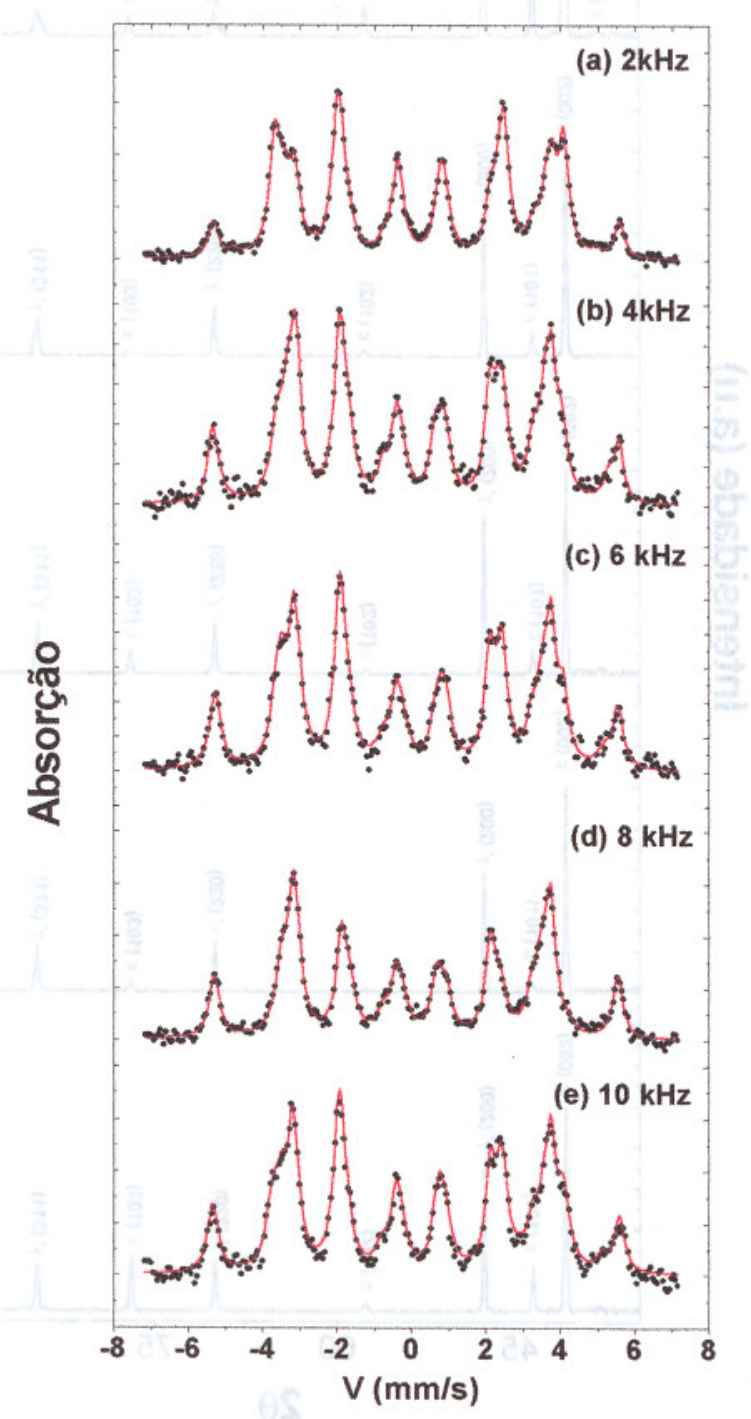

Figura 58 - Espectro de CEMS para amostras nitretadas em diferentes freqüências à temperatura de $500^{\circ} \mathrm{C}$ durante $3 \mathrm{~h}$. (a) $\mathrm{E011}, 2 \mathrm{kHz}$; (b) $\mathrm{E003}$, 4kHz; (c) E002, 6kHz; (d) E014, 8kHz; (e) E007, 10kHz. A linha contínua em vermelho é a curva ajustada aos pontos experimentais. 
As Figuras 59 e 60 mostram os espectros Mössbauer que representam a constituição da camada de compostos e a de difusão das amostras nitretadas nas freqüências de 2 e $10 \mathrm{kHz}$, depois de cada desgaste. Na Figura 59(a) e (b) estão os espectros de CEM da camada de compostos da superfície e depois da remoção de aproximadamente $5 \mu \mathrm{m}$ desta camada, respectivamente. A Figura 59(c) mostra o espectro depois da remoção de $10 \mu \mathrm{m}$, referente à camada de difusão. Finalmente, o espectro referente a matriz do $\alpha-\mathrm{Fe}$, após a remoção de $50 \mu \mathrm{m}$, Figura 59(d). A Tabela XVII apresenta os parâmetros obtidos no ajuste dos espectros Mössbauer nos vários desgastes.

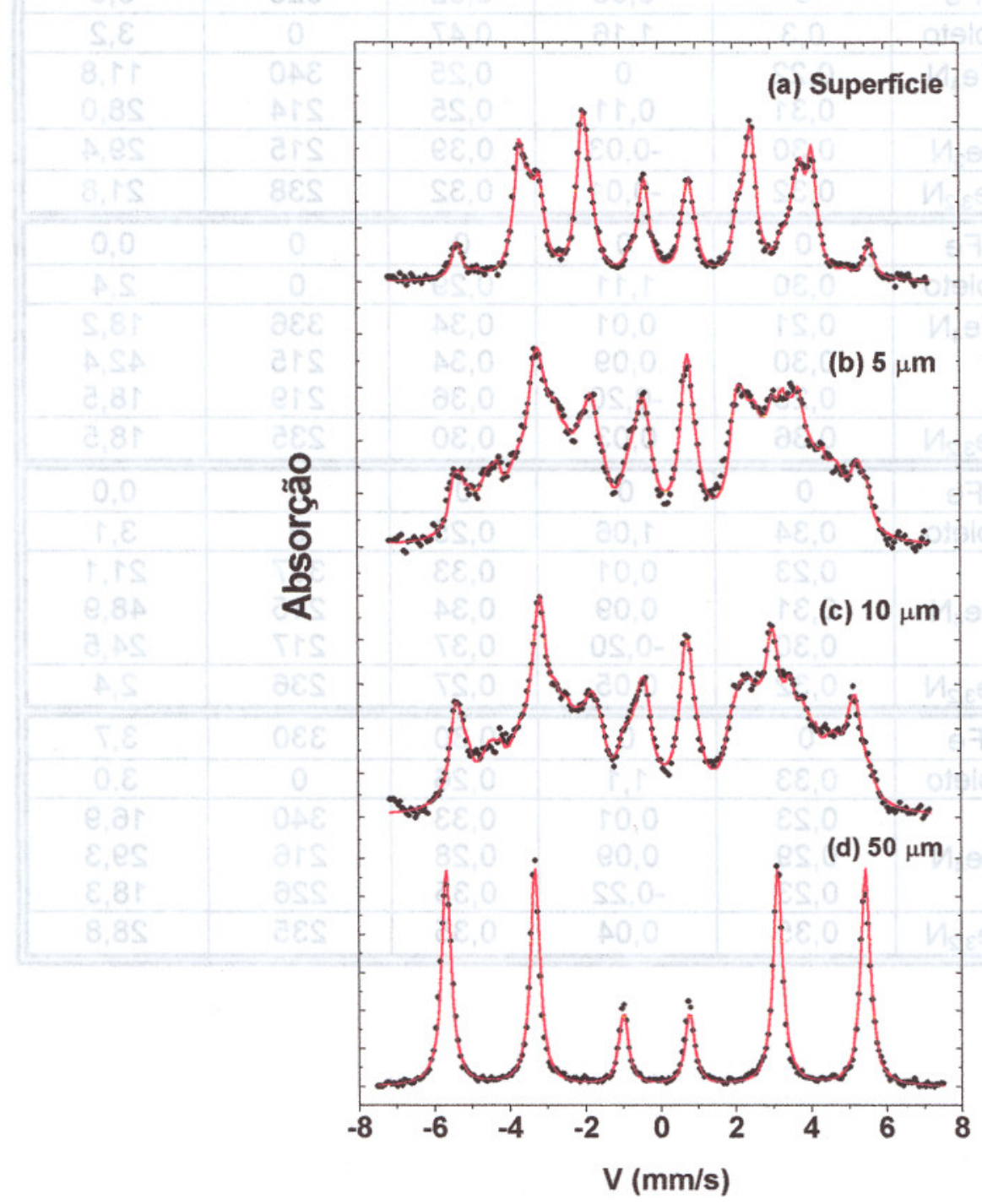

Figura 59 - Espectro de CEMS do ferro nitretado na freqüência de $2 \mathrm{kHz}$ durante $3 \mathrm{~h}$, a $\mathrm{T}=500^{\circ} \mathrm{C}$ : (a) espectro da superfície; (b), (c) e (d) são espectros depois da remoção de 5, 10 e 50 $\mu \mathrm{m}$ da camada nitretada, respectivamente. 
Tabela XVI - Relação das amostras nitretadas em diferentes frequiências com os parâmetros obtidos no ajuste dos espectros Mössbauer.

\begin{tabular}{|c|c|c|c|c|c|c|}
\hline $\begin{array}{c}\text { Amostra } \\
(\mathbf{k H z})\end{array}$ & Fase & $\begin{array}{c}\delta \\
(\mathrm{mm} / \mathrm{s})\end{array}$ & $\begin{array}{c}\Delta E_{Q} \\
(\mathrm{~mm} / \mathrm{s})\end{array}$ & $\begin{array}{c}\Gamma \\
(\mathrm{mm} / \mathrm{s})\end{array}$ & $\begin{array}{c}\mathrm{H} \\
(\mathrm{kOe})\end{array}$ & $\begin{array}{c}\text { Area } \\
\text { Relativa } \\
(\%)\end{array}$ \\
\hline \multirow{5}{*}{$\begin{array}{c}2 \\
(E 011)\end{array}$} & $\alpha-F e$ & 0 & 0 & 0 & 0 & 0 \\
\hline & Dubleto & 0,35 & 0,92 & 0,30 & 0 & 3,7 \\
\hline & $\gamma^{\prime}-\mathrm{Fe}_{4} \mathrm{~N}$ & $\begin{array}{l}0,23 \\
0,31 \\
\end{array}$ & $\begin{array}{l}0,01 \\
0,11\end{array}$ & $\begin{array}{l}0,30 \\
0,25\end{array}$ & $\begin{array}{l}339 \\
216 \\
\end{array}$ & $\begin{array}{l}10,9 \\
14,5\end{array}$ \\
\hline & $\varepsilon-\mathrm{Fe}_{3} \mathrm{~N}$ & 0,31 & $-0,04$ & 0,38 & 218 & 35,0 \\
\hline & $\varepsilon-\mathrm{Fe}_{3,2} \mathrm{~N}$ & $\begin{array}{l}0,32 \\
0,20\end{array}$ & $\begin{array}{c}-0,01 \\
0\end{array}$ & $\begin{array}{l}0,34 \\
0,25\end{array}$ & $\begin{array}{l}239 \\
303\end{array}$ & $\begin{array}{c}34,5 \\
1,4\end{array}$ \\
\hline \multirow{5}{*}{$\begin{array}{c}4 \\
\text { (E014) }\end{array}$} & $\alpha-\mathrm{Fe}$ & 0 & 0,05 & 0,32 & 328 & 5,8 \\
\hline & Dubleto & 0,3 & 1,16 & 0,47 & 0 & 3,2 \\
\hline & $\gamma^{\prime}-\mathrm{Fe}_{4} \mathrm{~N}$ & $\begin{array}{l}0,22 \\
0,31\end{array}$ & $\begin{array}{c}0 \\
0,11 \\
\end{array}$ & $\begin{array}{l}0,25 \\
0,25 \\
\end{array}$ & $\begin{array}{l}340 \\
214 \\
\end{array}$ & $\begin{array}{l}11,8 \\
28,0 \\
\end{array}$ \\
\hline & $\varepsilon-\mathrm{Fe}_{3} \mathrm{~N}$ & 0,30 & $-0,03$ & 0,39 & 215 & 29,4 \\
\hline & $\varepsilon-\mathrm{Fe}_{3,2} \mathrm{~N}$ & 0,32 & $-0,01$ & 0,32 & 238 & 21,8 \\
\hline \multirow{4}{*}{$\begin{array}{c}6 \\
(E 002)\end{array}$} & $\alpha-\mathrm{Fe}$ & 0 & 0 & 0 & 0 & 0,0 \\
\hline & Dubleto & 0,30 & 1,11 & 0,29 & 0 & 2,4 \\
\hline & $\gamma^{\prime}-\mathrm{Fe}_{4} \mathrm{~N}$ & $\begin{array}{l}0,21 \\
0,30 \\
0,25 \\
\end{array}$ & $\begin{array}{r}0,01 \\
0,09 \\
-0,20 \\
\end{array}$ & $\begin{array}{l}0,34 \\
0,34 \\
0,36 \\
\end{array}$ & $\begin{array}{l}336 \\
215 \\
219 \\
\end{array}$ & $\begin{array}{l}18,2 \\
42,4 \\
18,5 \\
\end{array}$ \\
\hline & $\varepsilon-\mathrm{Fe}_{3,2} \mathrm{~N}$ & 0,36 & 0,03 & 0,30 & 235 & 18,5 \\
\hline \multirow{4}{*}{$\begin{array}{c}8 \\
(E 003)\end{array}$} & $\alpha-\mathrm{Fe}$ & 0 & 0 & 0 & 0 & 0,0 \\
\hline & Dubleto & 0,34 & 1,06 & 0,25 & 0 & 3,1 \\
\hline & $\gamma^{\prime}-\mathrm{Fe}_{4} \mathrm{~N}$ & $\begin{array}{l}0,23 \\
0,31 \\
0,30\end{array}$ & $\begin{array}{r}0,01 \\
0,09 \\
-0,20\end{array}$ & $\begin{array}{l}0,33 \\
0,34 \\
0,37\end{array}$ & $\begin{array}{l}337 \\
215 \\
217\end{array}$ & $\begin{array}{l}21,1 \\
48,9 \\
24,5\end{array}$ \\
\hline & $\varepsilon-\mathrm{Fe}_{3,2} \mathrm{~N}$ & 0,32 & 0,05 & 0,27 & 236 & 2,4 \\
\hline \multirow{4}{*}{$\begin{array}{c}10 \\
(E 007)\end{array}$} & $\alpha-\mathrm{Fe}$ & 0 & 0 & 0,30 & 330 & 3,7 \\
\hline & Dubleto & 0,33 & 1,1 & 0,26 & 0 & 3,0 \\
\hline & $\gamma^{\prime}-\mathrm{Fe}_{4} \mathrm{~N}$ & $\begin{array}{l}0,23 \\
0,29 \\
0,23\end{array}$ & $\begin{array}{r}0,01 \\
0,09 \\
-0,22 \\
\end{array}$ & $\begin{array}{l}0,33 \\
0,28 \\
0,35\end{array}$ & $\begin{array}{l}340 \\
216 \\
226 \\
\end{array}$ & $\begin{array}{l}16,9 \\
29,3 \\
18,3 \\
\end{array}$ \\
\hline & $\varepsilon-\mathrm{Fe}_{3,2} \mathrm{~N}$ & 0,35 & 0,04 & 0,35 & 235 & 28,8 \\
\hline
\end{tabular}


Tabela XVII - Parâmetros Mössbauer de diferentes subespectros representados na Figura 59.

\begin{tabular}{|c|c|c|c|c|c|c|}
\hline $\begin{array}{l}\text { Profundidade } \\
(\mu \mathrm{m})\end{array}$ & Fase & $\begin{array}{c}\delta \\
(\mathrm{mm} / \mathrm{s})\end{array}$ & $\begin{array}{c}\Delta E_{Q} \\
(\mathrm{~mm} / \mathrm{s})\end{array}$ & $\begin{array}{c}\Gamma \\
(\mathrm{mm} / \mathrm{s})\end{array}$ & $\begin{array}{c}\mathrm{H} \\
(\mathrm{kOe})\end{array}$ & $\begin{array}{c}\text { Area } \\
\text { Relativa } \\
(\%)\end{array}$ \\
\hline \multirow{5}{*}{$\begin{array}{l}\text { Superficie } \\
\text { (E011) }\end{array}$} & $\alpha-\mathrm{Fe}$ & 0 & 0 & 0 & 0 & 0 \\
\hline & Dubleto & 0,35 & 0,92 & 0,30 & 0 & 3,7 \\
\hline & $\gamma^{\prime}-\mathrm{Fe}_{4} \mathrm{~N}$ & $\begin{array}{l}0,23 \\
0,31 \\
\end{array}$ & $\begin{array}{l}0,01 \\
0,11 \\
\end{array}$ & $\begin{array}{l}0,30 \\
0,25 \\
\end{array}$ & $\begin{array}{l}339 \\
216 \\
\end{array}$ & $\begin{array}{l}10,9 \\
14,5 \\
\end{array}$ \\
\hline & $\varepsilon-\mathrm{Fe}_{3} \mathrm{~N}$ & 0,31 & $-0,04$ & 0,38 & 218 & 23,0 \\
\hline & $\varepsilon-\mathrm{Fe}_{3,2} \mathrm{~N}$ & $\begin{array}{l}0,32 \\
0,22 \\
\end{array}$ & $\begin{array}{c}-0,01 \\
0 \\
\end{array}$ & $\begin{array}{l}0,34 \\
0,25 \\
\end{array}$ & $\begin{array}{l}239 \\
303 \\
\end{array}$ & $\begin{array}{l}46,5 \\
1,40 \\
\end{array}$ \\
\hline \multirow{6}{*}{$\begin{array}{c}5 \\
(E 029)\end{array}$} & $\alpha-F e$ & 0 & 0 & 0,31 & 328 & 11,5 \\
\hline & Dubleto & 0,22 & 1,20 & 0,43 & 0 & 5,5 \\
\hline & $\gamma^{\prime}-\mathrm{Fe}_{4} \mathrm{~N}$ & 0,25 & 0 & 0,47 & 341 & 4,5 \\
\hline & $\varepsilon-\mathrm{Fe}_{3} \mathrm{~N}$ & $\begin{array}{l}0,30 \\
0,20\end{array}$ & $\begin{array}{l}0 \\
0\end{array}$ & $\begin{array}{l}0,37 \\
0,60\end{array}$ & $\begin{array}{l}219 \\
285\end{array}$ & $\begin{array}{l}14,0 \\
20,0\end{array}$ \\
\hline & $\mathrm{Fe}_{2,67}^{\varepsilon^{-}} \mathrm{N}$ & $\begin{array}{l}0,26 \\
0,21 \\
\end{array}$ & $\begin{array}{l}0 \\
0\end{array}$ & $\begin{array}{l}0,42 \\
0,25 \\
\end{array}$ & $\begin{array}{l}206 \\
269 \\
\end{array}$ & $\begin{array}{c}10,0 \\
9,5 \\
\end{array}$ \\
\hline & $\varepsilon-\mathrm{Fe}_{3,2} \mathrm{~N}$ & 0,25 & 0 & 0,62 & 241 & 25,0 \\
\hline \multirow{8}{*}{$\begin{array}{c}10 \\
(E 022)\end{array}$} & $\alpha-\mathrm{Fe}$ & 0 & 0 & 0,40 & 330 & 20,5 \\
\hline & Dubleto & 0,25 & 1,20 & 0,45 & 0 & 6,0 \\
\hline & $y^{\prime}-\mathrm{Fe}_{4} \mathrm{~N}$ & 0,24 & 0 & 0,34 & 338 & 3,5 \\
\hline & $\varepsilon-\mathrm{Fe}_{3} \mathrm{~N}$ & $\begin{array}{l}0,29 \\
0,21 \\
\end{array}$ & $\begin{array}{l}0 \\
0\end{array}$ & $\begin{array}{l}0,31 \\
0,62 \\
\end{array}$ & $\begin{array}{l}221 \\
282 \\
\end{array}$ & $\begin{array}{c}5,0 \\
23,5 \\
\end{array}$ \\
\hline & $\begin{array}{c}\mathrm{Fe}^{-} \\
\mathrm{Fe}_{2,47} \mathrm{~N}\end{array}$ & 0,26 & 0 & 0,34 & 174 & 6,5 \\
\hline & $\begin{array}{c}\varepsilon^{-} \\
\mathrm{Fe}_{2,67} \mathrm{~N} \\
\end{array}$ & 0,26 & 0 & 0,36 & 205 & 12,5 \\
\hline & $\varepsilon-\mathrm{Fe}_{3,2} \mathrm{~N}$ & 0,24 & 0 & 0,60 & 238 & 20,5 \\
\hline & $\begin{array}{c}\alpha "- \\
\mathrm{Fe}_{16} \mathrm{~N}_{2} \\
\end{array}$ & 0,14 & 0,06 & 0,31 & 314 & 2,0 \\
\hline $\begin{array}{c}50 \\
(E 021)\end{array}$ & $\alpha-\mathrm{Fe}$ & 0 & 0 & 0,29 & 330 & 100 \\
\hline
\end{tabular}


As análises dos espectros Mössbauer da Figura 60 apresentam também diferenças nas quantidades das fases presentes na camada nitretada, como visto da Tabela XVIII. Com a remoção da camada nitretada, prevalece a fase $\varepsilon$ somada à fase $\alpha$ ".

Tabela XVIII - Parâmetros Mössbauer de diferentes subespectros representados na Figura 60.

\begin{tabular}{|c|c|c|c|c|c|c|}
\hline $\begin{array}{c}\text { Profundidade } \\
(\mu \mathrm{m})\end{array}$ & Fase & $\begin{array}{c}\delta \\
(\mathrm{mm} / \mathrm{s})\end{array}$ & $\begin{array}{c}\Delta E_{Q} \\
(\mathrm{~mm} / \mathrm{s})\end{array}$ & $\begin{array}{c}\Gamma \\
(\mathrm{mm} / \mathrm{s})\end{array}$ & $\begin{array}{c}\mathrm{H} \\
(\mathrm{kOe})\end{array}$ & $\begin{array}{c}\text { Área } \\
\text { Relativa (\%) }\end{array}$ \\
\hline \multirow{5}{*}{$\begin{array}{l}\text { Superficie } \\
\text { (E007) }\end{array}$} & $\alpha-\mathrm{Fe}$ & 0 & 0 & 0,30 & 330 & 3,7 \\
\hline & Dubleto & 0,33 & 1,1 & 0,26 & 0 & 3,0 \\
\hline & & 0,23 & 0,01 & 0,33 & 340 & 16,9 \\
\hline & $\gamma^{\prime}-\mathrm{Fe}_{4} \mathrm{~N}$ & $\begin{array}{l}0,29 \\
0,23\end{array}$ & $\begin{array}{r}0,09 \\
-0,22\end{array}$ & $\begin{array}{l}0,28 \\
0,35\end{array}$ & $\begin{array}{l}216 \\
226\end{array}$ & $\begin{array}{l}29,3 \\
18,3\end{array}$ \\
\hline & $\varepsilon-\mathrm{Fe}_{3,2} \mathrm{~N}$ & 0,35 & 0,04 & 0,35 & 235 & 28,8 \\
\hline \multirow{8}{*}{$\begin{array}{c}5 \\
(E 032)\end{array}$} & $\alpha-\mathrm{Fe}$ & 0 & 0 & 0,42 & 332 & 11,0 \\
\hline & Dubleto & 0,30 & 1,20 & 0,48 & 0 & 7,0 \\
\hline & $\gamma^{\prime}-\mathrm{Fe}_{4} \mathrm{~N}$ & 0,24 & 0 & 0,30 & 340 & 5,0 \\
\hline & $\varepsilon-\mathrm{Fe}_{3} \mathrm{~N}$ & $\begin{array}{l}0,28 \\
0,20\end{array}$ & $\begin{array}{l}0 \\
0\end{array}$ & $\begin{array}{l}0,37 \\
0,62\end{array}$ & $\begin{array}{l}218 \\
274\end{array}$ & $\begin{array}{l}13,5 \\
18,0\end{array}$ \\
\hline & $\varepsilon-\mathrm{Fe}_{2,47} \mathrm{~N}$ & 0,25 & 0 & 0,48 & 184 & 15,0 \\
\hline & $\varepsilon-\mathrm{Fe}_{2,67} \mathrm{~N}$ & 0,25 & 0 & 0,35 & 206 & 8,0 \\
\hline & $\varepsilon-\mathrm{Fe}_{3,2} \mathrm{~N}$ & 0,26 & 0 & 0,62 & 239 & 20,0 \\
\hline & $\begin{array}{c}\alpha "- \\
\mathrm{Fe}_{16} \mathrm{~N}_{2} \\
\end{array}$ & 0,15 & 0,07 & 0,28 & 317 & 2,5 \\
\hline \multirow{6}{*}{$\begin{array}{c}15 \\
\text { (E045) }\end{array}$} & $\alpha-\mathrm{Fe}$ & 0 & 0 & 0,44 & 330 & 30,0 \\
\hline & Dubleto & 0,25 & 1,18 & 0,35 & 0 & 4,0 \\
\hline & $\varepsilon-\mathrm{Fe}_{3} \mathrm{~N}$ & $\begin{array}{l}0,30 \\
0,18\end{array}$ & $\begin{array}{l}0 \\
0 \\
\end{array}$ & $\begin{array}{l}0,26 \\
0,62\end{array}$ & $\begin{array}{l}216 \\
288 \\
\end{array}$ & $\begin{array}{c}6,0 \\
12,0\end{array}$ \\
\hline & $\varepsilon-\mathrm{Fe}_{2,67} \mathrm{~N}$ & 0,26 & 0 & 0,61 & 206 & 22,0 \\
\hline & $\varepsilon-\mathrm{Fe}_{3,2} \mathrm{~N}$ & 0,32 & 0 & 0,62 & 235 & 23,0 \\
\hline & $\begin{array}{c}\alpha "- \\
\mathrm{Fe}_{16} \mathrm{~N}_{2} \\
\end{array}$ & 0,14 & $-0,06$ & 0,30 & 399 & 3,0 \\
\hline
\end{tabular}




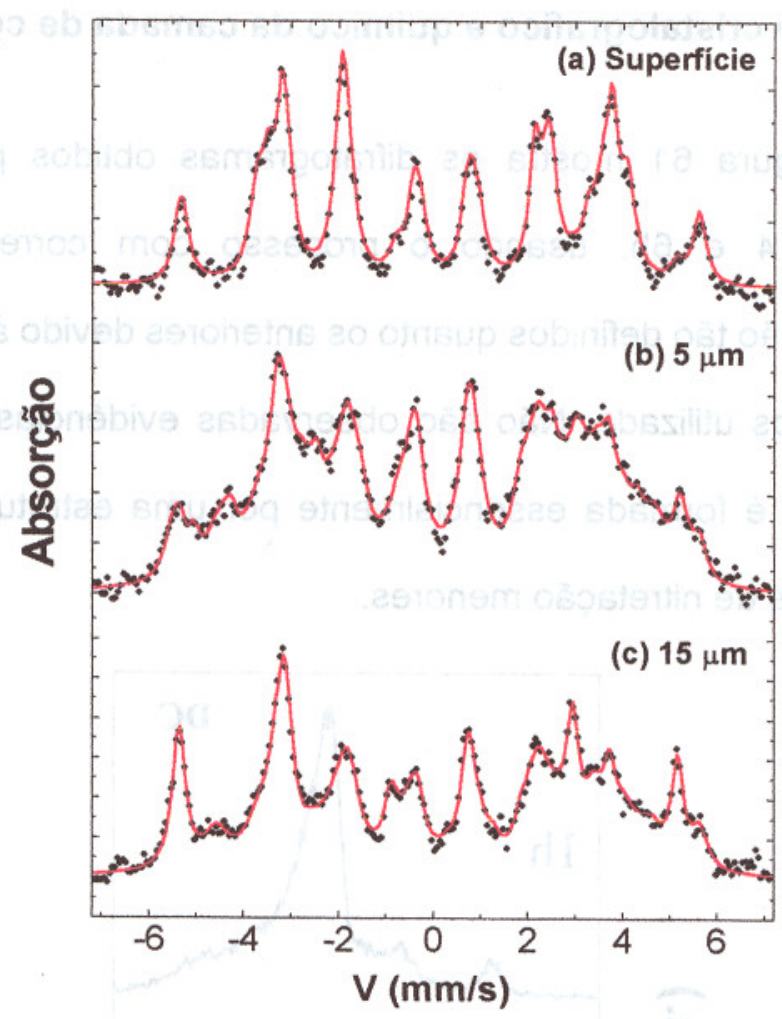

Figura 60 - Espectro de Mössbauer do ferro nitretado na freqüência de $10 \mathrm{kHz}$ durante $3 \mathrm{~h}$, a $\mathrm{T}=500^{\circ} \mathrm{C}$ : (a) espectro da superficie; (b) e (c) são espectros depois do desgaste de 5 e $15 \mu \mathrm{m}$ da camada nitretada, respectivamente.

\section{2 - AMOSTRAS DE AÇO AISI H12}

\subsubsection{Introdução}

A literatura é prodigiosa em trabalhos relativos às propriedades tribomecânicas dos aços, mas estudos sistemáticos relativos ao estado físico-químico dos aços nitretados são escassos. Como uma contribuição para este assunto, estudou-se o aço AISI H12, comparando os tratamentos de nitretação por plasma em correntes contínua e pulsada no estado físico-químico e na cinética de crescimento da camada de compostos.

A seguir serão apresentados os resultados obtidos no formato do artigo publicado, referência 74 . 


\subsubsection{Estado cristalográfico e químico da camada de compostos}

A Figura 61 mostra os difratogramas obtidos para as amostras nitretadas em 1, 4 e $6 \mathrm{~h}$, usando o processo com corrente direta. Estes difratogramas não são tão definidos quanto os anteriores devido às diferenças entre os dois difratômetros utilizado. Não são observadas evidências das reflexões da matriz do aço, que é formada essencialmente por uma estrutura martensita, até mesmo para tempos de nitretação menores.

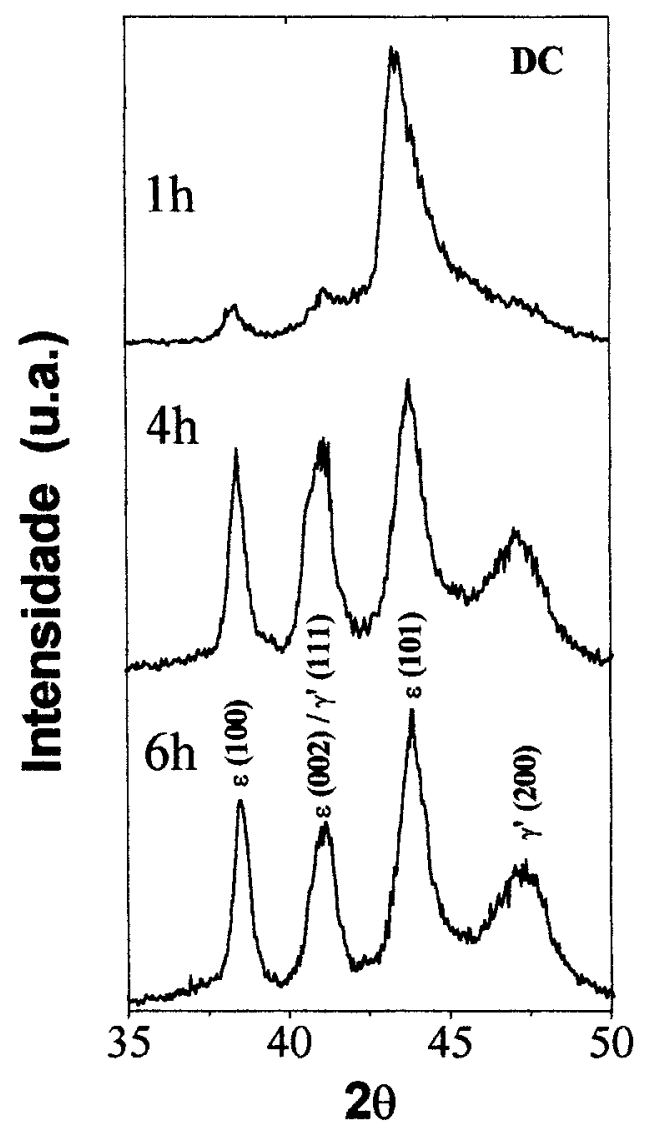

Figura 61 - Difratogramas de raios $X \theta-2 \theta$ das amostras nitretadas sob corrente direta (DC) durante 1, 4 e 6 h. As reflexões indexadas são indicadas.

A Figura 62 mostras os difratogramas obtidos para as amostras nitretadas em 1, 4 e $6 \mathrm{~h}$, usando o processo com corrente alternada. Para observar melhor as diferenças entre os processos em corrente direta e corrente alternada foram feitas medidas de difração de raios $X$ com ângulo de incidência rasante, como mostrada na Figura 63, para amostras nitretadas durante $6 \mathrm{~h}$. 


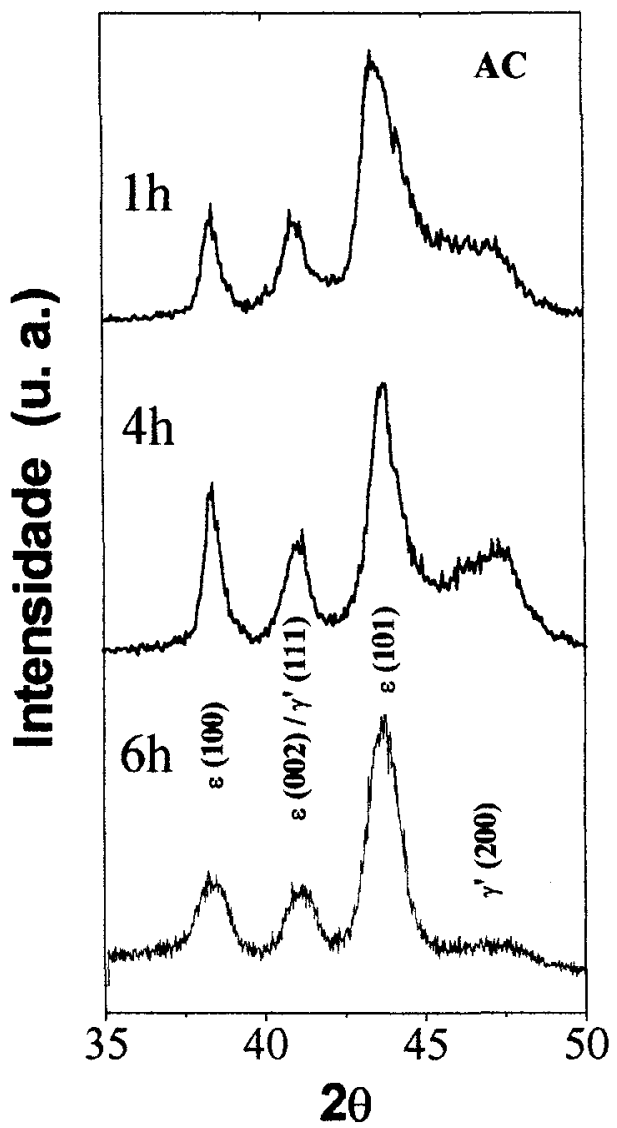

Figura 62 - Difratogramas de raios $x \theta-2 \theta$ das amostras nitretadas em corrente alternada (AC) durante 1, 4 e $6 \mathrm{~h}$. As reflexões indexadas são indicadas.

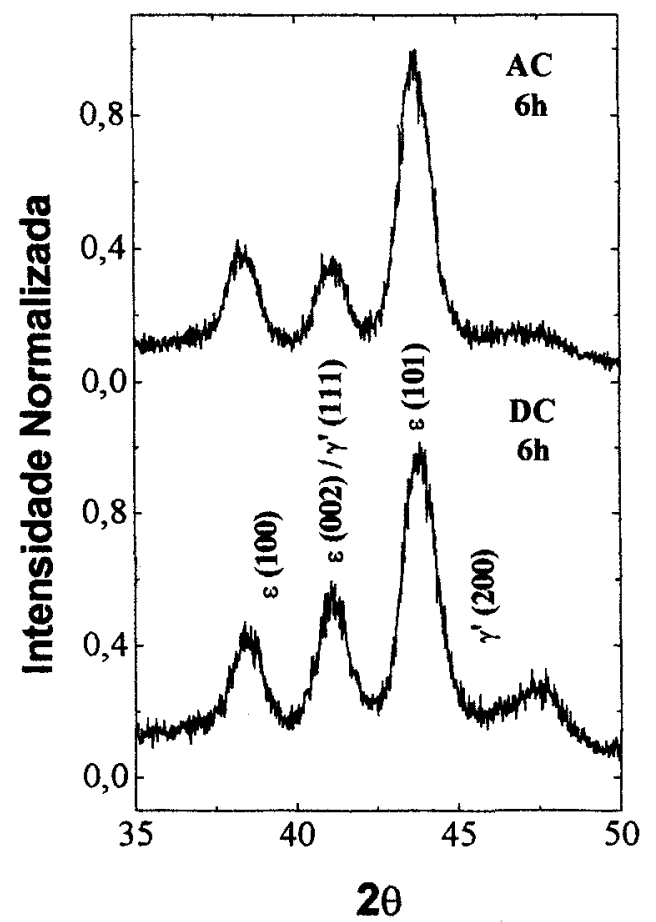

Figura 63 - Difratogramas de raios $x$ com ângulo rasante para as amostras nitretadas em AC e DC durante 6 h. As reflexões indexadas são indicadas. 
A Figura 64 apresenta espectros de CEMS para as amostras cujos difratogramas são mostrados na Figura 62. A Tabela XIX apresenta os parâmetros usados no ajuste dos espectros de CEMS e CXMS, para as amostras do aço $\mathrm{H} 12$ nitretada em corrente direta e corrente alternada.

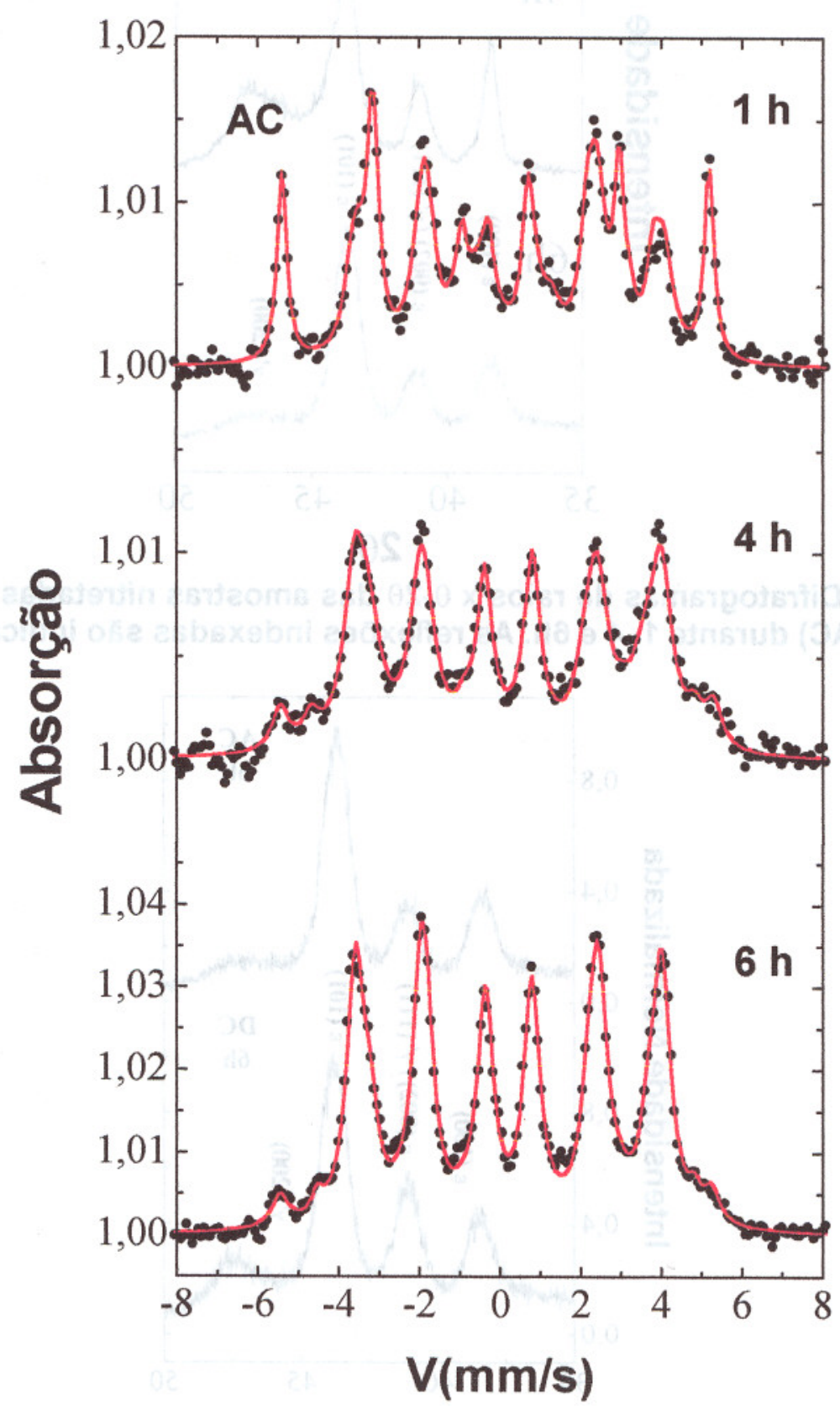

Figura 64 - Espectros de CEM das amostras nitretadas (AC) durante 1,4 e $6 \mathrm{~h}$. As curvas contínuas representam os ajustes do espectro. 
Tabela XIX - Valores típicos dos parâmetros obtidos no ajuste dos diferentes espectros de CEMS e CXMS apresentados neste trabalho.

\begin{tabular}{|c|c|c|c|}
\hline Componentes & $\mathbf{H}(\mathbf{k O e})$ & $\Delta \mathrm{E}_{\mathrm{Q}}(\mathrm{mm} / \mathbf{s})$ & $\delta(\mathrm{mm} / \mathbf{s})$ \\
\hline$\alpha^{\prime}$-martensita & 331 & 0,01 & 0,01 \\
\hline$\alpha^{\prime \prime}-(\mathrm{Fe}-\mathrm{N}-\mathrm{C})$ & - & - & $-0,12$ \\
austenita & - & 0,32 & 0,05 \\
\hline$\alpha^{\prime \prime}-\mathrm{Fe}_{16} \mathrm{~N}_{2}$ & 314 & 0,09 & 0,17 \\
\hline$\varepsilon-\mathrm{Fe}_{3,2}(\mathrm{C}, \mathrm{N})$ & 290 & 0.02 & 0,29 \\
& 241 & 0,02 & 0,32 \\
\hline$\varepsilon-\mathrm{Fe}_{2+x}(\mathrm{C}, \mathrm{N})$ & 220 & 0,03 & 0,32 \\
$x<1,2$ & 108 & 0,01 & 0,51 \\
& - & 0,95 & 0,45 \\
\hline$\gamma^{\prime}-\mathrm{Fe}_{4} \mathrm{~N}$ & 338 & 0,02 & 0,25 \\
& 210 & 0,25 & 0,32 \\
\hline
\end{tabular}

Como uma ilustração aos resultados de CXMS do aço $\mathrm{H} 12$ nitretado a Figura 65 mostra um espectro da amostra nitretada em corrente direta durante 1 h.

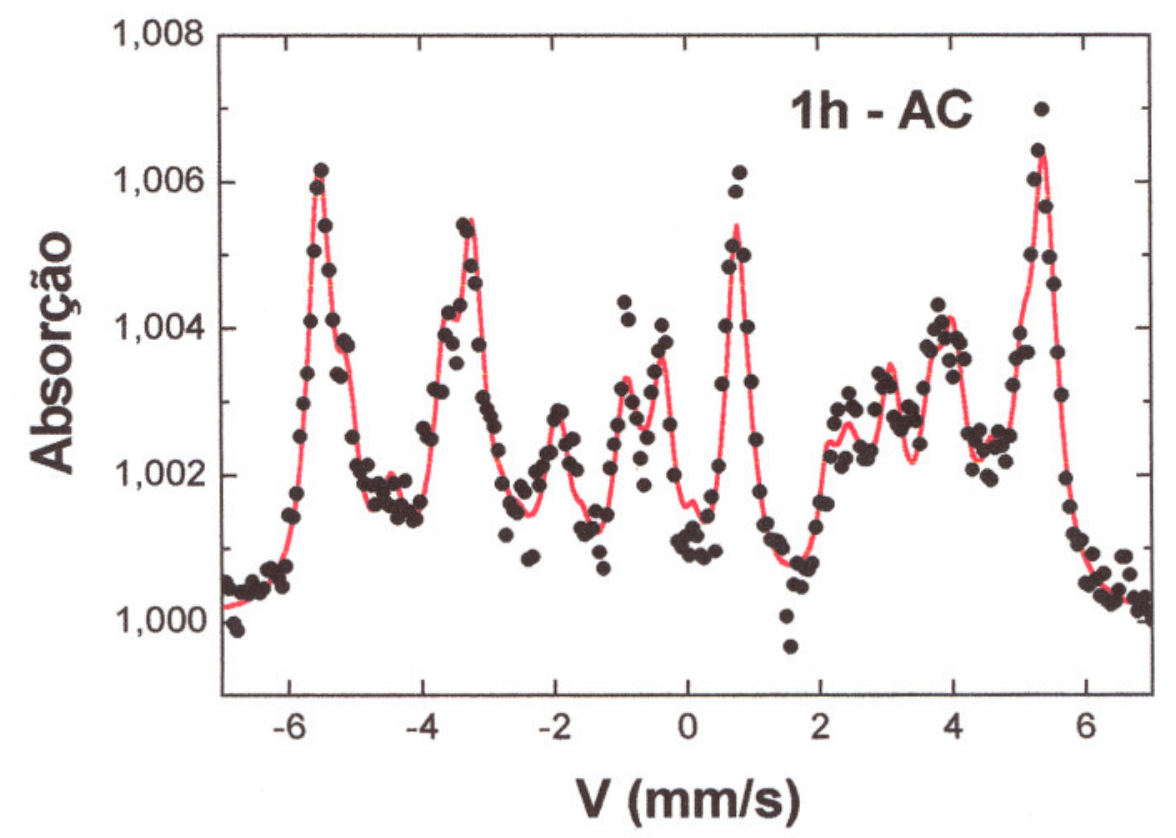

Figura 65 - Espectro de CXMS da amostra nitretada em DC durante $1 \mathrm{~h}$. A curva contínua representa o ajuste dos espectros, como ilustrado na Figura 46. 


\subsubsection{Perfis do corte transversal das amostras}

Três tipos de perfis do corte transversal foram medidos: microestrutural, de microdureza Vickers e de análise semi-quantitativa da concentração do nitrogênio. A Figura 66 ilustra uma micrografia ótica da amostra nitretada em DC durante $5 \mathrm{~h}$. Nela observa-se que existem duas regiões distintas. A primeira apresenta-se uma camada escura, com aspecto regular na interface. A segunda, continuação dessa primeira, é a matriz de aço H12. Os perfis de microdureza como uma função da profundidade de nitretação superficial são representados na Figura 67, para amostras nitretadas em DC durante 3 e $4 \mathrm{~h}$.

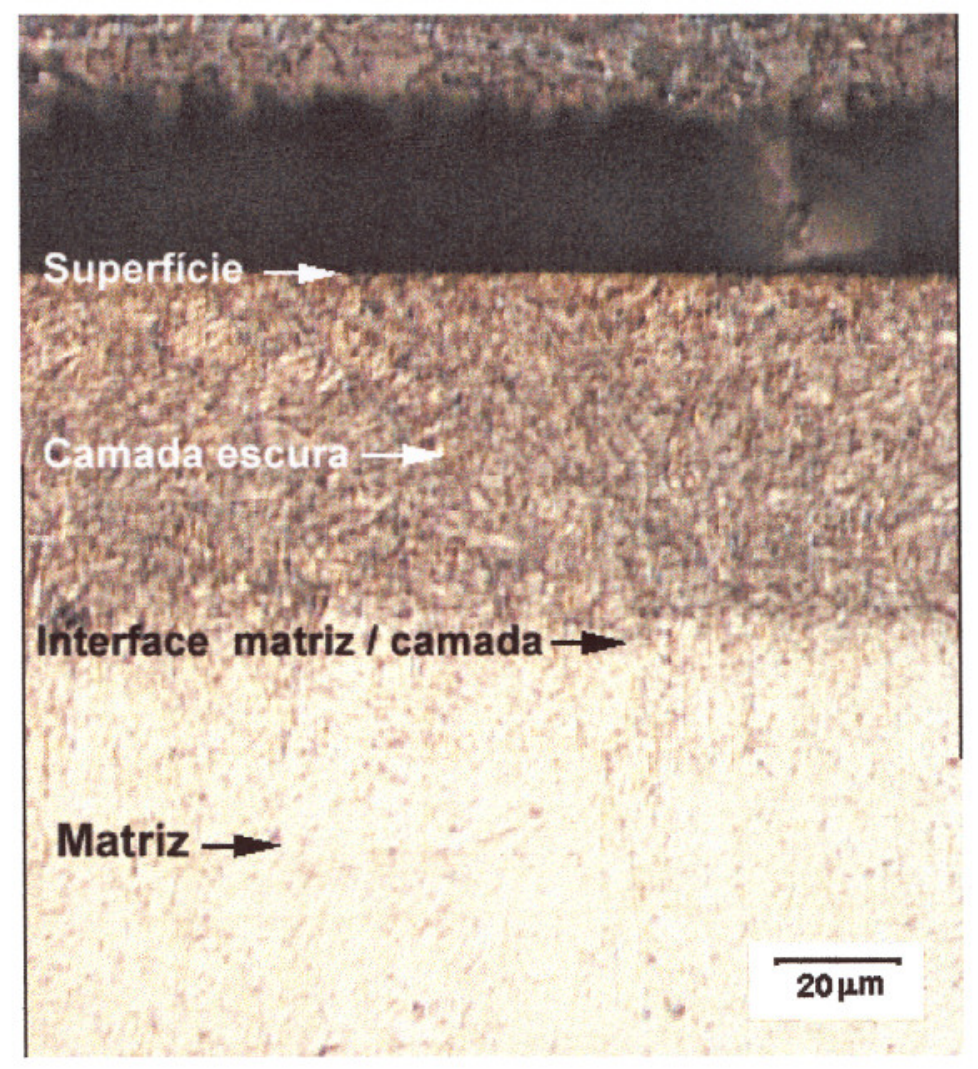

Figura 66 Micrografia ótica do corte transversal das amostras nitretadas em corrente direta (DC) durante $5 \mathrm{~h}$. 


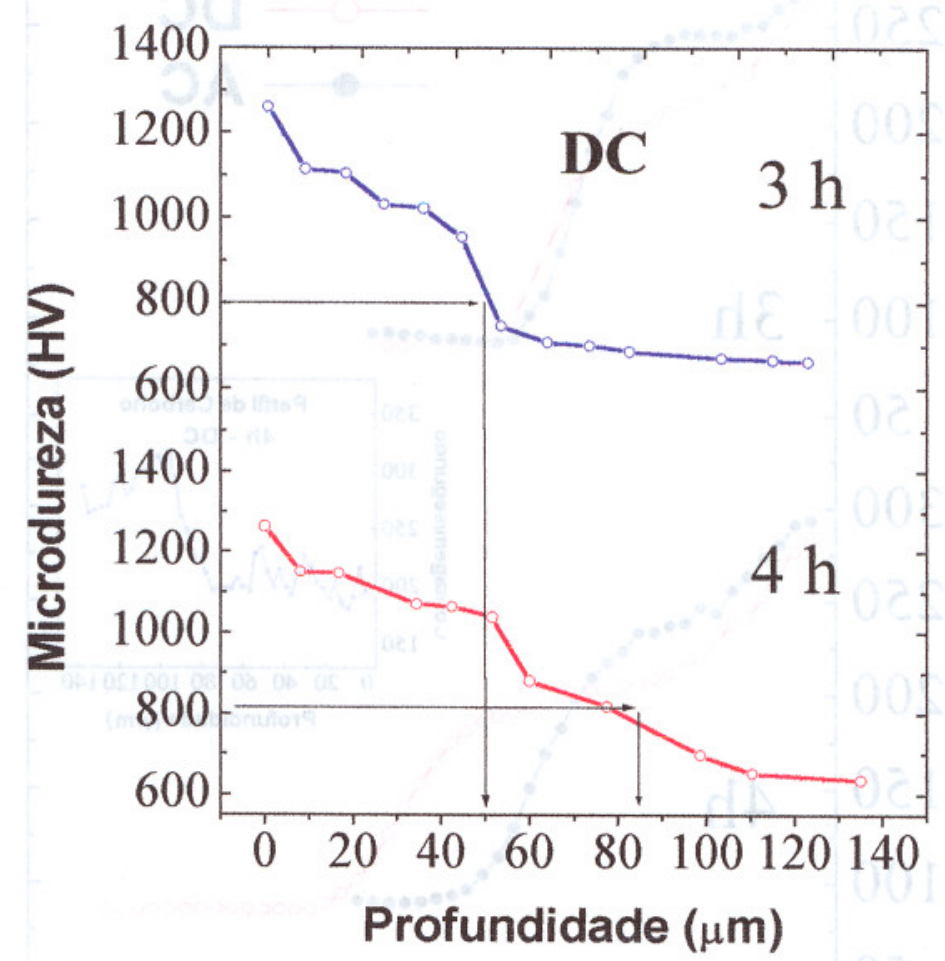

Figura 67 - Perfis de microdureza Vickers como uma função da profundidade da superficie nitretada para amostras nitretadas em corrente direta (DC) durante 3 e $4 \mathrm{~h}$.

A análise semi-quantitativa do nitrogênio nos perfis do corte transversal são mostrados na Figura 67 para as amostras nitretadas em DC e AC durante 3 e $4 \mathrm{~h}$. As medidas do perfil de carbono também foram realizadas em todas as amostras de aço $\mathrm{H} 12$ nitretadas. No interior da Figura 67 está apresentado um dos perfis mais regulares do carbono da amostra nitretada em corrente direta durante $4 h$. 


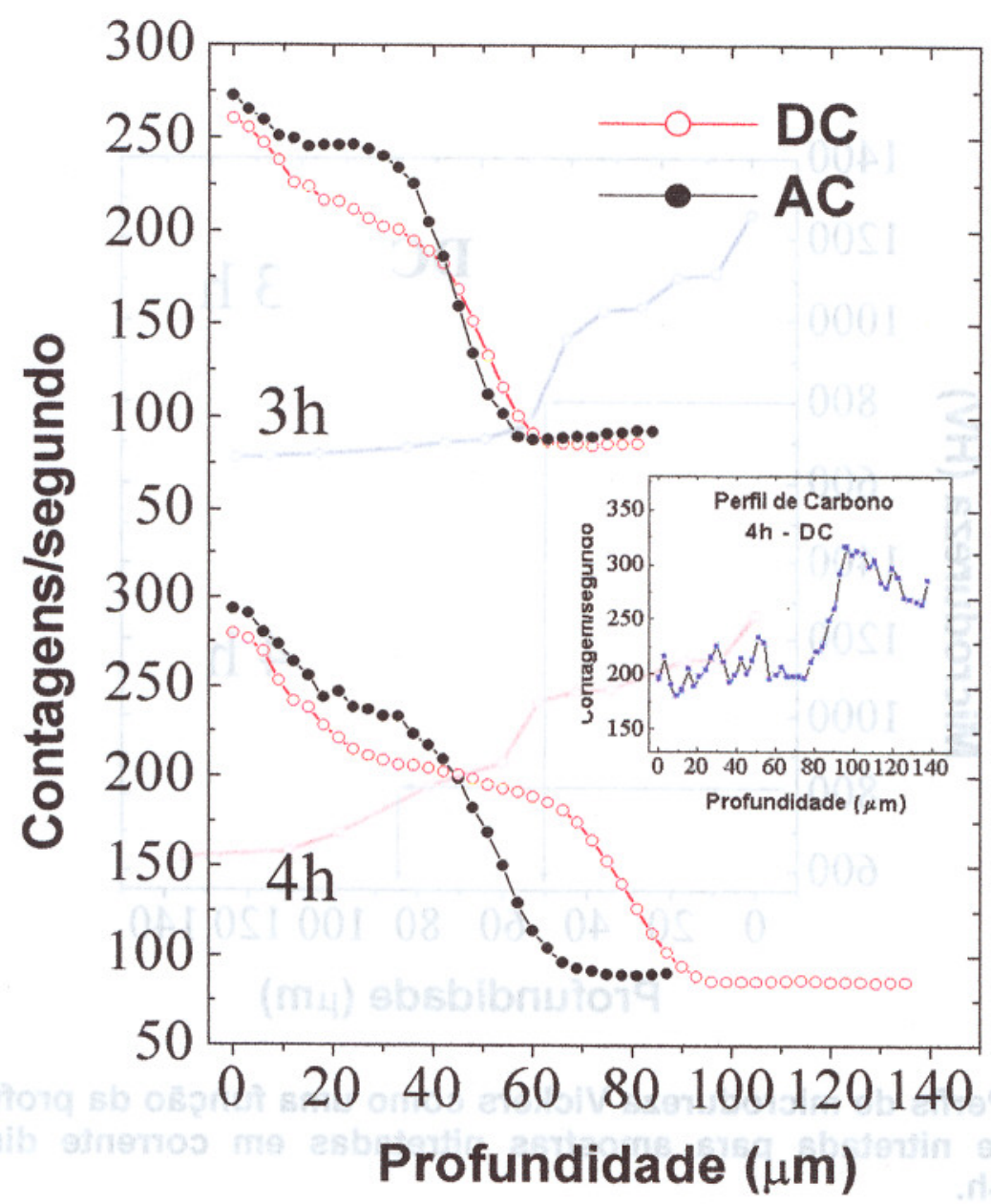

Figura 68 - Perfis do nitrogênio para amostras nitretadas em DC e AC durante 3 e $4 \mathrm{~h}$. No detalhe é mostrado o perfil de carbono para amostras nitretadas em corrente direta (DC) durante $4 \mathrm{~h}$. 


\title{
7 DISCUSSÃO
}

\subsection{ANÁLISES DOS RESULTADOS DAS AMOSTRAS DE FERRO}

\subsubsection{Fe nitretado em diferentes temperaturas}

\begin{abstract}
Microdureza - As medidas de microdureza mostram que o crescimento da espessura e da microdureza na camada nitretada do ferro é fortemente influenciado pela temperatura, mantendo-se os demais parâmetros constantes (tempo, pressão e corrente direta). Para a nitretação à $400^{\circ} \mathrm{C}$, a espessura total da camada de compostos não é significativa. Já para temperaturas de tratamento maiores, a espessura cresce acentuadamente até $550^{\circ} \mathrm{C}$, como pode ser vista na Figura 42.
\end{abstract}

Metalografia - Analisando-se as micrografias eletrônicas da Figura 43 pode ser observado o aspecto microestrutural da camada nitretada. Na Figura 43(a) existem duas regiões distintas. A primeira, próxima à superfície, denominada de camada de compostos, é formada por uma camada de espessura não homogênea de aproximadamente $3 \mu \mathrm{m}$. A segunda, abaixo desta, chamada de zona de difusão, é constituída de nitrogênio difundido na rede do ferro, estendendo-se até a matriz. Com o aumento da temperatura de nitretação, a camada de compostos torna-se contínua e homogênea, Figura 43(b), juntamente com uma camada de difusão, constituída de nitrogênio incorporado à rede do ferro como 
átomos intersticiais ou finamente disperso como precipitados de nitretos. Os pequenos precipitados são construídos pelo nitreto $\alpha$ "- $-\mathrm{Fe}_{16} \mathrm{~N}_{2}$, enquanto que os grandes precipitados são do $\gamma^{\prime}-\mathrm{Fe}_{4} \mathrm{~N}^{[66,71]}$, Figura 44. $\mathrm{O}$ aumento da temperatura provoca também o crescimento da camada de compostos, como pode se ver nas Figuras 43(b), (c) e (d).

A morfologia da camada nitretada nas temperaturas de 500 e $550^{\circ} \mathrm{C}$ apresenta varias regióes distintas. Para amostras nitretadas a $500^{\circ} \mathrm{C}$, observa-se a presença de 3 regiões distintas. A primeira constituída de uma mistura $\varepsilon+\gamma^{\prime}$, seguida de uma zona de transformação induzida por deformações devido ao bombardeamento iônico na superfície formada por austenita de nitrogênio ${ }^{\left[{ }^{4}\right]}$ e outra região mais interna constituída basicamente de ferrita com precipitados de nitretos $\left(\gamma^{\prime}-\mathrm{Fe}_{4} \mathrm{~N}\right.$ e $\alpha^{\prime \prime}-\mathrm{Fe}_{16} \mathrm{~N}_{2}$ ) nela dispersos, denominada de camada (ou zona) de difusão. No caso da amostra nitretada a $550^{\circ} \mathrm{C}$, observa-se uma estrutura alternada de ripas com diferentes orientações na região próxima da superfície (camada de compostos), bastante evidente na Figura 43(d). Estas ripas são compostas por pequenas quantidades de $\gamma^{\prime}$ e ferrita, formadas na matriz da fase $\varepsilon$. Logo abaixo desta, segue uma interface entre a camada de compostos e a zona de transformação constituída de uma mistura de $\varepsilon+\gamma^{\prime}$, seguida por uma zona de transformação também constituida de austenita de nitrogênio ${ }^{[74]}$, acompanhada da camada de difusão com as mesmas características da amostra nitretada a $500^{\circ} \mathrm{C}$.

Difração de raios $x$ - Das análises dos resultados de difração de raios $X(G A X D)$ foi possível identificar com maior precisão as fases de nitretos presentes na superfície das amostras tratadas nas temperaturas de $400,450,500$ e $550^{\circ} \mathrm{C}$. No difratograma referente à Figura $45(\mathrm{a})$, (b) e (c) observa-se que a fase $\varepsilon$ é texturizada ao longo da direção $<002>$, para a temperatura de nitretação de $400^{\circ} \mathrm{C}$, com parâmetros de rede $a=2,708(2) \AA$ e $c=4,388(6) \AA$, dando uma razão $c / a=1,620$. Utilizando a correlação entre os parâmetros de rede e a quantidade de nitrogênio 
no trabalho descrito por Jack $^{[49]}$ (ver Figura 30), encontrou-se a estequiometria $\mathrm{Fe}_{3,05} \mathrm{~N}$ para esta fase, concordando com a fase utilizada no ajuste do espectro de CEMS desta amostra. As fases $\gamma^{\prime}$ e $\alpha$-Fe também se encontram presentes nesta amostra, com reflexões de pequena intensidade, enquanto os difratogramas das amostras nitretadas à temperatura de $450^{\circ} \mathrm{C}$, mostram a presença das fases $\alpha, \varepsilon$ e $\gamma^{\prime}$. Para $\mathrm{T}=500^{\circ} \mathrm{C}$, apenas precipitados $\varepsilon$ e $\gamma^{\prime}$ estão presentes, Figura $45(\mathrm{~b})$.

São os seguintes os parâmetros de rede para a fase $\varepsilon, a=2,702(3) \AA$ e $c=4,390(4) \AA$ em amostras nitretadas à temperatura de $450^{\circ} \mathrm{C}$, fornecendo uma razão $c / a=1,624$. Outra vez, utilizando-se a razão $c / a^{[49]}$, determinou-se a concentração entre a quantidade de átomos de ferro e nitrogênio na fase $\varepsilon$ e encontrou-se a estequiometria de $\mathrm{Fe}_{3,25} \mathrm{~N}$, que é semelhante ao nitreto determinado na medida de CEMS, Tabela XII.

$\mathrm{Na}$ outra amostra tratada a $500^{\circ} \mathrm{C}$, os parâmetros de rede encontrados foram $a=2,700(3) \AA$ e $c=4,389(6) \AA$, dando uma razăo $c / a=1,625$ correspondente a uma mesma estequiometria para fase $\varepsilon$ determinada na amostra nitretada a $450^{\circ} \mathrm{C}$.

Analisando agora a amostra nitretada à temperatura de $550^{\circ} \mathrm{C}$, foi constatada também a presença dos nitretos $\varepsilon$ e $\gamma^{\prime}$, Figura 45(d), apresentando uma diminuição na intensidade da fase $\gamma^{\prime}$ em relação às amostras nitretadas em $\mathrm{T} \leq 500^{\circ} \mathrm{C}$, prevalecendo a fase $\varepsilon$. Os parâmetros de rede determinados foram $a=2,698(5) \AA c=4,380(6) \AA$, dando uma razão $c / a=1,62$ correspondente a uma estequiometria de $\mathrm{Fe}_{3,25} \mathrm{~N}$. Assim, a análise de difraçăo de raios $\mathrm{X}$ forneceu para as quatro amostras em questão, uma estequiometria aproximada à da encontrada na espectroscopia Mössbauer. Como o conteúdo percentual de ferro destas duas estequiometrias difere de aproximadamente $1 \%$, pode se dizer que a análise Mössbauer reflete as fases determinadas por raios X. A pequena discrepância dos dados de difração de raios $X$ deve então ser atribuída a erros inevitáveis, ao utilizar 
os dados gráficos do parâmetro de rede com o conteúdo de nitrogênio proposto por $\operatorname{Jack}^{[49]}$.

Com a determinação dos parâmetros de rede a e c, pode-se determinar a concentração de nitrogênio (em \% atômica) na superficie das amostras, utilizando a equação de Wriedt ${ }^{[77,78]}$.

$$
a=2,525 \AA+0,00747 \AA \times c_{N}
$$

onde a é o parâmetro de rede e $c_{N}$ é a concentração de nitrogênio em \% atômica.

A Tabela XX mostra a concentração de nitrogênio na superfície das amostras, medida a partir da determinação do parâmetro de rede da fase $\varepsilon$, pela difração de raios $\mathrm{X}$ em função da temperatura de nitretação.

Tabela XX - Concentração de nitrogênio em função da temperatura de nitretação.

\begin{tabular}{|c|c|c|}
\hline Temperatura $\left({ }^{\circ} \mathrm{C}\right)$ & $\begin{array}{c}\text { Concentraçăo de } \\
\text { Nitrogênio } \mathbf{C}_{\mathrm{N}}(\mathrm{at} . \%)\end{array}$ & $\begin{array}{c}\text { Parâmetro de Rede (a) } \\
(\mathbf{A})\end{array}$ \\
\hline 400 & $24,49(5)$ & $2,708(2)$ \\
\hline 450 & $23,69(7)$ & $2,702(3)$ \\
\hline 500 & $23,42(4)$ & $2,700(2)$ \\
\hline 550 & $23,16(1)$ & $2,698(5)$ \\
\hline
\end{tabular}

CEMS - Com a utilização da espectroscopia Mössbauer (CEMS), foi possivel confirmar os resultados de GAXD e quantificar as fases de nitretos presentes nas superfícies das amostras nitretadas a temperaturas entre 400 e $550^{\circ} \mathrm{C}$. O espectro Mössbauer da amostra nitretada a $400^{\circ} \mathrm{C}$, Figura $47(\mathrm{a})$ apresenta uma mistura de várias fases (Tabela XII) tendo como presença predominante, subespectros de linhas alargadas, $\Gamma=0,35 \mathrm{~mm} / \mathrm{s}$ (largura do pico interno do espectro). Estes subespectros são referentes a 3 fases $\varepsilon-\left(\mathrm{Fe}_{2,67} \mathrm{~N}, \mathrm{Fe}_{3} \mathrm{~N}\right.$ e $\mathrm{Fe}_{3,2} \mathrm{~N}$ ), com valores de campo hiperfino de $205 \mathrm{kOe}, 236 \mathrm{kOe}$ e $218 \mathrm{kOe}$. Outra fase presente é a $\gamma^{\prime}-\mathrm{Fe}_{4} \mathrm{~N}$, com dois sítios cristalográficos $\mathrm{Fe}(\mathrm{I})$ e $\mathrm{Fe}(\mathrm{II})_{\mathrm{A}}$, cujos campos hiperfinos são de $340 \mathrm{kOe}$ e $216 \mathrm{kOe}$, não apresentando o sítio $\mathrm{Fe}(\mathrm{ll})_{\mathrm{B}}$. 
Pode-se observar também a presença do subespectro referente ao $\alpha-\mathrm{Fe}$, com uma porcentagem de $8 \%$ da área espectral.

Elevando-se a temperatura de nitretação para $450^{\circ} \mathrm{C}$, Figura $47(\mathrm{~b})$, a camada de nitreto formada apresenta também a coexistência das fases $\varepsilon$ com $62 \%$ e $\gamma^{\prime} \operatorname{com} 31,5 \%$ das áreas relativas do espectro, com a presença de uma pequena fração de $1,5 \%$ do $\alpha-\mathrm{Fe}$. Comparando os parâmetros deste espectro com o anterior observa-se que ambos apresentam valores de $\delta$ aproximados. Os valores de $\mathrm{He} \Gamma$, visualmente diferentes para os dois espectros, podem ser explicados pelas diferentes temperaturas em que se encontraram os dois substratos durante a nitretação.

Elevando ainda mais a temperatura, para $500^{\circ} \mathrm{C}$, tem-se a presença das mesmas fases, apenas com modificações nas áreas relativas de cada uma delas, Figura $47(\mathrm{c})$. A porcentagem das áreas relativas é de $70,3 \%$ para fase $\varepsilon$ e $22,7 \%$ para $\gamma^{\prime}$, e pode-se observar uma diminuição da fração do $\alpha-\mathrm{Fe}$, em relação ao aumento da temperatura, causada pela maior solubilidade do nitrogênio na superfície.

Com o aumento da temperatura de tratamento para $550^{\circ} \mathrm{C}$ o subespectro referente ao $\alpha$-Fe desapareceu, prevalecendo as fases $\varepsilon$ e $\gamma^{\prime}$, com $80 \%$ e $12,5 \%$ das áreas relativas, conforme mostra o espectro CEMS da Figura 46(d). A fase $\gamma^{\prime}$ não apresentou um dos sítios $\mathrm{Fe}_{\|}$, cujo campo hiperfino é de $219 \mathrm{kOe}$. Já a fase $\varepsilon-\mathrm{Fe}_{3,2} \mathrm{~N}$ apresenta-se cristalina, com a presença dos dois sítios cristalográficos, com campos de $236 \mathrm{kOe}$ e $216 \mathrm{kOe}$, com largura de linha $\Gamma=0,30 \mathrm{~mm} / \mathrm{s}$ o que evidencia uma ocupação ordenada dos interstícios octaédricos pelos átomos de nitrogênio. Portanto, na temperatura de nitretação de $550^{\circ} \mathrm{C}$ a fase predominante é a $\varepsilon$. $O$ dubleto observado nos espectros com $\delta$ variando de $0,33 \mathrm{~mm} / \mathrm{s}$ a $0,35 \mathrm{~mm} / \mathrm{s}$ e $\Delta E_{Q}$ de 0,92 a $1,08 \mathrm{~mm} / \mathrm{s}$. O valor de seus $\delta$ corresponde a 
uma fase rica em nitrogênio e a variação pronunciada em $\Delta \mathrm{E}_{Q}$ juntamente com os grandes valores de suas larguras de linha indica variações no ambiente de rede do ferro, o que sugere se tratar de uma fase de baixa cristalinidade ${ }^{[5,42]}$. Um dubleto com parâmetros Mössbauer semelhantes foi encontrado por Nakagawa, em camadas de nitretos obtidas por técnicas de "RF Sputtering" ${ }^{[79]}$. Ele atribuiu o dubleto como pertencente a uma fase cfc, com estequiometria em torno de $\mathrm{Fe}_{1.6} \mathrm{~N}$. Por associação, o dubleto encontrado no presente estudo será atribuído a uma fase de austenita distorcida $\mathrm{Fe}_{1+\mathrm{x}}(\mathrm{x}<1)$. Este dubleto aparece em todos as amostras de ferro nitretadas nas diversas condições de nitretação.

A evolução dos nitretos formados no tratamento de nitretação por plasma pode ser representada também pelas análises de Mössbauer, através das porcentagens das fases determinadas pelo refinamento dos espectros das amostras nitretadas em diferentes temperaturas (Figura 69). Por exemplo, a porcentagem da área espectral atribuída às fases $\varepsilon-\mathrm{Fe}_{2,67} \mathrm{~N}, \varepsilon-\mathrm{Fe}_{3} \mathrm{Ne} \varepsilon-\mathrm{Fe}_{3,2} \mathrm{~N}$, para amostra nitretada a $400^{\circ} \mathrm{C}$ durante $3 \mathrm{~h}$, foi tomada como $58 \%$ da do espectro total.

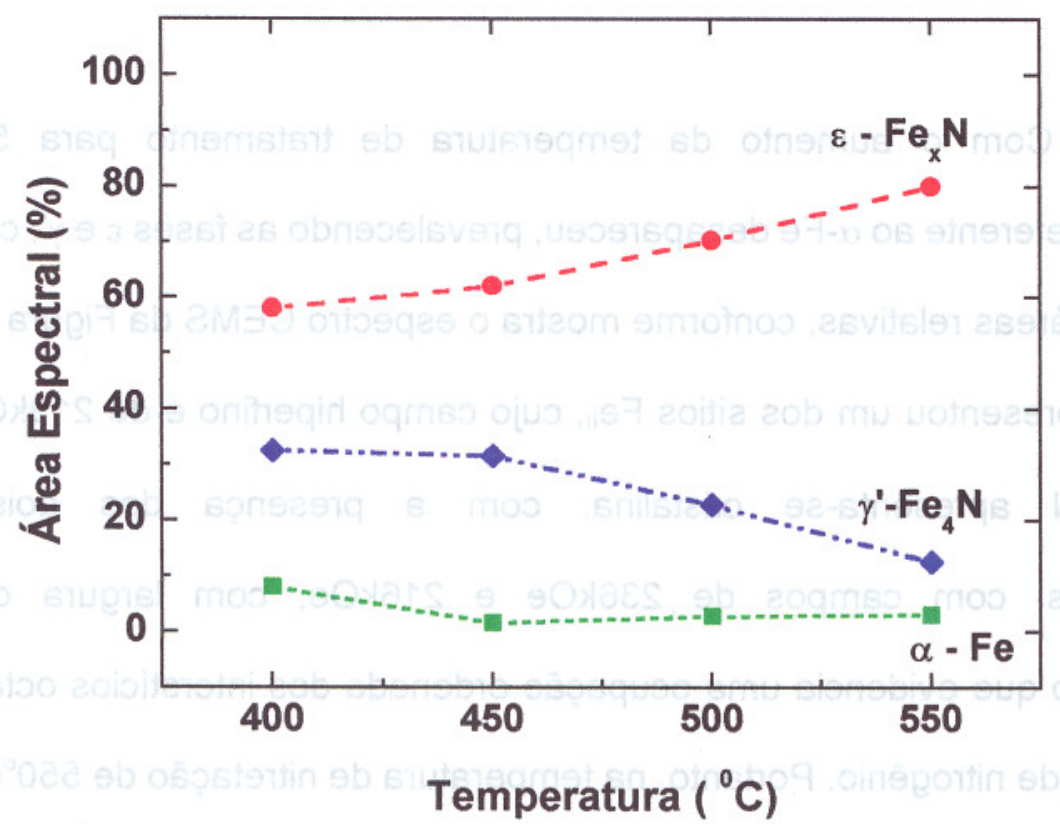

Figura 69 - Área espectral relativa de CEMS para as amostras nitretadas em corrente direta (DC) em diferentes temperaturas. 
As medidas de espectroscopia Mössbauer e difração de raios $X$ estão inteiramente consistentes com a composição química das camadas nitretadas próximas à superficie do ferro nitretado, embora alguns detalhes em particular sejam discriminados em cada uma das técnicas. Por exemplo, os nitretos $\varepsilon$ e $\gamma^{\prime}$ estão presentes em todas as temperaturas de nitretação, com diferentes contribuições claramente indicadas pela difração de raios $\mathrm{X}$ e confirmada pelas medidas de espectroscopia Mössbauer.

A maior presença da fase $\varepsilon$, em todas as amostras, é devida à quantidade de carbono existente no substrato $(0,02 \%$ em massa), que segundo Sun e Bell[ ${ }^{[80]}$ facilita a formação da fase $\varepsilon$ na camada de compostos. O comportamento de formação de fases observado por Kurny ${ }^{[81]}$ quando nitretou o ferro ARMCO (com $99,99 \%$ de pureza), foi o da obtenção apenas da fase $\gamma^{\prime}$.

As medidas de Mössbauer também enfatizam alguns aspectos não sugeridos pelas medidas de difração de raios $\mathrm{X}$. Por exemplo, baseado nos dados de difração de raios $X$ não é possível discriminar os precipitados $\varepsilon-F e_{x} N(2 \leq x \leq 3,2)$ com diferentes estequiometrias. Contudo, como os nitretos são metaestáveis, tendo diferentes parâmetros hiperfinos, principalmente campos hiperfinos diferentes, fica fácil discriminá-los pelos ajustes dos espectros Mössbauer.

A razão da área espectral $\varepsilon / \gamma^{\prime}$ de CEMS, obtida através da Figura 69 , para a amostra nitretada a $\mathrm{T}=550^{\circ} \mathrm{C}$, é aproximadamente 6,4 e de 1,7 para $\mathrm{T}=400^{\circ} \mathrm{C}$. Portanto, a camada $\varepsilon$ na amostra nitretada a $\mathrm{T}=550^{\circ} \mathrm{C}$ é muito mais espessa do que a formada $a T=400^{\circ} \mathrm{C}$, confirmando os resultados observados nas medidas de difração de raios $X$. Baseado nas medidas de microdureza, análises de MEV e dados de GAXD e CEMS, pode-se dizer que a dureza da camada nitretada em diferentes temperaturas cresce com o aumento da fase $\varepsilon$, confirmando a maior dureza desta fase em relação à $\gamma^{[82]}$. 
Desgaste seguido de CEMS - As análises de Mössbauer que representam a constituição das camadas composta e de difusão, para os desgastes de 5,10 e $50 \mu \mathrm{m}$, realizados nas amostras nitretadas nas diferentes temperaturas, apresentam as mesmas fases formadas, mas com proporções diferentes. Por exemplo, para o ferro nitretado a $\mathrm{T}=500^{\circ} \mathrm{C}$ o espectro da superficie é constituído principalmente das fases $\varepsilon-\mathrm{Fe}_{3,2} \mathrm{~N}$ e $\gamma^{\prime}-\mathrm{Fe}_{4} \mathrm{~N}$, enquanto que o espectro abaixo da superfície (camada de compostos) é formado principalmente do nitreto $\varepsilon$ e da fase $\alpha-\mathrm{Fe}$, com uma pequena quantidade relativa do nitreto $\gamma^{\prime}(\approx 2 \%)$. Neste caso, a fase $\varepsilon$ é caracterizada por quatro nitretos $\varepsilon-\left(\mathrm{Fe}_{2,47} \mathrm{~N}, \mathrm{Fe}_{2,67} \mathrm{~N}, \mathrm{Fe}_{3} \mathrm{~N}\right.$ e $\left.\mathrm{Fe}_{3,2} \mathrm{~N}\right)$, enquanto 0 nitreto $\gamma^{\prime}-\mathrm{Fe}_{4} \mathrm{~N}$ apresenta um único sítio de ferro com campo hiperfino $\mathrm{H}=340 \mathrm{kOe}$, diferente do espectro da superfície, que apresenta três sítios de ferro, Tabela XIV. Como pode se ver da Figura 49(c) e (d), a zona de transformação e a camada de difusão, além de serem constituídas dos mesmos componentes da Figura 49(b) apresentam o subespectro do nitreto $\alpha^{\prime \prime}-\mathrm{Fe}_{16} \mathrm{~N}_{2}$ em pequena quantidade, Tabela XIII.

A formação da fase $\varepsilon$ na camada de difusão pode ser explicada pelo aumento na quantidade de carbono. A razão para este crescimento de carbono na frente de nitretação por plasma está nas tensões provocadas pelo nitrogênio na camada nitretada, causando a difusão do carbono para regiões livres de tensões, isto é, para regiões próximas a superfície e para a camada de difusão ${ }^{[74,80]}$.

\subsubsection{Fe nitretado em tempos diferentes}

Microdureza - As medidas de microdureza da amostras nitretadas variando o tempo de nitretação de 1 a $6 \mathrm{~h}$ (com temperatura de $500^{\circ} \mathrm{C}$ e pressão de 6 mbar em corrente direta) apresentaram um largo intervalo de microdureza entre 
190 - 460HV. Nota-se que a dureza aumenta com o tempo de nitretação até 3h, quando a maior dureza superficial das amostras nitretadas é alcançada, isto é 460HV. Para tempos de nitretação maiores a dureza tende a diminuir, chegando ao valor de $310 \mathrm{HV}$ para amostras nitretadas com tempo de $6 \mathrm{~h}$, como pode se ver na Figura 50. Segundo Kuppusami ${ }^{[83]}$, isto pode ser devido ao fato de que, quanto mais alto o tempo de tratamento, as amostras estarão mais expostas à produção de precipitados de nitretos grandes (como $\gamma^{\prime}-\mathrm{Fe}_{4} \mathrm{~N}$ na forma de agulhas) dentro da camada, ocasionando a diminuição da dureza superficial. Quanto ao valor elevado da dureza superficial de $460 \mathrm{HV}$ da camada nitretada para estas amostras, pode ser explicado pelos trabalhos desenvolvidos por O'brien ${ }^{[84]}$, Endenhofer ${ }^{[85]}$ e Inal ${ }^{[86]}$. Eles observaram que aumentando a concentração de nitrogênio na superfície havia a formação de precipitados muito finos (nitretos), aumentando assim a resistência e a dureza de algumas ligas metálicas pela formação destes pequenos precipitados uniformemente dispersos.

A evolução dos nitretos na camada de compostos para amostras nitretadas, em diferentes tempos pode ser determinada pela profundidade da camada nitretada com dureza de $200 \mathrm{HV}$, como função da raiz quadrada do tempo de nitretação, mostrada na Figura 70. Como esperado, o crescimento obedece a uma lei parabólica ${ }^{[87,88]}$ com o tempo de tratamento, já que o processo é difusivo.

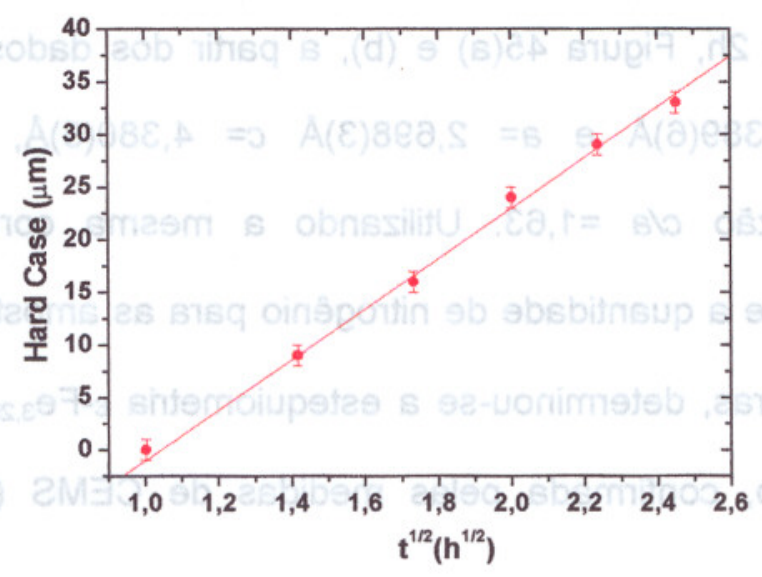

Figura 70 - O "hard case" como função da raiz quadrada do tempo de nitretação. 
Metalografia - As camadas nitretadas, formadas em diferentes tempos de nitretação, possuem características semelhantes entre si, como a camada de compostos e a de difusão mostrada na Figura 50. A única diferença observada entre as amostras está na evolução da espessura da camada nitretada, que cresce com o aumento do tempo de nitretação.

A camada de difusão de todas as amostras contém nitretos dispersos $\gamma^{\prime}$ (forma de agulhas), $\alpha$ " (forma de plaquetas), além dos poros intrínsecos advindos do processo de fundição, Figura 44.

Difração de raios $X$ - As análises de GAXD para os diferentes tempos de tratamento mostram que a camada superficial é constituida essencialmente de precipitados $\varepsilon-\mathrm{Fe}_{3} \mathrm{~N}$ e $\gamma^{\prime}-\mathrm{Fe}_{4} \mathrm{~N}$, não havendo evidências de reflexőes da matriz (essencialmente $\alpha-\mathrm{Fe}$ ), como nas amostras nitretadas a temperaturas menores que $500^{\circ} \mathrm{C}$. A camada de nitreto $\varepsilon$ é altamente texturizada ao longo da direção <002> com mistura da fase $\gamma^{\prime}$, para os tempos de nitretação $t<5$ h. Este comportamento é diferente para amostra nitretada por $6 \mathrm{~h}$, onde a orientação preferencial é encontrada na direção $<101>$. Com o aumento da temperatura de tratamento, outros picos da fase $\varepsilon$ começam a aparecer, tais como o (103), (102), (100), (200) e (201).

Os parâmetros de rede para a fase $\varepsilon$ obtidos nas amostras nitretadas nos tempos de 1 e $2 \mathrm{~h}$, Figura 45(a) e (b), a partir dos dados de raios $X$ são: $a=2,689(3) \AA, c=4,389(6) \AA$ e $a=2,698(3) \AA \quad c=4,380(5) \AA$, respectivamente, originando uma razão $c / a=1,63$. Utilizando a mesma correlação entre os parâmetros de rede e a quantidade de nitrogênio para as amostras nitretadas em diferentes temperaturas, determinou-se a estequiometria $\varepsilon-\mathrm{Fe}_{3,25} \mathrm{~N}$ para esta fase pobre em nitrogênio, confirmada pelas medidas de CEMS (Tabela XIV) que 
apresentaram uma porcentagem das áreas relativas de $83,5 \%$ para fase e $\gamma^{\prime}-\mathrm{Fe}_{4} \mathrm{~N}$, com menor concentração de nitrogênio.

Para tempos maiores que $T \geq 3 \mathrm{~h}$ os parâmetros de rede $a=2,703(2) \AA$ $c=4,386(4) \AA$ determinados resultaram em uma razão $c / a=1,622$ aproximada para todas as amostras, determinando uma estequiometria de $\varepsilon-\mathrm{Fe}_{3,25} \mathrm{~N}$, bem próxima a encontrada nas medidas de CEMS (Tabela XIV).

A Tabela XXI mostra a concentração de nitrogênio na superfície das amostras, medida a partir da determinação do parâmetro de rede da fase $\varepsilon$ pela difração de raios $X$, em função do tempo de nitretação.

Tabela XXI- Concentração de nitrogênio em função da temperatura de nitretação.

\begin{tabular}{|c|c|c|}
\hline $\begin{array}{c}\text { Tempo } \\
(\mathrm{h})\end{array}$ & $\begin{array}{c}\text { Concentração de Nitrogénio } \\
\mathrm{C}_{\mathrm{N}}(\text { at. } \%)\end{array}$ & $\begin{array}{c}\text { Parâmetro de Rede (a) } \\
(\mathrm{A})\end{array}$ \\
\hline 1 & $21,95(3)$ & $2,689(2)$ \\
\hline 2 & $23,16(4)$ & $2,698(2)$ \\
\hline $3,4,5 \mathrm{e} 6$ & $23,20(4)$ & $2,703(2)$ \\
\hline
\end{tabular}

CEMS - O espectro de CEMS de uma amostra nitretada por $1 \mathrm{~h}$, Figura 53(a) mostra a predominância da fase $\gamma^{\prime}-\mathrm{Fe}_{4} \mathrm{~N}$ (Tabela XIV), composta por três subespectros referentes aos sítios de ferro, sendo dois $\mathrm{Fe}(\mathrm{II})_{\mathrm{A}}$ e $\mathrm{Fe}(\mathrm{II})_{\mathrm{B}}$ com um campo hiperfino de $216 \mathrm{kOe}$ e o outro $\mathrm{Fe}_{\mathrm{l}}$ de $338 \mathrm{kOe}$. Também foi identificada a fase $\varepsilon$, com campos de 215 e $295 \mathrm{kOe}$, correspondendo aos nitretos $\mathrm{Fe}_{3} \mathrm{~N}$ e $\mathrm{Fe}_{3,2} \mathrm{~N}$, respectivamente, numa proporção menor do que a da fase $\gamma^{\prime}$. Também pode-se observar a presença de um sexteto referente ao $\alpha$-Fe pertencente ao substrato, indicando que a solubilidade do nitrogênio na amostra não foi total e outro subespectro referente a um dubleto com valor de $\Delta E_{Q}=0,99 \mathrm{~mm} / \mathrm{s}$ e $\delta=0.35 \mathrm{~mm} / \mathrm{s}$.

Aumentando-se o tempo de tratamento para $2 \mathrm{~h}$, Figura $53(\mathrm{~b})$, as fases encontradas neste espectro são basicamente as mesmas, ocorrendo apenas um decréscimo na área do subespectro $\alpha-\mathrm{Fe}$, indicando um pequeno aumento na 
solubilidade do nitrogênio na camada, bem como no subespectro referente ao sítio de ferro $\mathrm{Fe}_{1}(\mathrm{~A})$ da fase $\gamma^{\prime}-\mathrm{Fe}_{4} \mathrm{~N}$. Há também um sensível aumento nas áreas relativas a cada subespectro da fase $\varepsilon$, em relação à amostra nitretada durante 1 h.

Quando o tempo de nitretação foi de 3 h, Figura 53(c), as fases ainda permaneceram as mesmas. No entanto houve uma inversão nos valores das áreas relativas das fases $\gamma^{\prime}$ e $\varepsilon$, sendo que a fase preponderante agora é a $\varepsilon$. O dubleto desconhecido ainda aparece com $\Delta \mathrm{E}_{Q}=0,99 \mathrm{~mm} / \mathrm{s}$ e $\delta=0.35 \mathrm{~mm} / \mathrm{s}$. Já a fase $\alpha-F e$ desapareceu, indicando uma alta solubilidade do nitrogênio e o aumento da espessura da camada.

Para o tempo de nitretação igual a $4 \mathrm{~h}$, Figura $53(\mathrm{~d})$, os quatro sextetos da fase $\varepsilon$ e os dois da fase $\gamma^{\prime}$ fornecem um ajuste razoável. Contudo, um bom ajuste do espectro desta amostra só foi possivel com a inclusão do subespectro $\alpha-\mathrm{Fe}$ e do dubleto, $\Delta \mathrm{E}_{\mathrm{Q}}=0,99 \mathrm{~mm} / \mathrm{s}$ e $\delta=0,35 \mathrm{~mm} / \mathrm{s}$, mas com pequenos valores das áreas relativas $(\%)$, ver Tabela XIV. A maior contribuição para o espectro na amostra nitretada por $4 \mathrm{~h}$ vem dos subespectros, com um campo hiperfino de $236 \mathrm{kOe}$ e outro com $205 \mathrm{kOe}$, referentes à fase $\varepsilon-\mathrm{Fe}_{3,2} \mathrm{~N}$ e $\varepsilon-\mathrm{Fe}_{2,67} \mathrm{~N}$, mas com valor de área relativa menor do que da amostra com $3 \mathrm{~h}$ de tratamento, com relação à fase $\varepsilon-\mathrm{Fe}_{3,2} \mathrm{~N}$. A fase $\varepsilon-\mathrm{Fe}_{2,67} \mathrm{~N}$ que agora apareceu, pode ser interpretada como uma transição de fase para $\varepsilon-\mathrm{Fe}_{3} \mathrm{~N}$. Já o reaparecimento da fase $\alpha-\mathrm{Fe}$ é uma indicação de que a espessura da camada, para alguns pontos da amostra, é menor do que a penetração atingida pela técnica de CEMS (aproximadamente $0,3 \mu \mathrm{m}$ ), pois a análise metalográfica desta amostra mostrou falhas na camada nitretada.

Nitretando em tempos ainda maiores a fase $\left(\varepsilon-\mathrm{Fe}_{2,67} \mathrm{~N}\right)$ desaparece, confirmando o caráter de fase de transição. Como se pode ver na amostra nitretada 
com tempo de 5 h, Figura 53(e), o valor da área relativa do subespectro de campo hiperfino $236 \mathrm{kOe}$ e IS $=0,33 \mathrm{~mm} / \mathrm{s}$ da fase $\varepsilon-\mathrm{Fe}_{3,2} \mathrm{~N}$, volta a crescer.

Por último, tem-se a amostra que foi nitretada por 6h, Figura 53(f). Esta amostra apresentou um espectro de Mössbauer com predominância da fase $\varepsilon$, com aproximadamente $85 \%$ da área espectral relativa, de acordo com a tendência observada na amostra nitretada por $4 \mathrm{~h}$, Figura 71 . Os espectros de CEMS destas amostras confirmam as medidas de difração de raios $\mathrm{X}$ com incidência rasante, com parâmetros hiperfinos que podem ser atribuídos aos nitretos $\gamma^{\prime}-\mathrm{Fe}_{4} \mathrm{Ne} \varepsilon-\mathrm{Fe}_{3,2} \mathrm{~N}$.

A evolução dos nitretos de ferro com o aumento do tempo de tratamento pode ser representada também pelas análises Mössbauer, obtida pelas porcentagens das fases determinadas pelo refinamento dos espectros das amostras nitretadas em função do tempo, Figura 71. Utilizando o mesmo processo de análise nas medidas variando a temperatura de nitretação, a porcentagem da área espectral atribuído aos nitretos $\varepsilon-\mathrm{Fe}_{2,67} \mathrm{~N}, \varepsilon-\mathrm{Fe}_{3} \mathrm{~N}$ e $\varepsilon-\mathrm{Fe}_{3,2} \mathrm{~N}$ foram somadas e apresentadas como um nitreto $\varepsilon-\mathrm{Fe}_{\mathrm{x}} \mathrm{N}$. Os resultados da Figura 70 são consistentes com as medidas de GAXD com incidência rasante, com referência ao crescimento da fase $\varepsilon$.

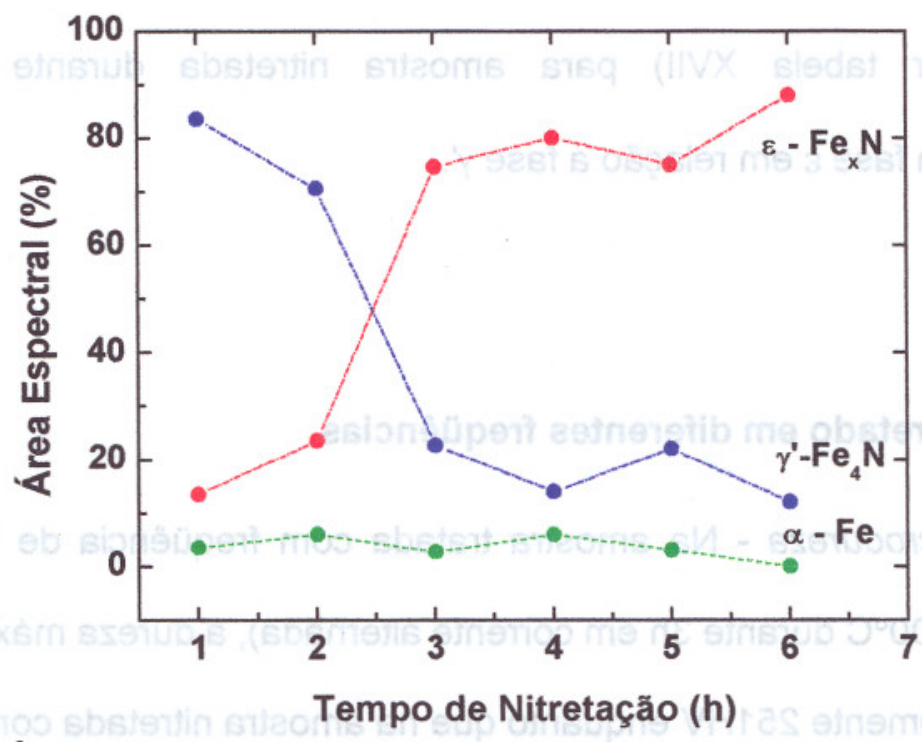

Figura 71 - Área espectral relativa de CEMS para as amostras nitretadas em corrente direta (DC), em diferentes tempos. 
As razões $\varepsilon / \gamma^{\prime}$ obtidas para CEMS, para os diferentes tempos de nitretação, indicam que a camada da fase $\gamma^{\prime}$ é mais espessa do que a de $\varepsilon$ até $t \leq 2 \mathrm{~h}$, quando há uma alteração em $t \geq 3$ h e a camada da fase $\varepsilon$ passa a ser mais espessa, como mostra a Figura 71. Este comportamento provavelmente pode ser explicado pela pequena concentração de nitrogênio para as amostras nitretadas em tempos menores que $2 \mathrm{~h}$ onde predomina a fase $\gamma^{\prime}$. Porém, quando $\mathrm{t} \geq 3 \mathrm{~h}$ há uma concentração maior de nitrogênio e a fase $\varepsilon$ é favorecida ${ }^{[5]}$ (ver Tabela XXI).

Desgaste seguido de CEMS - As análises dos espectros Mössbauer para os vários desgastes apresentam diferenças nas quantidades das fases presentes na camada nitretada. A concentração relativa das várias fases no ferro, em profundidades diferentes na camada de compostos, como pode ser visto na Tabela XVII, mostra que a quantidade da fase $\alpha$ aumenta com a profundidade, enquanto a quantidade do nitreto $\gamma^{\prime}$ decresce sensivelmente. Estes resultados mostram que a quantidade de nitrogênio na camada mais externa (superfície) é alta e decresce com a profundidade.

Os desgaste da camada nitretada dessas amostras apresentaram o mesmo comportamento observado na sistemática relativa à variação de temperatura (ver tabela XVII) para amostra nitretada durante $t=6 \mathrm{~h}$, com predominância da fase $\varepsilon$ em relação a fase $\gamma^{\prime}$.

\subsubsection{Fe nitretado em diferentes freqüências}

Microdureza - $\mathrm{Na}$ amostra tratada com freqüência de $10 \mathrm{kHz}$ (com temperatura de $500^{\circ} \mathrm{C}$ durante $3 \mathrm{~h}$ em corrente alternada), a dureza máxima atingida foi de aproximadamente $251 \mathrm{HV}$ enquanto que na amostra nitretada com freqüência de $2 \mathrm{kHz}$, a dureza máxima determinada foi de aproximadamente $330 \mathrm{HV}$. Voltando 
às micrografias das camadas nitretadas, assim como aos perfis de microdureza correspondentes, constata-se quase nenhuma diferença nas espessuras das camadas, como pode se ver na Figura 55.

Comparando os efeitos da freqüência na cinética de crescimento da camada de compostos é interessante observar a diminuição na espessura da camada com o aumento da freqüência, principalmente entre as amostras nitretadas com 2 e $4 \mathrm{kHz}$. Uma possível explicação é que o bombardeamento pulsado da superficie, para a amostra nitretada com freqüência de $2 \mathrm{kHz}$ é que o tempo em que o plasma fica ligado e portanto, bombardeando a superfície, é maior do que para amostra nitretada com freqüências iguais ou maiores que $4 \mathrm{kHz}$, e por conseqüência, a absorção do nitrogênio na superfície é maior, como mostra a Tabela XXII.

Metalografia - Analisando as micrografias eletrônicas, podem ser observados aspectos microestruturais das camadas nitretadas. Três regiōes podem ser observadas na Figura 56(a): uma região compacta, constituida de uma mistura de $\varepsilon+\gamma^{\prime}$ na camada de compostos, seguida por uma zona de transformação austenitica e finalmente uma camada de difusão de nitrogênio adjacente ao substrato. As Figuras 56(b), (c), (d) e (e) apresentam duas regiōes distintas. A primeira é a camada de compostos, constituída pela mistura de $\varepsilon+\gamma^{\prime}$. A segunda, continuação dessa primeira, estende-se até a matriz e é denominada camada de difusão. Comparando-se estas camadas com aquela da Figura 43(c), com plasma em corrente direta $\left(T=500^{\circ} \mathrm{C}\right.$ e $\left.t=3 \mathrm{~h}\right)$, observa-se o mesmo aspecto microestrutural das camadas como as da Figura 56(a). Uma razão para esta semelhança é que a variação da taxa de bombardeamento no plasma pulsado (com freqüência de $2 \mathrm{kHz}$ ), não seja suficiente para provocar mudanças consideráveis em relaçăo ao plasma em corrente direta. Quando se aumenta a freqüência do plasma, a área de transformação austenítica desaparece, como mostrado nas Figuras 56(b), (c), (d) e 
(e), ou seja, quando há um decréscimo da taxa de bombardeamento. 0 aspecto típico microestrutural das camadas nitretadas, para as freqüências de 4, 6, 8 e $10 \mathrm{kHz}$, não apresenta modificação apreciável que se possa atribuir aos parâmetros do processo.

Difração de raios $X$ - As análises de GAXD das camadas superficiais nitretadas consistem essencialmente de $\varepsilon-\mathrm{Fe}_{3} \mathrm{~N}$ e $\gamma^{\prime}-\mathrm{Fe}_{4} \mathrm{~N}$. Todas as amostras nitretadas em diferentes freqüências apresentam uma orientação preferencial ao longo da direção <002>. As reflexões da fase $\gamma^{\prime}$ estão presentes em todos os espectros (Figura 57) e crescem com o aumento da freqüência. Portanto, a contribuição da fase $\gamma^{\prime}$ é mais significativa para a frequêencia de $10 \mathrm{kHz}$.

Os parâmetros de rede para a fase $\varepsilon$ obtidos nas amostras nitretadas nas freqüências de 2 e $4 \mathrm{kHz}$, Figura $57(a)$ e (b), a partir dos dados de raios $X$ são: $a=2,704(2) \AA, c=4,380(6) \AA$ e $a=2,703(3) \AA c=4,382(6) \AA$, respectivamente, dando uma razão $c / a=1,621$. Analogamente ao que foi calculado na seção 7.1.1, encontrou-se a estequiometria $\varepsilon-\mathrm{Fe}_{3,10} \mathrm{~N}$ para esta fase, confirmada pelas medidas de CEMS (Tabela XVI) que apresentaram uma porcentagem das áreas relativas dos nitretos $\varepsilon-\mathrm{Fe}_{3} \mathrm{~N}$ e $\varepsilon-\mathrm{Fe}_{3,2} \mathrm{~N}$, aproximadamente. Para freqüências maiores que $4 \mathrm{kHz}$, a razão cla também aumentou para um valor de $1,623(a=2,702(2) \AA$ $c=4,386(6) \AA$, correspondente a uma concentração entre a quantidade de átomos de ferro e nitrogênio na fase $\varepsilon$ com estequiometria de $\mathrm{Fe}_{3,3} \mathrm{~N}$.

A Tabela XXII mostra a concentração de nitrogênio na superfície das amostras, calculada de maneira análoga à da seçăo 7.1 , a partir da determinação do parâmetro de rede da fase $\varepsilon$ pela difração de raios $X$, em função da freqüência do plasma. 
Tabela XXII - Concentração de nitrogênio em função da freqüência de nitretaçăo, determinados pela expressăo dada na referencia [77, 78].

\begin{tabular}{|c|c|c|}
\hline $\begin{array}{c}\text { Freqüência } \\
(\mathbf{k H z})\end{array}$ & $\begin{array}{c}\text { Concentração de Nitrogênio } \\
\mathbf{C}_{\mathbf{N}}(\mathbf{a t} . \%)\end{array}$ & Parâmetro de Rede a (A) \\
\hline 2 & $23,96(6)$ & $2,704(2)$ \\
\hline 4 & $23,82(8)$ & $2,703(3)$ \\
\hline 6,8 e 10 & $23,69(6)$ & $2,702(2)$ \\
\hline
\end{tabular}

CEMS - As medidas de CEMS são consistentes com as de GAXD.

Os espectros Mössbauer das amostras, variando a freqüência, apresentaram também, como nas outras sistemáticas, uma mistura de várias fases, tendo $\varepsilon$ e $\gamma^{\prime}$ como fases preponderantes. Outra fase encontrada consiste de dubleto com $\delta$ variando de $0,30 \mathrm{~mm} / \mathrm{s}$ a $0,35 \mathrm{~mm} / \mathrm{s}$ e $\Delta E_{Q}$ de $0,92 \mathrm{~mm} / \mathrm{s}$ a $1,11 \mathrm{~mm} / \mathrm{s}$, atribuída a uma fase metaestável de $F e_{1+x} N(x<1)^{[42]}$.

A evolução do nitreto de ferro, apresentada pelo gráfico da área espectral como função da freqüência de nitretação, é mostrada na Figura 72. Usando o mesmo processo de análise utilizado nas medidas variando a temperatura de nitretação a porcentagem da área espectral atribuído aos nitretos $\varepsilon$ $\mathrm{Fe}_{2,67} \mathrm{~N}, \varepsilon-\mathrm{Fe}_{3} \mathrm{~N}$ e $\varepsilon-\mathrm{Fe}_{3,2} \mathrm{~N}$ foram somadas e apresentadas como um nitreto $\varepsilon-\mathrm{Fe} \times \mathrm{N}$. Quanto ao decréscimo da área espectral da fase $\varepsilon$, observada na Figura 72 a explicação para este comportamento seria no baixo potencial de nitretação ${ }^{[85]}$, que favorece a formaçăo da fase $\gamma^{\prime}$. 


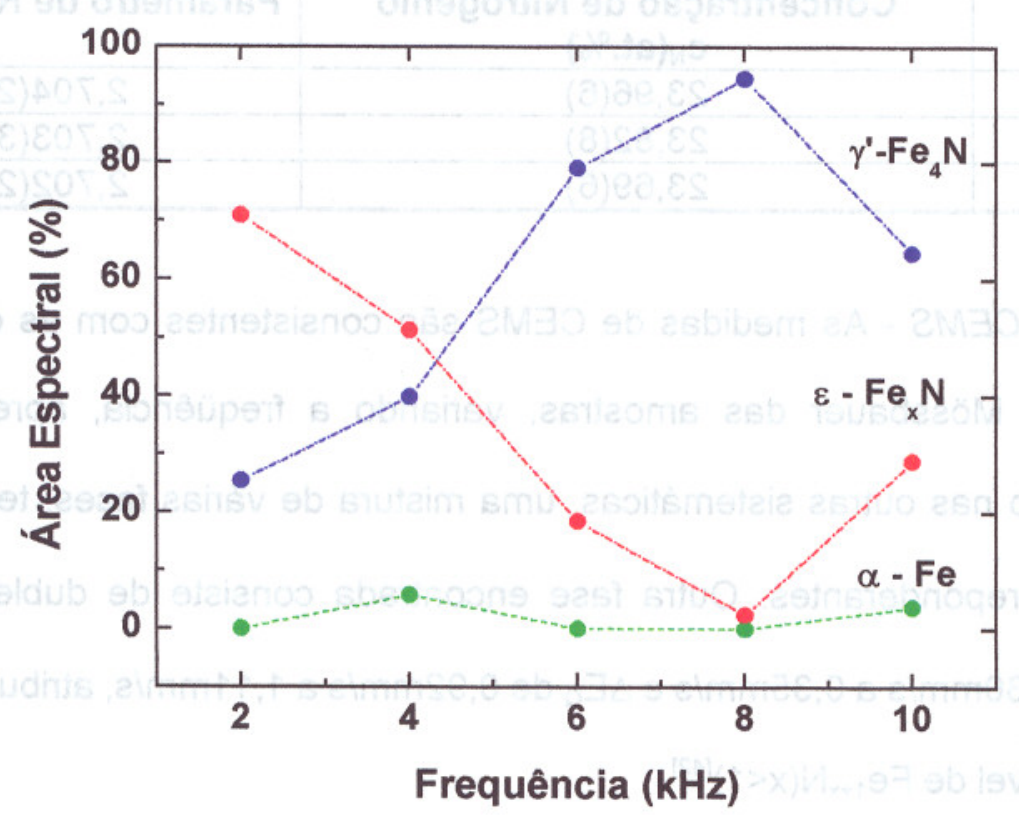

Figura 72 - Área espectral relativa de CEMS para as amostras nitretadas em corrente alternada, com diferentes freqüências.

Desgaste seguido de CEMS - Na Figura 59(a) - (d) estão apresentados os espectros de CEMS da camada superficial e depois dos desgastes de 5,10 e $50 \mu \mathrm{m}$, do ferro nitretado em corrente alternada com freqüência de $2 \mathrm{kHz}$, respectivamente. A figura 59(b) apresenta uma camada constituída principalmente da fase $\varepsilon$. A Figura 58(c) mostra o espectro depois da remoção de $10 \mu \mathrm{m}$, referente à zona de transformação, formada principalmente da fase $\varepsilon$, com uma pequena quantidade de $\alpha-\mathrm{Fe}, \mathrm{Fe}_{1+x} \mathrm{~N}(x<1)$ e $\gamma^{\prime}-\mathrm{Fe}_{4} \mathrm{~N}$. Finalmente, o espectro referente à matriz do $\alpha-\mathrm{Fe}$, após a remoção de $50 \mu \mathrm{m}$, Figura 59(d). Através dos ajustes destes espectros pode se observar, de maneira análoga, espectros das amostras nitretadas em diferentes temperaturas e tempos, $O$ aumento da fase $\varepsilon$ com a profundidade, Tabela XVII. Este comportamento repete-se para amostras de ferro nitretadas com freqüência de $10 \mathrm{kHz}$, como pode ser verificado na Tabela XVIII, referente aos espectros da figura 60 . 


\subsection{ANÁLISES DOS RESULTADOS DAS AMOSTRAS DO AÇO AISI H12}

Analisando os difratogramas de raios $\mathrm{X}$ conclui-se que a espessura da camada de compostos efetiva é maior que o alcance efetivo sondado pela radiação do $\mathrm{CuK \alpha}{ }^{[89]}$, aproximadamente de $10 \mu \mathrm{m}$. A camada de compostos consiste essencialmente de $\varepsilon-\mathrm{Fe}_{2-3}(\mathrm{C}, \mathrm{N})$ e $\gamma^{\prime}-\mathrm{Fe}_{4} \mathrm{~N}$. A camada de carbonitretos $\varepsilon$ é altamente texturizada na direção <101> para a amostra nitretada por $1 \mathrm{~h}$, mas mostra um claro caráter policristalino para tempos de nitretação crescentes. As reflexões $\gamma^{\prime}$ estão virtualmente ausentes do difratograma da amostra nitretada por 1h e aparecem e crescem monotonicamente com o aumento do tempo de nitretação, Figura 61. Este comportamento é um pouco diferente do encontrado para as amostras nitretadas em corrente alternada. Como pode se ver na Figura 62 , a intensidade normalizada da reflexão $\varepsilon\{100\}$ para amostra nitretada por $1 \mathrm{~h}$ de é aproximadamente $70 \%$ da que foi medida para a amostra nitretada durante $6 \mathrm{~h}$. Portanto, para o passo inicial do processo de nitretação, a contribuição da componente $\gamma^{\prime}$ é mais significativa para as amostras nitretadas em corrente alternada do que para as nitretadas em corrente direta.

Os difratogramas mostrados nas Figuras 61 e 62 sugerem que a situação é revertida após $4 \mathrm{~h}$. Esta tendência pode ser melhor apreciada pelas medidas de difração de raios $X$ com ângulo de incidência rasante, como mostrada claramente na Figura 63, para amostras nitretadas durante $6 \mathrm{~h}$. A intensidade normalizada de $\gamma^{\prime}\{200\}$ é de 0,17 para as amostras nitretadas em corrente alternada e 0,29 para as nitretadas em corrente direta.

Os espectros de CEMS para as amostras do aço AISI H12 sem nitretação confirmam as medidas de difração de raios $X$ (DRX) com os parâmetros hiperfinos, e podem ser atribuídos à martensita $\alpha^{\prime}-(\mathrm{Fe}, \mathrm{C}, \mathrm{N})^{[90]}$. Os espectros de CEMS mostrados na Figura 63 foram ajustados pela adição de subespectros 
correspondentes a $\alpha^{\prime}, \gamma^{\prime}, \varepsilon_{3}$ e $\varepsilon_{x}$, com parâmetros hiperfinos apresentados na Tabela $X I X$, os quais são bastante similares aos previamente publicados ${ }^{[58,59,61,62,63,64,91]}$.

O subespectro $\varepsilon_{3}$ representa o carbonitreto $\varepsilon-\mathrm{Fe}_{3,2}(\mathrm{C}, N)$, enquanto que $\varepsilon_{x}$ corresponde a $\varepsilon-F e_{x}(C, N)$, com $2 \leq x \leq 3,2$. Um ajuste típico de um subespectro é ilustrado na Figura 45, para uma amostra nitretada durante $1 \mathrm{~h}$. Estes espectros foram ajustados com $30 \%$ de $\alpha^{\prime}, 30 \%$ de $\gamma^{\prime}, 33 \%$ de $\varepsilon_{3}$ e $7 \%$ de $\varepsilon_{x} .0$ espectro de CEMS para uma amostra nitretada em corrente alternada, Figura 63, consiste de $31 \%$ de $\alpha^{\prime}, 20 \%$ de $\gamma^{\prime}, 33 \%$ de $\varepsilon_{3}$ e $16 \%$ de $\varepsilon_{x}$. Para tempos de nitretação $t \geq 2 h$, todos os espectros de CEMS são semelhantes em ambos os processos. Diferenças secundárias, como mostradas pelas áreas espectrais relativas, só podem ser discriminadas pelos procedimentos de ajuste. Estas tendências são também observadas nas medidas de CXMS, como pode se visto nas Tabelas XXIII e XXIV.

Tabela XXIII - Áreas espectrais relativas de CEMS e CXMS para amostras nitretadas nas condições de corrente direta.

\begin{tabular}{|c|c|c|c|c|c|c|}
\hline $\begin{array}{c}\text { Tempo de } \\
\text { nitretação } \\
\text { (h) }\end{array}$ & $\begin{array}{c}\alpha^{\prime} \\
\text { CEMS/ } \\
\text { CXMS }\end{array}$ & $\begin{array}{c}\alpha^{\prime \prime} \\
\text { CEMS/ } \\
\text { CXMS }\end{array}$ & $\begin{array}{c}\gamma \\
\text { CEMS/ } \\
\text { CXMS }\end{array}$ & $\begin{array}{c}\gamma^{\prime} \\
\text { CEMS/ } \\
\text { CXMS }\end{array}$ & $\begin{array}{c}\varepsilon_{32} \\
\text { CEMS/ } \\
\text { CXMS }\end{array}$ & $\begin{array}{c}\varepsilon_{x}(x<3.2) \\
\text { CEMS/ } \\
\text { CXMS }\end{array}$ \\
\hline 1 & $30 / 49$ & $0 / 13$ & $0 / 5$ & $30 / 4$ & $33 / 19$ & $8 / 10$ \\
\hline 2 & $14 /--$ & $0 /--$ & $0 /--$ & $23 /--$ & $54 /--$ & $9 /--$ \\
\hline 3 & $12 / 42$ & $0 / 6$ & $0 / 0$ & $25 / 12$ & $54 / 34$ & $9 / 7$ \\
\hline 4 & $12 / 39$ & $0 / 5$ & $0 / 2$ & $25 / 10$ & $53 / 37$ & $10 / 7$ \\
\hline 5 & $--/ 42$ & $--/ 8$ & $--/ 3$ & $--/ 13$ & $--/ 29$ & $--/ 5$ \\
\hline 6 & $7 /--$ & $0 /--$ & $0 /--$ & $35 /--$ & $51 /--$ & $7 /--$ \\
\hline
\end{tabular}


Tabela XXIV - Áreas espectrais relativas de CEMS e CXMS para amostras nitretadas nas condições de corrente alternada.

\begin{tabular}{|c|c|c|c|c|c|c||}
\hline $\begin{array}{c}\text { Tempo de } \\
\text { nitretação } \\
(\mathrm{h})\end{array}$ & $\begin{array}{c}\alpha^{\prime} \\
\text { CEMS/ } \\
\text { CXMS }\end{array}$ & $\begin{array}{c}\alpha^{\prime \prime} \\
\text { CEMSI } \\
\text { CXMS }\end{array}$ & $\begin{array}{c}\gamma \\
\text { CEMSI } \\
\text { CXMS }\end{array}$ & $\begin{array}{c}\gamma^{\prime} \\
\text { CEMS/ } \\
\text { CXMS }\end{array}$ & $\begin{array}{c}\varepsilon_{3.2} \\
\text { CEMS/ } \\
\text { CXMS }\end{array}$ & $\begin{array}{c}\varepsilon_{\mathrm{x}}(\mathrm{x}<3.2) \\
\text { CEMS/ } \\
\text { CXMS }\end{array}$ \\
\hline 1 & $30 / 48$ & $0 / 10$ & $0 / 4$ & $20 / 7$ & $33 / 26$ & $16 / 5$ \\
\hline 2 & $10 /--$ & $0 /--$ & $0 /--$ & $19 /--$ & $64 /-$ & $7 /--$ \\
\hline 3 & $7 / 40$ & $0 / 9$ & $0 / 2$ & $21 / 7$ & $66 / 35$ & $6 / 7$ \\
\hline 4 & $11 / 0$ & $0 /--$ & $0 /--$ & $25 /--$ & $54 /--$ & $10 /--$ \\
\hline 5 & $--/ 40$ & $--/ 10$ & $--/ 2$ & $--/ 11$ & $--/ 33$ & $--/ 4$ \\
\hline 6 & $5 /--$ & $0 /--$ & $0 /--$ & $24 /--$ & $61 /--$ & $11 /--$ \\
\hline
\end{tabular}

A perspectiva geral da evolução de camada de compostos é ilustrada através do gráfico das áreas espectrais relativas, (ver Tabela XXIII), como uma função do tempo de nitretação. A Figura 73, das amostras nitretadas em corrente alternada juntamente com a Figura 74 das amostras nitretadas em corrente contínua são consistentes com as medidas de difração de raios $x$ na qual concordam com o crescimento da camada de compostos com o tempo de nitretação. Por exemplo, a área espectral relativa atribuída a $\varepsilon_{3,2}+\varepsilon_{x}$ (referente a fase $\varepsilon$ nas Figuras 73 e 74 ) conta com $49 \%$ do espectro total da amostra $A C$ e $40 \%$ da DC, em acordo com a Figura 61 e 62 . Além de que as amostras DC apresentam um aumento notável da componente $\gamma^{\prime}$ (ver Figura 74) para tempos de nitretação $\mathrm{t}>3 \mathrm{~h}$, confirmando os resultados mostrados na Figura 63. 


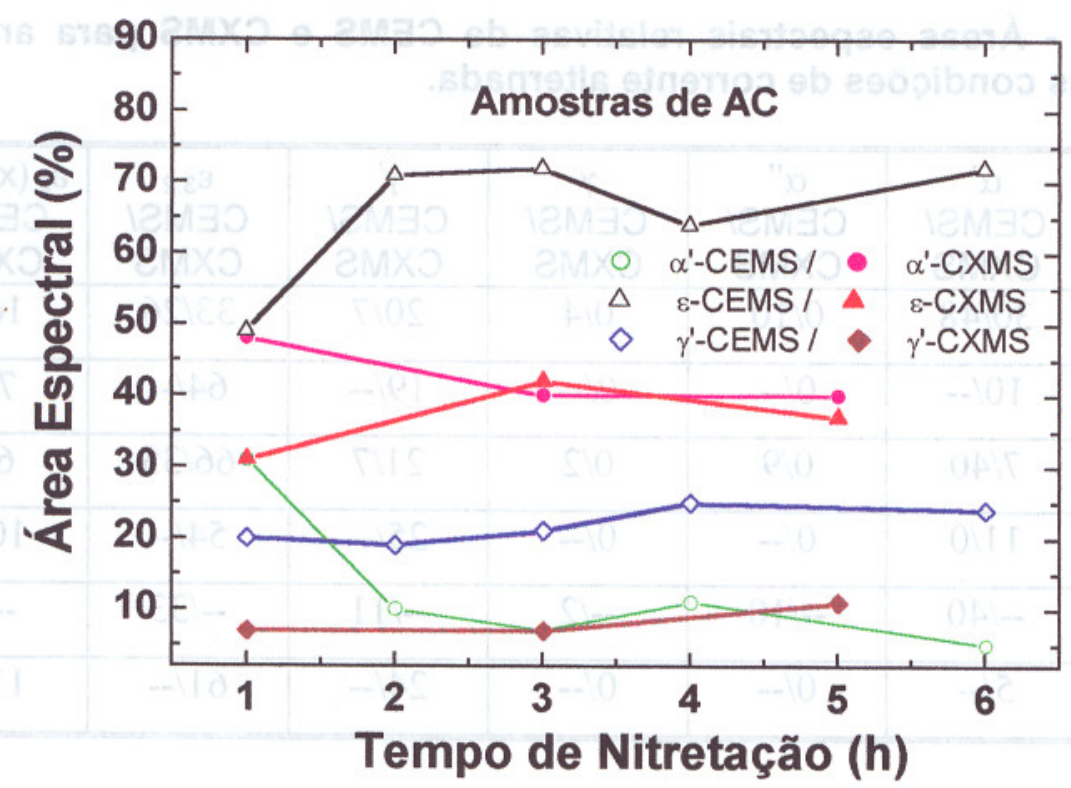

Figura 73 - Áreas espectrais relativas para os espectros de CEMS (símbolos abertos) e CXMS (símbolos fechados) de amostras em corrente alternada (AC).

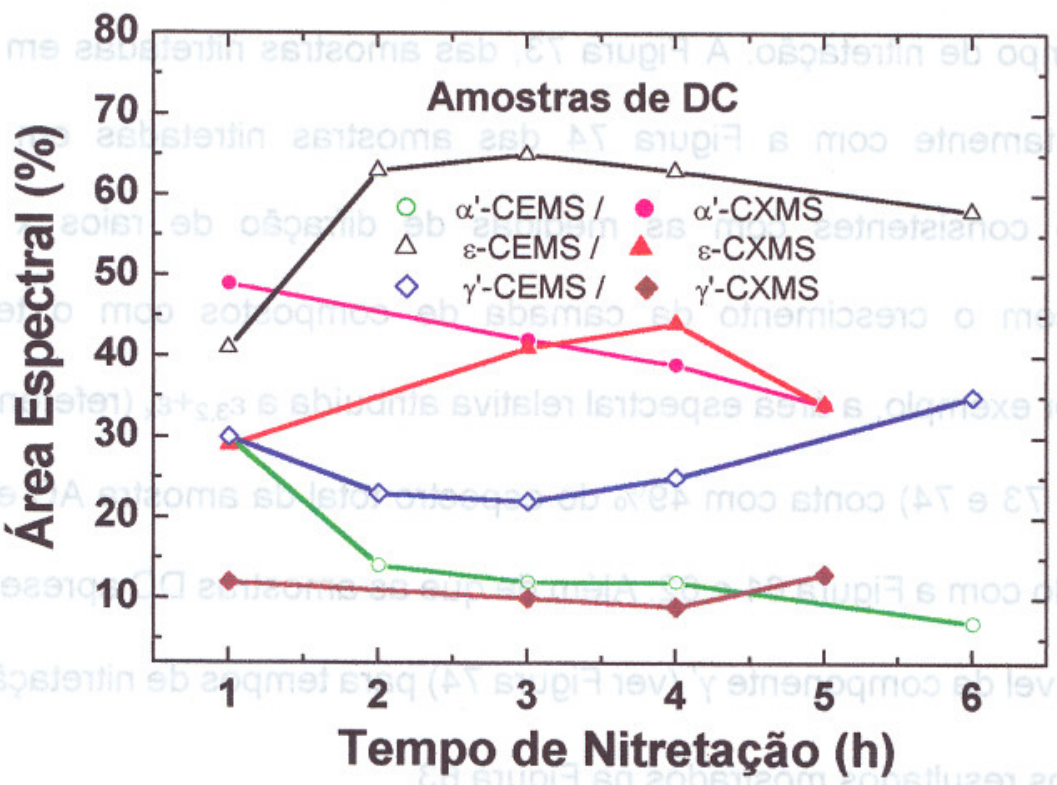

Figura 74 - Áreas espectrais relativas para os espectros de CEMS (símbolos abertos) e CXMS (símbolos fechados) da amostra em corrente direta (DC).

A presença do carbono na matriz do aço, em adição ao aumento da concentração devido à contaminação do tratamento, pode induzir à formação precipitados $\theta-\mathrm{Fe}_{3} \mathrm{C}$. Os parâmetros desta fase ${ }^{[92]}$ foram utilizados no ajuste dos espectros de CXMS, mas foram logo descartados, pois não deu ajuste. Como 
esperado, precipitados de $\alpha$ "- $\mathrm{Fe}_{16} \mathrm{~N}_{2}$ foram observados nos espectros de CXMS, como uma conseqüência do resfriamento lento. Nas discussões abaixo, a pequena área espectral atribuída ao nitreto $\alpha "-\mathrm{Fe}_{16} \mathrm{~N}_{2}$ năo foi considerada. As medidas de CXMS têm também sugerido a existência de pequenas quantidades de austenita $\gamma$ próxima à camada de difusão. $O$ dubleto quadrupolar presente no espectro de CXMS tem sido observado no ferro submetido a sucessivas implantações de nitrogênio e carbono, mas não foi atribuído a nenhum nitreto ou carboneto conhecido $^{[62]}$. Foram propostos um dubleto e um singleto com $\delta_{\mathrm{Fe}_{\theta}}=-0,12 \mathrm{~mm} / \mathrm{s}$ atribuídos à austenita, contendo carbono e nitrogênio. Fora das condições de equilíbrio, a formação de uma fase austenítica não é possível abaixo de $567^{\circ} \mathrm{C}$. Contudo, tanto a nitretação por plasma, como a implantação iônica, são tratamentos não constantes (equilibrados). Em um trabalho prévio, Kurny ${ }^{[81]}$ explicou a formação da austenita durante a nitretação do ferro ARMCO, considerando a possibilidade de difusão do nitrogênio da fase $\gamma^{\prime}$ supersaturada para a matriz $\alpha$, que fica muito rica em nitrogênio e eventualmente transforma-se em austenita. É interessante notar que as condições experimentais usadas por esses autores são bem parecidas com utilizadas neste trabalho. A austenita de Fe-N foi também observada no aço $38 \mathrm{NCD} 4^{[93]}$ e no ferro, implantados com nitrogênio ${ }^{[94]}$.

Além da proposta de Kurny acima, um outro mecanismo plausivel pode ser associado ao aquecimento localizado induzido pelo bombardeamento iônico de alta energia, elevando a temperatura local acima da média do valor medido pelo termopar. A formação da austenita tem sido atribuida a este mecanismo, em materiais implantados com nitrogênio ${ }^{[93]}$. A regiăo rica de carbono, próxima à camada de difusão pode se comportar localmente como um aço alto carbono. Assim, depois da sua formação, por um ou outro mecanismo descrito acima, a austenita pode ser retida à temperatura ambiente, devido à grande 
quantidade de carbono presente. Infelizmente, a austenita é observada em pequena quantidade, que está abaixo do limite de detecção do DRX. A austenita é detectada pelas medidas Mössbauer, pois é uma componente paramagnética, com subespectros compostos de um dubleto e um singleto, que pode ser facilmente distinguida dos sextetos magnéticos de outras componentes.

Dentro das limitações experimentais, todas estas técnicas fornecem perfis de profundidade semelhantes. A espessura da camada de compostos pode ser estimada da Figura 66, pela avaliação visual. Por outro lado, a espessura do "hard case" pode ser estimada dos perfis de microdureza, assumindo arbitrariamente $800 \mathrm{HV}$ como a mínima dureza da camada nitretada. A dureza do aço $\mathrm{H}-12$ temperado, antes de nitretado é de $600 \pm 50 \mathrm{HV}$. Como ilustrado na Figura 66, a espessura do "hard case" é de aproximadamente $45 \mu \mathrm{m}$ para as amostras nitretadas em corrente direta durante $3 \mathrm{~h}$ e de $85 \mu \mathrm{m}$ para as nitretadas durante $4 \mathrm{~h}$. As espessuras das camadas composta e do "hard case", como uma função do tempo de nitretação, são mostradas na Figura 75 , para todas as amostras em corrente direta e corrente alternada. As semelhanças entre as curvas são notáveis. Para tempos de nitretação $t \leq 3 \mathrm{~h}$ a espessura da camada de compostos e do "hard case" em corrente alternada são mais espessas do que em corrente direta, enquanto que o inverso é verdadeiro para tempos de nitretação maiores do que $3 \mathrm{~h}$. Este comportamento é apoiado pelas medidas de microanálise eletrônica. Como pode se ver na Figura 68, a espessura do perfil da amostra nitretada em DC, com tempo de nitretação de $4 \mathrm{~h}$, é maior do que a da amostra em corrente alternada, enquanto que dentro do erro experimental, é semelhante ao tempo de nitretação de $3 \mathrm{~h}$.

As medidas do perfil de carbono foram realizadas, mas o grande espalhamento dos dados não permite estabelecer uma interpretação conclusiva. No interior da Figura 68 está apresentado um dos perfis mais regulares do carbono 
obtidos. Apesar do espalhamento e da falta de reprodutibilidade do padrão, todos os perfis de carbono mostram esta mesma tendência.

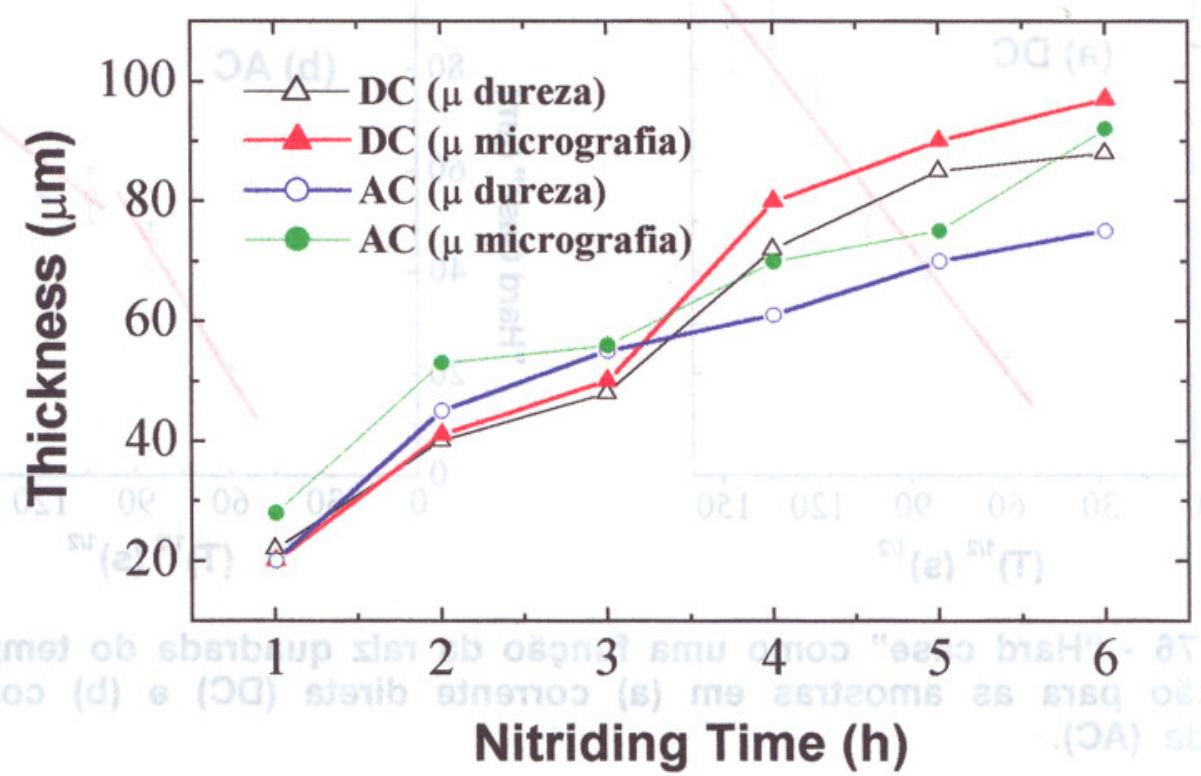

Figura 75 - Espessura da camada de compostos e do "Hard case" como uma função do tempo de nitretação para as amostras em corrente direta (DC) e corrente alternada (AC).

O "hard case", como uma função da raiz quadrada do tempo de nitretação, mostrada na Figura 76, representa a cinética de crescimento da camada de compostos, para as amostras tratadas em corrente direta e corrente alternada. A curva da Figura 76(a) obedece à lei parabólica, embora a tendência de saturação seja sugerida para tempos de nitretação $t>5$ h. A curva da Figura 76 (b) é claramente derivada da lei parabólica. O crescimento da camada de compostos das amostras (AC) acontece em passos com diferentes cinéticas. No estágio inicial ( $t<3 \mathrm{~h})$ a taxa de crescimento da camada de compostos é maior do que no estágio final ( $t>2 h)$. Resultados similares foram relatados em vários trabalhos utilizando nitretação por

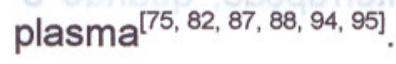



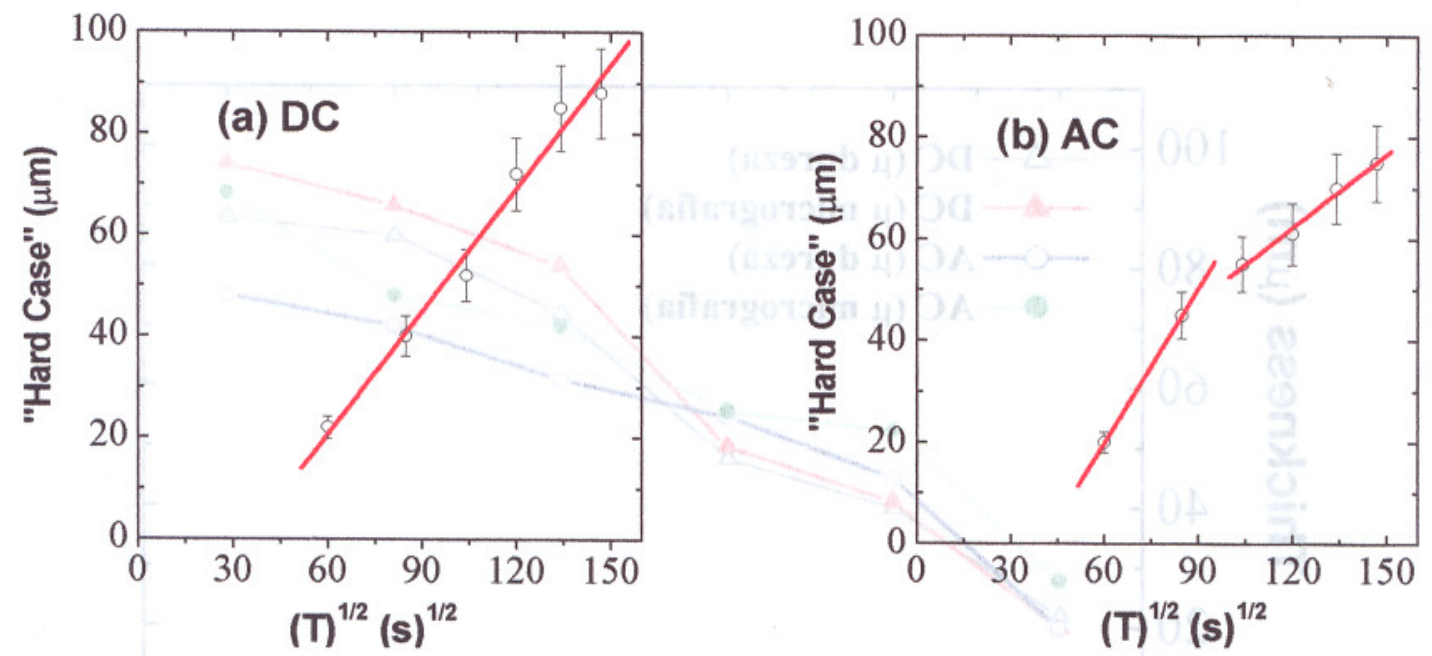

Figura 76 - "Hard case" como uma função da raiz quadrada do tempo de nitretação para as amostras em (a) corrente direta (DC) e (b) corrente alternada (AC).

As medidas de espectroscopia Mössbauer e de difração de raios $X$ estão inteiramente consistentes com a composição química das camadas nitretadas próximas à superfície, embora alguns detalhes em particular são discriminados em cada uma das técnicas. Por exemplo, o crescimento do carbonitreto $\varepsilon$ na camada é claramente indicado pela difração de raios $X$, para amostras nitretadas durante $1 \mathrm{~h}$ em corrente direta, enquanto que para corrente alternada, uma camada policristalina, incluindo uma orientação fortuitamente cristalina é fortemente sugerida (ver Figura 61 e 62). Amostras preparadas em diferentes grupos apresentaram sistematicamente este tipo de comportamento, que parece ser um fenômeno dependente do processo. Uma possível explicação pode ser o bombardeamento continuo da superfície pelos ions energéticos, que ocorre quando o plasma em corrente direta é usado, comparado com a interrupção, quando o plasma pulsado é usado. Assim, o carbonitreto $\varepsilon$ da camada externa é continuamente bombardeado durante o processo em corrente direta e para tempos 
menores que $1 \mathrm{~h}$ a camada permanece fina, favorecendo a retenção da textura ou da orientaçăo preferencial <101>. Para tempos maiores, a camada de carbonitreto $\varepsilon$ é espessa o suficiente e a textura é destruída. Pelo contrário, para o processo em corrente alternada o bombardeamento iônico é essencialmente limitado pelo ciclo de trabalho. Enquanto isso, a nitretação é sustentada pelas espécies ativas ${ }^{[96]}$, e o crescimento da camada de compostos externa destrói a textura <101>, até mesmo para tempos de nitretação menores.

As medidas de Mössbauer também enfatizam alguns aspectos não sugeridos pelas medidas de difração de raios $X$. Por exemplo, baseado nos dados de difração de raios $X$ não é possível discriminar os precipitados $\varepsilon-F e_{x}(C, N)$ com diferentes estequiometrias. Contudo, como estes carbonitretos são metaestáveis, apresentando diferentes parâmetros hiperfinos, principalmente campos hiperfinos diferentes, fica fácil discriminá-los pelos ajustes dos espectros Mössbauer, como mostrado na Figura 46. $O$ propósito principal aqui não é o de distinguir entre diferentes carbonitretos $\varepsilon$, mas comparar a dependência das áreas espectrais relativas de $\varepsilon$ (isto é $\varepsilon_{x}+\varepsilon_{3,2}$ ) e $\gamma^{\prime}$, nas condições de nitretação em corrente direta e corrente alternada.

Como mostrada nas Figuras 73 e 74, a razão da área espectral CEM $\varepsilon / \gamma^{\prime}$ para amostra nitretada a $t=1 \mathrm{~h}$ é de aproximadamente 2,5 para amostras nitretadas em corrente alternada (AC) e 1,3 para amostras nitretadas em corrente direta (DC). Portanto, a camada $\varepsilon$ na amostra nitretada em corrente alternada é muito mais espessa do que em corrente direta, confirmando o argumento utilizado na discussão da textura $\langle 101\rangle$, observada na medida de difração de raios $X$. Comparando os efeitos dos processos DC e $A C$, no crescimento cinético da camada de compostos, é interessante observar a evoluçăo da camada $\gamma^{\prime}$. A área espectral de $\gamma^{\prime}$ é aproximadamente constante, entre 20 e $25 \%$, para espectros 
CEMS e entre 8 e $10 \%$ para espectros CXMS, para todas as amostras AC, enquanto varia consideravelmente, como função do tempo de nitretação, para as amostras DC. A Figura 74 mostra uma tendência de crescimento de $\gamma^{\prime} e$ um decréscimo de $\alpha^{\prime}$ para espectros de CXMS. Este comportamento sugere que a camada de compostos em $D C\left(\varepsilon+\gamma^{\prime}\right)$ é mais espessa do que em $A C$, para tempos de nitretação $\mathbf{t}>4 h$, em acordo com a Figura 75.

Como esperado, os perfis de nitrogênio são inteiramente consistentes com as medidas de microscopia ótica e microdureza, Figuras 66, 67, 68 e 75. Diferentemente, as medidas dos perfis de carbono foram bastante dispersas, para todas as amostras, referente às regiões ricas em carbono observadas próximas à interface camada de compostos/matriz do aço, como ilustrado na Figura 68 . Em adição ao carbono pré-existente na matriz do aço, resíduos de moléculas de gás na câmara de vácuo, durante a preparação da amostra, bem como o carbono que permanece depois do polimento mecânico, são os principais fatores responsáveis pela contaminação de carbono próximo da superficie. Tal contaminação tem sido descrita durante a implantação do Ti por Singer ${ }^{[97]}$. Portanto, enquanto o perfil de nitrogênio para amostras equivalentes de grupos diferentes é quase o mesmo, o perfil de carbono parece depender fortemente de algumas condições de preparação.

De acordo com o modelo de Sun and Bell ${ }^{[98]}$ a explicação da descarbonetação da região próxima da superficie e o enriquecimento de carbono na frente de nitretação por plasma está nas tensões provocadas pelo nitrogênio na camada nitretada, causando a redistribuição do carbono. Os átomos de carbono no aço difundem-se para regiões livres de tensões, isto é, para a superfície e para a camada de difusão.

Comportamento cinético - Os resultados mostrados na Figura 75 podem ser explicados através de dois mecanismos competitivos que ocorrem no 
processo de nitretação por plasma (DC e AC). São eles: a "Sputtering Rate" $(S R)^{[89]}$ e a "Radiation-Enhanced Diffusion" (RED) ${ }^{[100,101]}$. Espera-se que o SR seja mais importante do que RED, devido à camada de defeitos formada no interior da camada "sputtering". Em conseqüência da continuidade do bombardeamento iônico, SR e RED são mais significativos em DC do que em AC. Portanto, a superfície da amostra DC é mais extensivamente bombardeada do que a da amostra AC e por esta razão, a camada de compostos AC é mais espessa do que a $D C$, para tempos menores que $3 \mathrm{~h}$.

Com o aumento do tempo de nitretaçăo, o mecanismo RED começa a ser mais importante, pois a camada de defeitos se difunde, escapando dos efeitos de "sputtering". Em tal condição, a camada de compostos no processo de nitretaçăo em DC cresce mais rapidamente do que uma AC. Para um aumento maior para o tempo de nitretação (tsat), os efeitos de SR e RED tornam-se equivalentes ${ }^{[102]}$ e a saturação global é atingida. A figura 75 sugere que $t_{\text {sat }} \geq 6 \mathrm{~h}$ para a nitretação em CC e $t_{\text {sat }}>6$ hara a nitretação AC. Da simulação da formação de nitretos de ferro durante a nitretação por plasma do $\alpha-F e$, foi obtido que a $t_{\text {sat }} \cong 4 h^{[95]}$. Considerando o efeito do substrato no crescimento da camada de compostos, a simulação ajusta muito bem aos resultados experimentais obtidos. $O$ tempo de saturaçăo da Figura 75 é também bastante similar ao que foi publicado para o aço usado por Albarran $^{[75]}$.

As transições de regime de taxa alta de crescimento da camada nitretada para uma mais baixa correspondem ao momento ao qual o SR torna-se mais significativo para as amostras AC. Parece que a ausência do regime de taxa alto no processo DC é devido ao bombardeamento iônico contínuo, sem nenhum intervalo dominante. 


\subsection{CORRELAÇÕES}

Das análises obtidas nas diversas etapas deste estudo, um resumo dos principais fenômenos envolvidos no processo resultante das variações na condição de tratamento é apresentado nos quadros 1 e 2 . No quadro 1 são apresentadas as correlações referentes à nitretação do ferro $(99,83 \%)$ relativas às diferentes temperaturas $\left(400-550^{\circ} \mathrm{C}\right)$, tempos $(1-6 \mathrm{~h})$ e freqüência $(2-10 \mathrm{kHz})$, com os demais parâmetros de nitretação constantes. No quadro 2, para a nitretação do aço AISI H12, são apresentadas as correlações entre a nitretação em corrente direta (DC) e corrente alternada (AC), variando o tempos de nitretação.

\begin{tabular}{|l|c|c|c|c|c|c|}
\hline \multirow{2}{*}{$\begin{array}{c}\text { Ferro } \\
(99,98 \%)\end{array}$} & \multicolumn{3}{|l|}{ Camada Superficial } & \multicolumn{3}{l|}{ Camada Interna } \\
\cline { 2 - 7 } & $\varepsilon / \gamma^{\prime}$ & Es & $\mathrm{D}$ & $\mathrm{C}_{\mathrm{N}}(\% \mathrm{at})$ & $\varepsilon / \gamma^{\prime}$ & $\mathrm{Di}$ \\
\hline$\uparrow$ Temperatura & $\uparrow$ & $\uparrow \uparrow$ & $\uparrow \uparrow$ & $\downarrow$ & $\uparrow$ & $\uparrow$ \\
\hline$\uparrow$ Tempo & $\uparrow$ & $\uparrow$ & $\downarrow$ & $\uparrow$ & $\uparrow$ & $\downarrow$ \\
\hline$\uparrow$ Freqüência & $\downarrow$ & $\downarrow$ & $\downarrow$ & $\downarrow$ & $\uparrow$ & $\downarrow$ \\
\hline
\end{tabular}

Quadro 1 - Efeito das variações nos parámetros de nitretação no ferro. Legenda: Es, espessura; $D$, dureza Vickers; Di, dureza Vickers proxima a camada superficial; $\uparrow$ aumento; $\uparrow \uparrow$ aumento significativo; $\downarrow$ diminuiçăo.

\begin{tabular}{|c|c|c|c|c|}
\hline \multirow{2}{*}{$\begin{array}{c}\text { Aço AISI H12 } \\
\text { (DC) }\end{array}$} & \multicolumn{3}{|c|}{ Camada Superficial } & Camada Interna \\
\cline { 2 - 5 } & $\varepsilon / \gamma^{\prime}$ & Es & $D$ & $\varepsilon / \gamma^{\prime}$ \\
\hline$\uparrow$ Tempo & $\downarrow$ & $\uparrow$ & - & $\uparrow$ \\
\hline $\begin{array}{c}\text { Aço AISI H12 } \\
\text { (AC) }\end{array}$ & Camada Superficial & & Camada Interna \\
\cline { 2 - 5 } & $\varepsilon / \gamma^{\prime}$ & Es & $D$ & $\varepsilon / \gamma^{\prime}$ \\
\hline$\uparrow$ Tempo & $\uparrow$ & - & - & $\uparrow$ \\
\hline
\end{tabular}

Quadro 2 - Efeito das variações nos parámetros de nitretação no ferro. Legenda: Es, espessura; $D$, dureza Vickers; - pouco significativo; $\uparrow$ aumento; $\downarrow$ diminuição.

Entre os parâmetros analisados na nitretação do ferro, quadro 1, o efeito da temperatura foi o mais significativo no aumento da dureza da camada superficial. 0 aumento da temperatura e do tempo afeta significativamente as fases, promovendo - aumento de $\varepsilon$ na camada superficial. Contudo, a variação do tempo não apresentou uma diminuição na dureza da camada superficial. Na camada mais 
interna, o maior efeito foi com relação à temperatura de tratamento, com o aumento da dureza próximo da superficie (Di). Com o aumento da freqüência observou-se uma diminuição na maioria dos parâmetros medidos e apenas na relação entre as fases houve um crescimento de $\varepsilon$ na camada interna. Este foi um comportamento análogo ao observado nas amostras nitretadas, aumentando-se o tempo e a temperatura de tratamento.

Com relação ao aço AISI H12, quadro 2, a nitretação em corrente direta $(D C)$ e pulsada $(A C)$ apresentam efeitos diferentes em relação às fases formadas. $O$ aumento no tempo para o tratamento em DC provoca a diminuição de $\varepsilon$, promovendo o crescimento de $\gamma^{\prime}$, enquanto que 0 inverso ocorre para 0 tratamento $\mathrm{AC}$. Na camada interna, o aumento da fase $\varepsilon$ é observado nos dois processos. 


\section{SUGESTÕES PARA FUTUROS TRABALHOS}

Considerando-se a extensão e a importância do assunto tratado neste trabalho, alguns problemas mostraram-se interessantes de serem cuidadosamente estudados, a fim de melhor se conhecer os mecanismos envolvidos no processo de nitretação por plasma.

- Estender o trabalho a outros tipos de aços carbono e ligas contendo elementos formadores de nitretos, tais como: $\mathrm{Cr}, \mathrm{Al}, \mathrm{V}$ e Ti. Para estes casos, se faz necessário o uso de outras técnicas, como microscopia de transmissão e XPS (Espectroscopia de Fotoelétrons Excitados por Raios X).

- A identificação dos nitretos de ferro $\left(\varepsilon-\mathrm{Fe}_{2 \leq \times \leq 3,2} \mathrm{~N}\right.$ e $\left.\gamma^{\prime}-\mathrm{Fe}_{4} \mathrm{~N}\right)$ através da técnica de XPS, pois a caracterização dos nitretos de ferro foi baseada principalmente no efeito Mössbauer. Mesmo considerando-se que a técnica Mössbauer evidencie estes nitretos, é interessante caracterizá-los por XPS, uma vez que não existe na literatura resultados obtidos por esta outra técnica.

- Estudo das tensões residuais na camada nitretada, por difração de raios X.

- Estudo da influência das correntes contínua e pulsada nas propriedades mecânicas de propagação de trincas curtas por fadiga, fadiga por fretting e fadiga por contato. 


\section{CONCLUSÃO}

Através das investigações dos estados físico e químico do ferro nitretado, com relação aos parâmetros de nitretação (temperatura, tempo e freqüência do plasma) pode-se concluir o seguinte:

- A camada de compostos próxima à superfície, como investigada por GAXD e CEMS, consiste de uma mistura de precipitados $\gamma^{\prime}-\mathrm{Fe}_{4} \mathrm{~N}$ e $\varepsilon-\mathrm{Fe} \times \mathrm{N}(2 \leq x \leq 3,2)$, observados por todas as técnicas utilizadas. A presença da fase $\varepsilon$ em todas as amostras é devido à quantidade de carbono existente no ferro $(0,02 \%$ em massa).

- A proporção entre as fases $\gamma^{\prime}$ e $\varepsilon$ na superficie das amostras é dependente das condiçōes de nitretação. Para as nitretaçōes onde se varia a temperatura, a fase $\varepsilon$ é predominante e cresce com o aumento da temperatura. Já para diferentes tempos de nitretação, a quantidade da fase $\gamma^{\prime}$ é maior para $t \leq 2 \mathrm{~h}$ e esta tendência é revertida para $t>3 h$, quando a fase $\varepsilon$ prevalece. $O$ mecanismo provavelmente responsável por este comportamento é o alto potencial de nitretação para $t>3 h$. Para as nitretações variando-se a freqüência do plasma, o potencial de nitretação é baixo, favorecendo a formação da fase $\gamma^{\prime}$ para $f>4 \mathrm{kHz}$.

- A camada abaixo da camada de compostos, na zona de difusão, como investigada por CEMS, consiste de uma mistura de $\gamma^{\prime}-\mathrm{Fe}_{4} \mathrm{~N}, \varepsilon-F e_{x} \mathrm{~N}(2 \leq x \leq 3,2)$, $\alpha "-\mathrm{Fe}_{16} \mathrm{~N}_{2}$ e $\alpha-\mathrm{Fe}$, com uma porcentagem relativa da fase $\varepsilon$ maior do que as outras 
fases. O provável mecanismo responsável por essa formação nas presentes amostras é atuante na região rica de carbono criada pela nitretação por plasma, fazendo com que o Fe comporte-se como um aço carbono.

A investigação sistemática dos estados cristalino e químico da camada de compostos, bem como o perfil de microdureza do aço AISI H12 tratado nas condições de corrente direta (DC) e alternada ( $A C)$, foi realizada através de técnicas analíticas DRX e GAXD, CEMS e CXMS, microanálise eletrônica, micrografia ótica e microdureza Vickers, e sugerem o seguinte:

- A camada de compostos próxima à superfície (observada por CEMS), consiste de uma mistura de precipitados $\gamma^{\prime}-\mathrm{Fe}_{4} \mathrm{Ne} \varepsilon-\mathrm{Fe}_{\mathrm{x}}(\mathrm{N}, \mathrm{C})$.

- A camada de compostos próxima à zona de difusão (observada por CXMS), consiste de uma mistura de precipitados $\gamma^{\prime}-\mathrm{Fe}_{4} \mathrm{~N}, \varepsilon-\mathrm{Fe} e_{x}(\mathrm{~N}, \mathrm{C})$ e $\alpha "-\mathrm{Fe}_{16} \mathrm{~N}_{2} \mathrm{e}$ austenita $\gamma-(\mathrm{Fe}-\mathrm{N}-\mathrm{C})$. Três mecanismos podem ser responsáveis pela a formação da austenita retida nas presentes amostras: (i) o nitrogênio liberado da supersaturação da fase $\gamma^{\prime}$ para a matriz, que fica rica em nitrogênio e eventualmente transforma a austenita retida em austenita $\gamma-(\mathrm{Fe}-\mathrm{N}-\mathrm{C})$; (ii) 0 aquecimento localizado induzido pelo bombardeamento iônico de alta energia, elevando a temperatura local acima do valor médio medido pelo termopar, induzindo a transformação da fase $\alpha$ ' para a fase austenítica contendo nitrogênio; (iii) a região rica em carbono próxima à zona de difusão pode se comportar localmente como um aço carbono. Assim, após a formação de austenita por (i) ou (ii), ela pode ser retida à temperatura ambiente, devido à grande quantidade de carbono. 
- Os perfis dos cortes transversais investigados por microscopia ótica e por microanálise são consistentes com os obtidos por microdureza Vickers.

- O comportamento cinético viola a lei parabólica e enfatiza os efeitos do sputtering do catodo e da difusão por radiação (radiation-enhanced diffusion). Sistematicamente, com os efeitos de sputtering e radiation-enhanced diffusion para tempos $t<2 h$, a camada de compostos obtida por corrente alternada $(A C)$ é mais espessa do que a obtida por corrente direta (DC). A situação é revertida para tempos maiores que $3 \mathrm{~h}$.

Quanto à correlação entre as características da camada nitretada no ferro e no aço ferramenta $\mathrm{H} 12$, pode-se chegar às seguintes conclusões:

- Apesar da investigação ter sido realizada no $\mathrm{Fe}(0,02 \%$ em massa de $\mathrm{C})$, não é feita qualquer referência aos carbonitretos de ferro, como no aço $\mathrm{H} 12$, pois a quantidade de carbono no ferro é pequena para se apreciada por Mössbauer. A associação das fases presentes nas amostras de ferro e de aço $\mathrm{H} 12$ com respeito ao teor de carbono, revelou uma maior quantidade do nitreto $\gamma^{\prime}-\mathrm{Fe}_{4} \mathrm{~N}$ no ferro do que no aço, para nitretações em corrente alternada $(A C)$. A razão para este comportamento está na maior concentração de carbono no aço em relação ao ferro, favorecendo a formação da fase $\varepsilon$.

- Como era esperado, o crescimento cinético da camada nitretada no tratamento em corrente direta (DC), tanto para o ferro quanto para o aço $\mathrm{H} 12$ obedece à lei parabólica com o tempo de nitretação. 


\section{REFERÊNCIAS BIBLIOGRÁFICAS}

[1] YILBAS, B. S. et al. Investigation into some tribological properties of plasma nitrided hot-worked tool steel AISI H11. Journal of Materials Engineering and Performace, v.5, n.2, p.220-224, 1996.

[2] SHOHET, J. L. Plasma - aided manufacturing. IEEE Transactions on Plasma Science, v.19, n.5, p.220-224, 1991.

[3] ALVES, CLODOMIRO JÚNIOR. Nitretação por plasma pulsado: Equipamento, preparação e caracterização das camadas nitretadas. São Carlos, 1995. Tese (Doutorado) - Universidade Federal de São Carlos.

[4] KWON, S.C. et al. Geometric effect of ion nitriding on the nitride growth behavior in hollow tube. Joumal of Materials Engineering and Performace, v.1, n.3, p.353-358, 1992.

[5] SANTOS, C. A. Composição superficial e propriedades mecânicas e tribológicas de aços carbono implantados com nitrogénio. Porto Alegre, 1984. 61p. Tese (Doutorado) - Universidade Federal do Rio Grande do Sul.

[6] KURNEY. A. S. W. et al. Nitriding of steels - an overview. In: GUPTON, P. S., ed. The heat treating source book. Metals Park, ASM, 1986, p. 127-133.

[7] HUDIS, M. Study of ion-nitriding. Journal of Applied Physics, v.44, n.4, p. 148996, 1973.

[8] TIBBETTS, G. G. Role of nitrogen atoms in ion-nitriding. Joumal of Applied Physics, v.45, n.11, p. 5072-3, 1974.

[9] EDENHOFER B. Physical and metalurgical aspects of ionitriding. Heat treatment of metals., v.1, part.1, p. 23-28, 1974.

[10] EDENHOFER B. Production ionitriding. In: AMERICAN SOCIETY FOR METALS, comp. Source book on nitriding, Metals Park, p. 181-5, 1986.

[11] KOVACS, W. L. Comercial and economic trends in ion nitriding/carburizing. In: INTERNATIONAL CONFERENCE ON ION NITRIDING/CARBURIZING, 2. Cincinnati, 1989. Anais. Proceeding Materials Park, ASM International, 1989. p.5-17. 
[12] ROSSNAGEL, S. M. et al. Handbook of plasma processing technology fundamentals, etching, deposition and surface interactions. New Jersey, Noyes, p.523, 1989.

[13] NASSER, ESSAM. Fundamentais of gaseous ionization and plasma electronics. John Wiley \& Sons, INC, 1971.

[14] DRESSLER, Sidney. Plasma Treatments. In: SURFACE MODIFICATION TECHNOLOGIES (SUDARCHAN, T. S.) New York and Basel, (1989). Cap.5, p.317-419.

[15] CHAPMAN, BRIAN. Glow discharge process - sputtering and plasma etching. New York, John Wiley \& Sons, 1980. Cap. 4, p.77-138.

[16] BELL, A. T. Abstract: Fundamentals of Plasma Chemistry. Joumal of Vacuum Science Technology, v.16, n.2, p. 418-19, 1979.

[17] PETITJEAN, L.; RICARD, A. Emission spectroscopy study of $\mathrm{N}_{2}-\mathrm{H}_{2}$ glow discharge for metal surface nitriding. Joumal of Physics $D$ : Applied Physics, v.17, p.919-929, 1990.

[18] HESS, D. W. Plasma-material interaction. Joumal of Vacuum Science Technology A, v.8, n.3, p. 1677-1684, 1990.

[19] AHMED, N. A. G. Ion plating technology. New York, Willey, 19871987), p171.

[20] RUSET C. The influence of pressure on temperature uniformity in the plasma nitriding process. Heat treatment of metals, v.3, p. 81-84, 1991.

[21] PETITJEAN, L; Etude d"une decharge electrique dans un melange azote hydrogene pour la nitruration de surfaces metalliques. Orsay, Universidad Paris - Sud, 1982, 153p.

[22] HOMBECK F.; BELL T. Envirommentally harmless plasma thermochemical process. Surface Enginnering, v.7, n.1, p.45-51, 1991.

[23] WOLFGANG, R. and LÜHR, J. Plasma (ion)nitriding and plasma (ion)nitrocarburizing units, applications and experiences. In: INTERNATIONAL CONFERENCE ON ION NITRIDING /CARBURIZING, 2, Cincinnati, 1989. Anais. Proceeding Materials Park, ASM International, 1989, p.147-156.

[24] DRESSLER, Sidney. Plasma Treatments. In: SURFACE MODIFICATION TECHNOLOGIES (SUDARCHAN, T. S.) New York and Basel, (1989). Cap.5, p.317-419.

[25] O'BRIEN, J. M. Plasma (ion)nitriding. Metals Handbook ASM. v.4, p. 420-424, 1991.

[26] VERMA R.; PODOB M. Plasma nitriding: state of the art. Industrial heating., p.14-17, 1985.

[27] GRÜN R. Industrial advances for plasma nitriding. In: INTERNATIONAL CONFERENCE ON ION NITRIDING ICARBURIZING, 2, Cincinnati, 1989. Anais. Proceeding Materials Park, ASM International, 1989, p.1157-163. 
[28] DRESSLER, S. Plasma parameter control for industrial situations: the role of hot wall plasma nitriding furnaces. In: INTERNATIONAL CONFERENCE ON ION NITRIDING /CARBURIZING, 2, Cincinnati, 1989. Anais. Proceeding Materials Park, ASM International, 1989, p.183-193.

[29] BOYER, H. E. Case hardening of steel. In: ASM International. Cap.3: Other gaseous case-hardening methods, cap.6: Heat treatment considerations. (1987).

[30] CLAYTON D. B. and SACHS K. Reduction of 'white layer'on the surface of nitrided components, Heat treatment' 76, The Metals Society, London, p. 1-6, 1976.

[31] SUCHENTRUNK R. et al. Plasma surface engineering - innovative process and coating systems for high - quality products. Surface Coatings Technology, v.112, p.351-357, 1999.

[32] LAMPE T. et al. Compound Layer Formation during Plasma Nitriding and Plasma Nitrocarburising. Surface Engineering, v.9, n.9, p. 69-76, 1993.

[33] JONES S. W. et al. Ion nitriding. Heat treatment, p. 71-77, 1973.

[34] RICARD A. J. and GANTOIS M. Excited State of Plasma for Steel surface Nitriding, Process. In: 1 st INTERNATIONAL CONFERENCE ON PLASMA SURFACE ENGINEERING, Garmisch-Partenkirchen, 1988, p. 83-90.

[35] BORBA, ELENICE CAVICHIOLI. Estudo experimental da nitretação em ligas $\mathrm{Fe}-\mathrm{C}$ e nitrocementaçào no ferro puro por plasma. Florianópolis, 1998. 13 e 18p. Tese (Doutorado) - Universidade Federal de Santa Catarina.

[36] WERTHEIM, G. K. Mössbauer Effect: Principles and Applications. 1.ed. New York, Academic Press inc., 1964.

[37] SILVA, MARIA TERESINHA XAVIER. Aplicação do efeito Mössbauer: análise de amostras de basalto. Porto Alegre, 1977. Dissertação (Mestrado) Universidade Federal do Rio Grande do Sul.

[38] MEISEL W. Corrosion process and their inhibition as studied by Mössbauer conversion and other electron spectroscopies. Hyperfine Interactions, v.45, p.73-90, 1989.

[39] SCHAAF P.; GONSER U. Depth analysis by combination of conversion electron, conversion $\mathrm{x}$-ray Mössbauer spectroscopy. Hyperfine Interactions, v.57, p.2101-2104, 1990.

[40] STEVENS J. G.; SHENOY G. K. Móssbauer spectroscopy, London, Chapman and Hall, 1981.

[41] FLEWITT P. E. J.; WILD R.K. Physical methods for materials characterisation. Bristol, Institute of Physics Pub., 1994. Cap. 5, p.230-239. 
[42] ARGEMIRO SOARES DA SILVA SOBRINHO. Estudo por espectroscopia Mössbauer e ótica da formação de camada de nitretos de ferro em pósdescarga. Florianópolis, 1994. Dissertação (Mestrado) - Universidade Federal de Santa Catarina.

[43] LONG, J. G. Mössbauer Spectroscopy Applied to Inorganic Chemistry. In: Plenum Press; Modern Inorganic Chemistry. 1.ed. New York, 1984. Cap. 3, p.27-42.

[44] RECHENBERG, H. R. Introduçăo à espectroscopia Mössbauer. IFUSP. 1995. p. 1-51.

[45] GANCEDO, J. R. et al. CEMS Methodology. Hyperfine Interactions, v.66, p. 83$94,1991$.

[46] ISOZUMI Y. et al. A new detector assembly for conversion electrons and $\mathrm{X}$-rays from Mössbauer effect. Nuclear Instruments and Methods in Physics Research, v. 120, p. $23-28,1974$.

[47] KORFF, S. A.; PRESENT, R. D. On the Role of Polytomic in fast counters. Physical Review, v.65, n.9-10, p. 274-282,1944.

[48] WILKINSON P. G.; JOHNSTON H. L. The absorption spectra of methane, carbon dioxide, water vapor, and ethylene in the vaccum ultraviolet. Journal of Chemical Physics, v.18,n.2, p. 190-193,1950.

[49] JACK K. H. The Iron-nitrogen Sytem: The Crystal Structures of $\varepsilon-P h a s e$ Iron Nitrides. Acta Crystallographica, v.5, p. 404-411,1952.

[50] HANSEN M. Metallurgy and metallurgical engineering series. MacGraw-Hill Book Company, p.671, 1958.

[51] JACK, D. H.; JACK K. H. Invited Review: Carbides and Nitrides in Steel. Materials Science and Engineering, v.11, p. 1-27, 1973.

[52] PADILHA F. A. Materiais de engenahria microestrutura e propriedades. 1. ED. São Paulo, Ed. Hermus, 1997. Cap. 7, p.103-120. Defeitos Puntiformes e soluçōes sólidas.

[53] DeCRISTOFARO, N.; KAPLOW, R. Mössbauer Spectroscopy of Hexagonal Iron-Nitrogen Alloys. Metallurgical Transactions A, v. 8a, p.425-430,1977.

[54] JACK K. H. The occurence and the crystal structure of $\alpha$ "-iron nitride; a new type of interstitial alloy formed during the tempering of nitrogen-martensite. Proceedings of the royal society of London A, v.208, p. 216-224, 1951.

[55] FOCT, J. Joumal of Physique, Colloque C6, v.12, 487-491, 1974.

[56] MORIYA, T. et al. Mössbauer Effect in Iron-Nitrogen Alloys and Compounds. Joumal Physical Society of Japan, v.35, n.5, p.1378-1385, 1973.

[57] ANDRIAMANDROSO D. et al. Mössbauer Resonance Studies on Sn substituted $\mathrm{Fe}_{4} \mathrm{~N}$. Materials Research and Bulletin, v.19, p.1187-1194. 1984. 
[58] NOZIK, A. et al. High resolution Mössbauer Spectrum of $\mathrm{Fe}_{4} \mathrm{~N}$. Solid State Communications, v.7, p.1677-1679, 1970.

[59] EICKEL, K. H.; PITSCHI, W. Magnetic Properties of the Hexagonal Iron Nitride $\varepsilon-\mathrm{Fe}_{3,2} \mathrm{~N}$. Phys. Status Solidi. v.39, p.121-129,1970.

[60] BAINBRIDGE, J. Mössbauer and X-Ray investigation of $\varsigma_{-}-\mathrm{Fe}_{2} \mathrm{~N}$. Journal Physics Chemical Solids. v. 34, p. 1579-1586, 1973.

[61] SIMON G., VASCONCELLOS M. A. Z., DOS SANTOS c. A., Effects of argon irradiation on a plasma-nitrided carbon steel. Surface and Coating Technology. v. 102, p. 90-96, 1998.

[62] DOS SANTOS C. A. BAUMVOL I. J. R., GARCIA E. A., BEHAR M. Carbonitride precipitation by sucessive implatation of carbon and nitrogen into pure iron. Joumal of Physics D-Applied Physics. v.17, n. 5, p. 969-977,1984.

[63] DOSSANTOS C.A., DEBARROS B. A. S., DESOUZA J.P., BAUMVOL I. J. R. Iron nitride and carbonitride phases in a nitrogen implanted carbon-steel. Applied Physics Letters. V.41, n. 3, p. 237-239, 1982.

[64] FIRRAO D. et al. The Influence of Carbon on Nitrogen Substitution in iron $\varepsilon-$ Phases. Joumal of Materials Science. v.17, p. 1773-1788,1982.

[65] JACK K. H. The iron-nitrogen system: the structures of $\mathrm{Fe}_{4} \mathrm{~N}$ and $\mathrm{Fe}_{2} \mathrm{~N}$. Proceedings of the royal society of London A, v.105, p. 34-41, 1948.

[66] INOKUTI Y. et al. Formation of $\mathrm{Fe}_{3} \mathrm{~N}, \mathrm{Fe}_{4} \mathrm{~N}$ and $\mathrm{Fe}_{16} \mathrm{~N}_{2}$ on the surface of iron. Metallurgical Transactions A, v.6, p.773-784, 1975.

[67] HONG, D.; HILLERT, M. An assessment of the Fe-C-N sytem. Zeitschrift fur Metallkunde, v.82, n.4 p.310-316, 1991.

[68] JACK K. H. The iron-carbon-nitrogen system. Proceedings of the royal society of London A, v.195, p. 41-55, 1948.

[69] RIOFANO, ROSAMEL MELITA MUÑOZ. Efeito das variáveis de nitretação por plasma na resistência à abrasão de um aço "maraging". São Carlos, 1997. Dissertação (Mestrado) - Universidade de Săo Paulo - São Carlos.

[70] MRIDHA S.; JACK D. H. Etching techniques for nitrided irons and steels. Metallography, v.15, p.163-175, 1982.

[71] ABADA L. et al. Information depths of conversion $x$-ray Mössbauer spectra in plasma nitrocarburized surface layers. Physics Status Solidi A. v.139, p.181187, 1993.

[72] CARLOS Henrique da Silva. Estudo da carga normal e da velocidade no coeficiente de atrito do par polietileno de alta densidade e aço carbono galvanizado. São Paulo, 1998. 76p. Dissertação (Mestrado) - Escola Politécnica, Universidade de São Paulo

[73] JIS G0562. Methods of measuring nitrided case depth for iron and steel. Surface Engineering. v.11, n.1, p.57-60, 1995. 
[74] MIOLA E. J. et al. Near-surface composition and microhardness profile of plasma nitrided $\mathrm{H}-12$ tool steel. Materials Science and Engineering A. v.256, p.60-68, 1998.

[75] ALBARRAN J. L. et al. Nitride width and microhardness in $\mathrm{H}-12$ ion nitrided steel. Materials Letters. v.15, p.68-72, 1992.

[76] METIN E.; INAL O. T. formation and growth of iron nitrides during ion-nitriding. Joumal of Materials Science, v.22, p.2783-2788, 1987.

[77] WRIEDT H. A. et al. Laser nitriding of iron: Nitrogen profiles and phases. Alloy Phase Diagrams, v.8, p.355-5, 1987.

[78] SCHAAF P. et al. Characterization of laser-nitreded iron and sputtered iron nitride films. Hyperfine Interactions, v. 95, p.199-225, 1995.

[79] NAKAGAWA, $\mathrm{H}$. et al. ${ }^{57} \mathrm{Fe}$ Mössbauer study of $\mathrm{FeN}_{\mathrm{x}}(\mathrm{x}=0.25 \sim 0.91)$ Alloys. Hyperfine Interactions, v.69, p.455-58, 1991.

[80] SUN Y.; Bell T. Plasma surface engineering of low alloy steel. Materials Science and Engineering A, v.140, p.419-434,1991.

[81] KURNY A. S. et al. On formation of austenite during ion nitriding of Armco iron. Joumal of Less-Common Metals, v.144, p.201-207, 1988.

[82] FIGUEROA U. et al. Growth kinetics of concomitant nitride layers in postdischarge conditions: modeling and experiment, Surface Coatings Technology, v.86-87, p. 728-734, 1996.

[83] KUPPUSAMI, P. et al. Kinetics of growth of plasma nitrided layers on a titanium modified stainless steel. Surfeca Engineering, v.9, n. 2, p.142-147, 1993.

[84] O'BRIEN, J. M. Plasma (ion)nitriding. Metals Handbook ASM. v.4, p. 420-424, 1991.

[85] EDENHOFER B. Physical and metalurgical aspects of ionitriding. Heat treatment of metals. v.1, part.2, p. 59-67, 1974.

[86] INAL, O. T. et al. Identification of the Reactive Species and Modeling of the lon Nitriding Process. In: INTERNATIONAL CONFERENCE ON ION NITRIDING ICARBURIZING, 2, Cincinnati, 1989. Anais. Proceeding Materials Park, ASM International, 1989, p.57-66.

[87] SUN Y.; Bell T. A numerical model of plasma nitriding of low alloy steels. Materials Science and Engineering A, v.224, p.33-47,1997.

[88] D'HAEN J. et al. Structure analysis of plasma-nitride pure iron, Surface and Coating Technology, v.74-75, p.405-411, 1995.

[89] DELHEZ R. et al. Role of X-ray Diffraction Analysis in Surface Engineering: Investigation of Microstructure of Nitrided Iron and Steels. Surface Engineering, v.3, n.4, p. 331-342, 1987. 
[90] DeCRISTOFARO, N.; KAPLOW, R. Intertitial Atom Configurations in Stable and Metastable Fe-N and Fe-C solid solutions. Metallurgical Transactions A, v.8a, p.35-44, 1977.

[91] LE CAER G. et al. Mössbauer effect study of $\varepsilon$-carbide: influence of particle size. Physics. Status Solidi A, v.6, p. K97-K100, 1971.

[92] RON M., MATHALONE Z., Hyperfine Interactions of ${ }^{57} \mathrm{Fe}$ in $\mathrm{Fe}_{3} \mathrm{C}$. Physical Review B, v.4, n. 3, p. 774-777, 1971.

[93] CARBUCICCHIO M. et al. Surface Mössbauer analysis of $38 \mathrm{NCD} 4$ steel ion implanted with nitrogen. Journal Applied Physics, v.52, n.7, p.4589-4592, 1981.

[94] Rauschenbach B.; Kolitsch A. Formation of compounds by nitrogen ion implation in iron, Physics. Status Solidi A, v.80, p.211-222, 1983.

[95] DIMITROV V. I. Et al. A diffusion model of metal surface modification during plasma nitriding. Applied Physics A. v.63, p.475-480, 1996.

[96] MICHEL $H$. et al. Progress in the analysis of the mechanisms of ion nitriding. Surface and Coatings Technology. v.72, p. 103-111, 1995.

[97] SINGER I. L. Carburization of steel surfaces during implatation of Ti ions at high fluences. Joumal Vac. Sci. Technol. A, v.1, n.2, p.419-422, 1983.

[98] SUN Y.; Bell T. A numerical model of plasma nitriding of low alloy steels. Materials Science and Engineering A, v.140, p.419,1991.

[99] MELETIS E. I.; YAN S. Low-pressure ino nitriding of AISI 304 austenitic stainless steel with an intensified glow discharge. Joumal Vac. Sci. Technol. A, v.11, n.1, p.25-33, 1993.

[100] DIENES G. J.; DAMASK A. C. Radiation enhanced diffusion in solids. Joumal of Applied Physics. v.29, n.12, p.1713-1721, 1958.

[101] ANTONCIK E. On the theory of enhanced diffusion in high-temperature antimony-implanted silicon. Radiation Effects and Defects in Solids. v.127, p.7582, 1993.

[102] VALIEV S. H. et al. The radiation simulated diffusion role in high dose, low energy, high temperature ion implantation. Nuclear Instruments and Methods in Physics Research B. v.127-128, p.265-268, 1997. 